\title{
Development and Evaluation of Anti-corrosion and Anti-bacterial Polymer Coatings for Circulation Coins
}

\author{
by
}

\author{
Bingjie Xiao
}

A thesis submitted to the Faculty of Graduate and Postdoctoral Affairs in partial fulfillment of the requirements for the degree of

\author{
Master of Applied Science \\ in \\ Mechanical Engineering
}

Carleton University

Ottawa, Ontario

(C) 2015, Bingjie Xiao 


\title{
Development and Evaluation of Anti-corrosion and Anti-bacterial Polymer Coatings for Circulation Coins
}

by

\author{
Bingjie Xiao
}

A thesis submitted to the Faculty of Graduate and Postdoctoral Affairs in partial fulfillment of the requirements for the degree of

\author{
Master of Applied Science \\ in \\ Mechanical Engineering
}

Professor Xiao Huang, Thesis Co- Supervisor

Professor Rong Liu, Thesis Co- Supervisor

Professor Metin I. Yaras, Chair, Department of Mechanical and Aerospace Engineering 


\section{Abstract}

Loonies and quarters, made of a carbon steel core with multi-ply brass plating and nickel plating, have been used as Canadian circulation coins for decades. More recently, the Royal Canadian Mint has proposed additional requirements for the coins to have anti-wear, anti-corrosion and anti-bacterial functions. Therefore an effective coating with such functions is explored in this study. Five candidate polymers are investigated; they are polyurethane, advanced liquid glass, silicone R-2180, polytetrafluoroethylene, and standard liquid glass. Among them, only polyurethane, advanced liquid glass and silicone R-2180 have passed the preliminary appearance examination and are subjected to further testing. Anti-corrosion test in artificial human sweat environment is conducted on the coated coins. The experimental results demonstrate that these three polymer coatings have good anti-corrosion ability on quarters, and for loonies, the advanced liquid glass and silicone coatings exhibit better performance. Anti-bacterial test is performed on the advanced liquid glass coating by adding E. coli onto the coin specimens, and then the amounts of bacteria left on the specimens are calculated after certain durations. The experimental results show that the advanced liquid glass coating has better bacterial resistance than uncoated quarters, but it is not as good as loonies with brass plating. Based on all required coating attributes, advanced liquid glass is regarded as the most promising coating for circulation coins. 


\section{Acknowledgements}

It is my pleasure to have this opportunity to thank people who provided help for this research.

First, I would like to extend my deepest gratitude to my thesis supervisors Drs. Xiao Huang and Rong Liu for their advice, guidance, and patience during the whole process of research. Without their help, I could not have completed this work and overcome many difficulties.

I would also like to sincerely thank Professors Alex Wong and Andrew Speirs for their help and advice on the anti-bacterial experiments.

And, I would like to thank Iain Brooks, Xianyao Li, and Raine Kampman, the staff at RCM, for sharing information on Canadian coins.

In addition, I would like to thank Steve Truttmann and David Raude for their help and experienced advice on material preparation and processing.

Moreover, I would like to thank Dr. Jianqun Wang due to his huge help in SEM/EDX examinations.

As well, I would also like to thank my colleague, Ayman Ibrahim, for his support and cooperation through this journey.

Financial support was provided by National Research Council of Canada and RCM. This research will not be possible without their support.

Lastly, I would like to appreciate my mother and father for their constant encouragement and support. 


\section{Table of Contents}

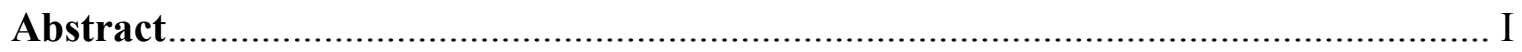

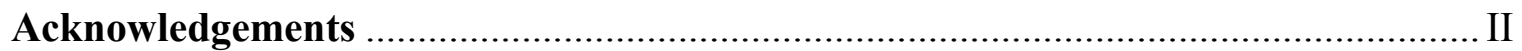

Table of Contents .......................................................................................................

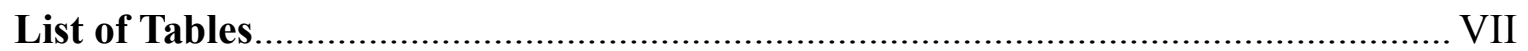

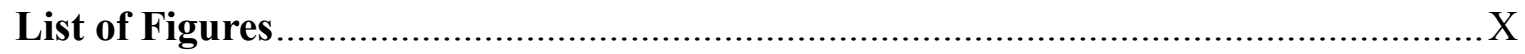

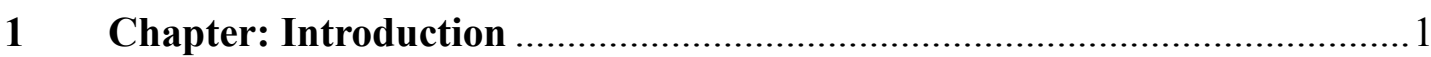

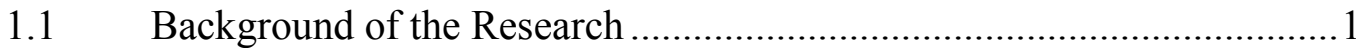

1.1.1 Corrosion Problems of Circulation Coins ....................................... 1

2.1.1 Bacterial Infection Problems ......................................................2

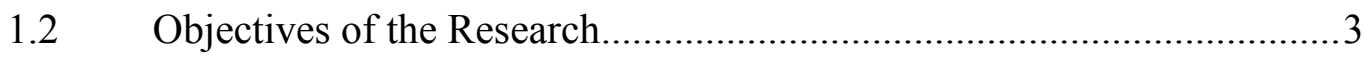

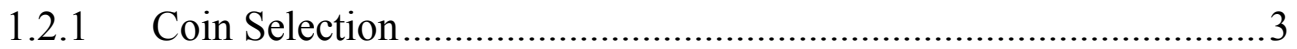

3.1.1 Coating Material Selection ............................................................ 3

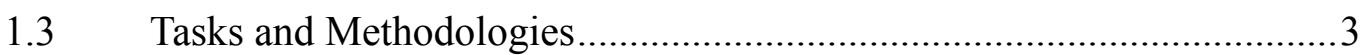

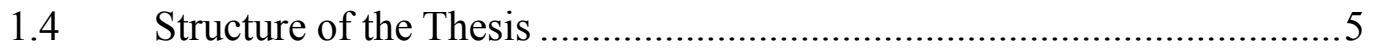

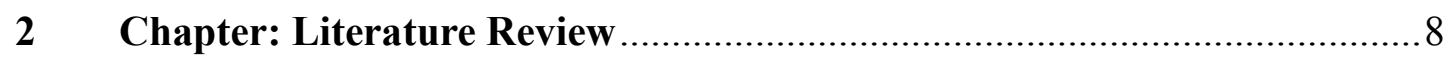

$2.1 \quad$ History of Circulation Coins ............................................................. 8

2.2 Coin Manufacturing Methods .............................................................. 10

2.2.1 The Royal Canadian Mint ................................................................. 10

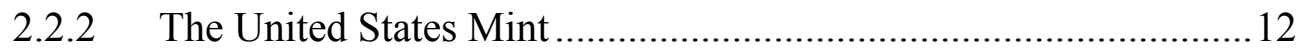

2.3 Requirements for Coin Materials .......................................................... 13

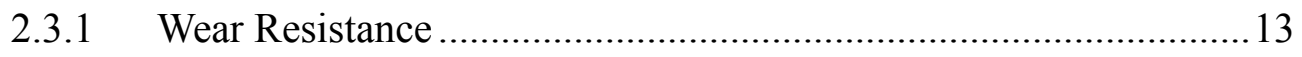

2.3.2 Anti-corrosion Measures................................................................ 14

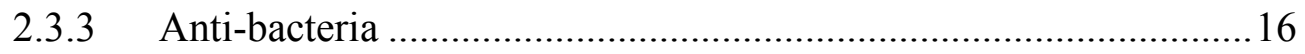

2.4 Corrosion Resistant Polymer Coatings ................................................. 18

2.4.1 Conducting Polymer Coatings …................................................ 18

2.4.2 Self-healing Organic Polymer Coatings ........................................ 19

2.5 Antibacterial Coatings for Circulation Coins .....................................22

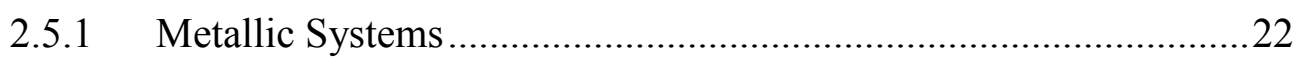




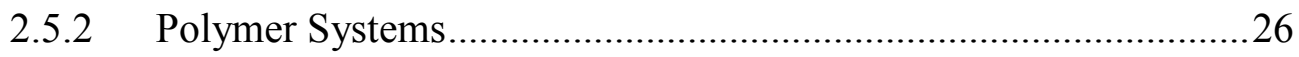

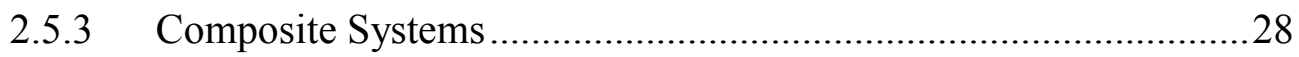

2.6 Coating Deposition Methods ..........................................................29

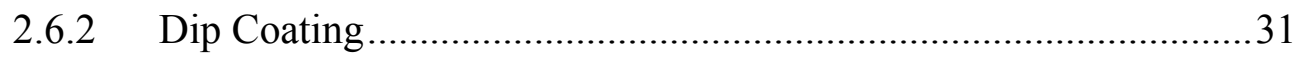

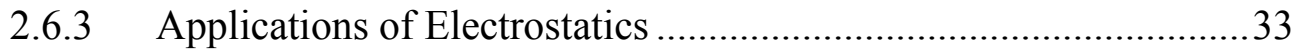

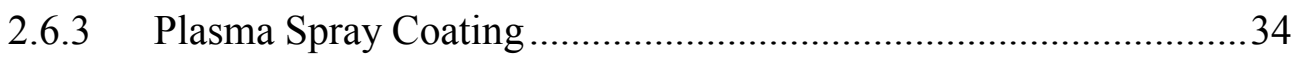

3 Chapter: Materials and Coating Fabrication ...............................................

3.1 Material selection and specifications ...................................................36

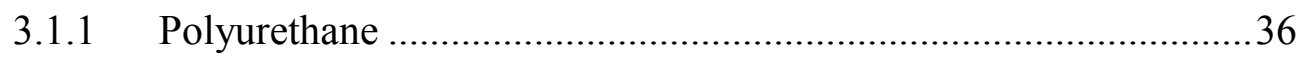

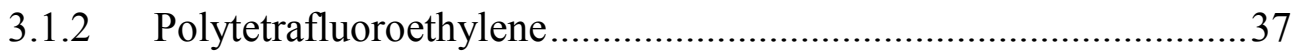

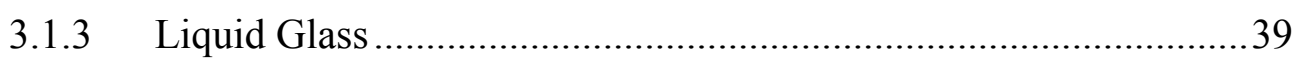

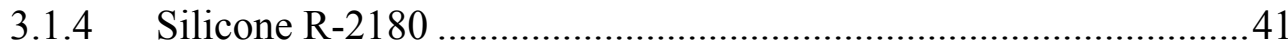

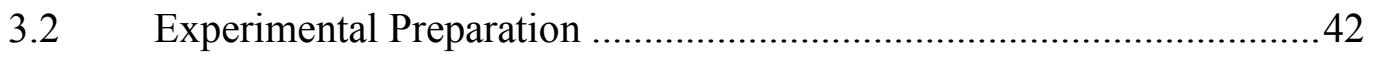

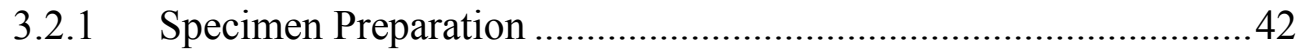

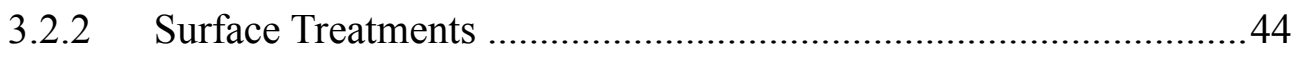

3.2.3 Equipment Preparation ..............................................................46

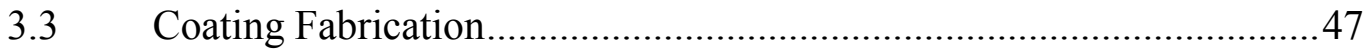

3.3.1 Parameter Selection for Polyurethane and Advanced Liquid Glass47

3.3.2 Process Parameter Selection for Polytetrafluoroethylene and Standard Liquid Glass Spin ..............................................................49

3.3.3 Parameter Selection for Silicone R-2180 Application ....................50

3.3.4 Parameter Selection for Curing Process .......................................50

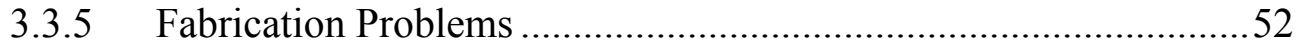

4 Chapter: Bare and Coated Coin Characterization .....................................53

4.1 Microstructure Investigation of Cross-sections of Circulation Coins ...53

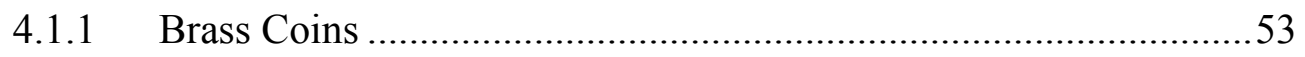

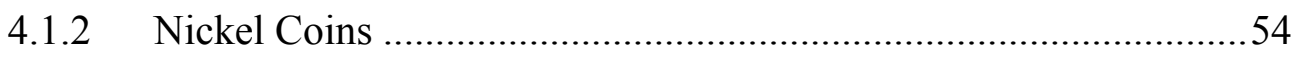

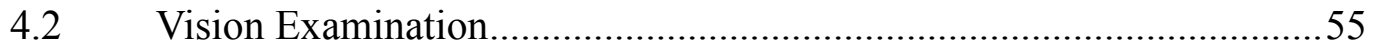

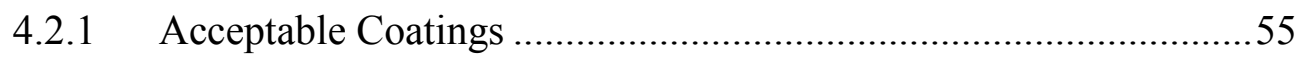




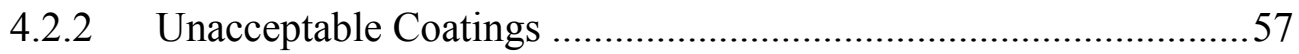

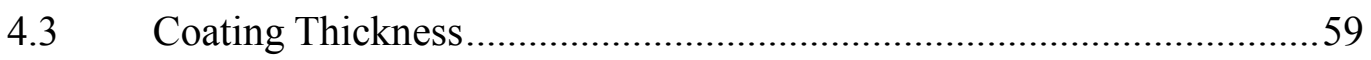

4.3.1 Polyurathane Thickness Examination..........................................61

4.3.2 Advanced Liquid Glass ...........................................................6 63

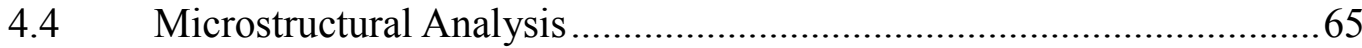

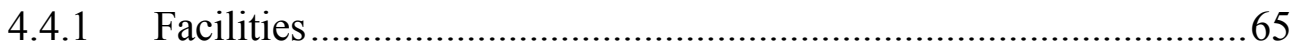

4.4.2 Polyurethane and Advanced Liquid Glass Coatings ......................66

4.3.3 Standard Liquid Glass........................................................... 75

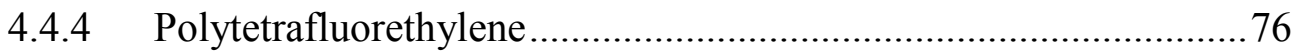

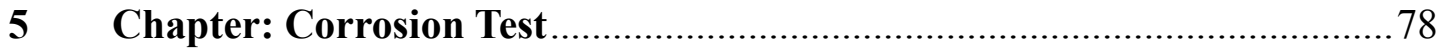

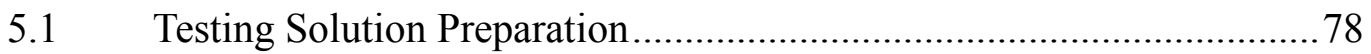

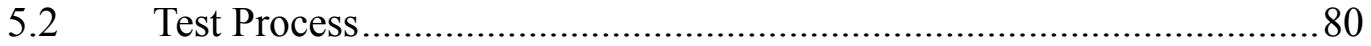

5.2.1 Experiment I and Experiment II ............................................. 80

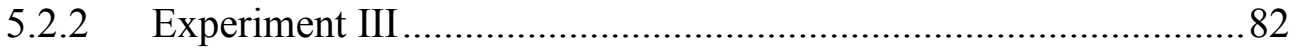

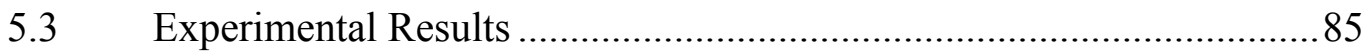

5.3.1 Experiment I and Experiment II ................................................85

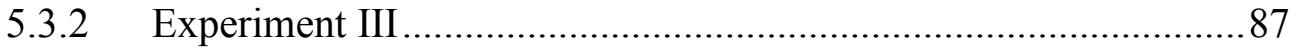

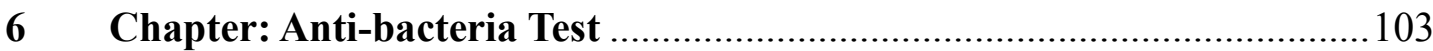

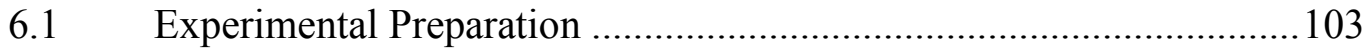

6.1.1 Selection of Test Methods............................................................103

6.1.2 Preparation Process .................................................................. 105

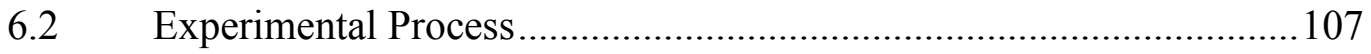

6.2.1 Experiment I .................................................................. 107

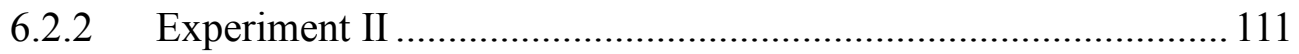

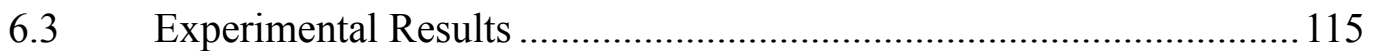

6.3.1 Experiment I Results ........................................................... 115

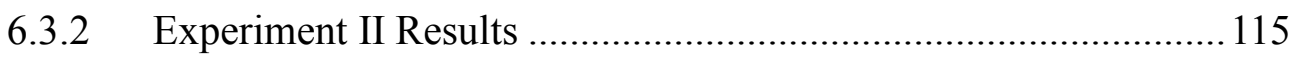

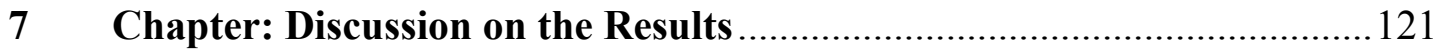

7.1 Qualifying Candidate Coating Materials ........................................... 121 


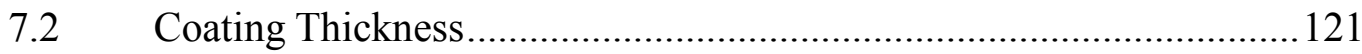

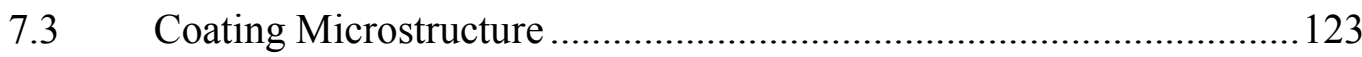

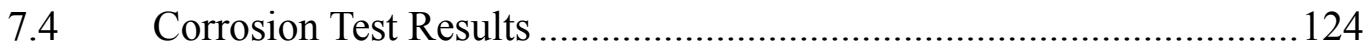

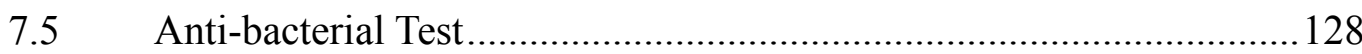

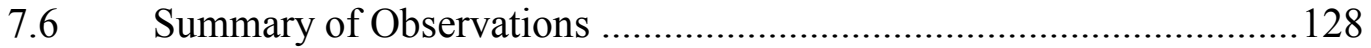

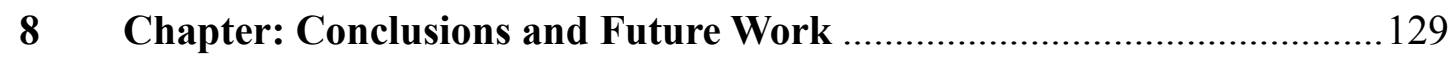

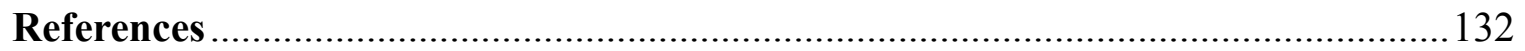

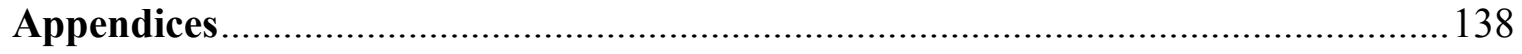




\section{List of Tables}

Table 2-1: Circulation coins in Canada (chemical composition in wt\%) [11] 10

Table 2-2: Circulation coins in the United States (chemical composition in wt\%) [14]...12

Table 2-3: Weight loss rates of Canadian nickel coins [16]. .14

Table 2-4: Percentage of the five coins found contaminated with the particular type of microorganism.

Table 2-5: Minimum inhibition concentrations of Ag nanoparticles [48].

Table 2-6: Antibacterial activities of different weight chitosans ( $0.1 \%$ concentration)

against 11 different types of bacteria $(\log \mathrm{CFU} / \mathrm{ml})$ [55]. .28

Table 3-1: Coating process parameters for polyurethane/advanced liquid glass on brass coins. 48

Table 3-2: Coating process parameters for polyurethane/ advanced liquid glass on nickel

coins.

Table 3-3: Coating process parameters for polytetrafluoroethylene on brass coins.

Table 3-4: Coating process parameters for standard liquid glass on brass coins. .50

Table 4-1: EDX results of the cross section of brass coin. .54

Table 4-2: EDX results of the cross section of nickel coin.

Table 4-3: Comparison of the EDX results between bare and heat-treated coins. .57

Table 4-4: EDX results of PUR coated coin processed at $500 \mathrm{rpm}$. .73

Table 4-5: EDX results of the ALG coated coin processed at $500 \mathrm{rpm}$. .74

Table 4-6: EDX results of the silicone R-2180 coated coin. .75 
Table 4-7: EDX results of the center of the standard liquid glass coated coin processed at $500 \mathrm{rpm}$ .76

Table 5-1: Coins used in anti-corrosion experiment I and experiment II. .81

Table 5-2: Coin specimens for anti-corrosion experiment III. .83

Table 5-3: Photographical showing of the corroded coatings on brass coins

Table 5-4: Photographical showing of corroded areas on nickel coins. .90

Table 5-5: Photos and SEM images of PUR coated coins after corrosion test. 92

Table 5-6: Photos and SEM images of ALG coated coins after anti-corrosion test. .93

Table 5-7: Photos and SEM images of silicone R-2180 coated coin after anti-corrosion test.

Table 5-8: Photos and SEM images of coated, bare and heat-treated nickel coins after corrosion test. .95

Table 5-9: EDX results of PUR coated brass coin processed at $1200 \mathrm{rpm}$ for $50 \mathrm{~s}$. .96

Table 5-10: EDX results of PUR coated nickel coin processed at $1000 \mathrm{rpm}$ for $50 \mathrm{~s} \ldots . . .97$

Table 5-11: EDX results of ALG coated brass coin processed at $700 \mathrm{rpm}$ for $50 \mathrm{~s}$ .98

Table 5-12: EDX results of ALG coated nickel coin processed at $1000 \mathrm{rpm}$ for $40 \mathrm{~s}$.....99

Table 5-13: EDX results of silicone R-2180 coated brass coin 100

Table 5-14: EDX results of silicone R-2180 coated nickel coin. 101

Table 5-15: EDX results of bare and heat-treated brass coins. 101

Table 5-16: EDX results of bare and heat-treated nickel coins 102

Table 6-1: Antibacterial ability of bare nickel coins. 118

Table 6-2: Antibacterial ability of ALG coated nickel coins. 119 
Table 7-1: Approximate minimum thickness of the PUR and ALG coatings on brass and nickel coins.

Table 7-2: Summary of test results. 


\section{List of Figures}

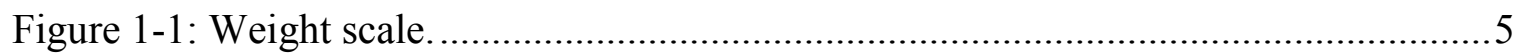

Figure 2-1: Ancient Italy coins in $3^{\text {rd }}$ century BC [6] .............................................

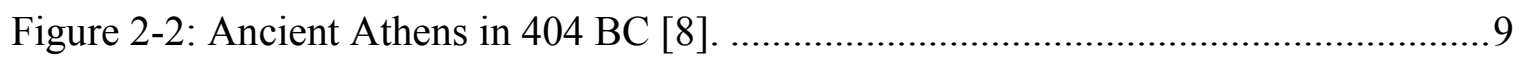

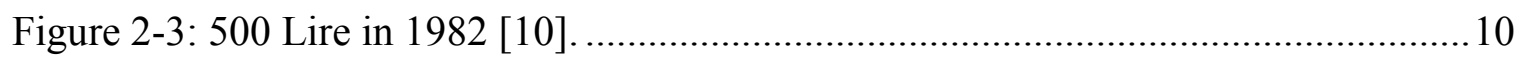

Figure 2-4: Latest Canadian coins: (a) one-dollar coin, and (b) two-dollar coin [11]...... 11

Figure 2-5: The manufacturing process of circulation coins in the US mint: (a) blanking,

(b) annealing, (c) upsetting, and (d) stamping [15].

Figure 2-6: Schematic of the self-healing process of polymers: (a) coating having microcapsules with self-healing protecting paint on carbon steel plate, (b) paint released by damage to the coating layer, and (c) a crack covered by a self-healed paint coating $[31]$

Figure 2-7: Paint protection test results determined via scratch test considering the effect of capsule diameter of PU microcapsules [31]. .20

Figure 2-8: Paint protection test results determined via scratch test according to the effects of the additives and capsule concentration in the paint layer [31].

Figure 2-9: SEM images of the scratched regions before immersion: (a) control coating before immersion, (b) self-healing coating before immersion, (c) control coating after immersion in salt water for $48 \mathrm{hr}$, and (d) self-healing coating after immersion in salt water for $48 \mathrm{hr}[31]$.

Figure 2-10: Schematic of the tentative events in contact killing: (a) copper dissolving from the copper surface and causing cell damage, (b) ruptured cell membrane because of 
copper and other stress phenomena, leading to loss of membrane potential and cytoplasmic content, (c) generation of reactive oxygen species by copper ions, causing further cell damage, and (d) genomic and plasmid DNA degraded [37]

Figure 2-11: Different stages of spin coating: (a) dispensation, (b) acceleration, (c) flow dominant, and (d) evaporation dominant [62].

Figure 2-12: Schematic showing of dip coating process [64]. .32

Figure 2-13: Illustration of the evolution process of the liquid layer during natural drying

process: (a) top view, and (b) side view [65]...... .32

Figure 2-14: Schematic of spray coating setup [67].

Figure 2-15: Schematic illustration of electrostatic process in computer-driven printers [69]

Figure 3-1: Polyurethane: (a) the bottle of polyurethane, and (b) the liquid polyurethane.

Figure 3-2: Polytetrafluoroethylene: (a) the bottle of polytetrafluoroethylene, and (b) the liquid polytetrafluoroethylene. 39

Figure 3-3: Standard liquid glass: (a) the bottle of standard liquid glass, and (b) standard liquid glass.

Figure 3-4: Advanced liquid glass: (a) the bottle of advanced liquid glass, and (b) advanced liquid glass.

Figure 3-5: Structure of polyorganosiloxanes.

Figure 3-6: Silicone R-2180: (a) the bottles of silicone R-2180 part A and part B, and (b) the mixture of part A and part B. 42 
Figure 3-7: Cleaning process: (a) ultrasonic cleaner, and (b) beaker containing coins in the ultrasonic cleaner.

Figure 3-8: Acid etching process: (a) phosphoric, and (b) coins in the acid solution. .......44

Figure 3-9: Sandblast process: (a) sandblast operation, (b) cleaned bare coin, and (c) sandblasted coin.

Figure 3-10: 600 grit polished process: (a) polish machine, (b) cleaned bare coin, and (c) 600 grit polished coin. 45

Figure 3-11: Coating equipment: (a) WS-650 spin coater, (b) high pressure gas valve, and (c) balance. 46

Figure 3-12: Silicone R-2180 application process: (a) solution of silicone R-2180, (b) silicone added onto the coin, and (c) coating application done. .50

Figure 3-13: Curing process: (a) coated coins in a steel tray, (b) the tray placed into the furnace, (c) Vulcan 3-550 furnace, and (d) curing time and temperature set at the display.

Figure 4-1:Bare and qualified coated brass coins: (a) bare coin, (b) PUR coated coin, (c) silicone coated coin; and (d) ALG coated coin. .56

Figure 4-2: Comparison in color change between heat-treated and coated coins: (a) heat-treated coin; (b) bare coin .56

Figure 4-3: Bare, heat-treated and qualified coated nickel coins: (a) PUR coated coin; (b) ALG coated coin; (c) bare coin, and (d) heat-treated coin.

Figure 4-4: SLG coated coins produced at different spin speeds: (a) $500 \mathrm{rpm}$; (b) 700

rpm; and (c) 1000 rpm. .58 
Figure 4-5: Comparison in color change between the two types of liquid glass coated coins and bare coin: (a) bare coin, (b) SLG coated coin, and (c) ALG coated coin. .58

Figure 4-6: PTFE peeled off by nail. .59

Figure 4-7: Coins coated with polytetrafluorethylene. .59

Figure 4-8: Resin spreading due to centrifugal forces [90]. .60

Figure 4-9: Coating thickness variations with spin speed for PUR coated brass coins $( \pm 3$ $\mu \mathrm{m})$

Figure 4-10: Coating thickness variations with spin time for PUR coated nickel coins $( \pm 3$ $\mu \mathrm{m})$

Figure 4-11: Coating thickness VS. spin speed for brass and nickel coins for $30 \mathrm{~s}( \pm 3$ $\mu \mathrm{m})$

Figure 4-12: Coating thicknesses with spin time for ALG coatings on brass coins $( \pm 3$ $\mu \mathrm{m})$

Figure 4-13: Coating thicknesses with spin time for ALG coatings on nickel coins $( \pm 3$ $\mu \mathrm{m})$

Figure 4-14: Coating thicknesses VS. rotational speed for ALG coatings for $30 \mathrm{~s}( \pm 3 \mu \mathrm{m})$.

Figure 4-15: Tescan Vega-II XMU Scanning Electron Microscope (SEM) with an Energy

Dispersive X-ray (EDX) spectroscopy system. .66

Figure 4-16: SEM images of microstructure at the center of the polyurethane and advanced liquid glass coated coins processed at $500 \mathrm{rpm}$ : (a) PUR coating at 80X, (b) ALG coating at $80 X,(c)$ PUR coating at $1 \mathrm{kX}$, and (d) ALG coating at $1 \mathrm{kX}$. .68 
Figure 4-17: SEM images of microstructure at the edge of polyurethane and advanced liquid glass coated coins processed at $500 \mathrm{rpm}$ : (a) PUR coating at 80X, (b) ALG coating at $80 \mathrm{X}$, PUR coating at $1 \mathrm{kX}$, and (d) ALG coating at $1 \mathrm{kX}$. .68

Figure 4-18: SEM images of microstructure at the center of polyurethane and advanced liquid glass coated coins processed at $700 \mathrm{rpm}$ : (a) PUR coating at 80X, (b) ALG coating at $80 \mathrm{X}$, PUR coating at $1 \mathrm{kX}$, and (d) ALG coating at $1 \mathrm{kX}$.

Figure 4-19: SEM images of microstructure at the edge of polyurethane and advanced liquid glass coated coins processed at $700 \mathrm{rpm}$ : (a) PUR coating at 80X, (b) ALG coating at $80 \mathrm{X}$, (c) PUR coating at $1 \mathrm{kX}$, and (d) ALG coating at $1 \mathrm{kX}$ .70

Figure 4-20: SEM images of microstructure at the center of polyurethane and advanced liquid glass coated coins processed at $1000 \mathrm{rpm}$ : (a) PUR coating at 80X, (b) ALG coating at $80 \mathrm{X}$, PUR coating at $1 \mathrm{kX}$, and (d) ALG coating at $1 \mathrm{kX}$. .71

Figure 4-21: SEM images of microstructure at the edge of polyurethane and advanced liquid glass coated coins processed at $1000 \mathrm{rpm}$ : (a) PUR coating at 80X, (b) ALG coating at $80 \mathrm{X}$, PUR coating at $1 \mathrm{kX}$, and (d) ALG coating at $1 \mathrm{kX}$.

Figure 4-22: SEM image of microstructure at the center of the standard liquid glass coated coin processed at $500 \mathrm{rpm}$. .76

Figure 4-23: SEM images of microstructure of the polytetrafluorethylene coated coins processed at $700 \mathrm{rpm}$ : (a) grit blasting, (b) acid etching, and (c) polishing. .77

Figure 5-1: Artificial sweat chemical compositions: (a) sodium chloride, (b) sodium chloride powder, (c) sodium hydroxide, (d) sodium hydroxide powder, (d) acetic acid, and (f) acetic acid. 
Figure 5-2: $\mathrm{pH}$ value controlling of artificial sweat: (a) prepared liquid solution, (b) measuring $\mathrm{pH}$ value, and (c) $\mathrm{pH}$ value results.

Figure 5-3: Anti-corrosion tests simulating human sweat conditions: (a) experiment I

set-up, and (b) experiment II set-up.

Figure 5-4: Corrosion test for double-side coated coins: (a) two coins with a hole at the center, and (b) coins dipped in ALG. .82

Figure 5-5: Coin specimens selected for corrosion experiment III .84

Figure 5-6: Corrosion experiment III: (a) delicate task wipe, (b) wetted cloth on the wipe,

(c) beaker put on a heater, and (d) sealed beaker with aluminum foil .85

Figure 5-7: Corroded coins after experiment I. .86

Figure 5-8: Corroded coins after experiment II. .86

Figure 6-1: Schematic of CFU theory. 104

Figure 6-2: Three sizes of micropipettors.

Figure 6-3: Operating procedures for preparation of petri dishes: (a) LB and agar, (b) liquid solution of the mixture of LB and agar, (c) bottles in an autoclave, (d) liquid 20 cycle selected, (e) digital water bath, and (f) completed LB - agar plates. 106 Figure 6-4: Tested coins. (top left - bare copper, top right - ALG coated copper, lower left - nickel, lower middle-Al, and lower right - plastic)

Figure 6-5: Experiment I preparation process: turning on the flame, and (b) cleaning the bench by ethanol. 108

Figure 6-6: Transferring process: (a) vibrating blue tubes, (b) naming blue tubes by coin types, and (c) labeling black tubes. 109 
Figure 6-7: Serial dilution: (a) vibrating black tubes, and (b) completed dilutions. 109

Figure 6-8: Completed petri dishes for various coins: (a) nickel coin plates, (b) plastic coin plates, (c) Chinese coin plates, (d) double-side coated coin plates, and (e) bare copper coin plates.

Figure 6-9: Culturing process: (a) dishes in the incubator, and (b) incubator. 111

Figure 6-10: Schematic of MCN 520 serial dilution process.

Figure 6-11: Comparison in color change between the brass coins with LB solution and MCN 520 culture.

Figure 6-12: Collecting bacteria process in a sterile chamber: (a) cleaned components in the sterile chamber, (b) wetting cotton tips with LB solution, (c) wiping the surfaces of coins, and (d) labeled tubes 114

Figure 6-13: Schematic of experiment II process. 114

Figure 6-14: Real circulation coins studied in bacteria growth test.

Figure 6-15: Antibacterial ability of bare nickel coin: CFU vs. time. 116

Figure 6-16: Antibacterial ability of ALG coating on nickel coin: CFU vs. time. 116

Figure 6-17: Antibacterial ability of bare brass coin: CFU vs. time.

Figure 7-1: Coating thicknesses VS. rotational speed for the PUR and ALG coatings produced for $30 \mathrm{~s}$ spin duration on brass and nickel coins.

Figure 7-2: Coating thickness variations with spin time for the PUR and ALG coatings produced at $1000 \mathrm{rpm}$ on brass and nickel coins.

Figure 7-3: Schematic diagram for the mechanism of brass corrosion under wet-dry cyclic conditions [92]. 


\section{Chapter: Introduction}

\subsection{Background of the Research}

The Royal Canadian Mint ( $\mathrm{RCM})$ is a for-profit crown corporation producing circulation, numismatic and bullion coins for both domestic and international markets. It also operates full-service gold and silver refineries, storage facilities and precious metal exchange traded receipts. As the world-class producer of circulation and non-circulation coins for Canada and other countries, the RCM has been unceasingly improving and developing their products to meet the customer requirements and social/environmental regulations. Currently, the RCM aims at producing coins resistant to corrosion and bacteria.

\subsubsection{Corrosion Problems of Circulation Coins}

Circulation coins lose original gloss and color after being in circulation for a certain period of time. This change in surface appearance is mainly caused by human sweat, an acidic fluid that damages the surfaces of coins gradually. One of the objectives of this research was to improve the corrosion resistance of loonies (brass plated) and quarters (nickel plated). These two types of coins may have the following corrosion problems:

(1) The corrosion behavior of brass can be divided into two aspects: dezincification, and stress corrosion. Dezincification is a dealloying process which always occurs on the brass that contains more than $15 \%$ zinc. Zinc is released from the alloy faster than copper, and as a result, the surface of the coin becomes porous. The corrosion of copper occurs later. The other theory is that copper and zinc dissolve at the same time, and copper re-deposits when fluid chemistry changes [1]. 
(2) Pure nickel and most nickel based alloys have good corrosion resistance than stainless steels and excellent mechanical properties. Nickel is also resistant to aqueous corrosion under certain environments. Nickel is an ideal base material for the coins as it can be alloyed with significant quantities of copper, iron, and tungsten. Appreciable corrosion of nickel can be observed only in an aggressive acidic medium or in the presence of ions such as $\mathrm{Cl}^{-}[2]$. In this case, the quarter (nickel plated) has better anti-corrosion ability than the loonie (brass plated).

\subsubsection{Bacterial Infection Problems}

Circulation coins carry contaminants and bacteria when being passed from one person to another. This presents significant health issue when proper hand washing is not followed immediately after handling the coins. Repeated chemical spray or application to remove the bacteria has led to a growing resistance of micro-organisms against antibacterial treatment [3], not to mention the negative impact on the environment. If the coins can resist bacterial growth, the spreading or ingestion of bacteria due to the use of coins can be eliminated or reduced. As such, it is beneficial to the well being of general public if circulation coins have effective antibacterial function.

Based on the information available in literature, there seem to be a wide variety of materials with anti-bacterial function. Bacterial infection in medical implants is a well-recognized risk, leading to fatality in severe cases. As such, there have been many research teams in the world focusing on the development and testing of antibacterial coatings or devices [4]. However, the antibacterial coating for the coins requires certain unique characteristics such as the need to maintain the original surface features (color and 
reflectivity), long term durability (no spalling or cracking and resistant to wear and corrosion) and also relatively low cost. These requirements dictate the use of a polymer based, transparent thin coating with antibacterial features incorporated.

\subsection{Objectives of the Research}

\subsubsection{Coin Selection}

This research focuses on two most commonly used coins: quarter and loonie. The former has a matrix of steel $(94 \mathrm{wt} \%)$ and copper $(3.8 \mathrm{wt} \%)$ and plated with nickel $(2.2$ $\mathrm{wt} \%$ of the total weight) for corrosion resistance. The latter is made of iron matrix and plated with brass $(70 \mathrm{Cu}-30 \mathrm{Zn})$ to impart golden color. The tested coins were all blanks supplied by RCM.

\subsubsection{Coating Material Selection}

Five candidate coating materials were selected in this research. These are polyurethane (PUR), polytetrafluorethylene (PTFE), advanced liquid glass (ALG), standard liquid glass (SLG), and silicone R-2180. ALG is the only material that has reported anti-bacterial ability among the five candidates, therefore it was the focus of this study.

\subsection{Tasks and Methodologies}

The application of polymer coatings requires three processes: pre-process (surface treatment), deposition process and curing. This research began with extensive literature review and comparison of several potential coating systems based on their antibacterial 
function, durability, availability and cost. The deposition is primarily carried out by spinning due to the need for optical performance. The coated coins were investigated for their optical property and coating/substrate adhesion in the initial stage. The acceptable ones (adherent ability and surface appearance) were examined to obtain information on microstructure, coating thickness, anti-corrosion and antibacterial performance. Wear characteristics are also important for circulation coins because coins are handled by people every day; another team member focuses his study on tribological behavior of coated coins. The main tasks in the present research are summarized as follows:

(1) The materials PUR, PTFE, ALG, SLG, and silicone R-2180 were coated on brass and nickel coins using spin coating technique with different process parameters (spin speed and spin duration).

(2) The coated coins were examined visually to screen the initial coating candidates thus minimizing the number of the coated coins for further corrosion and bacteria tests.

(3) The microstructures of the acceptable coatings were analyzed using Scanning Electron Microscope (SEM) equipped with Energy Dispersive X-ray (EDX) spectrometer.

(4) The coating thickness was assessed based on the weight changes, which were obtained by experimental measurement using a weigh balance with precision to $+/-$ $0.1 \mathrm{mg}$. Figure 1-1 shows the weight scale used in this research. This scale is supplied by Acculab. 


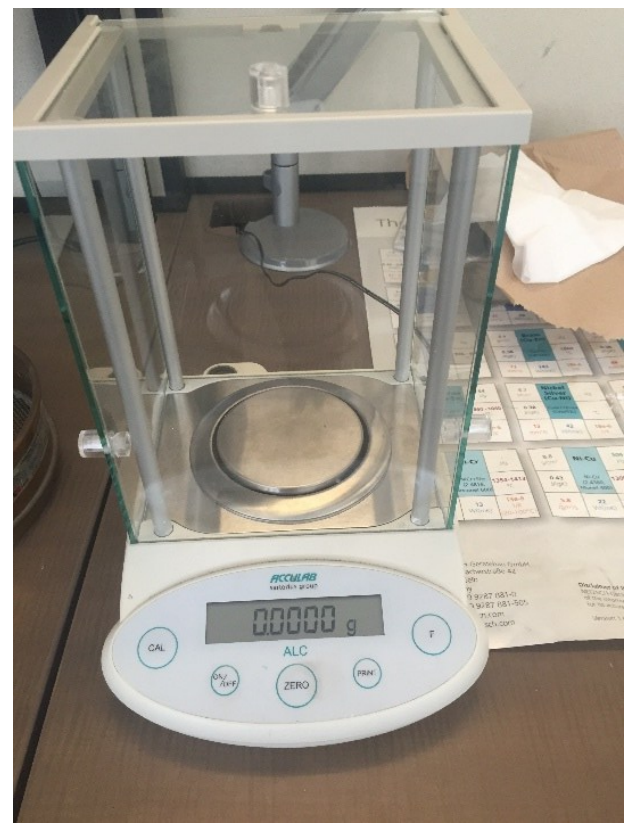

Figure 1-1: Weight scale.

(5) Corrosion test was performed by immersing the coated coins into artificial sweat solution. In order to further investigate the corrosion behavior of these coatings, visual examination, and SEM/EDX analyses were conducted on the coins to determine the anti-corrosion ability of each coating.

(6) Bacterial test was carried out on bare brass, bare nickel and ALG coated coins. The anti-bacterial abilities of the bare and coated coins were determined via the colony-forming unit (CFU) calculation..

\subsection{Structure of the Thesis}

This thesis consists of eight chapters including the introduction of the research, literature review, candidate coating materials for circulation coins and coating fabrication experiments, characterization of coating's microstructure such as defects and cracks, as well as coating thickness, corrosion tests and results, bacterial tests and results, discussion, and finally conclusions and future work. The contents of each chapter are summarized as 
follows:

Chapter 1 introduces the background of the research including currently used circulation coins and the existing problems pertinent to corrosion and bacterial transfer; methods of applying the coatings and coating characterization and lastly the objectives of this research

Chapter 2 is the literature review covering the history of circulation coins, minting technologies, requirements for the coating on the coins, antibacterial coatings based on metallic, polymer and composition systems, anti-corrosion coatings including conducting polymers and self-healing polymers. Finally, coating deposition via spin, dipping, and plasma are discussed.

Chapter 3 introduces the candidate coating materials for the circulation coins, explains the reasons for the selection of these materials, and describes the coin surface preparation and coating fabrication.

Chapter 4 provides the details of experiments conducted to characterize the coated coins. Visual examination, SEM analysis, relationship between coating thickness and spin speed and time are performed to characterize five initial coating materials.

Chapter 5 describes the anti-corrosion tests on the coated and bare coins to investigate the effectiveness of the coatings on the corrosion resistance of the coins. Different testing methods are used on the coated and bare coins and the test results are analyzed and compared.

Chapter 6 describes the bacterial tests on the coated and bare coins to investigate the effects of coatings in terms of anti-bacteria ability. Different bacterial media are prepared 
on the ALG coated and bare coins and the test results are analyzed and compared. By comparing the amounts of bacteria remaining on the coating and bare coins, the benefit of ALG is determined. The amount of bacteria on the coin specimens are calculated using the CFU method.

Chapter 7 discusses the experimental results from visual examination, coating thickness analysis, microstructure of the coatings, anti-corrosion and anti-bacterial tests.

Chapter 8 provides a summary of the outcomes of this research and outlines the main contributions. In addition, future work towards the final target of this project is proposed. 


\section{Chapter: Literature Review}

\subsection{History of Circulation Coins}

Coins are currencies made of metal which have standard design. Although it is hard to determine the real origin of the earliest coins, coinage was a Greek phenomenon. The use of coinage was widely spread in Greek territories [5].

The ancient $\mathrm{Pb}$ coin (Figure 2-1) is now on display at the National Archaeological Museum of Taranto (Italy). This coin was discovered in 1948 near Parabita (province of Lecce, Italy). It was created in the $3^{\text {rd }}$ or $4^{\text {th }}$ century $\mathrm{BC}$. The $\mathrm{Pb}$ coin has a bi-layer coating, with $\mathrm{Cu}$ interlayer and an $\mathrm{Ag}$ top layer. In modern society, it is very rare that $\mathrm{Ag}$ is cemented directly onto a $\mathrm{Pb}$ substrate. Iron was used to recover $\mathrm{Cu}$, for coin making, from sulphate solution in ancient China and Arabic Spain. Ancient people used simply electrochemical methods to coat coins, for example, they dissolved metallic Ag in nitric acid to generate Ag containing salt solutions, and then dipped copper blanks into these solutions to make a copper or silver coating. Copper solutions were made by different types of hydration process [6].

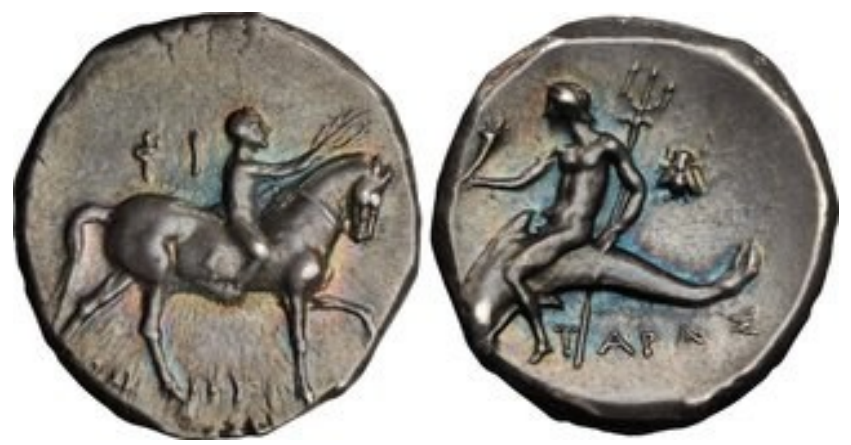

Figure 2-1: Ancient Italy coins in $3^{\text {rd }}$ century BC [6].

In Roman times, coating technologies in creating $\mathrm{Au}$ or Ag layer as thin as possible were developed to save precious metals. The Greeks manufactured silver plated coins by 
copying the methods from the Romans. According to a research on a fragment of a Greek plated coin made by Athens in 404 BC (Figure 2-2), a silver layer with thickness of approximately $150 \mu \mathrm{m}$ was placed on pure copper core. It was believed that a copper blank was first wrapped with a silver foil on both sides and then striking force and heat were applied to bond and diffuse the bonding. This manufacturing method improved the adherence of the coating layer and copper substrate [7].
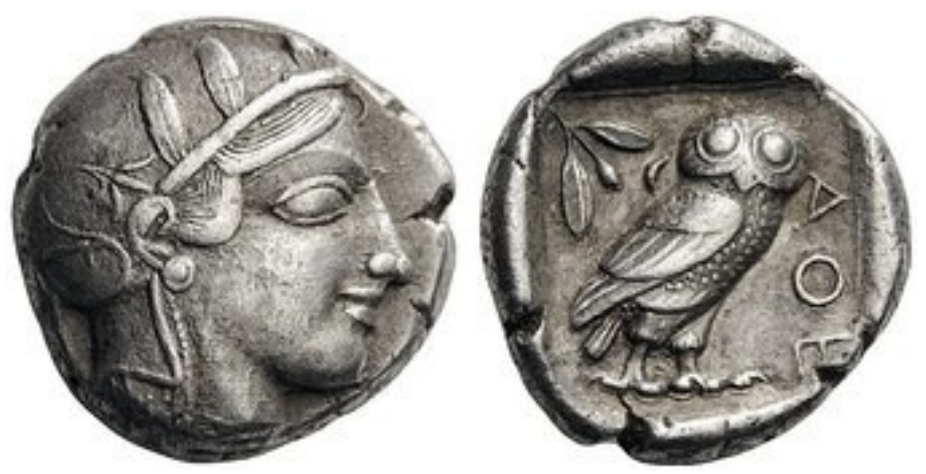

Figure 2-2: Ancient Athens in 404 BC [8].

During fifth and sixth centuries AD, people in Rome used bronze coins for daily usage. According to the microstructures of the coins investigated with optical microscopy and $\mathrm{SEM}, \mathrm{Cu}-\mathrm{Sn}-\mathrm{Pb}$ alloys were the main elements in these coins [9].

In 1982, the Italian Government Mint first produced a large scale of bimetallic coins (500 Lire), see Figure 2-3. Although the costs of manufacturing the bimetallic coins were higher and the manufacturing process was more complex, these coins had advantages, for example, ease of distinguishing and good aesthetic features. The coins were produced in two steps: the center was first placed inside the outer ring, and then the two parts were forced together [10]. 


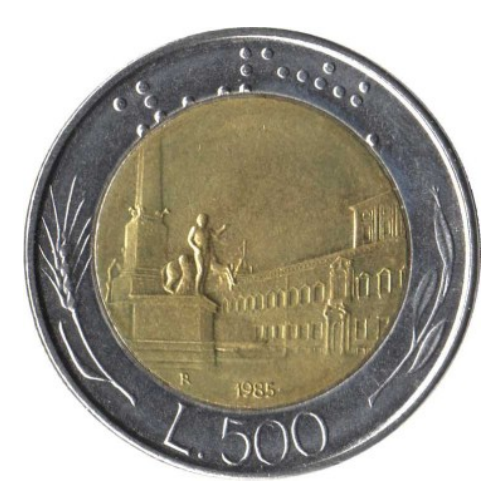

Figure 2-3: 500 Lire in 1982 [10].

\subsection{Coin Manufacturing Methods}

\subsubsection{The Royal Canadian Mint}

In Canada, over 1 billion circulation coins are minted every year in Winnipeg. The effigy of monarch has been stroked on coins since 1908. There are six types of circulation coins in Canada, as listed in Table 2-1 [11].

\begin{tabular}{cccc}
\hline & five-cent & ten-cent & twenty-five-cent \\
\hline \multirow{3}{*}{ Composition } & $94.5 \%$ steel, & $92 \%$ steel, & $94 \%$ steel, 3.8\% copper, \\
& $3.5 \%$ copper, & $5.5 \%$ copper, & $2.2 \%$ nickel plating \\
& $2 \%$ nickel plating & $2.5 \%$ nickel & two-dollar \\
\hline fifty-cent & one-dollar & Outer ring: multi-ply nickel \\
& $93.51 \%$ steel, & Multi-ply brass & plated steel insert: multi-ply \\
Composition & $4.75 \%$ copper, & plated steel & brass plated aluminum \\
& $2.1 \%$ nickel plating & & bronze \\
\hline
\end{tabular}

Table 2-1: Circulation coins in Canada (chemical composition in wt\%) [11].

Since 2000, multi-ply plated steel (MPPS) technique has been applied to manufacture one-cent, five-cent, twenty-five-cent and fifty-cent circulation coins. MPPS is a unique electroplating process where the steel core is plated with alternating layers of different metals such as copper, nickel and brass. Multi-ply method reduces the usage of nickel, 
copper or bronzer than other minting techniques. The multi-ply process is more efficient than single-ply plating so it also saves time. Thanks to the MPPS, RCM can control the plating thickness of each layer and develop the electromagnetic signatures that the coins, produced by the non-plated processes, do not possess [11]. On April 10 ${ }^{\text {th }}, 2012$, the Royal Canadian Mint created new one-dollar and two-dollar circulation coins, as shown in Figure 2-4. The leading-edge security features and multi-ply plated steel technology make the coins more durable and cost-effictive [11]. In addition, the tails side of both coins has a laser micro-engraving, and the two-dollar coin also has a virtal image and edge-lettering [12][13].

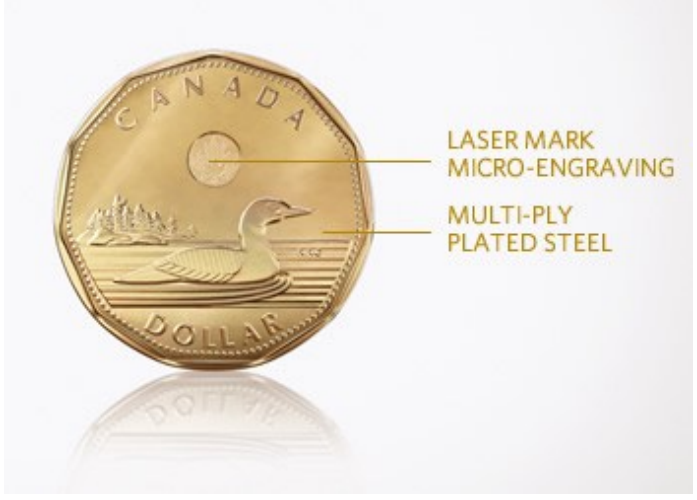

(a)

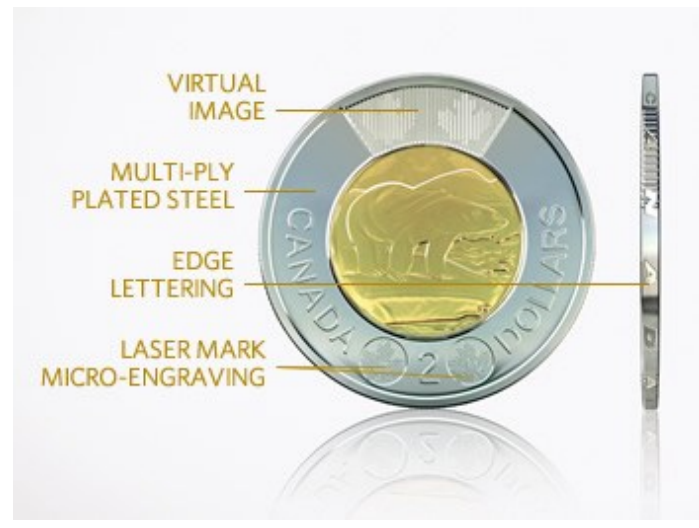

(b)

Figure 2-4: Latest Canadian coins: (a) one-dollar coin, and (b) two-dollar coin [11].

The Winnipeg Mint produces large numbers of circulation coins every day for Canadian and foreign circulation. The producing method can be divided into four main process: (1) blanks are punched out from large coiled strips of core steel by high pressure at a rate of 13000 blanks per minute; (2) the blanks are processed to remove rough edges and rimmed, annealed, and cleaned; (3) multi-ply plating technique is used to enhance security and provide surface features (4) after plating, the coins are dried, polished and inspected by camera to determine the color and surface defects [11] 


\subsubsection{The United States Mint}

The first circulation coin was produced in the United States in 1793. In the United States, there are seven coin denominations, as described in Table 2-2 [14].

\begin{tabular}{llllllll}
\hline & Cent & Nickel & Dime & $\begin{array}{l}\text { Quarter } \\
\text { Dollar }\end{array}$ & $\begin{array}{l}\text { Half } \\
\text { Dollar }\end{array}$ & $\begin{array}{l}\text { Presidential } \\
\$ 1\end{array}$ & $\begin{array}{l}\text { Native } \\
\text { American } \\
\$ 1 \text { Coin }\end{array}$ \\
\hline & Copper & Cupro- & Cupro- & Cupro- & Cupro- & -Brass & Brass \\
Composition & plated & Nickel & Nickel & Nickel & Nickel & $88.5 \% \mathrm{Cu}$ & $88.5 \% \mathrm{Cu}$ \\
& Zinc & $25 \%$ & $8.33 \%$ & $8.33 \%$ & $8.33 \%$ & $6 \% \mathrm{Zn}$ & $6 \% \mathrm{Zn}$ \\
& $2.5 \%$ & $\mathrm{Ni}$ & $\mathrm{Ni}$ & $\mathrm{Ni}$ & $\mathrm{Ni}$ & $3.5 \% \mathrm{Mn}$ & $3.5 \% \mathrm{Mn}$ \\
& $\mathrm{CU}$ & & & & & $2 \% \mathrm{Ni}$ & $2 \% \mathrm{Ni}$ \\
\hline
\end{tabular}

Table 2-2: Circulation coins in the United States (chemical composition in wt\%) [14].

The minting process in the United States is composed of six steps. The first step is blanking. Except one cent coin, the other coins are punched from coiled strips of metal on a blanking press. One cent blanks are manufactured externally. The second step is annealing, washing and drying. The cupronickel blanks are softened by annealing in a special furnace and cleaned by a chemical solution in rotating barrels, after that they are washed, cleaned and dried. The third step is upsetting. The planchets are performed with an edge-rolling operating on the upsetting machine. This machine can roll the edges for the same thickness on the one-cent and five-cent coins. In addition, the edge is hardened during the upsetting process thus it can prevent the soft metal from squirting at the interface between the collar and die during stamping. Finally, the blanks are stamped with the designed patterns. This is a single strike. Most presses can strike four coins at one time, while others simultaneously strike two coins. After manufacturing process is completed, technologists use magnifying glass to inspect the coins and to see if they have 
any defects. At the end, an automatic counting machine counts the coins and drops them into secured container [14][15].

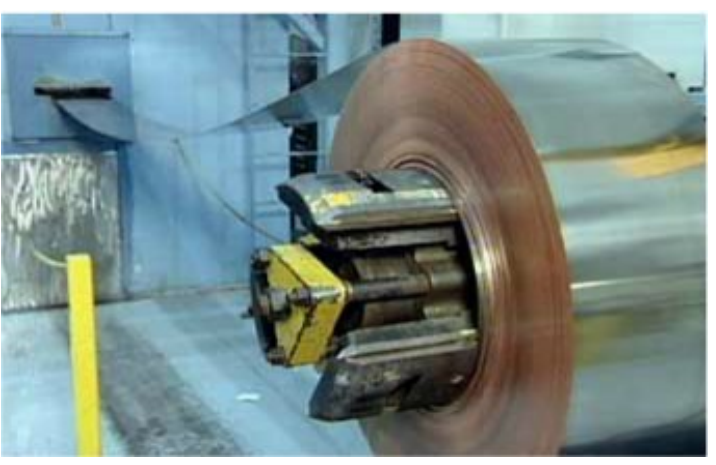

(a)

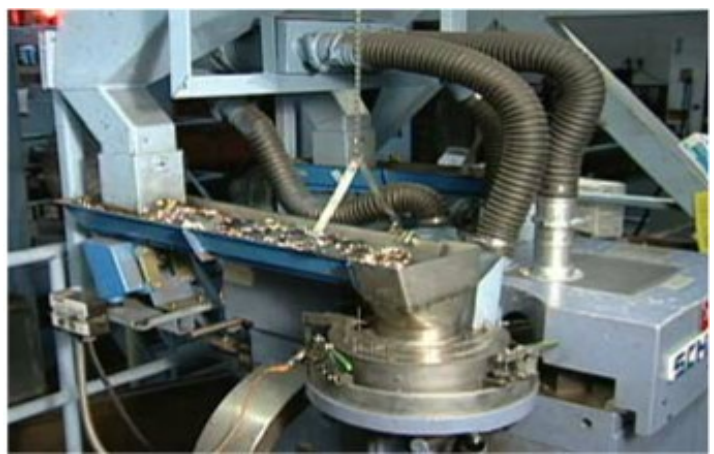

(c)

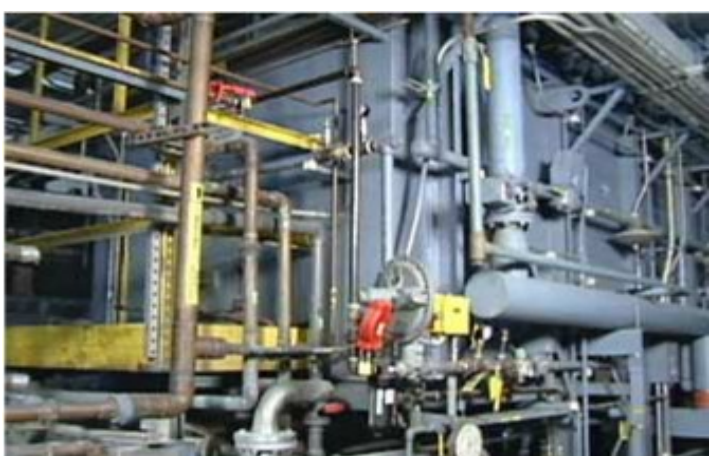

(b)

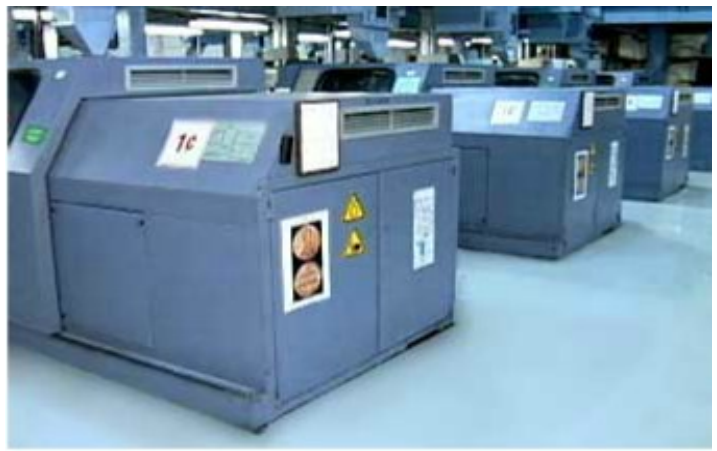

(d)

Figure 2-5: The manufacturing process of circulation coins in the US mint: (a) blanking, (b) annealing, (c) upsetting, and (d) stamping [15].

\subsection{Requirements for Coin Materials}

\subsubsection{Wear Resistance}

Wear test for circulation coins can be conducted with various types of vibratory and tumbling machines [16]. In 1968, 434 nickel Canadian 5 cent coins from 1922 to 1966 were collected to examine the weight changes of the coins after circulation; the obtained weight change data are given in Table 2-3. It is seen that 10 cent and 25 cent coins had poorer anti-abrasion ability than 5 cent coin. 


\begin{tabular}{|c|c|c|c|c|c|c|}
\hline \multirow[b]{2}{*}{ Coin } & \multicolumn{6}{|c|}{ Nominal dimensions } \\
\hline & $\begin{array}{l}\text { Weight } \\
\text { (g) }\end{array}$ & $\begin{array}{c}\text { Diameter } \\
(\mathrm{mm})\end{array}$ & $\begin{array}{l}\operatorname{Rim} \\
(\mathrm{mm})\end{array}$ & $\begin{array}{c}\text { Surface area } \\
\qquad\left(\mathrm{mm}^{2}\right)\end{array}$ & $\begin{array}{l}\text { Weight loss } \\
\text { rate (mg/year) }\end{array}$ & $\begin{array}{l}\text { Average surface } \mathrm{Ni} \\
\text { loss rate }(\mu \mathrm{m} / \text { year })\end{array}$ \\
\hline $\begin{array}{l}5 \text { cent } \\
(1986)\end{array}$ & 4.54 & 21.2 & 1.75 & 823 & 0.85 & 0.12 \\
\hline $\begin{array}{l}5 \text { cent } \\
(1984)\end{array}$ & 4.54 & 21.2 & 1.75 & 823 & 1.0 & 0.14 \\
\hline $\begin{array}{l}10 \text { cent } \\
(1984)\end{array}$ & 2.07 & 18.0 & 1.10 & 571 & 1.3 & 0.26 \\
\hline $\begin{array}{l}25 \text { cent } \\
(1984)\end{array}$ & 5.05 & 23.9 & 1.50 & 1010 & 2.7 & 0.30 \\
\hline
\end{tabular}

Table 2-3: Weight loss rates of Canadian nickel coins [16].

The common wear test on coins is to tumble coins in a rotating cylinder and then measure the weight losses after a certain period of time. Before the test, the coins should be cleaned and weighed, and then immersed in an artificial human sweat solution. Finally, they are placed inside a rotating cylinder. After the test, the coins are weighed again to evaluate the weight changes [16].

\subsubsection{Anti-corrosion Measures}

Coins made of gold, silver, and iron would be corroded when being exposed in air during daily use. Compounds such as oxides, sulfides, carbonates and others can form on the surfaces of coins because of chemical and physical reactions with oxygen, water vapor, carbon dioxide as well as other organic compounds. These compounds then form dark spots on the surfaces. They may also cause cracking because the hardness and the abrasion resistance of such areas are affected [17].

Tarnish on the gold coins are commonly seen in the museum collections. Brown spots were seen on the surfaces of Austrian gold metals minted in 1736 to 1879 and the 
Tensho - Oban gold coin in the Museum of the Bank of Japan minted in the late sixteenth century. In order to analyze the reasons for tarnishing, Chinese gold panda coins, produced in 2001, were investigated. Inductively coupled plasma mass spectrometry (ICP-MS) was used to analyze the chemical composition of the corroded coins; a XJZ-1A optical/metallographic microscope (OM) was used to examine the visible tarnish spot; the micrograph and components of the spots were obtained via SEM and EDX [18]. From these analysis results, it was suggested that the tarnish was mainly caused by the silver impeded in the coins. The main compounds of the tarnish were silver sulfide $\left(\mathrm{Ag}_{2} \mathrm{~S}\right)$ and silver sulfate $\left(\mathrm{Ag}_{2} \mathrm{SO}_{4}\right)$. To prevent gold coins from tarnishing, transparent polysilicone coating was developed to prevent the coins from corrosion. This organic silicone coating was prepared by the reaction between the alkoxy groups of methyltrimethoxy-silane (MTMS) and $\gamma$-aminopropyltriethoxysilane (APTES) and hydroxyl groups of hydroxyl terminated silicone oil (HTSO) with an acid resin as the catalyst [17].

The research group of Universidade do Porto conducted a study on a medieval coin (from 1155 - $1188 \mathrm{AD})$. The coin was composed of $\mathrm{Au}, \mathrm{Cu}(30 \mathrm{wt} \%)$ and $\mathrm{Ag}(33 \mathrm{wt} \%)$, and other elements $(1 \% \mathrm{~Pb}+0.2 \% \mathrm{Sn}+0.4 \% \mathrm{Zn}$, in weight $)$. They investigated the corrosion products on the coin. Copper and silver suffered from corrosion due to the reaction with chlorides as follows [19]:

$$
\begin{aligned}
& 2 \mathrm{Ag}+2 \mathrm{NaCl}+1 / 2 \mathrm{O}_{2}+\mathrm{H}_{2} \mathrm{O} \leftrightarrows 2 \mathrm{AgCl}+2 \mathrm{NaOH} \\
& 2 \mathrm{Ag}+\mathrm{H}_{2} \mathrm{~S}+1 / 2 \mathrm{O}_{2} \leftrightarrows \mathrm{Ag}_{2} \mathrm{~S}+\mathrm{H}_{2} \mathrm{O} \\
& 2 \mathrm{Ag}+1 / 2 \mathrm{O}_{2} \leftrightarrows \mathrm{Ag}_{2} \mathrm{O} \\
& 1 / 2 \mathrm{O}_{2}+2 \mathrm{H}_{2} \mathrm{O}+2 \mathrm{CuCl} \leftrightarrows \mathrm{Cu}_{2}(\mathrm{OH})_{3} \mathrm{Cl}+\mathrm{HCl}
\end{aligned}
$$




$$
\mathrm{HCl}+\mathrm{Cu} \leftrightarrows \mathrm{CuCl}+1 / 2 \mathrm{H}_{2}
$$

\subsubsection{Anti-bacteria}

Although there are many reports on the bacterial examination of paper currency, few studies were reported on coins. In fact, bacteria can attach to coins, which can become a source of infections. Two research teams in Lisbon and Kenya attempted to determine the bacterial diversity on circulation coins. Scientists in Kenya classified coins by users in different occupations. Coins were collected from greengrocers, shoe shiners, butchers, restaurant attendants, roast corn vendors, and school children. In this experiment, coins were saved in plastic containers; and then, they were transported to the laboratory [21]. Similarly, in Lisbon, researchers selected coins from two cities, Casablanca and Lisbon [22]. This selection was based on that these two countries are only $585 \mathrm{~km}$ apart, have a similar climate and environment but distinctly different cultural habits. The selected coins, Moroccan Dirham (MAD in Casablanca) and Euro (EUR in Lisbon) were chosen respectively from Casablanca's Voyageurs train station and Institution Superior Technology (IST). All collected coins were put in plastic bags, which were marked with the location, gender and storage (pocket or wallet). Both teams used sterile tryptone soy broth (TSB) as a catalyst to help aerobic bacteria grow as TSB provides nutrients for fast growth of bacteria [22][21].

\subsubsection{Experiments in Kenya}

Several types of bacteria were considered in this research. Generally, bacterial can be classified as gram-positive and gram-negative bacteria. The difference lies in the cell wall structure. Gram-positive bacteria have thick peptidoglycan in the bacterial cell wall, while 
the peptidoglycan of gram-negative bacteria is thin [20]. Table 2-4 shows the results of the bacteria diversities detected on the sample coins. First of all, Bacillus cereus and Staphylococcus aureus were analyzed as they can cause various diseases among humans and animals [21]. Their toxins are pathogenic agents in food, thus infection will occur if people handle food directly by hand after they use coins. Secondly, Enterobacteria and Enterococci are also potential pathogens which can cause opportunistic infections if hosts have weak immunity. It was found that both bacteria and fungi survived on the coins collected. Except gram negative cocci (which can cause skin infections and fever), every type of bacteria was found on the coins. In conclusion, coins have potential risk of spreading infections especially when food and money are handled together [21].

\begin{tabular}{|c|c|c|c|c|c|}
\hline \multirow{3}{*}{ Coin source } & \multicolumn{5}{|c|}{ Type of organism, total number of isolates and proportion (\%) of coins contaminated } \\
\hline & G+ve Bacilli & $\mathrm{G}+\mathrm{ve}$, catalase & $\mathrm{G}+\mathrm{ve}$, catalase & G-ve, rods & G-ve, cocci \\
\hline & No. $(\%)$ & $\begin{array}{c}+\mathrm{ve}, \text { cocci } \\
\text { No. }(\%)\end{array}$ & $\begin{array}{c}\text {-ve, cocci } \\
\text { No. (\%) }\end{array}$ & & \\
\hline Butchers & 240 & 240 & 240 & 740 & 0 \\
\hline $\begin{array}{l}\text { Matatu } \\
\text { conductors }\end{array}$ & 5100 & 120 & 120 & 0 & 0 \\
\hline Greengrocers & 240 & 240 & 240 & 540 & 0 \\
\hline $\begin{array}{l}\text { School } \\
\text { children }\end{array}$ & 5100 & 7100 & 480 & 240 & 120 \\
\hline $\begin{array}{l}\text { Maize } \\
\text { Roasters }\end{array}$ & 5100 & 120 & 120 & 0 & 0 \\
\hline Shoe shiners & 340 & 7100 & 120 & 120 & 0 \\
\hline $\begin{array}{l}\text { Food kiosks } \\
\text { attendants }\end{array}$ & 5100 & 360 & 240 & 340 & 0 \\
\hline $\begin{array}{l}\text { Grocery shop } \\
\text { attendants }\end{array}$ & 240 & 360 & 0 & 360 & 120 \\
\hline $\begin{array}{l}\text { Total number } \\
\text { of isolates } \\
\text { and isolate } \\
\text { type } \\
\text { proportions }\end{array}$ & 2931.8 & 2623.7 & 1314.3 & 2123 & 22.2 \\
\hline
\end{tabular}

Table 2-4: Percentage of the five coins found contaminated with the particular type of microorganism. 


\subsubsection{Experiments in Lisbon}

The experiment results of bacterial diversity in Lisbon were almost the same as those in Kenya. Additionally, the team in Lisbon summarized useful conclusions about the distribution of bacteria. One of them was that most bacteria was found near the rim engraved at the edges of coins, where dirt was easily trapped and helped bacteria survive. Another conclusion was that coins in pockets generated more bacteria than coins in wallets [22].

\subsection{Corrosion Resistant Polymer Coatings}

Metals such as aluminum, copper, and zinc have good mechanical properties and are widely applied in the coin industry. However, corrosion always causes surface material loss of these metals [23]. Corrosion often occurs when metallic materials are in moist or chloride containing environments. Therefore, some deposition and application technologies of the coatings on coins have been developed to increase corrosion resistance. Although long-term corrosion cannot be avoided, it can be delayed by corrosion inhibiting coatings [24]. Organic coatings are often used to protect metallic substrates from atmospheric corrosion due to their inertness [25]. Inorganic ingredients usually work as corrosion inhibitors. Organic-inorganic composite coatings, as such conducting polymers (CPs), are attractive in providing corrosion protections [26].

\subsubsection{Conducting Polymer Coatings}

Conducting polymers (CPs) such as polyaniline (Pani) and polypyrrole (Ppy) are usually deposited on carbon steel, iron, and other metals [28]. Polyaniline is the general 
name for many oxidation states of linear polymers made from aniline $\left(\mathrm{C}_{6} \mathrm{H}_{5} \mathrm{NH}_{2}\right)$. It has been extensively studied because of its good environmental stability and ease of synthesis. In 1985, DeBerry reported that Pani could reduce the corrosion rate of stainless steels in sulfuric acid [27][28]. Ppy films on iron performed well as physical barriers to chemical reagents, and reduced corrosion rates. The degree of corrosion protection of conducting polymer coatings depended on their structure and electronic properties [29].

Electrochemical deposition is the easiest technique to apply conducting polymers onto metallic substrates. A small concentration (2 - $10 \mathrm{wt} \%)$ of inorganic pigments as fillers are usually added into CPs to improve corrosion resistance. CPs added to other organic coatings, such as epoxy resins, polyurethanes, polyalkyds, can provide good corrosion protection in harsh environments [26].

\subsubsection{Self-healing Organic Polymer Coatings}

Autonomic healing materials can repair themselves and continuously provide corrosion resistance, have gained much attention recently. These polymers can repair themselves when they are damaged without intervention, thus reducing maintenance costs. Methods for gaining the healing function have been developed including encapsulation, reversible chemistry, nanoparticle phase separation, and others [31]. Among these self-healing materials, however, microencapsulation is the most efficient and widely used method [31]. Traditional polymeric coatings are very thin and in direct contact with the corrosive environment, thus $\mathrm{O}_{2}$ and $\mathrm{H}_{2} \mathrm{O}$ cannot be avoided when the coatings are damaged. Self-healing coatings are highly stable in the corrosive environment [29].

Figure 2-6 shows the self-healing mechanism where the coating will react with water in 
air, and self-heal.

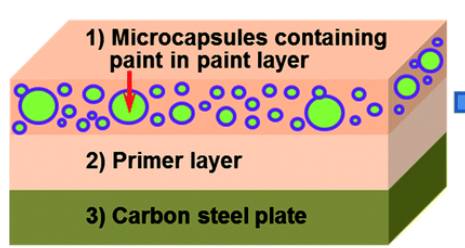

(a)

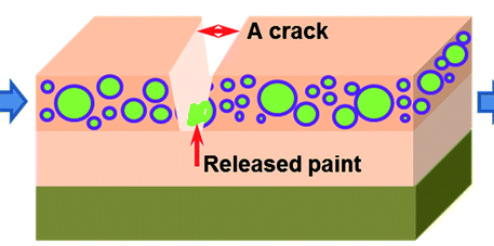

(b)

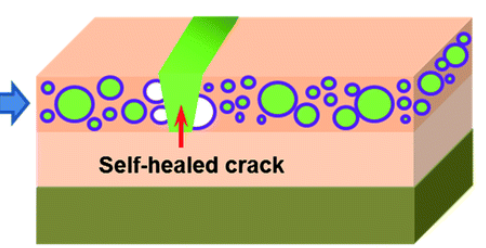

(c)

Figure 2-6: Schematic of the self-healing process of polymers: (a) coating having microcapsules with self-healing protecting paint on carbon steel plate, (b) paint released by damage to the coating layer, and (c) a crack covered by a self-healed paint coating [31].

\subsubsection{Polyurethane Microcapsules}

Polyurethane (PUR) microcapsules, containing hexamethylene diisocyanate (HDI), have good self-healing properties. When microcapsules are combined with polydimethylsiloxane (PDMS) healing agent, the resulting composite polymer would have better anti-corrosion abilities. A PUR microcapsule shell can be made up of diol-diisocya-nate prepolymers based on 1, 4 -butanediol (BD), or 4,4-diphenylmethane diisocyanate (MDI) [31].

According to Figure 2-7 and Figure 2-8, the healing efficiency depends on the size of PUR microcapsule and the concentration of the capsule. The relationships between the efficiency and concentration, and the efficiency and the size of capsule, are quite linear. The healing ability increases with the size and the concentration of the capsule [31].
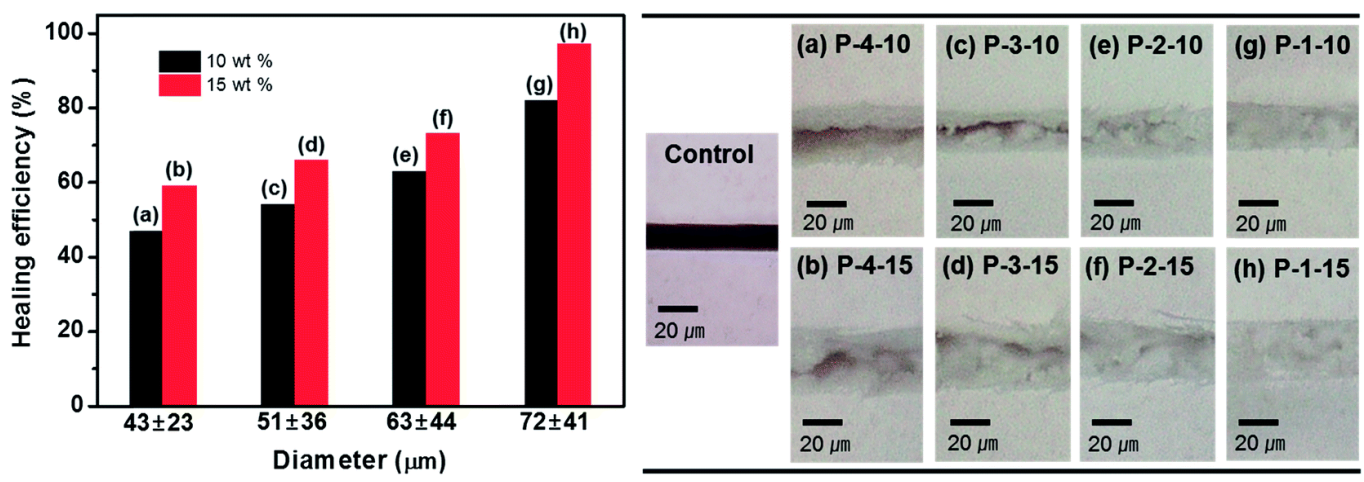

Figure 2-7: Paint protection test results determined via scratch test considering the effect of capsule diameter of PU microcapsules [31]. 

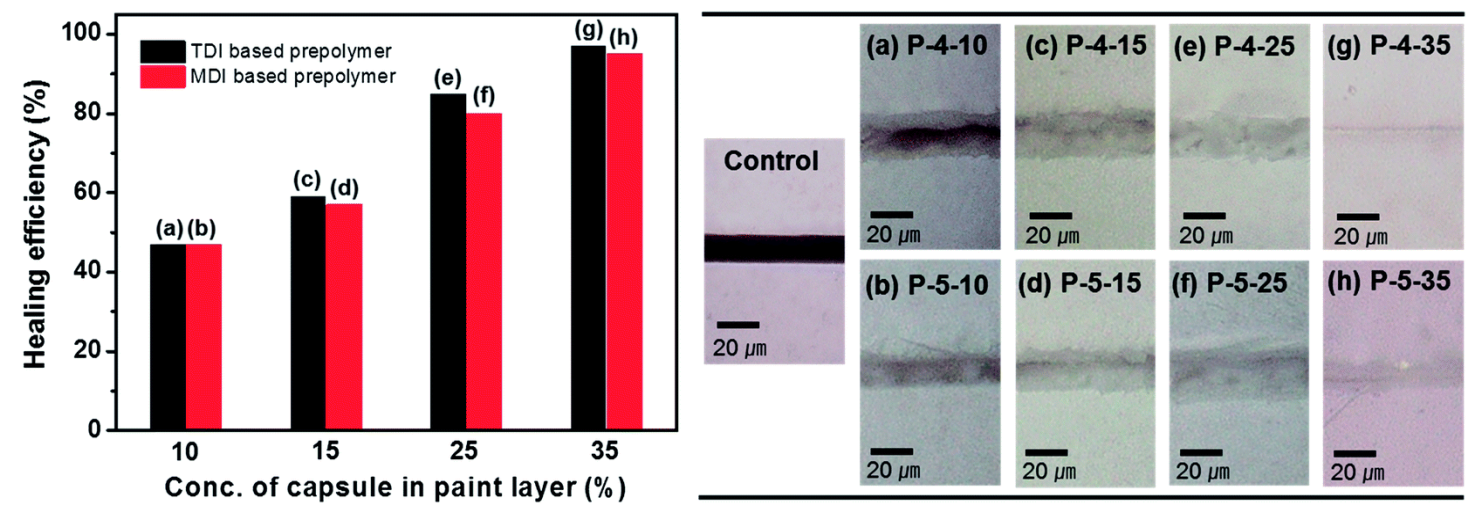

Figure 2-8: Paint protection test results determined via scratch test according to the effects of the additives and capsule concentration in the paint layer [31].

\subsubsection{Organic Silane Microcapsules}

Organic silane molecules can hydrolyze in a wet environment and form a solid film, a potential self-healing material without the help of self-healing additive. Organic silane could be synthesized with poly(urea-formaldehyde) (PUF) and perfluoroocyl triethoxysilane (POTS) [31]. Figure 2-9 presents the difference between a control coating and a self-healing coating with organic silane.
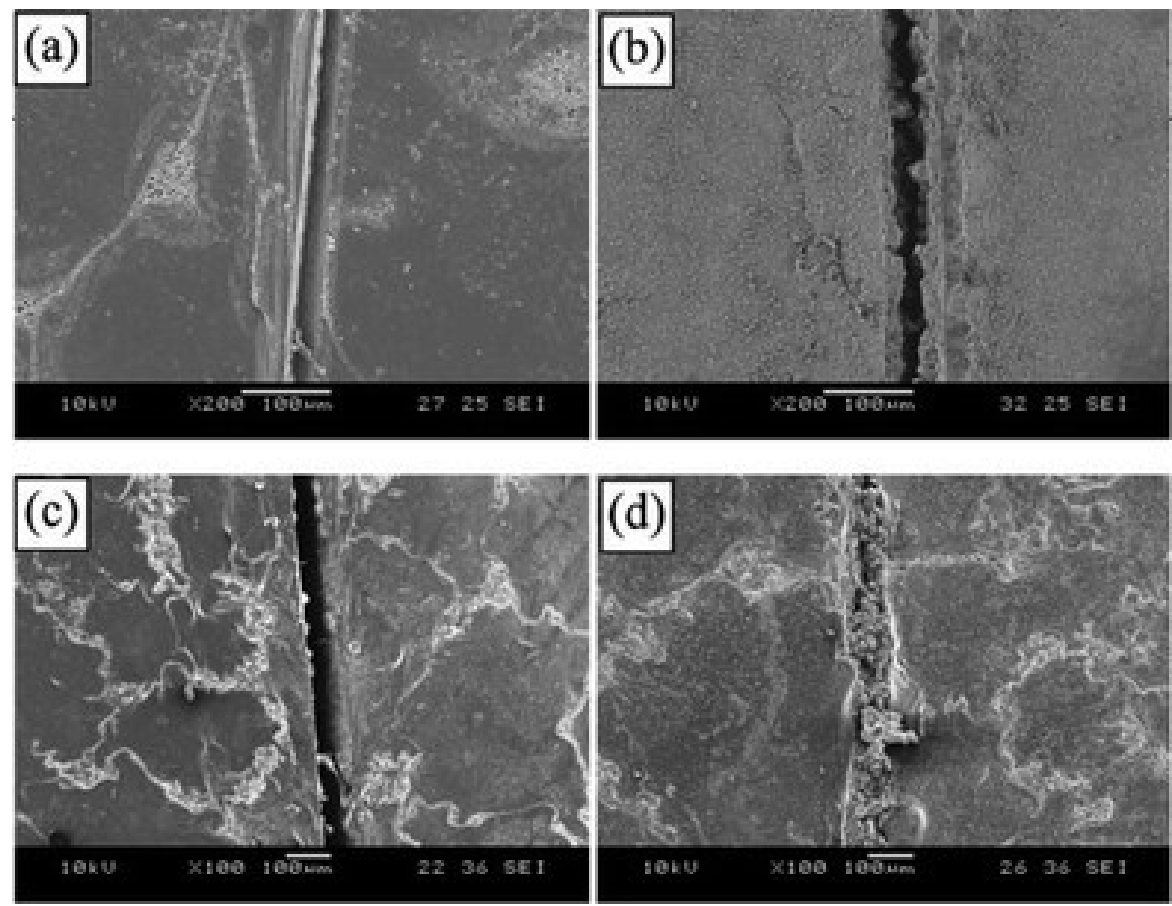

Figure 2-9: SEM images of the scratched regions before immersion: (a) control coating before immersion, (b) self-healing coating before immersion, (c) control coating after immersion in salt water for $48 \mathrm{hr}$, and (d) self-healing coating after immersion in salt water for $48 \mathrm{hr}$ [31]. 


\subsubsection{Other Self-healing Coatings}

The following are are few more coatings with self-healing capability:

-AQALIC CS-7S can absorb water and swell so that it can be applied onto cold-rolled steel for reducing oxygen diffusion.

-Poly(HFBMA-co-ITEGMA) copolymer is used to protect aluminium alloys from corrosion.

-Expoxy resin with poly(o-phenylenediamine) (PoPD) nanotubes can be coated onto mild steel substrates [32].

\subsection{Antibacterial Coatings for Circulation Coins}

Antibacterial ability is an important function of the coatings for circulation coins [33][34]. Bacteria can survive in most environments when it adheres to surfaces. Moreover, bacteria can generate a biofilm over surfaces, creating perfect environments to accelerate the regeneration rate [35]. For this reason, antibacterial coatings should withstand bacterial adhesion or even kill bacteria [36].

\subsubsection{Metallic Systems}

Several metallic materials have been employed as antimicrobial agents such as copper, silver, zinc and titanium dioxide [37]. Among them, silver is most effective in terms of its antibacterial function and has been applied widely for a long time.

\subsubsection{Copper}

Using copper in medicine became common in the 19th and early 20th centuries. Currently, the use of copper as a self-sanitizing material gains many interests from 
various research groups. In 2008, the U.S. Environmental Protection Agency (EPA) defined copper and many of its alloys as antimicrobial materials, based on their ability to kill $99.9 \%$ of most bacteria within $2 \mathrm{hr}$ [38]. Copper can rapidly kill many bacterial species such as Escherichia coli, Staphylococcus aureus, and others. Solid copper kills bacteria by contact. This means that bacteria on copper suffers from immediate membrane damage and DNA degradation [39]. High temperature, copper content in the alloys and relative humidity all help increase the efficiency of bacteria killing. Figure 2-10 shows the mechanism of contact killing [37].

Generally, $\mathrm{Cu}_{2} \mathrm{O}$ is generated on copper by contact with dry oxygen-containing atmosphere. For contact killing, there is a difference between $\mathrm{CuO}$ and $\mathrm{Cu}_{2} \mathrm{O}$. Antimicrobial efficacy of $\mathrm{Cu}_{2} \mathrm{O}$ is similar to pure copper, while $\mathrm{CuO}$ is less, because $\mathrm{Cu}^{+}$ is more toxic to bacteria than $\mathrm{Cu}^{2+}$ [38]. In this case, copper can kill bacterial quickly in dry condition. However, if cell suspensions in the form of aqueous solution were applied onto copper directly, the time of contact killing would be extented [37] [40].

When copper particles are reduced from a micrometer to a nanometer scale, the anti-bacterial ability is enhanced dramatically, because it would results in higher surface-to-volume ratio. Nanoparticles of $\mathrm{CuO}, \mathrm{Cu}, \mathrm{Cu}_{2} \mathrm{O}$ are widely used in the medical field for their good antibacterial ability and can be easily mixed with polymers [41]. 


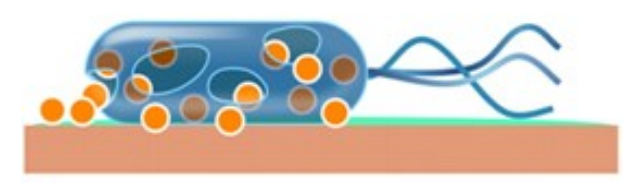

(a)

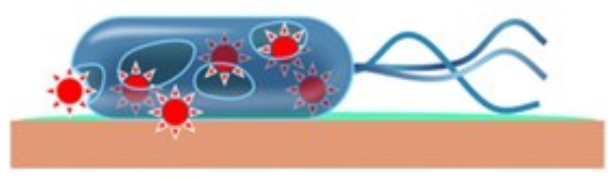

(c)

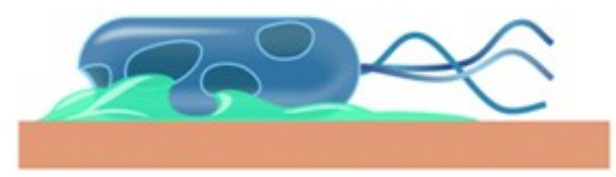

(b)

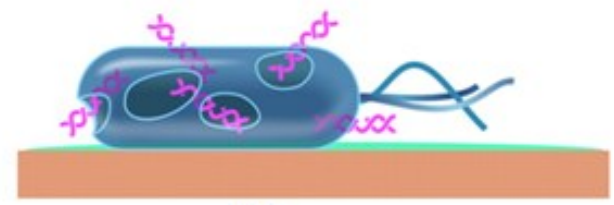

(d)

Figure 2-10: Schematic of the tentative events in contact killing: (a) copper dissolving from the copper surface and causing cell damage, (b) ruptured cell membrane because of copper and other stress phenomena, leading to loss of membrane potential and cytoplasmic content, (c) generation of reactive oxygen species by copper ions, causing further cell damage, and (d) genomic and plasmid DNA degraded [37].

\subsubsection{Titanium Dioxide}

Titanium dioxide $\left(\mathrm{TiO}_{2}\right)$ can generate strong oxidizing power when exposed to ultraviolet light (the wavelength is under $385 \mathrm{~nm}$ ), which can decompose organic compounds and microbial organisms such as bacteria, viruses, and cancer cells. Therefore $\mathrm{TiO}_{2}$ acting as a photocatalyst is widely used in sterilization of medical equipment, food preparation and air-conditioning filters, etc. [42] [43].

\subsubsection{Silver}

Silver salts have been famous for their antibacterial function for a long time. According to the Gabor's report, they were first used as a medical agent in 702-705 BC. In 1800s, silver nitrate had become an important material for treating skin ulcers, compound fractures and wounds [44]. Ag ions and Ag based compounds are widely used in antimicrobial systems [45]. Since 1954, silver nanoparticles working as colloidal silver have been registered as biocidal material in the United States, and nanosilver is considered a good antibacterial surface coating agent [46][47].

The ability of nanosilver to interact with bacteria depends on the size and shape of 
the particles. Usually, the size range of nanosilver is from 1 to $100 \mathrm{~nm}$. There are various methods to generate colloidal silver. One of the simplest methods is to use silver nitrate and gallic acid [48]. Although silver nanoparticles have strong antibacterial ability, disadvantages such as easy aggregation, the uncontrollable release rate of the silver ions and cytotoxicity consequences limit a range of applications of silver in various fields. Recent research has been focused more on seeking helpful polymers synthesized with nanosilver. These types of new nanocompositions have better antibacterial function [49].

The data in Table 2-5 show that $7 \mathrm{~nm}$ silver nanoparticles exhibit the best antibacterial ability against both E.coli and S.aureus as the smaller particles can kill the cell more readily. The size of silver nanoparticle is inversely proportional to its antibacterial ability. Researchers explained that the smallest-size silver nanparticles had the greatest cytotoxicity to cells [48]. Nanosilver has three modes of killing gram-negative bacteria: 1-10 $\mathrm{nm}$ nanosilver hits the cell membrane directly; nanosilver can penetrate inside the bacteria and interact with DNA or protein for further damage; released silver ions also help enhance antibacterial activity [49].

\begin{tabular}{lll}
\hline Sample & \multicolumn{2}{l}{ Minimum inhibition concentration $(\mu \mathrm{g} / \mathrm{mL})$} \\
\cline { 2 - 3 } & Bacteria \\
\cline { 2 - 3 } & E.coli & S.aureus \\
\hline 7-nm silver nanoparticles & 6.25 & 7.5 \\
29-nm silver nanoparticles & 13.02 & 16.67 \\
89-nm silver nanoparticles & 11.79 & 33.71 \\
\hline
\end{tabular}

Table 2-5: Minimum inhibition concentrations of Ag nanoparticles [48]. 
Although nanosilver has strong antibacterial ability, it has several disadvantages such as easy aggregation, cytotoxicity, hard to control the releasing rate of silver ions. For these reasons, polymeric materials, as matrices or carriers, help develop perfect coating matrix with nanosilver.

Polyvinylpyrrolidone (PVP) works as an agent to prevent nanosilver against aggregation [50]. Three materials are used for the synthesis: Ethylene glycol, PVP, and silver nanoparticles. Firstly, ethylene glycol is heated to $160^{\circ} \mathrm{C}$. Then silver nitrate and PVP are added into ethylene glycol with continuous stirring for $1 \mathrm{hr}$. Finally, ultracentrifugate at $30 \mathrm{rpm}$ is used for $30 \mathrm{~min}$ to get the silver nanoparticles coated with PVP when the solution is cooled down to room temperature [51].

\subsubsection{Polymer Systems}

Bioactive polymers with antibacterial function can be used as antimicrobial agents in coatings. Through anion exchange reactions at the nitrogen of the polycation, polymer containing ${ }^{-} \mathrm{OH}$ usually have good antibacterial ability [52]. The main advantage of antimicrobial polymers is non-toxic which makes it suitable for food related applications. Also, they are chemically stable and cannot permeate through skin, hence they do no harm human beings. Therefore an increasing number of researchers have focused their studies on polymeric agents in the antibacterial fields [53]. According to the research of Timofeeva et al. antimicrobial action can be influenced by molecular weight, type of microorganism and alkylation effect [54]. For example, chitosan is a new natural nontoxic polymer containing $50 \mathrm{wt} \%$ chitin which can be obtained from shrimps and shells rich in alkali sodium hydroxide [55][56]. Chitosan has many desirable properties such as good 
film-forming ability, antimicrobial activity and solubility in aqueous materials [57]. Because of these unique features, chitosan has found many applications, for example, coatings, gels, and carriers. In carrier form, the effectiveness of transformation depends on the molecular weight $(\mathrm{Mw})$ of chitosan and the degree of deacetylation (DD). In addition, Mw and DD can determine the cytotoxicity of cells and antimicrobial ability of chitosans [58].

Table 2-6 shows the results of antibacterial activities for different Mw chitosans. The concentration of chitosan was controlled at $0.1 \%$. It is shown that chitosan is more effective to gram-positive bacteria than to gram-negative bacteria; every chitosan repels most gram-positive bacteria, but only chitosan with $\mathrm{Mw}=746 \mathrm{kDa}\left(1 \mathrm{kDa}=10^{3} \mathrm{~g} / \mathrm{mol}\right)$ performs well at killing gram negative bacteria. Chitosans whose Mws are respectively equal to 1106 and $224 \mathrm{kDa}$ have the least resistance against gram-negative bacteria than the chitosans with different Mw values [55].

\begin{tabular}{|c|c|c|c|c|c|c|c|c|c|}
\hline & \multirow{2}{*}{ Bacteria } & \multirow{2}{*}{ Initial } & \multirow{2}{*}{ Control } & \multicolumn{6}{|c|}{ Mw (kDa) } \\
\hline & & & & 1671 & 1106 & 746 & 470 & 224 & 28 \\
\hline \multirow{4}{*}{ Gram(-) } & Escherichia coli & 6.92 & 8.59 & 4.94 & 5.59 & 4.28 & 4.66 & 5.48 & 5.61 \\
\hline & $\begin{array}{l}\text { Pseudomonas } \\
\text { fluorescens }\end{array}$ & 6.64 & 8.79 & 3.76 & 5.47 & 1.57 & 6.45 & 7.70 & 6.17 \\
\hline & $\begin{array}{l}\text { Salmonella } \\
\text { typhimurium }\end{array}$ & 6.54 & 8.62 & 4.89 & 8.13 & 5.21 & 4.28 & 8.23 & 8.62 \\
\hline & $\begin{array}{l}\text { Vibrio } \\
\text { parahaemolyticus }\end{array}$ & 6.64 & 8.79 & 5.49 & 5.31 & 4.50 & 3.29 & 5.39 & 5.85 \\
\hline \multirow{3}{*}{$\operatorname{Gram}(+)$} & $\begin{array}{c}\text { Listeria } \\
\text { monocytogenes }\end{array}$ & 6.36 & 8.31 & ND & 3.10 & ND & 3.57 & 0.30 & 2.38 \\
\hline & $\begin{array}{c}\text { Bacillus } \\
\text { megaterium }\end{array}$ & 5.24 & 8.51 & 0.99 & 3.62 & 1.69 & 2.23 & 2.09 & 2.48 \\
\hline & Bacillus cereus & 5.72 & 7.54 & 2.32 & 1.60 & ND & ND & 2.27 & 2.15 \\
\hline
\end{tabular}




\begin{tabular}{ccccccccc}
\hline $\begin{array}{c}\text { Staphlococcus } \\
\text { aureus }\end{array}$ & 6.55 & 8.11 & 0.53 & 1.58 & ND & ND & 1.47 & 2.34 \\
\hline $\begin{array}{c}\text { Lactobacillus } \\
\text { plantarum }\end{array}$ & 5.69 & 8.45 & 3.56 & 0.54 & 0.54 & 4.80 & ND & ND \\
\hline $\begin{array}{c}\text { Lactobacillus } \\
\text { brevis }\end{array}$ & 6.44 & 9.31 & 1.78 & ND & 4.55 & 4.29 & 1.09 & 1.08 \\
\hline $\begin{array}{c}\text { Lactobacillus } \\
\text { bulgaricus }\end{array}$ & 6.78 & 9.02 & 4.2 & 1.93 & 5.92 & 6.48 & 1.01 & 2.40 \\
\hline
\end{tabular}

Table 2-6: Antibacterial activities of different weight chitosans (0.1\% concentration) against 11 different types of bacteria (log CFU/ml) [55].

\subsubsection{Composite Systems}

Traditional antimicrobial agents typically have strong toxicity which harms the environment. If they were used in food packaging, a serious problem would be caused by the diffusion of these agents. Therefore, antimicrobial polymers that act as matrices containing antimicrobial agents are advantageous to antimicrobial agents. These composite coatings are chemically stable, have less risk of permeating the skin of human beings and can enhance the antimicrobial efficiency [53].

\subsubsection{Synthesized Polymers with Nanosilver}

With the addition of polymers, the physical and chemical properties of silver nanoparticles become more stable, meanwhile polymers can further enhance antibacterial ability. There are a few examples of such composite coatings as detailed in the following sections [35].

\section{(1) PDMS + Ag Nanoparticles}

Poly(dimethylsiloxane) (PDMS) is a group of polymetric organosilicon which is often referred to as silicone. It acts like a viscous liquid when the temperature is high enough, while it is in an elastic semi-solid state at low temperatures. This polymer attracts 
specific attention for its useful properties such as flexibility, easy molding, non-toxicity and chemical inertness [59]. On the other hand, it has several disadvantages. for example poor mechanical properties and intolerance to organic solvents. Metal nanoparticles can help minimize these. The synthesis method works as follows. Metal powders are mixed into PDMS; and hardener (curing agent) is then added into the mixture. The hardener cross-links the elastomer and helps nanoparticles disperse better in the matrix. The Young's modulus of nanoparticle-containing coating is three times higher than that of the pure PDMS coating. Meanwhile, silver nanoparticles give PDMS anti-bacterial ability, which makes them widely applied in biomedical fields [60].

\section{(2) Chitosan with Ag Nanoparticles}

Chitosan is one of the best polymers to synthesize with silver nanoparticles. This natural polymer which has antibacterial ability itself can help create an ideal composite coating for antibacterial applications [49]. Ag/chitosan composites exhibit excellent antibacterial activity with relatively low Ag content. Ag/chitosan nanocomposites also have excellent surface activity. Ag nanocomposites with water-soluble chitosan and $\mathrm{N}$-alkyl chitosan which are modified chitosan demonstrate greater antimicrobial activity than non-modified chitosan [57].

\subsection{Coating Deposition Methods}

\subsubsection{Spin Coating}

There are many methods to apply polymer thin films onto a solid substrate. The most convenient technique is the spin coat method. After spinning, the solvent evaporates, and 
the rest forms a solid polymer film on the substrate after curing. Thin, uniform film coatings can be achieved via this method [61]. Figure 2-7 shows the four major steps of spin coating process.

Obviously, the thickness of the coatings can be influenced by the spinning speed, the concentration of the polymer solution and the molar mass of the polymers. However, it is difficult to formulate a theoretical equation estimating coating thickness with respect to these factors because the solvent evaporation rate and fluid rheology make the formulation very complex [61].

Some formulas have been developed and used to calculate the coating thickness. If solvent evaporation is ignored, the basic equation considering the physics of the spin coating process was suggested by Emslie et Al. [61]:

$$
-\eta \frac{\partial^{2} v}{d z^{2}}=\rho \omega^{2} r
$$

where $\eta$ is the viscosity, $\rho$ is the polymer density, $\omega$ is the spin speed, $z$ is z-axis, $v$ is spin speed. According to the continuity equation of the flux and boundary conditions [61].

$$
\begin{gathered}
-\frac{d h}{d t}=\frac{2 \rho \omega^{2}}{3 \eta} h^{3} \\
h(t)=\frac{1}{\left(h_{0}^{-2}+\frac{4 \rho \omega^{2}}{3 \eta} t\right)^{1 / 2}}
\end{gathered}
$$

where $h_{0}$ is the initial film thickness, $h$ is the final coating thickness and $t$ is the spin time. 


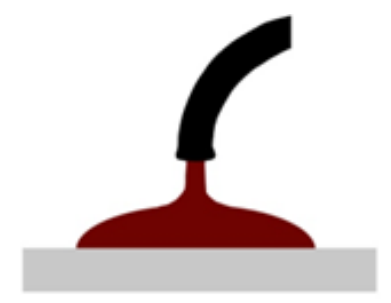

(a)

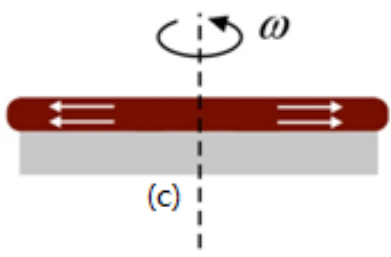

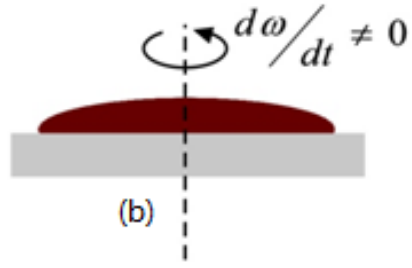

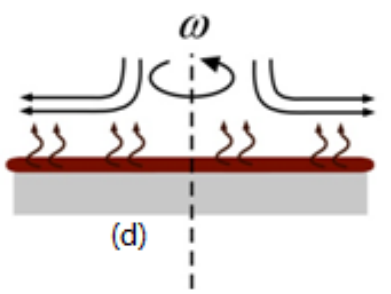

Figure 2-11: Different stages of spin coating: (a) dispensation, (b) acceleration, (c) flow dominant, and (d) evaporation dominant [62].

\subsubsection{Dip Coating}

Dip coating method requires less equipment and is cost effective than other methods like chemical vapor deposition (CVP) and sputtering. The dip-coating process is simple, works for large surfaces and is adapted for many materials such as polymers, sol-gel, colloids, etc. [63]. Figure 2-12 shows the schematic of dip coating process. The substrate is dipped into the solution and then withdrawn at a controlled speed [64].

The quality of the coatings formed by dipping is influenced by the solvent selection, solution concentration, operating temperature and withdrawal rate. Since the dip coating process often uses natural drying ambient temperature, this causes thickness variations if the high boil solvent is used. Figure 2-13 illustrates the natural drying process. Varying evaporation rate of the solvent and the flow velocity of the solution results in uneven coatings, as seen in Figure 2-13(b). 


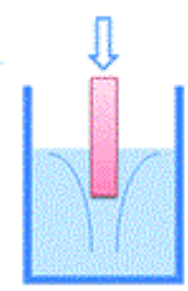

Immersion

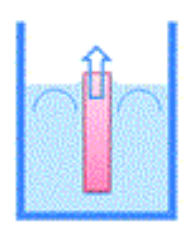

Start-up

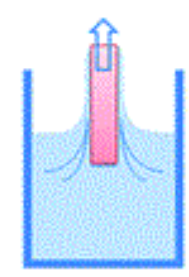

Deposition \&

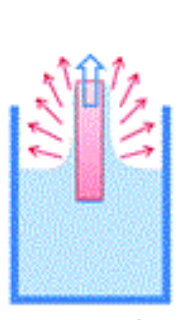

Evaporation

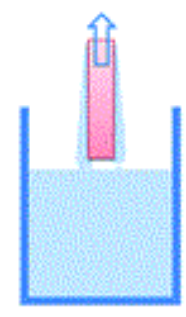

Drainage

Figure 2-12: Schematic showing of dip coating process [64].

Lifting direction

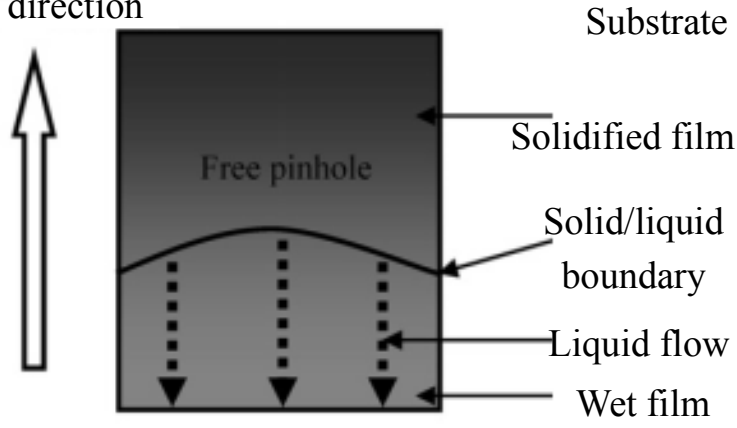

(a)

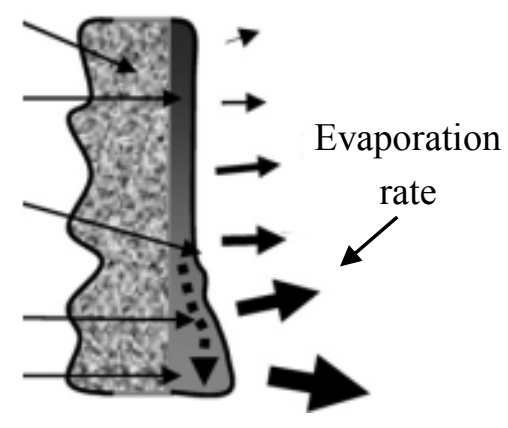

(b)

Figure 2-13: Illustration of the evolution process of the liquid layer during natural drying process: (a) top view, and (b) side view [65].

In addition, the thickness and structure of the coating can be controlled by evaporation parameters and withdrawal speed. IYang et al. [66] determined the relationship between the coating thickness, liquid viscosity and withdrawal speed as

$$
t_{p}=\left(J / \xi_{p}\right)\left\{\left(\eta-\eta_{s}\right) / \eta_{0}\right\}^{1 / \alpha}(\eta U / \rho g)^{1 / 2}
$$

where $t_{p}$ is the dried thickness, $J$ is a dimensionless flow parameter given by $j / U t_{0}$, where $j$ is the volume flow rate per unit width and $t_{0}$ is a characteristic thickness, $U$ is the withdrawal speed, $\eta$ and $\eta_{s}$ are viscosities of the solution and solvent, respectively, $\eta_{0}$ and $\alpha$ are the intercept and gradient of a plot of $\log \left(\eta-\eta_{s}\right)$ versus $\log C_{p}$, respectively, $C_{p}$ is the mass concentration of the polymer solution, and $\xi_{p}$ is the ratio of the density of the polymer to that of the solution. This equation is suitable for ideal films, ignoring the dry conditions influence [66]. 


\subsubsection{Spray Coating}

The major considerations of spray coating are the formation of good droplets of a solution and the effective deposition on the substrate. The coating solution breaks up into small droplets via atomization. Air pressure is a simple method used for atomization where the liquid passing through the nozzle becomes tiny droplets. Ultrasonic atomization, having high frequency of sound vibration, helps form a good mist of solution. Figure 2-14 shows the ultrasonic spray process. The concentration of the polymer, the solvent type, the temperature of the substrate, the distance between the spray nozzle and substrate as well as the air pressure, are all the process parameters, which can influence the uniformity of the coating. Generally, an increase in temperature, the distance between the nozzle and substrate and the evaporation rate of the solvent can accelerate the drying of coatings [67].

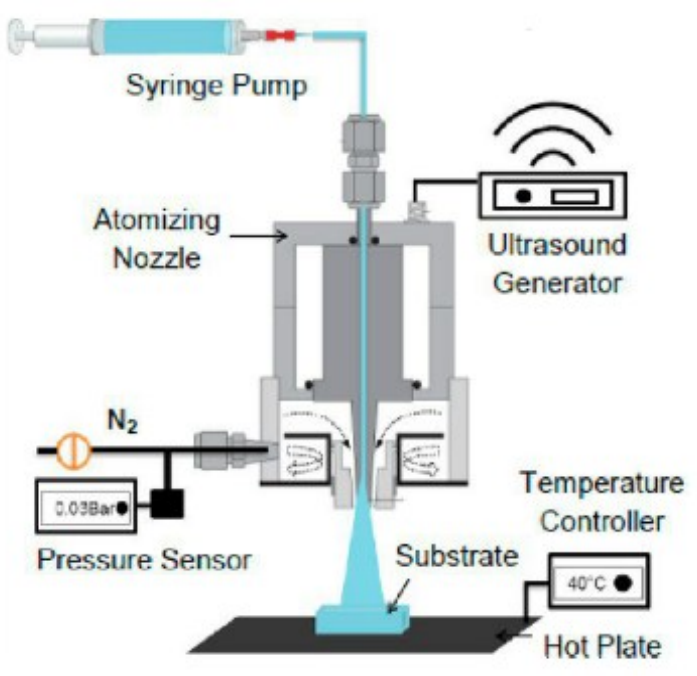

Figure 2-14: Schematic of spray coating setup [67].

\subsubsection{Applications of Electrostatics}

Electrostatics theory was originated in the early 1950s. In this method, a charging 
electrode is placed in the atomizer with a electrostatic spray gun. When the electrode gets charge, the coating material in the powder form is atomized and then ionized by the electrode, see Figure 2-15. Between the electrode and grounded workpiece, an electrostatic field is created. The negatively charged particles are attracted to the grounded workpiece [68].

There are seven types of electrostatic process for spray coating application. They are electrostatic air spray atomization; electrostatic high-volume, low pressure (HVLP) atomization; electrostatic airless atomization; electrostatic air-assisted atomization; electrostatic electrical atomization; electrostatic rotary-type bell atomization; electrostatic rotary-type disk atomization [68].

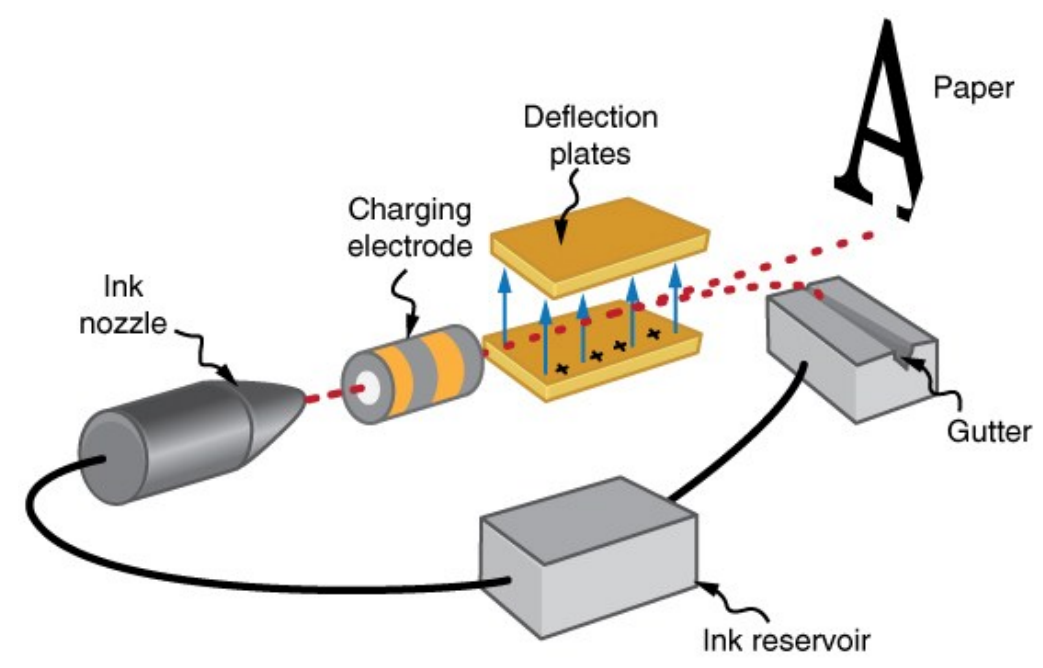

Figure 2-15: Schematic illustration of electrostatic process in computer-driven printers [69].

\subsubsection{Plasma Spray Coating}

Plasma spraying (PS) has been developed in recent decades, in which a powder material is injected into a hot plasma, then melted and accelerated. When the coating material reaches the substrate, it solidifies and a coating is formed with a typical lamellar structure [70]. Plasma spray possesses the special feature of high efficiency and high 
production rate; however, the coatings usually contain higher porosity . Depending upon applications, a wide range of plasma can be generated under different conditions. Many types of plasma spray have been developed [71]. Generally, plasma can be divided into local thermodynamic equilibrium plasma (LTE, also called thermal plasma) and non-local thermodynamic equilibrium plasma (non-LTE, also called cold plasma) [72].

Low pressure plasma spraying (LPPS) process, also known as vacuum plasma spraying (VPS), was invented in 1990 and is a thermal spray process where powder is injected into a hot plasma [73][74]. Low pressure plasmas are non-LTE [72]. In LPPS, the deposition occurs with an inert gas applied at a pressure (below $1.3 \mathrm{kPa}$ ) to avoid oxidation. Therefore, for oxidation-sensitive materials, LLPS is always the best option. Moreover, plasma spray can also produce a thin coating over a large area quickly, with high coating quality, particularly good adhesion, and wear resistance [73][74][75]. 


\section{Chapter: Materials and Coating Fabrication}

\subsection{Material selection and specifications}

After extensive literature review, five candidate materials were selected as potential coatings for circulation coin applications based on their transparency/gloss, application method, ability to resist bacteria growth and also abrasion resistance. These materials are polyurethane, polytetrafluoroethylene, standard liquid glass, advanced liquid glass, and silicone R-2180.

\subsubsection{Polyurethane}

Polyurethane (PUR or PU) is a polymer composed of organic units jointed by urethane links. It is produced by the polyaddition reaction of either a diisocyanate or a polymeric isocyanate with a polyol in the presence of suitable catalysts and additives [76]. By combining different types of isocyanates and polyols under different conditions, different grades of polyurethane can be produced with various chain lengths, cross-links and extenders [77]. The main constituent of polyurethane is the urethane group, which can be chemically expressed as

$$
-\mathrm{NHCO}-\mathrm{O}-
$$

It has a wide range of applications from clothing, footwear, furniture industry to high level industrial coatings, corrosion resistant coatings, etc. This is a unique material which combines the elasticity of rubber with the toughness and durability of metals [78]. This combination gives it good physical, thermal, chemical resistance, high tensile strength and abrasion resistant property. In this research, the polyurethane in the form of liquid was provided by MINWAX, US. It has a beige color in the liquid form, as seen in Figure 
3-1.

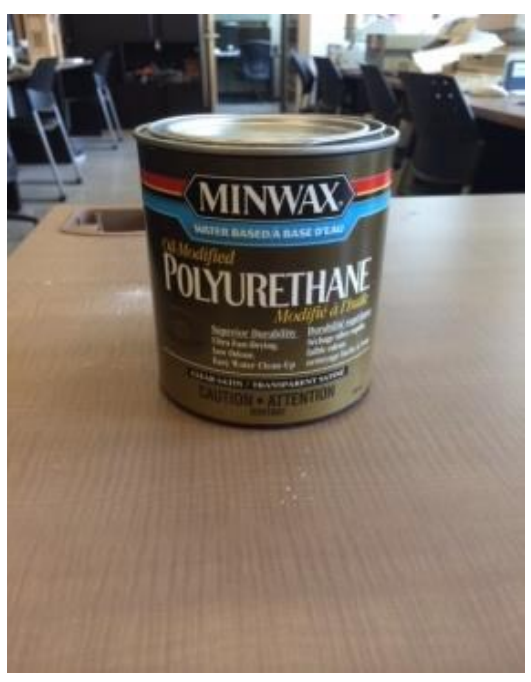

(a)

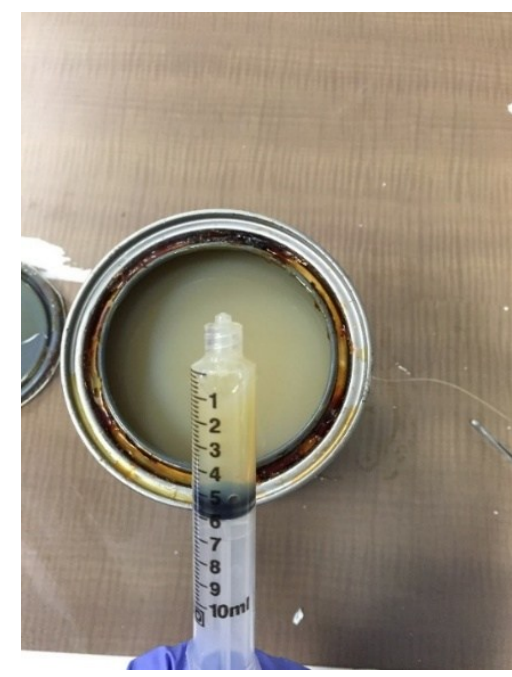

(b)

Figure 3-1: Polyurethane: (a) the bottle of polyurethane, and (b) the liquid polyurethane.

Polyurethane has various applications because its properties can be modified by catalysts, auxiliary compound, and raw material selection, but there are two limiting factors that restrict its applications: (1) instability at temperature above $90^{\circ} \mathrm{C}$; and (2) flammability [79]. The US Army applies polyurethane coatings as protection against chemical warfare agents. This coating must endure a wide range of climatic environment $\left(-80^{\circ} \mathrm{C}\right.$ to $\left.80^{\circ} \mathrm{C}\right)$ resistance [80]. Polyurethane can also be used as vibration dampers, isolation materials, adhesives, in various coatings, different kinds of plastics and elastomers and matrix resins of composites [81].

\subsubsection{Polytetrafluoroethylene}

Polytetrafluoroethylene (PTFE) is a synthetic fluoropolymer with extraordinary properties [82]. It has a wide applications ranging from the food industry to medical, aerospace and computer industries. It is known for its low coefficient of friction ( 0.05 to 0.10 ) and a high temperature resistance (up to $260^{\circ} \mathrm{C}$ ) [83][84]. The functional group in 
polytetrafluoroethylene is tetrafluoroethylene. Its basic unit can be expressed as

$$
-(\mathrm{CF} 2-\mathrm{CF} 2) \mathrm{n}-
$$

Polytetrafluoroethylene exhibits good friction and wear behavior, which can be attributed to its unique structure. The polytetrafluoroethylene structure represents a rigid cylindrical rod with a smooth surface because of the fluorine atom running helically along the surface [85]. This contributes to the low values of coefficient of friction. Polytetrafluoroethylene was also considered for use as a lubricator because of its good physical and chemical properties, especially chemical inertness, low friction and wear characteristics [86].

The effects of sliding speed and temperature on the friction and wear properties of polytetrafluoroethylene were studied previously [87]. It was found that the wear rate was influenced by the width of molecular bands rather than crystallinity of the polymer. Friction on the other hand was affected by both factors. This study also revealed that wear rate can be reduced extensively when polytetrafluoroethylene was quenched into ice water from melting state rather than slow cooling. The low friction coefficient of polytetrafluoroethylene was due to the characteristics of its extended linear chain molecules, which was responsible for forming low shear strength films on its surface during sliding [88].

The polytetrafluoroethylene (PTFE) used in this research was supplied by Dupont. The product code is $852 \mathrm{G}-201$. The color of this liquid polymer is milky, as shown in Figure 3-2. 


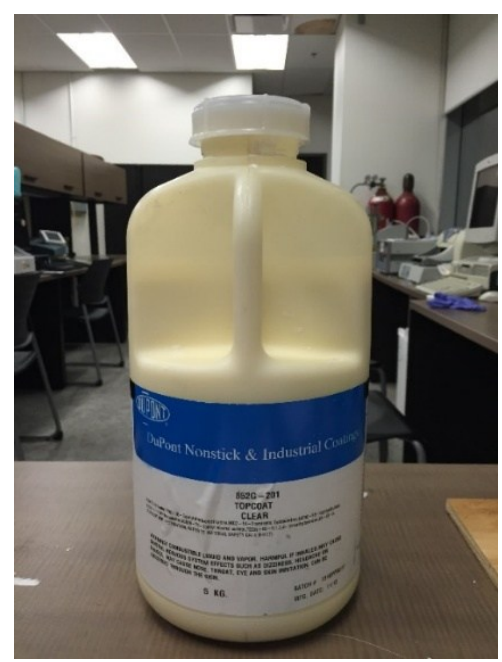

(a)

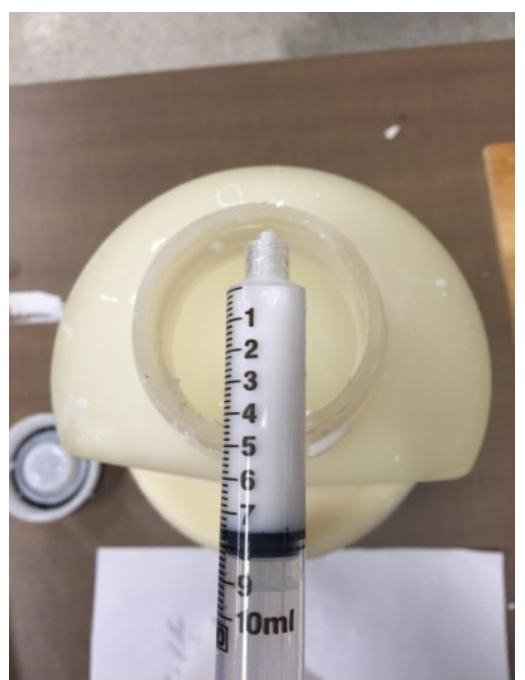

(b)

Figure 3-2: Polytetrafluoroethylene: (a) the bottle of polytetrafluoroethylene, and (b) the liquid polytetrafluoroethylene.

\subsubsection{Liquid Glass}

Liquid glass is transparent, non-toxic and can prevent surfaces against a host of environmental degradations. This material is mainly composed of silicon dioxides which are used primarily in the production of glass.

There were two distinct liquid glass products used in this experiment, standard and advanced, see Figure 3-3 and Figure 3-4. The difference between these two liquid glasses is that the advanced one has anti-bacterial, anti-corrosion, and anti-abrasion functions while the standard one only has anti-abrasion and anti-corrosion abilities. The advanced liquid glass contains ethanol as an anti-microbes agent. Liquid glass is widely used in medical equipments, cars, bandages and other fields, because of these benefits. 


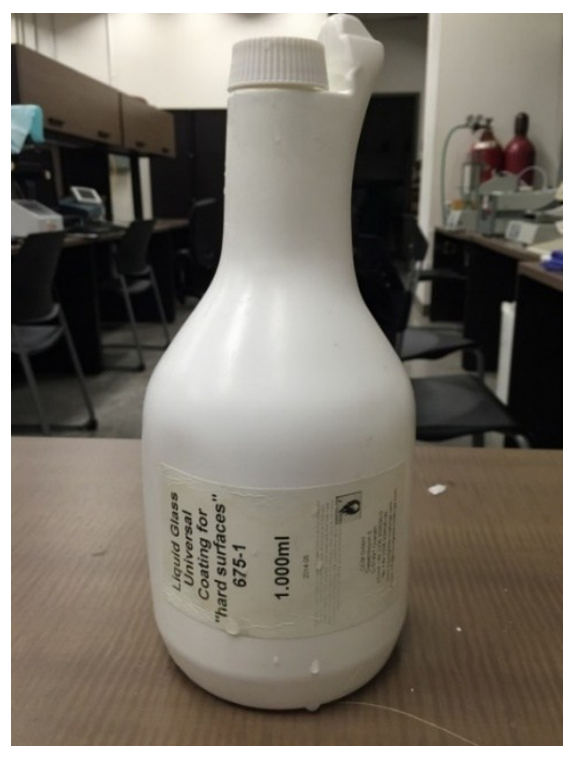

(a)

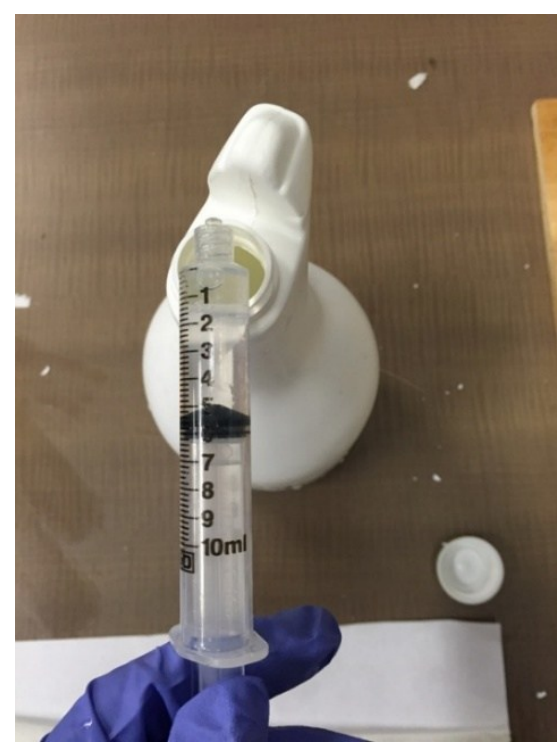

(b)

Figure 3-3: Standard liquid glass: (a) the bottle of standard liquid glass, and (b) standard liquid glass.

The advanced liquid glass is provided by Liquid Glass Shield. According to the materials MSDS sheet from the supplier, the active agent of advanced liquid glass is siloxane $\left(\mathrm{R}_{2} \mathrm{SiO}\right)$ with antimicrobial compounds such as ethanol $(90-95 \%)$. Its solvent is butanone $(1-5 \%)$.

Butanone, known as methyl ethyl ketone (MEK), is an organic compound represented by $\mathrm{CH}_{3} \mathrm{C}(\mathrm{O}) \mathrm{CH}_{2} \mathrm{CH}_{3}$. Butanone is a common solvent used in manufacturing of plastics, glues, painting remover and other products as a cleaning agent. It has similar functions to acetone while having higher boiling temperature and lower evaporation rates. The solvent plays an important role in forming polymer [89]. 


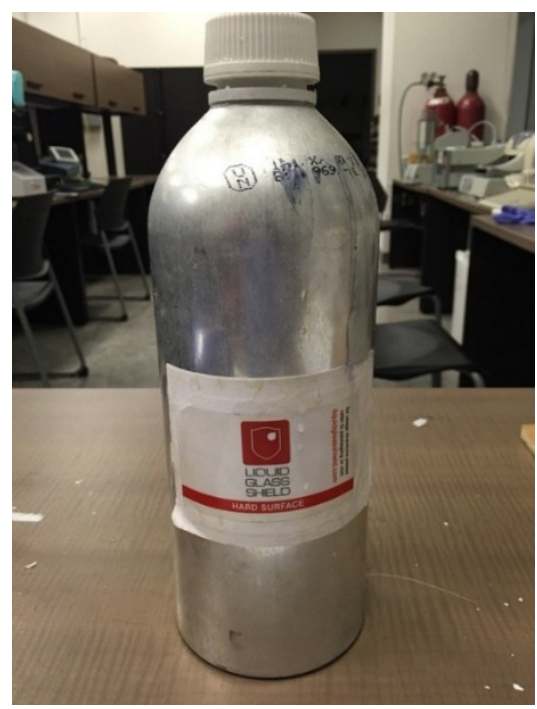

(a)

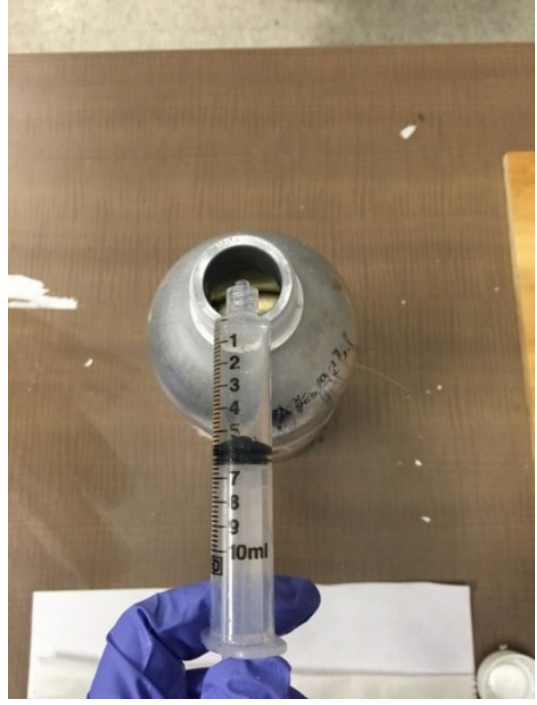

(b)

Figure 3-4: Advanced liquid glass: (a) the bottle of advanced liquid glass, and (b) advanced liquid glass.

\subsubsection{Silicone R-2180}

Silicone, also named as polyorganosiloxanes, has good adhesion to various surfaces, good durability, remain elastic at low temperatures and resistance to breakdown at high temperatures. Figure 3-5 shows the structure of polyorganosiloxane, where the $R$ groups stand for functional organic constituent such as methyl, phenyl or trifluoropropyl.<smiles></smiles>

Figure 3-5: Structure of polyorganosiloxanes.

Silicone R-2180 is composed of two parts: (1) Part A contains platinum catalyst and silicone base; (2) Part B is made by adding crosslinker and inhibitor into the base. The silicone base is a silicone polymer with silica working as a reinforcing filler. Silica enhances the van der Waals forces of the cured silicone polymers and hydrogen bonding between hydroxyl groups on silica surface and siloxane backbone of polymer. With the 
help of organosilicones, the compatibility of silica in polymer is improved. The reason for the presence of the two-part system is that the mixture of part A and part B is easily hardened at room temperature, giving it short shelf life. Therefore, this polymer had to be separated into two parts, and they were mixed at a ratio of 1:1 prior to any coating process. To obtain the mixture, $20 \mathrm{ml}$ of part $\mathrm{A}$ and $20 \mathrm{ml}$ of part $\mathrm{B}$ were added into a 80 $\mathrm{ml}$ beaker, and then a stick was used to stir the solution. The silicone R-2180 used in this experiment was supplied by NuSil Technology LLC, see Figure 3-6.

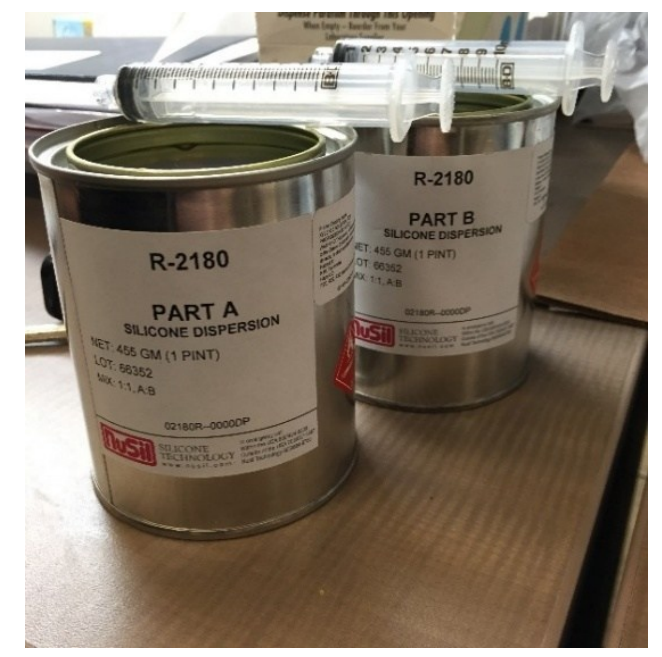

(a)

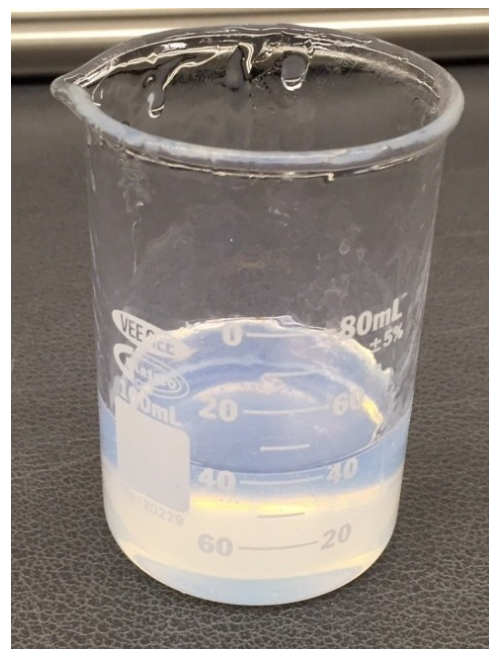

(b)

Figure 3-6: Silicone R-2180: (a) the bottles of silicone R-2180 part A and part B, and (b) the mixture of part $A$ and part $B$.

\subsection{Experimental Preparation}

\subsubsection{Specimen Preparation}

Proper cleaning of coin surfaces prior to coating application is critical to the success of the coating process. All the coin surfaces should be considered contaminated. Even freshly painted or recently cleaned surfaces will collect dust and dirt quickly, and should be cleaned carefully before coating application. The main problem regarding the coin was finger prints. This should be prevented only by handling the coins with clean tweezers. 
Failure to adhere to the cleaning process can cause adhesion loss and result in reduced durability and performance of the coating. After the cleaning step, all substrates (coins) should be completely dried with hot air. Any trapped moisture can cause premature failure due to bubbling or degassing. It was necessary to repeat the process each time to ensure a completely clean and contaminant-free surface.

An ultrasonic cleaner filled with water was used for the cleaning process, as shown in Figure 3-7. Using tweezers, coins were placed into a clean beaker filled with water along with a few drops of liquid soap. The beaker was then placed into the ultrasonic cleaner that ran for $20 \mathrm{~min}$. Following this step, the beaker was placed under running water to ensure that the coins were soap free. After 10 min rinsing, the water was drained carefully out of the beaker and it was filled with acetone. Tweezers were also placed in the acetone beaker to ensure that they were clean as they are to be used to pick up the coins at the end of the cleaning process. The acetone beaker was then placed back into the ultrasonic cleaner for $15 \mathrm{~min}$. Shortly after, the beaker was removed from the ultrasonic cleaner. Using the clean tweezers, the coins were picked one by one and placed $1 \mathrm{~cm}$ away from hot stream to dry thoroughly each side. The coins were finally wrapped with a clean paper and taken immediately to the spin coater for coating application.

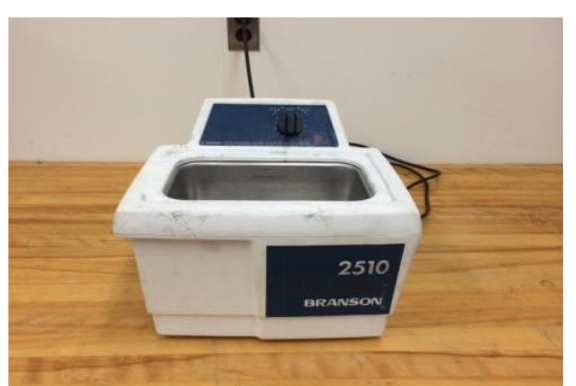

(a)

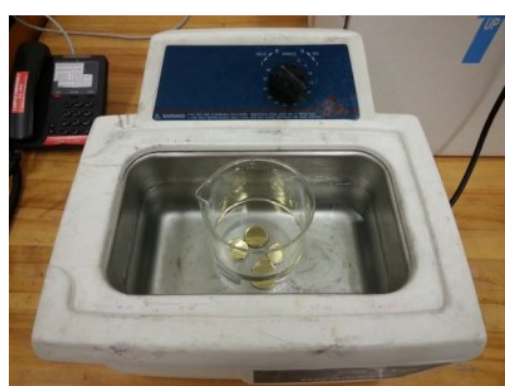

(b)

Figure 3-7: Cleaning process: (a) ultrasonic cleaner, and (b) beaker containing coins in the ultrasonic cleaner. 


\subsubsection{Surface Treatments}

Since the adhesion ability of polytetrafluorethylene is very poor, some treatments were taken to improve it.

\subsubsection{Acid Etching Process}

After cleaning, a few coins were etched with phosphoric acid in an attempt to enhance adhesion. This was done by mixing $50 \mathrm{ml}$ of phosphoric acid with $375 \mathrm{ml}$ of water into a beaker, see Figure 3-8. The coins were etched for $20 \mathrm{~min}$ or until a slight color change occurred. After that, these coins were placed under running water for $5 \mathrm{~min}$, followed by acetone cleaning in ultrasonic cleaner for $5 \mathrm{~min}$ and then thoroughly dried.

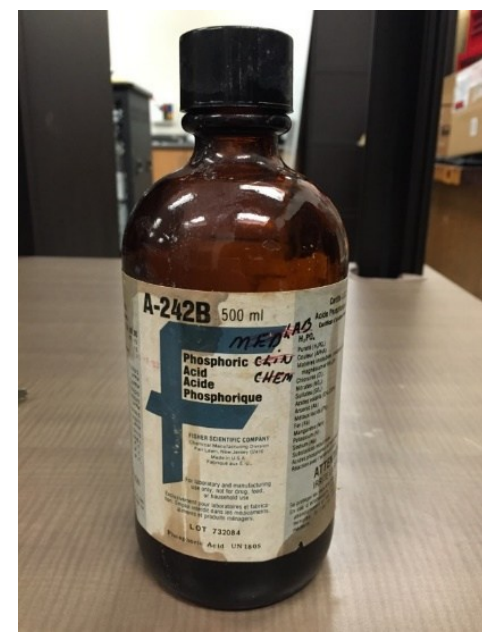

(a)

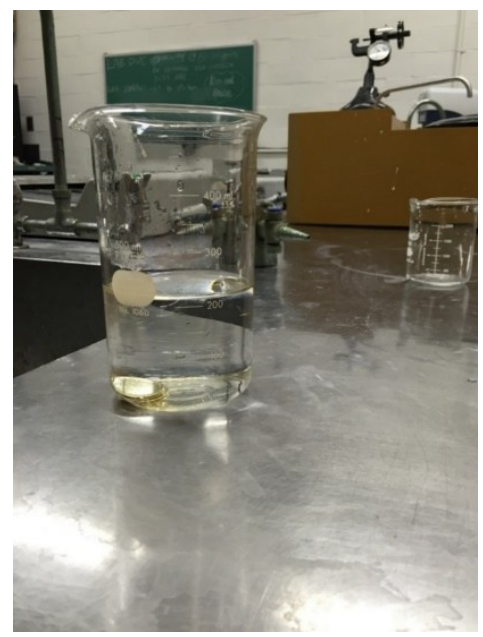

(b)

Figure 3-8: Acid etching process: (a) phosphoric, and (b) coins in the acid solution.

\subsubsection{Grit Blasting Process}

Grit blasting is an alternative method to acid etching. Grit blasting was used to roughen the surface of the coins leading to potentially better adhesion. During the grit blasting, the pressure was set to 80 psi while maintaining the nozzle at 90 degrees with a 1 inch distance from the substrate. Figure 3-9(a) is a grid blasting machine used to grid-blast the coins prior to cleaning. Figure 3-9(b) and Figure 3-9(c) show a comparison 
between a clean coin and a sandblasted coin before coating application. It can be seen that sandblasting significantly changed the appearance of the coins.

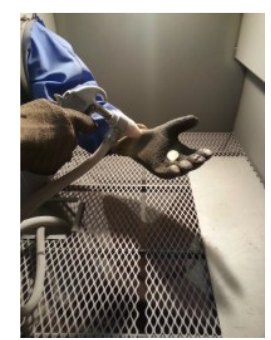

(a)

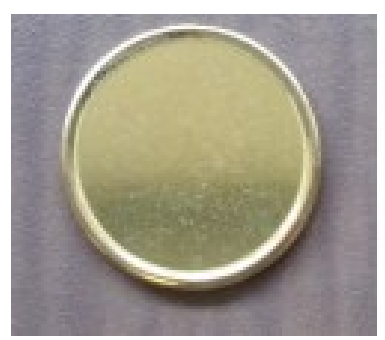

(b)

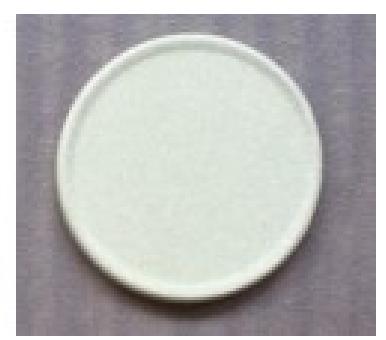

(c)

Figure 3-9: Sandblast process: (a) sandblast operation, (b) cleaned bare coin, and (c) sandblasted coin.

\subsubsection{Grinding Process}

Grinding is another method used to enhance the adhesion of the coating material onto the coin surface. Since both blanks and PTFE have low friction coefficient, grinding was attempted to enhance the adhesion. A few coins were selected for grinding using 600 grit sand paper before any cleaning process. Figure 3-10 shows the comparison between a grinded coin and a cleaned coin. This method also changed the characteristics of the coin, because the surface of the coin lost its original luster after polishing. As the coin contains a round edge, it was also difficult to grind the entire surface of the coin.

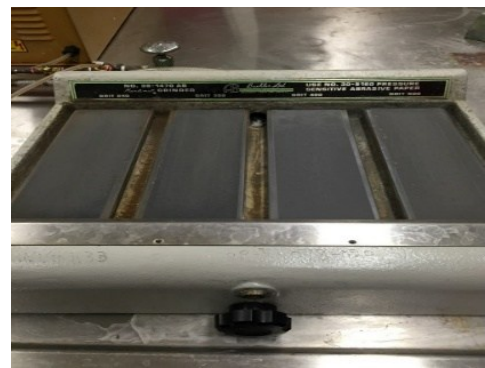

(a)

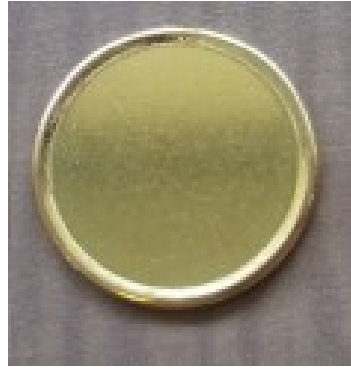

(b)

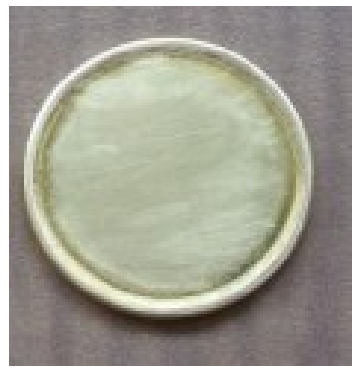

(b)

Figure 3-10: 600 grit polished process: (a) polish machine, (b) cleaned bare coin, and (c) 600 grit polished coin. 


\subsubsection{Equipment Preparation}

There are many methods that can apply a coating on a substrate. In this research since the coating material is in liquid form and the coating is expected to be highly uniform on the substrate, a spin coater was used. It is based on the principle of centrifugal force. The coin was placed in the spin coater and the coating material was applied onto the coin, then the coin was rotated at a high speed. The centrifugal force redistributes the coating material from the center to cover the entire surface of the coin. The main advantage of the spin coater is that the coating thickness is usually thinner and can be controlled by spin speed and spin time. Due to the specific requirement from RCM that the coating thickness should not exceed $10 \mu \mathrm{m}$, a spin coater is selected for this research.

In this experiment, the spin coater WS-650 was provided by Laurel Technologies. Figure 3-11 shows the system used in this study; it consists of the spin coater, nitrogen cylinder, high pressure gas valve, tubing, drain container, a balance used to measure the flatness of the vacuum chuck of the coater, motor for generating vacuum and spin processor.

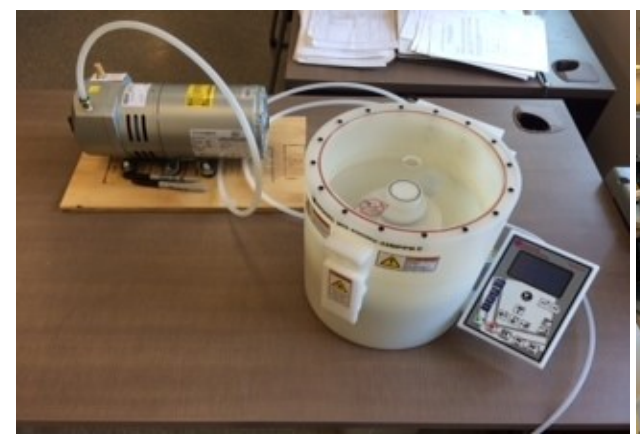

(a)

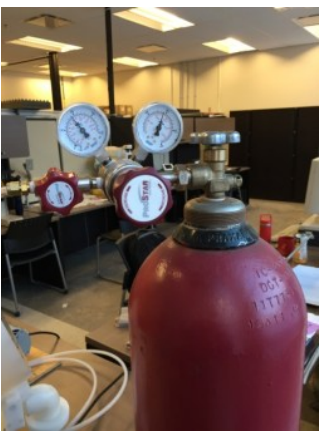

(b)

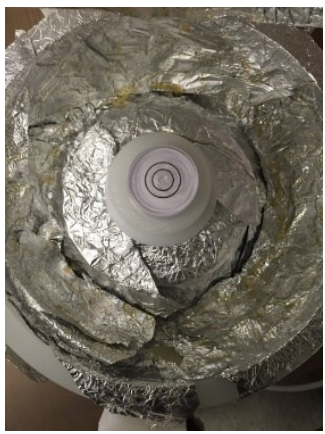

(c)

Figure 3-11: Coating equipment: (a) WS-650 spin coater, (b) high pressure gas valve, and (c) balance.

Vacuum suction was used to hold the coin in place inside the spin coater. Nitrogen gas served as a purge to prevent any damages to the spin coater. The pressure outlet from 
the nitrogen cylinder was kept between 60 to 70 psi.

The spin coater should be positioned on a perfectly flat surface to ensure uniform coating on the coin surface. The balance (Figure 3-11(c)) was used for this purpose.

The drain container should be connected to the process chamber before starting the coater. This is because while using the spin coater for coating excess coating material would be spun into the process chamber.

After all the above steps were followed, the spin coater was connected to the power source. The motor that helped generate the vacuum to hold the coins in place was also connected to the power source.

\subsection{Coating Fabrication}

\subsubsection{Parameter Selection for Polyurethane and Advanced Liquid Glass}

There are two types of coating techniques that can be employed with the use of a spin coater. They are static and dynamic. In the static method, the desired quantity of the liquid coating is applied on the specimen when it is at rest and then the specimen is rotated so that the coating spreads evenly throughout the specimen surface. The coating process is repeated at different intervals and at different speeds. In the dynamic method, liquid coating material is applied on the specimen surface while the specimen is spinning; the coating is formed with continuous spinning of the specimen for the required amount of time and at a predetermined speed, in order to achieve the coating thickness required.

In this research, the static method was selected for applying the polymer coating on circulation coins. The following steps were followed to coat the coins. There are two 
different modes on the controller: Edit mode and Run mode. Using the Edit mode the number of steps required to apply the coating, the time interval of each step, the spin speed of each step can be set. After the programming, the valve for the nitrogen gas supply should be opened and the motor required to create vacuum turned on before placing the specimen on the stand.

When the specimen has been placed in the coater, the vacuum button on the display is pressed. The coin is held in position with the help of vacuum. It is important that the coin is at the exact centre, to ensure a uniform coating. Table 3-1 and Table 3-2 summarize the coating process parameters for polyurethane and advanced liquid glass on brass and nickel coins. The applied quantity of liquid coating materials was controlled approximately at $1 \mathrm{ml}$. The acceleration of the spin speed was set at $500 \mathrm{rpm} / \mathrm{s}$.

\begin{tabular}{|c|c|c|}
\hline Specimen & Spin speed (rpm) & Time (s) \\
\hline 1 & 100 & 30 \\
\hline 2 & 300 & 30 \\
\hline 3 & \multirow{5}{*}{500} & 10 \\
\hline 4 & & 20 \\
\hline 5 & & 30 \\
\hline 6 & & 40 \\
\hline 7 & & 50 \\
\hline 8 & \multirow{5}{*}{700} & 10 \\
\hline 9 & & 20 \\
\hline 10 & & 30 \\
\hline 11 & & 40 \\
\hline 12 & & 50 \\
\hline 13 & \multirow{5}{*}{1000} & 10 \\
\hline 14 & & 20 \\
\hline 15 & & 30 \\
\hline 16 & & 40 \\
\hline 17 & & 50 \\
\hline 18 & 1200 & 30 \\
\hline 19 & 1500 & 30 \\
\hline
\end{tabular}

Table 3-1: Coating process parameters for polyurethane/advanced liquid glass on brass coins. 


\begin{tabular}{|c|c|c|}
\hline Specimen & Spin Speed (rpm) & Time (s) \\
\hline 1 & \multirow{3}{*}{500} & 10 \\
\hline 2 & & 20 \\
\hline 3 & & 30 \\
\hline 4 & \multirow{3}{*}{700} & 10 \\
\hline 5 & & 20 \\
\hline 6 & & 30 \\
\hline 7 & \multirow{3}{*}{1000} & 10 \\
\hline 8 & & 20 \\
\hline 9 & & 30 \\
\hline 10 & 1200 & 30 \\
\hline
\end{tabular}

Table 3-2: Coating process parameters for polyurethane/ advanced liquid glass on nickel coins.

\subsubsection{Process Parameter Selection for Polytetrafluoroethylene and Standard}

\section{Liquid Glass Spin}

Table 3-3 and Table 3-4 give the coating parameters for polytetrafluoroethylene and standard liquid glass on brass coins. These two coatings are tested using different process parameter because of adhesion issues and also non-transparent nature of the coatings. For every specimen of polytetrafluoroethylene and standard liquid glass, the spin duration was set to $30 \mathrm{~s}$.

\begin{tabular}{|c|c|c|c|}
\hline $\begin{array}{c}\text { Preparation } \\
\text { procedure }\end{array}$ & Specimen & Spin speed (rpm) & \multirow{2}{*}{ Time (s) } \\
\hline \multirow{3}{*}{ Acid etching } & 1 & 500 & \multirow{2}{*}{30} \\
\cline { 2 - 3 } & 2 & 700 & \multirow{2}{*}{30} \\
\cline { 2 - 3 } Grit blasting & 3 & 1000 & \multirow{2}{*}{30} \\
\cline { 2 - 3 } & 5 & 500 & \multirow{2}{*}{30} \\
\cline { 2 - 3 } & 6 & 1000 & \\
\hline \multirow{3}{*}{ Polishing } & 7 & 500 & \\
\cline { 2 - 3 } & 9 & 1000 & \\
\cline { 2 - 3 } & 9 & 700 & \\
\hline
\end{tabular}

Table 3-3: Coating process parameters for polytetrafluoroethylene on brass coins. 


\begin{tabular}{|c|c|c|}
\hline Specimen & Spin speed (rpm) & \multirow{2}{*}{ Time (s) } \\
\cline { 1 - 2 } 1 & 500 & \multirow{2}{*}{30} \\
\hline 2 & 700 & \\
\hline 3 & 1000 & \\
\hline
\end{tabular}

Table 3-4: Coating process parameters for standard liquid glass on brass coins.

\subsubsection{Parameter Selection for Silicone R-2180 Application}

For silicone R-2180, the application method is quite different from the other four materials. Since this material was too viscous, the spin coater cannot be used to apply it. A brush technique was selected as the application method. $2 \mathrm{ml}$ silicone R-2180 was added at the center of the coin by a syringe, see Figure 3-12(a). Then a cleaned paint brush was used to spread the drop to cover the entire surface of the coin, see Figure 3-12(b). When the coating looked smooth, the application process was considered complete, see Figure 3-12(c).

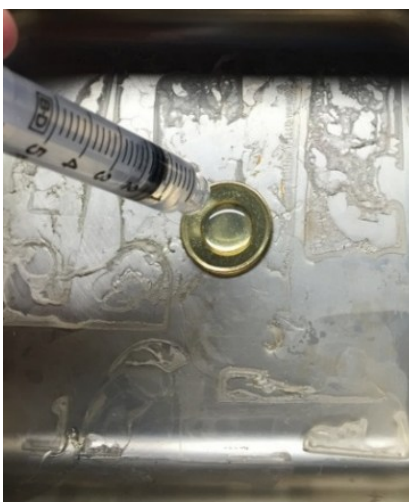

(a)

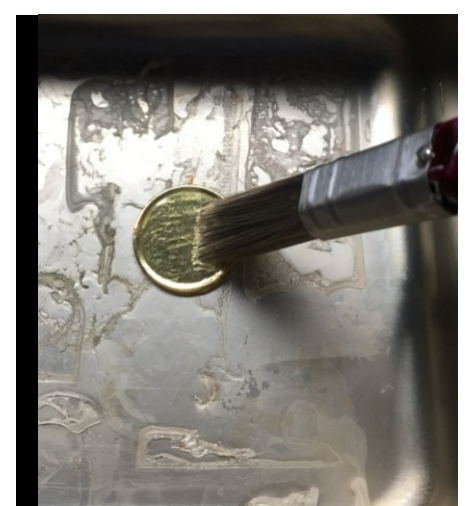

(b)

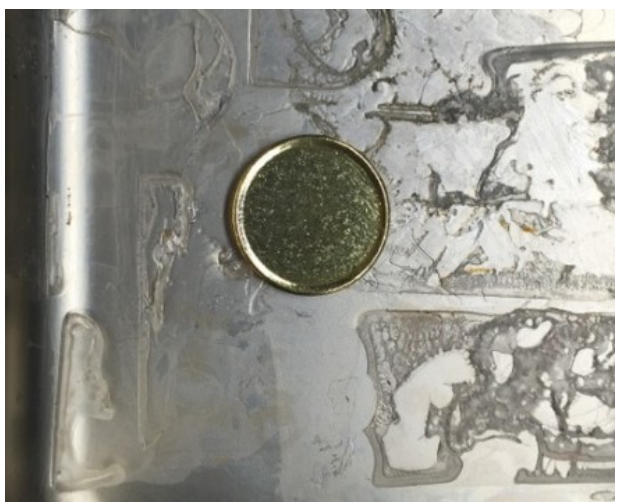

(c)

Figure 3-12: Silicone R-2180 application process: (a) solution of silicone R-2180, (b) silicone added onto the coin, and (c) coating application done.

\subsubsection{Parameter Selection for Curing Process}

For better adhesion and hardness, the coated specimens should be heated to cure the polymer coating according to manufacturer's specifications. For polyurethane, the curing process was simply air curing for 12 to $24 \mathrm{hr}$, but in case of the other coatings, the curing 
process took place at high temperatures. For polytetrafluoroethylene, the curing process involved two steps: (1) drying with hot air for one to two min. and (2)furnace baking at $385^{\circ} \mathrm{C}$ for $30 \mathrm{~min}$. The coins coated with advanced and standard liquid glass were baked at $250^{\circ} \mathrm{C}$ for $1 \mathrm{hr}$. The coins coated with silicone R-2180 was heated in three steps: (1) air dry for $30 \mathrm{~min}$, (2) furnace curing at $75^{\circ} \mathrm{C}$ for $45 \mathrm{~min}$, and (3) finally the temperature of the furnace was increased up to $150^{\circ} \mathrm{C}$ to hold for 135 minutes. After the curing process was completed, the specimens were cooled in ambient air.

The Vulcan 3-550 benchtop furnace used in this research was supplied by the Ney Tech company. As soon as the coating application was completed, the specimens were placed into a steel tray in order to avoid any contact between the coins and the furnace. After the tray was put into the furnace, a curing process was carried out under the selected curing time and the temperature (Figure 3-13).

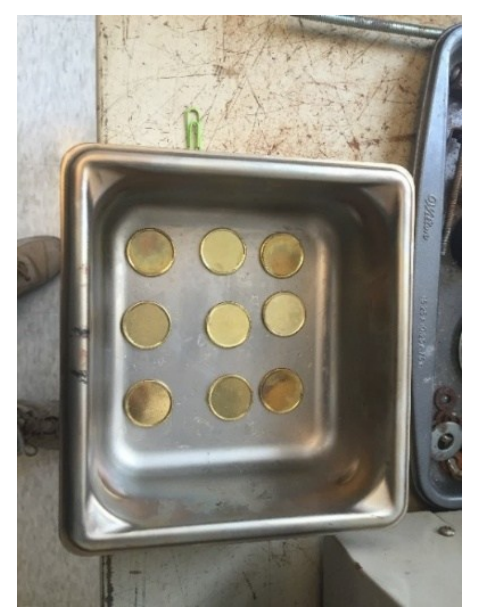

(a)

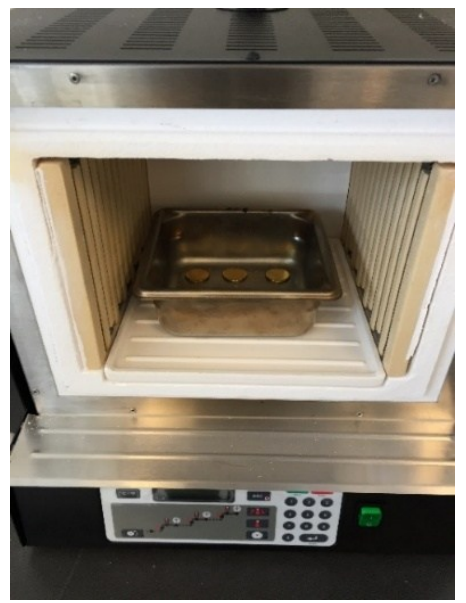

(b) 


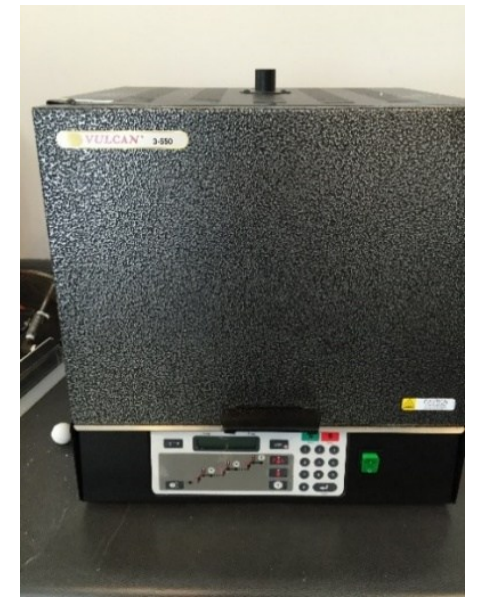

(c)

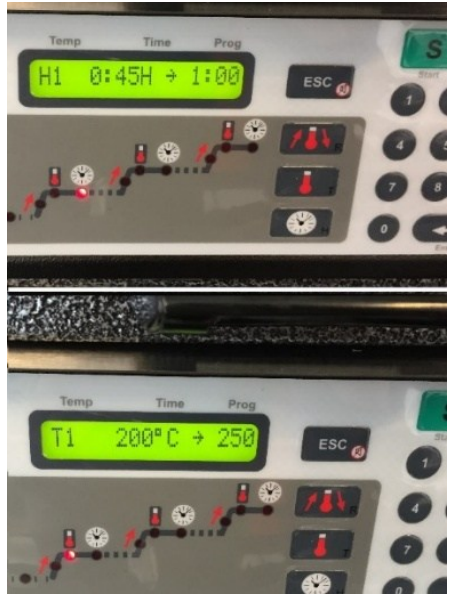

(d)

Figure 3-13: Curing process: (a) coated coins in a steel tray, (b) the tray placed into the furnace, (c) Vulcan 3-550 furnace, and (d) curing time and temperature set at the display.

\subsubsection{Fabrication Problems}

Although the spin coater is quite simple and efficient, producing high quality coatings and being able to control the coating thickness by spin speed and duration are challenging. The vacuum pressure used to hold the coin was very high so coating the opposite side of the coin became impossible as the vacuum pressure tended to pull the existing coating off. Furthermore, for coatings requiring oven curing, the first coated and cured side of the coin can become overheated, and sometimes, discolored. As such, most of the experimental work detailed here is based on coatings on one side of the coins. 


\section{Chapter: Bare and Coated Coin Characterization}

\subsection{Microstructure Investigation of Cross-sections of Circulation Coins}

Because two types of circulation coins are composed by multiply layers, SEM/EDX test was conducted on the cross sections of a brass coin and a nickel coin.

\subsubsection{Brass Coins}

As mentioned in Chapter 2, loonies are multi-ply brass plated steel. The brass plating is composed of $30 \mathrm{wt} \%$ zinc and $70 \mathrm{wt} \%$ copper. In order to determine the compositions of the layers, a brass blank was cut into half and polished. Based on the color differences (Table 4-1), the cross section was divided into four areas.

The percentage of iron decreases from the core to the surface; and it reaches $35 \mathrm{wt} \%$ near the surface. Nickel is predominantly high in area 3, measured at $30 \mathrm{wt} \%$. Copper is high near the surface, reaching around $30 \mathrm{wt} \%$, and decreases as it gets close to the centre. Similar to copper, zinc is also high near the surface $(15 \mathrm{wt} \%)$. The other elements, aluminium, silicon and calcium, are present in minor quantities in few areas and are completely absent in other areas. These elements were as assumed to be impurities in the system.

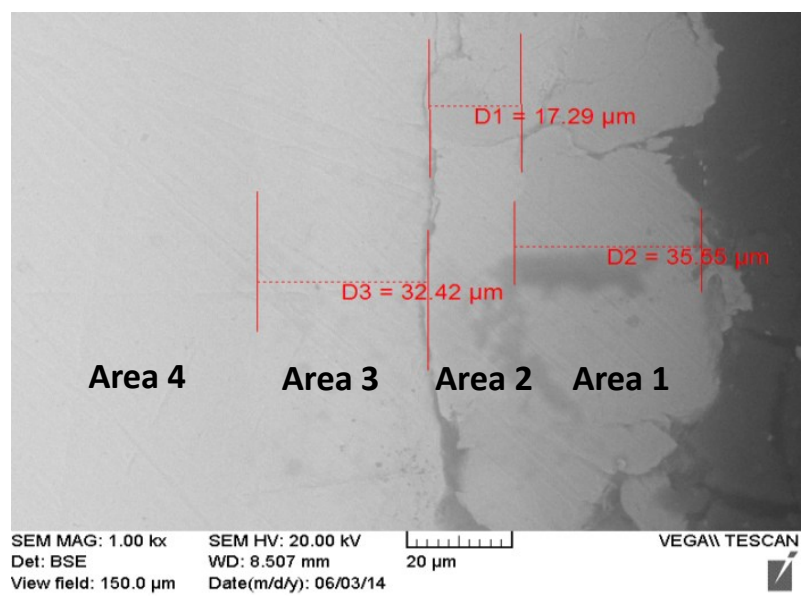




\begin{tabular}{|c|c|c|c|c|c|c|c|c|c|}
\hline $\mathrm{Wt} \%$ & $\mathrm{Fe}$ & $\mathrm{Ni}$ & $\mathrm{Cu}$ & $\mathrm{Zn}$ & $\mathrm{O}$ & $\mathrm{Al}$ & $\mathrm{Si}$ & $\mathrm{Ca}$ & Total \\
\hline Area 1 & 37.57 & 3.10 & 34.75 & 14.79 & 7.09 & 0.78 & 1.22 & 0.70 & 100 \\
\hline Area 2 & 42.09 & 4.67 & 31.87 & 13.32 & 5.95 & 0.53 & 1.05 & 0.52 & 100 \\
\hline Area 3 & 49.92 & 27.02 & 11.43 & 4.75 & 5.00 & 0.62 & 0.90 & 0.36 & 100 \\
\hline Area 4 & 87.30 & 3.00 & 5.98 & 2.43 & 0.44 & 0.85 & 0.81 & & 100 \\
\hline
\end{tabular}

Table 4-1: EDX results of the cross section of brass coin.

\subsubsection{Nickel Coins}

As shown in the SEM image in Table 4-2, four different areas were analyzed by EDX. According to the results, there are two main metallic elements in the nickel coin: nickel and iron. The nickel content decreases from surface to the core, while the content of iron increases when the location was close to the core.

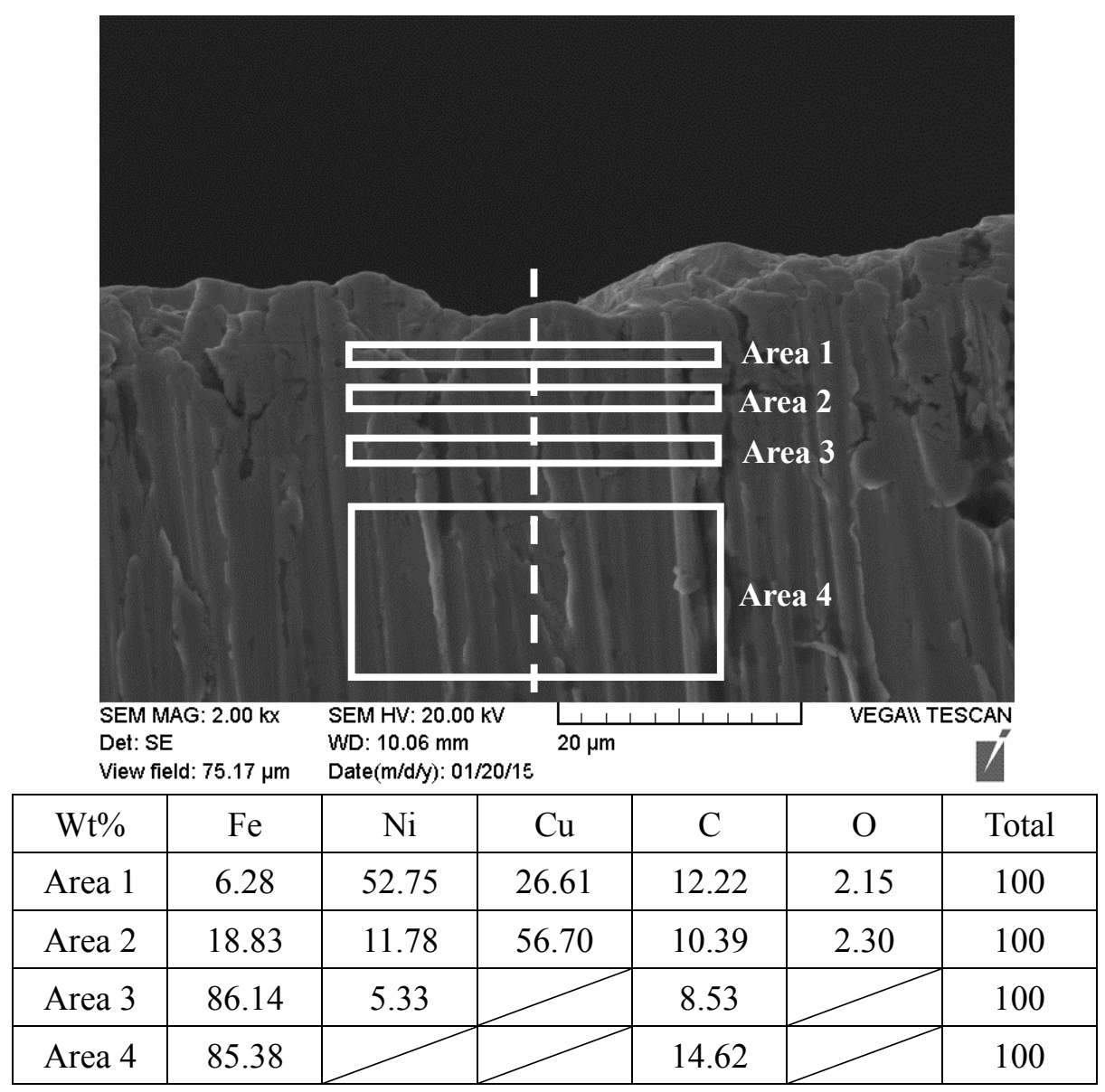

Table 4-2: EDX results of the cross section of nickel coin. 


\subsection{Vision Examination}

The preliminary evaluation of the coatings on the coins was to examine if the selected materials were acceptable in terms of their appearance. The criterion is that the coatings must not change the surface features such as color, reflectivity and weight. This requirement dictates that the coatings should be thin and transparent. For this examination, all the tested coins were photographed with a Canon 5D Mark III camera, before and after coating. The parameters of the camera were set up as follows: focal length $=35 \mathrm{~mm}$; exposure time $=1 / 200 \mathrm{~s}$; fNumber $=\mathrm{f} 2.2$; and ISO $=100$. In order to investigate the influence of spin speed and time on the coating thickness, fifty-eight coins (thirty-eight brass coins and twenty nickel coins) were coated with polyurethane and advanced liquid glass, respectively, at different spin speeds and for different spin times. However, it was found that the coatings of the same kind had no visible difference in appearance.

\subsubsection{Acceptable Coatings}

With the selected process parameters, polyurethane, advanced liquid glass, silicone R-2180, polytetrafluorethylene and standard liquid glass were deposited on coins. Based on visual examination, polyurethane (PUR), advanced liquid glass (ALG), silicone R-2180 were qualified for further testing. The bare and coated coins with three different materials are shown in Figure 4-1. It is shown that the coating films on all the coins did not influence the original reflectivity of the brass coins. Among which, the polyurethane coated coin is the closest to the bare one in terms of color and gloss. 


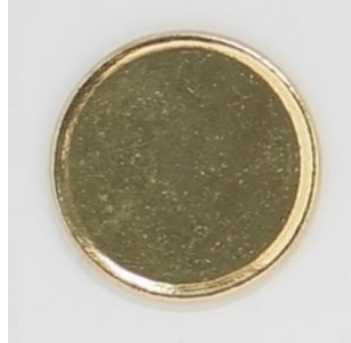

(a)

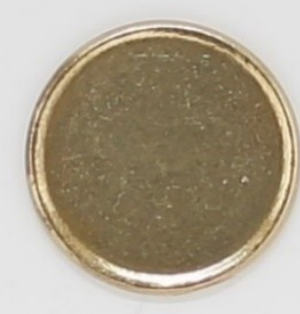

(b)

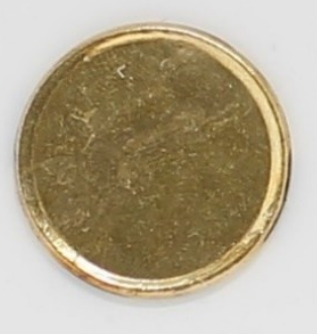

(c)

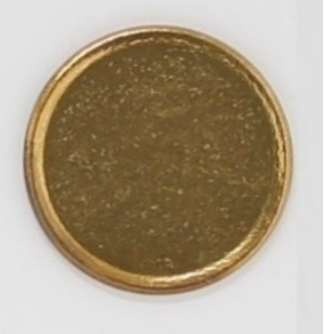

(d)

Figure 4-1:Bare and qualified coated brass coins: (a) bare coin, (b) PUR coated coin, (c) silicone coated coin; and (d) ALG coated coin.

It was found that some color change on silicone and ALG coated coins was not caused by the coatings but the brass coin itself due to the curing process where high temperature oxidation may have taken place to darken the coin surface. To confirm this observation, heat treatment was performed on a bare brass coin, where the coin was placed in a furnace at $250^{\circ} \mathrm{C}$ for $1 \mathrm{hr}$, which simulated the curing process for the ALG. As shown in Figure 4-2, the heat-treated bare coin is darker than the uncoated coins. Table 4-3 shows the EDX results of the heat-treated and bare coins, which further confirm the presence of oxidation on the heat treated coin.

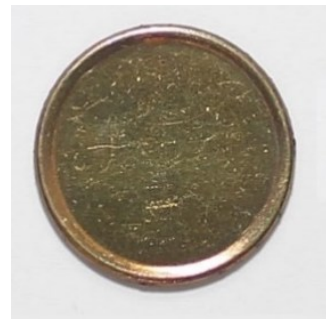

(a)

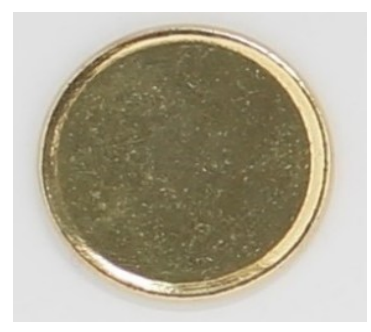

(b)

Figure 4-2: Comparison in color change between heat-treated and coated coins: (a) heat-treated coin; (b) bare coin 

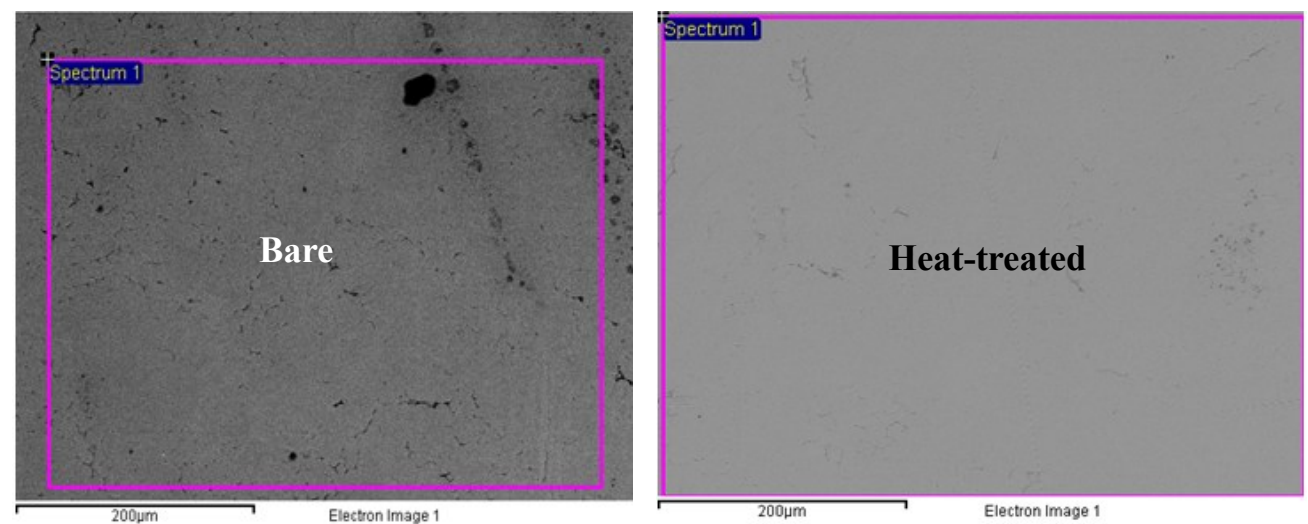

\begin{tabular}{|c|c|c|c|c|}
\hline $\mathrm{Wt} \%$ & $\mathrm{Cu}$ & $\mathrm{Zn}$ & $\mathrm{O}$ & Total \\
\hline Bare & 69.70 & 30.30 & & 100 \\
\hline Heat-treated & 69.53 & 28.29 & 2.19 & 100 \\
\hline
\end{tabular}

Table 4-3: Comparison of the EDX results between bare and heat-treated coins.

The nickel coins coated with polyurethane and advanced liquid glass have no visible difference with bare and heat-treated coins, as shown in Figure 4-3. This is because nickel coins are not as easily oxidized by heat as copper coins, thus the curing process of the ALG coating did not influence the coin color.

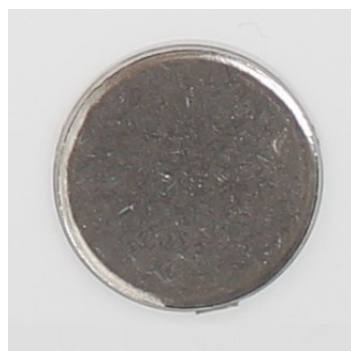

(a)

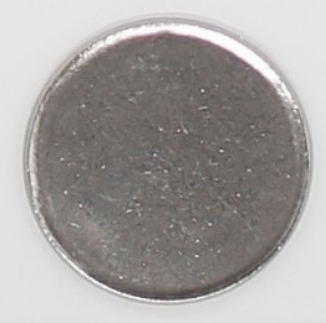

(b)

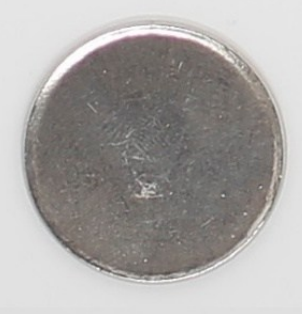

(c)

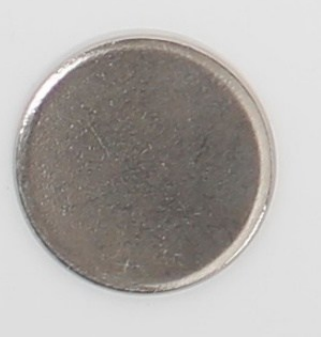

(d)

Figure 4-3: Bare, heat-treated and qualified coated nickel coins: (a) PUR coated coin; (b) ALG coated coin; (c) bare coin, and (d) heat-treated coin.

\subsubsection{Unacceptable Coatings}

Polytetrafluorethylene and standard liquid glass were found not suitable as coatings for the coins. These two materials changed the appearance of the coins noticeably. For standard liquid glass, the coatings produced under various spin conditions all had pale blue tint (Figure 4-4). Figure 4-5 further compares SLG coated coin to ALG coated coin; 
here the difference in color is clearly seen.

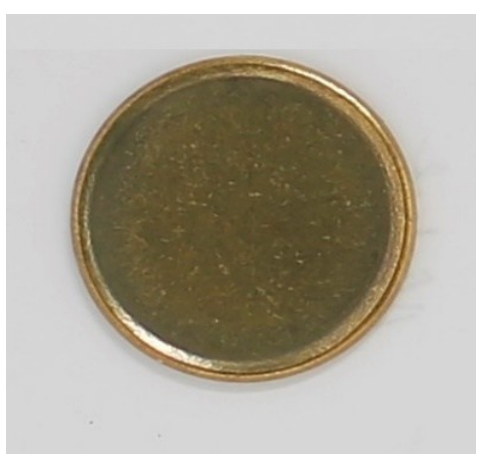

(a)

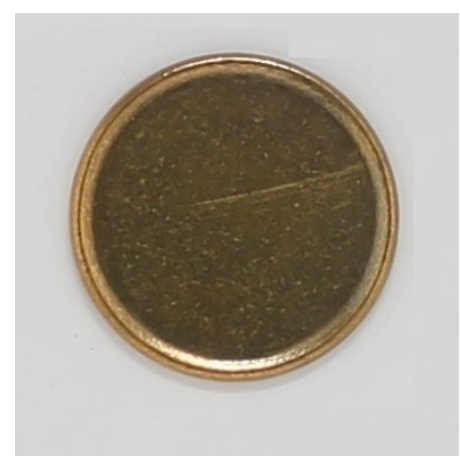

(b)

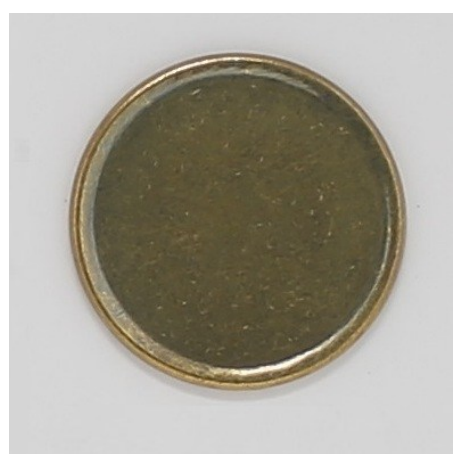

(c)

Figure 4-4: SLG coated coins produced at different spin speeds: (a) 500 rpm; (b) 700 rpm; and (c) 1000 rpm.

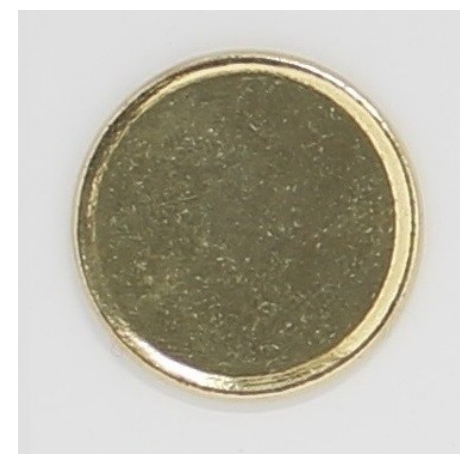

(a)

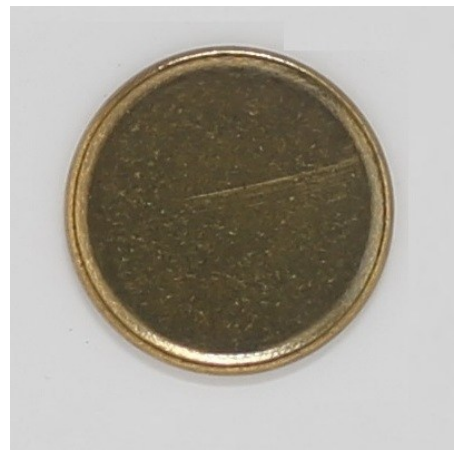

(b)

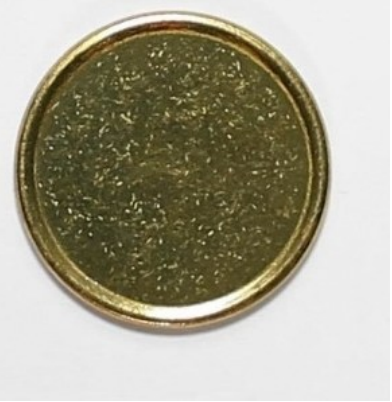

(c)

Figure 4-5: Comparison in color change between the two types of liquid glass coated coins and bare coin: (a) bare coin, (b) SLG coated coin, and (c) ALG coated coin.

Polytetrafluorethylene exhibited the worst adhesion. Although three surface treatments were attempted before the coating was applied, the adhesion was nevertheless very poor. Except the coating on the coin treated with grit blasting, the coatings on the other coins can be scraped off by nail (Figure 4-6). Additionally, the color of Polytetrafluorethylene coating was milky instead of transparent; the coating thickness also does not look uniform, as shown in Figure 4-7. 


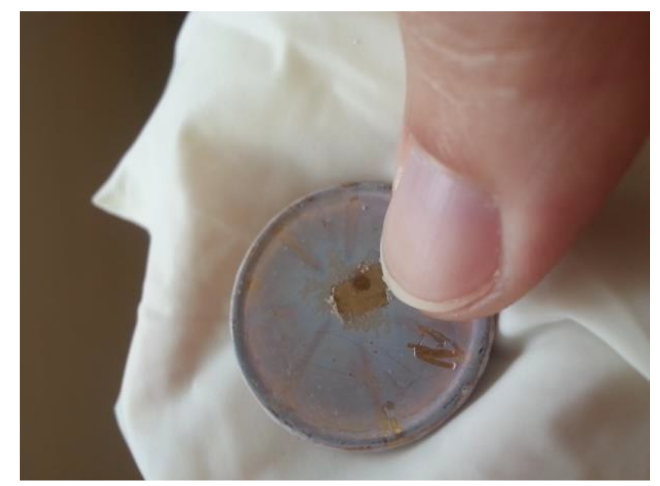

Figure 4-6: PTFE peeled off by nail.

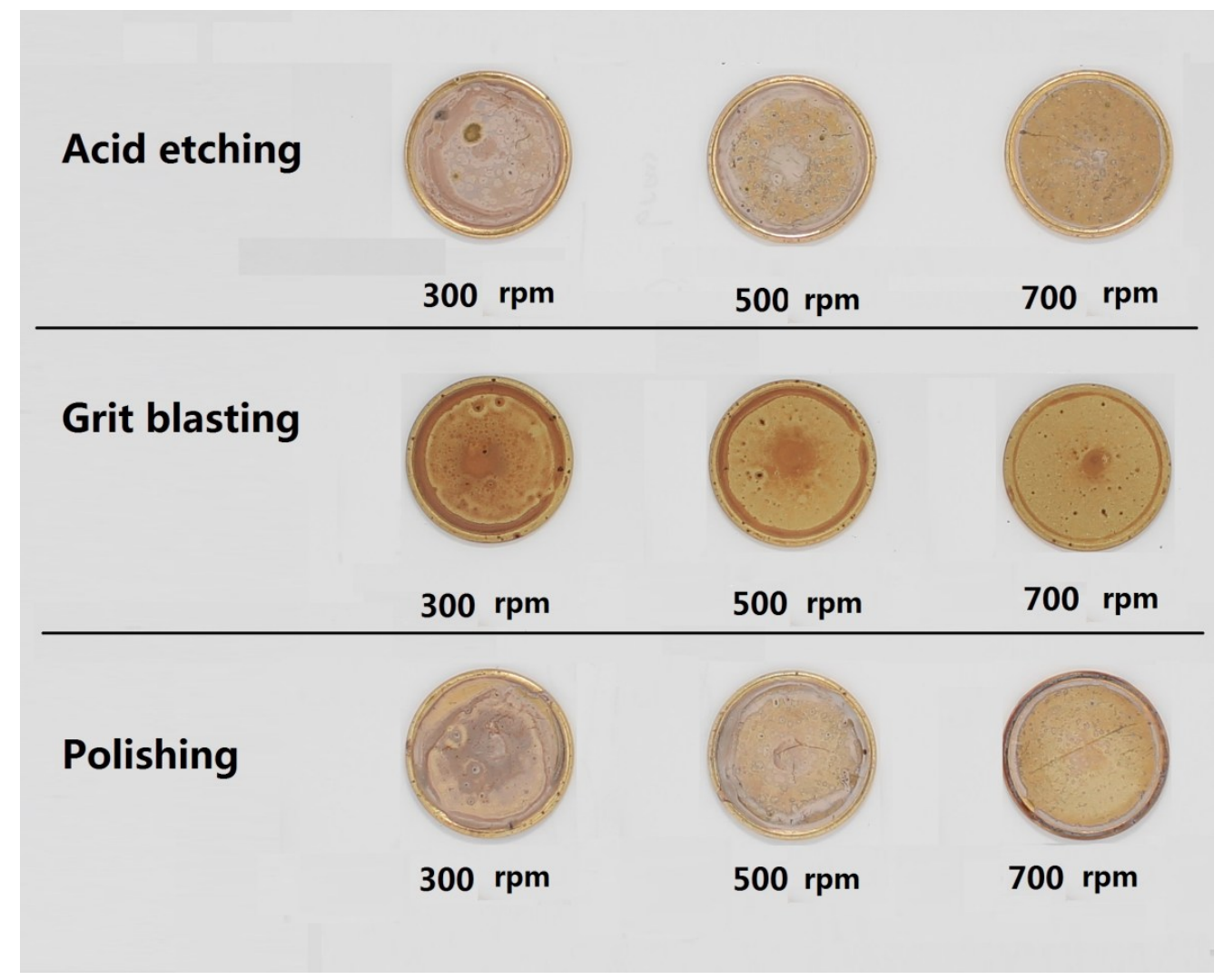

Figure 4-7: Coins coated with polytetrafluorethylene.

\subsection{Coating Thickness}

In most coating applications, the film thickness is considered to be the most important factor. In spin coating factors such as spin speed, spin duration, acceleration, fume exhaust (coating evaporation rate) and curing time influence the properties of the films. Since the coating requirements for the coins from the Royal Canadian Mint are very specific in terms of thickness (approximately $10 \mu \mathrm{m}$ ), the variations of the coating 
thickness with spin speed and duration (time) of the coating process were investigated. The centripetal acceleration generated by spinning causes the resin to spread (Figure 4-8), and off the edge of the substrate, thus forming a thin coating [90].

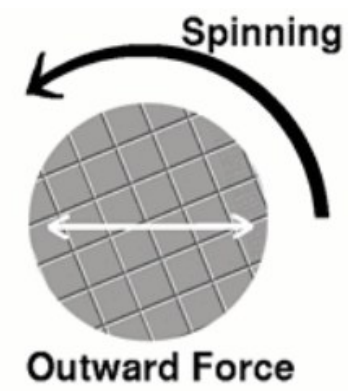

Figure 4-8: Resin spreading due to centrifugal forces [90].

A rule of thumb for using a spin coater is that the thickness $(t)$ of a spin coated film is inversely proportional to the square root of spin velocity $(\omega)[90]$.

$$
t \propto \frac{1}{\sqrt{\omega}}
$$

Prior to any coatings, all tested coins followed the same cleaning process aforementioned. Although five candidate materials were explored in this research, the disqualified materials, polytetrafluorethylene (PTFE) and standard liquid glass (SLG) were not considered in coating thickness study. For silicone R-2180, the coating thickness cannot be controlled due the manual brush operation. Therefore, only the polyurethane and advanced liquid glass (ALG) coatings were investigated. A balance with reading accuracy of $+/-0.1 \mathrm{mg}$ was used to weigh the coins before and after the coating process. Once the weight changes of each coating was acquired, the following equation was used to calculate the actual coating thickness, assuming that the coating thickness is uniform over the entire surface on one side of the coin.

$$
t=\frac{V}{A}=\frac{\Delta W}{\rho A}
$$


where $t$ is the film thickness, $V$ is the coating volume, $\Delta W$ is the weight difference before and after coating, $\rho$ is the density of the cured polymer and $A$ is the surface area of the substrate.

Prior to coating, the spin coater was programmed to spin at the desired time and rotational speed. Since polyurethane and advanced liquid glass have different viscosities, and the relationship between the coating thickness and spin speed and time were not previously known, a wide range of spin speed and time were tested. After these initial tests, the desired thickness of each material coating can be predicted and obtained for a certain spin speed and time. In addition, since these two materials may have different viscosities on brass and on nickel, the coating thickness on both nickel and brass coins was investigated.

The densities of polyurethane and advanced liquid glass are assumed to be $\rho_{P U R}=$ $275 \mathrm{~g} / \mathrm{L}$ and $\rho_{A L G}=0.8 \mathrm{~g} / \mathrm{cm}^{3}$, respectively. It was provided by the Royal Canadian Mint that the diameters of brass coins and nickel coins are $D_{\text {brass }}=26.09 \mathrm{~mm}$ and $D_{\text {nickel }}=$ $23.69 \mathrm{~mm}$. Thus the surface areas of these two types of coins are:

$$
\begin{aligned}
& A_{\text {brass }}=\pi R^{2}=\pi\left(\frac{D_{\text {brass }}}{2}\right)^{2}=534.34 \mathrm{~mm}^{2} \\
& A_{\text {nickel }}=\pi R^{2}=\pi\left(\frac{D_{\text {nickel }}}{2}\right)^{2}=440.55 \mathrm{~mm}^{2}
\end{aligned}
$$

\subsubsection{Polyurathane Thickness Examination}

To establish the relationship between the coating thickness on brass coin and rotational speed, the rotational speed was tested in the range from $100 \mathrm{rpm}$ to $1500 \mathrm{rpm}$ with increment of $200 \mathrm{rpm}$ (except $300 \mathrm{rpm}$ for the last increment) and the same spin duration of $30 \mathrm{~s}$ was used. For nickel coins, the speed was tested from $500 \mathrm{rpm}$ to 1200 
rpm with the same increment as for brass coins, and the same spin duration. To find the relationship between the coating thickness and spin time for brass coins, varying spin durations from $10 \mathrm{~s}$ to $50 \mathrm{~s}$, with an increment of $10 \mathrm{~s}$, were tested at $500 \mathrm{rpm}, 700 \mathrm{rpm}$ and $1000 \mathrm{rpm}$. For nickel coins, $10 \mathrm{~s}$ to $50 \mathrm{~s}$ with an increment of $20 \mathrm{~s}$ were tested at 500 rpm, $700 \mathrm{rpm}$ and $1000 \mathrm{rpm}$.

Based on the data, the relationships between coating thickness and spin time, and that between coating thickness and spin speed are plotted in Figure 4-9, Figure 4-10, and Figure 4-11. As shown, the coating thickness generally decreases with increasing speed and time. As shown in Figure 4-11 for the brass coins, the coating thickness variation can be divided into two regions. From $100 \mathrm{rpm}$ to $500 \mathrm{rpm}$, the coating thickness varies greatly. From $500 \mathrm{rpm}$ to $1500 \mathrm{rpm}$, the coating thickness is barely influenced by the speed. The effect of base alloy is also apparent from this investigation; for example, the smallest thickness of polyurethane on brass coins is about $10 \mu \mathrm{m}$ while it on nickel coins varies from 96.12 to $52.00 \mu \mathrm{m}$. The error band of the coating thickness is around $\pm 3 \mu \mathrm{m}$.

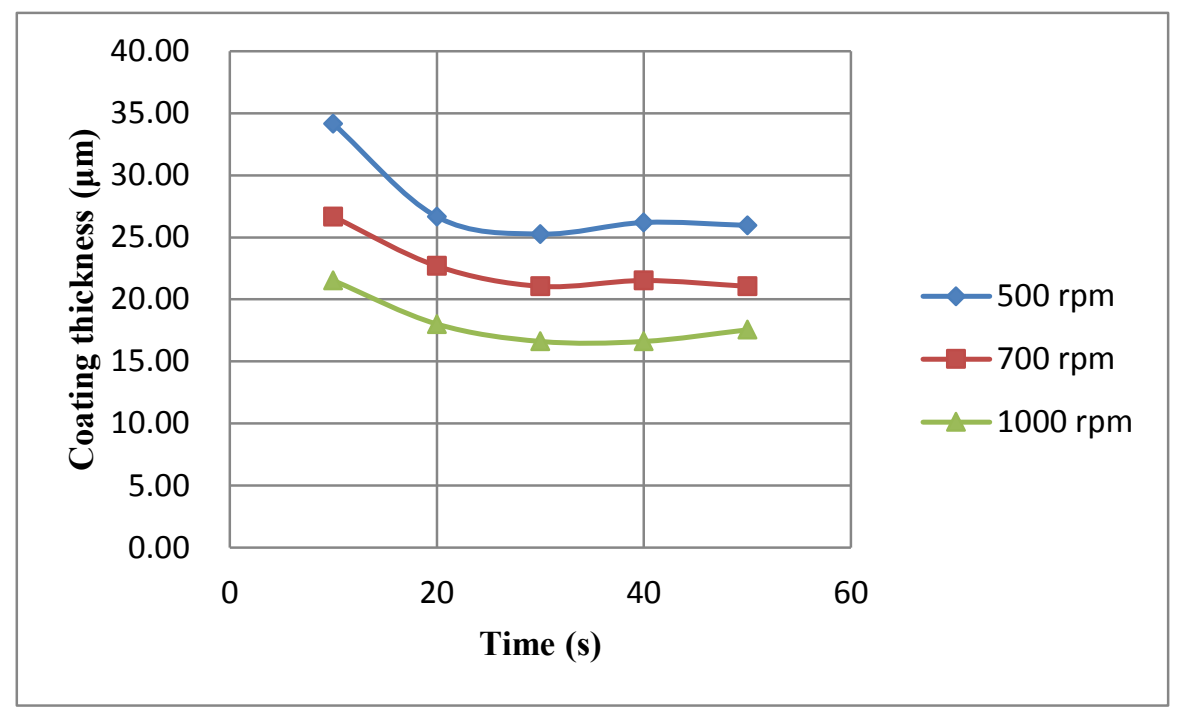

Figure 4-9: Coating thickness variations with spin speed for PUR coated brass coins $( \pm 3 \mu \mathrm{m})$. 


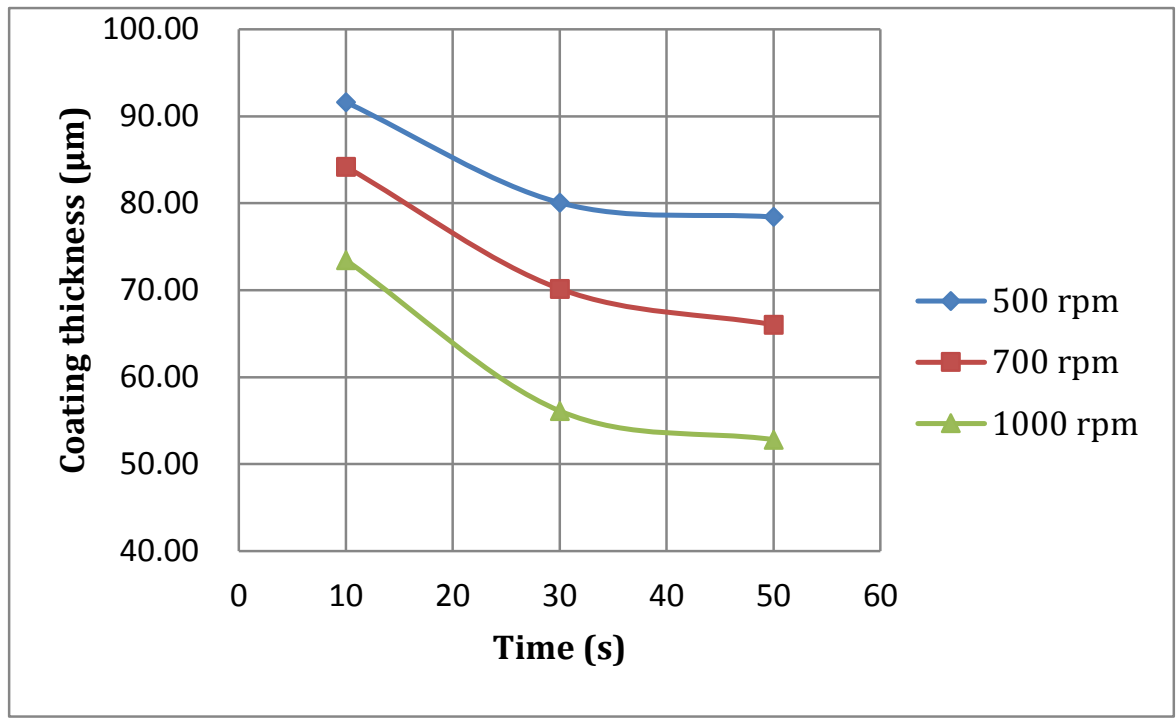

Figure 4-10: Coating thickness variations with spin time for PUR coated nickel coins $( \pm 3 \mu \mathrm{m})$.

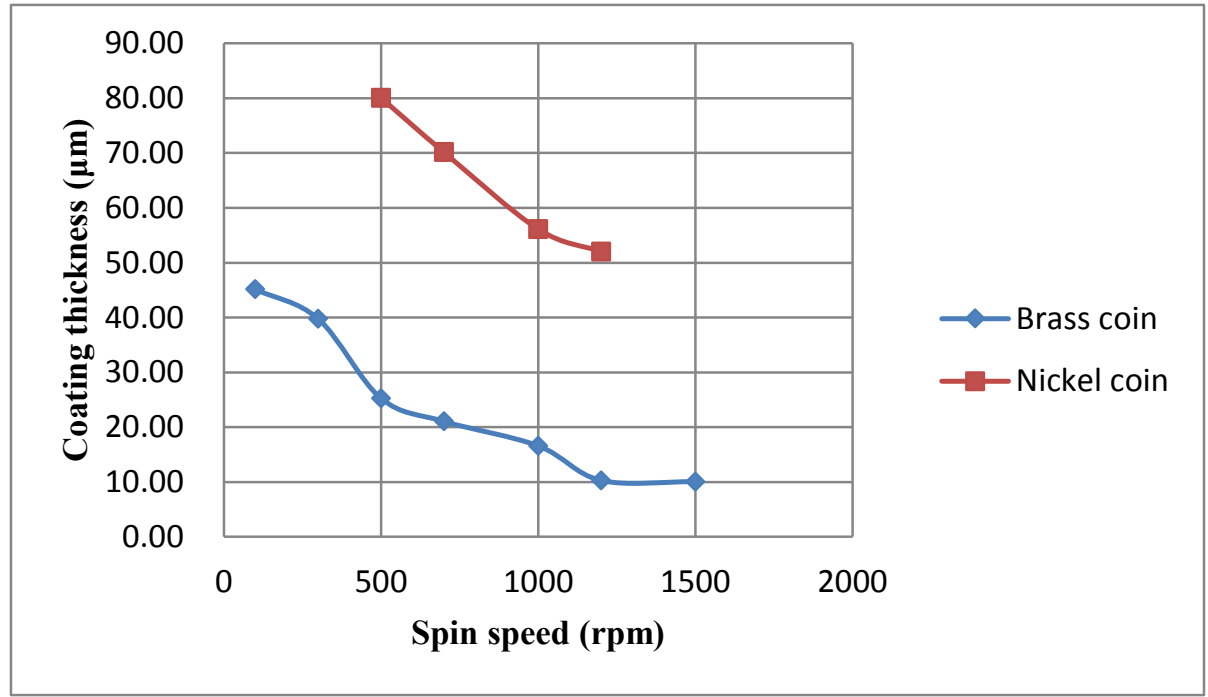

Figure 4-11: Coating thickness VS. spin speed for brass and nickel coins for $30 \mathrm{~s}( \pm 3 \mu \mathrm{m})$.

\subsubsection{Advanced Liquid Glass}

For advanced liquid glass, the same process parameters as for polyurethane were used to produce the coatings. It was determined that the ALG coatings were generally thinner than the PUR coatings. From the results shown in Figure 4-12 and Figure 4-13, the ALG coating thickness ranges from $2.34 \mu \mathrm{m}$ to $16.38 \mu \mathrm{m}$ on brass coins, and 3.4 to 12.20 $\mu \mathrm{m}$ on nickel coins. It can be observed in Figure 4-12 that the three curves exhibit same tendency with the change of spin duration. However, when the rotational speed 
reached $1000 \mathrm{rpm}$, the coating thickness is hardly influenced by spin time. For nickel coins, the coatings produced at $500 \mathrm{rpm}$ were the thickest, and the coating thickness reduces with increasing spin speed as well (Figure 4-13). The effect of substrate alloy on coating thickness variation is illustrated in Figure 4-14. When the time reaches $\sim 50 \mathrm{~s}$, thickness of AGL on copper becomes constant while that on nickel continues to change. This phenomenon is caused by the difference in friction coefficients between brass and nickel. Brass has lower friction coefficient than nickel, when the coins were rotated, ALG can flow with less resistance on brass than that on nickel. Therefore, the ALG coating can reach thinner coating thickness after $50 \mathrm{~s}$.

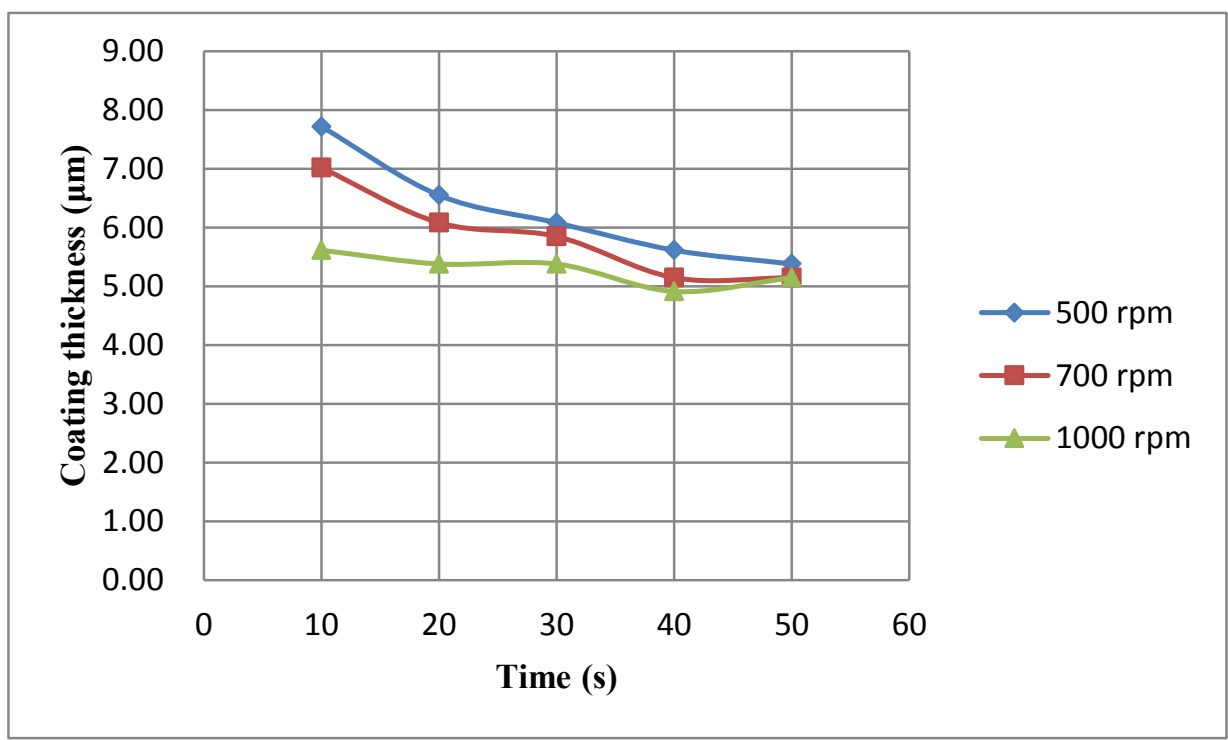

Figure 4-12: Coating thicknesses with spin time for ALG coatings on brass coins $( \pm 3 \mu \mathrm{m})$. 


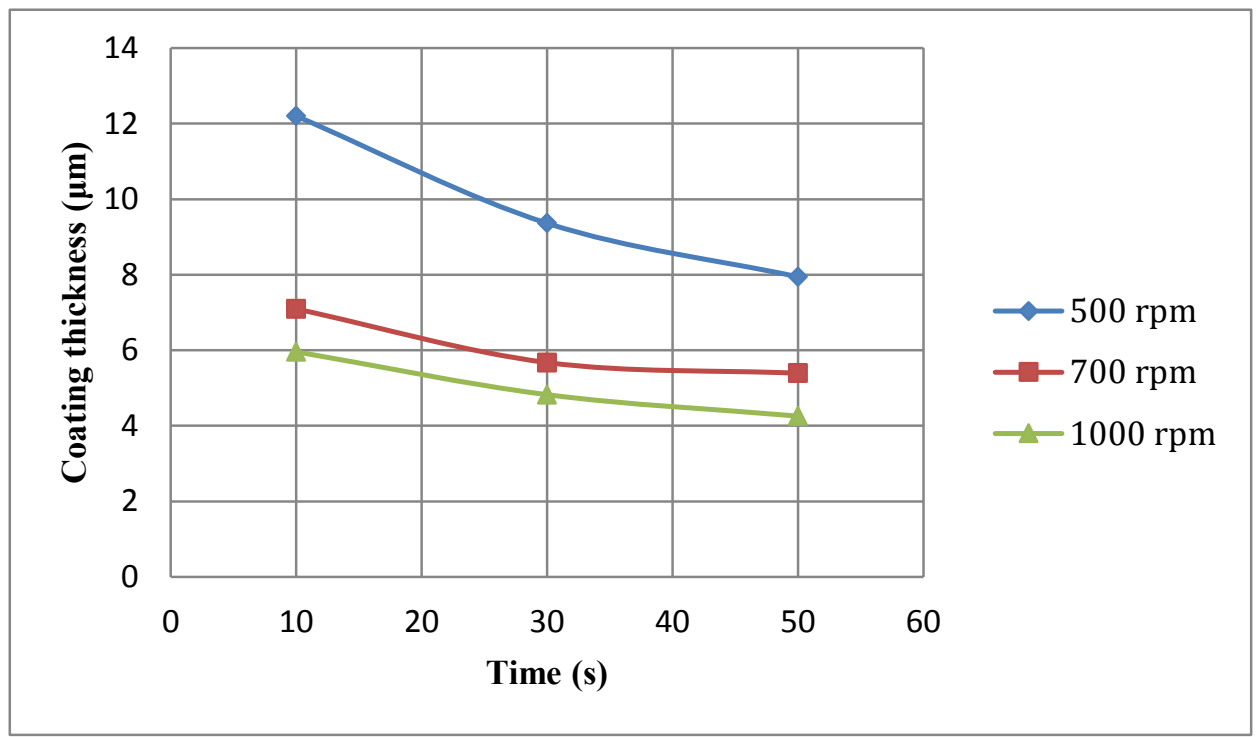

Figure 4-13: Coating thicknesses with spin time for ALG coatings on nickel coins ( $\pm 3 \mu \mathrm{m})$.

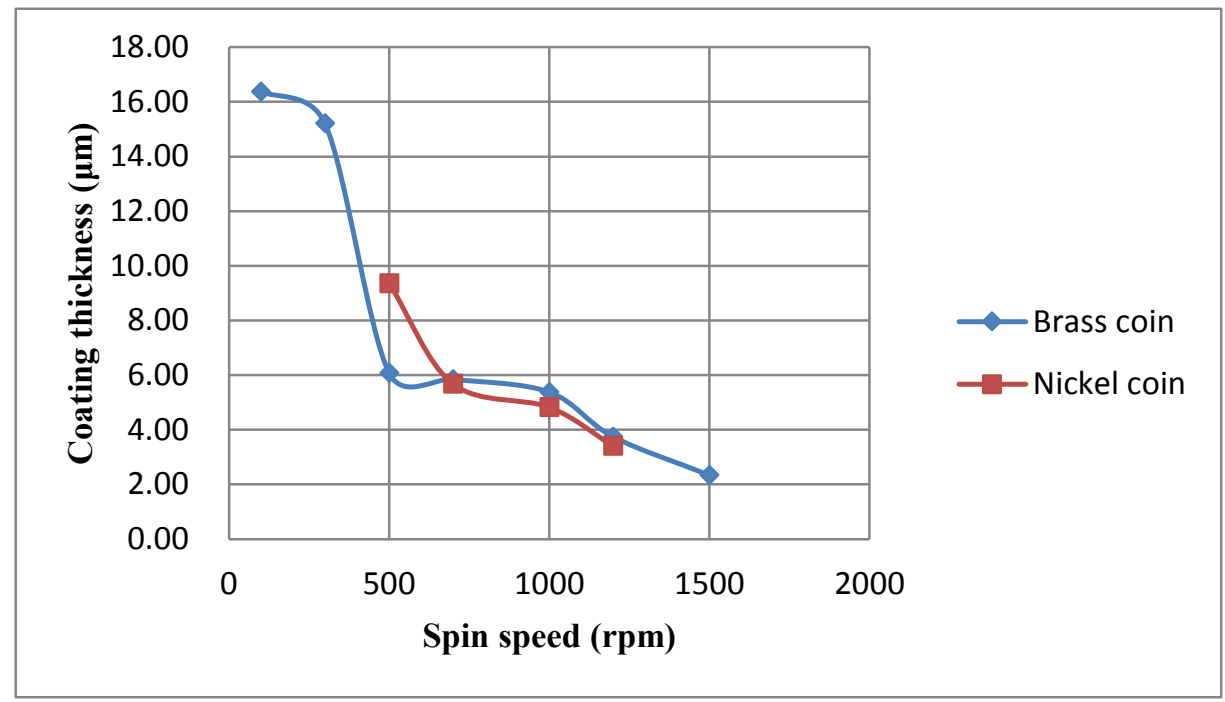

Figure 4-14: Coating thicknesses VS. rotational speed for ALG coatings for $30 \mathrm{~s}$ ( $\pm 3 \mu \mathrm{m})$.

\subsection{Microstructural Analysis}

\subsubsection{Facilities}

Microstructure analyses of the coating specimens were performed on a Tescan Vega-II XMU scanning electron microscope (SEM), shown in Figure 4-15, equipped with an Oxford energy dispersive X-ray (EDX) spectroscopy system for elemental and quantitative determination. The SEM images of the coating specimens were captured by a 
focused beam of electrons. To enable the samples to be conductive, all sample surfaces were coated with a gold film. When observing the SEM images, the bright area represents thinner coating or bare coin. Each coating was also analyzed with the EDX system to provide the chemical constituents in a specific area. However, EDX system is unable to accurately quantify the light elements whose atomic number is below eight, such as carbon and oxygen; The measured percentages of these elements can only be used as a reference.

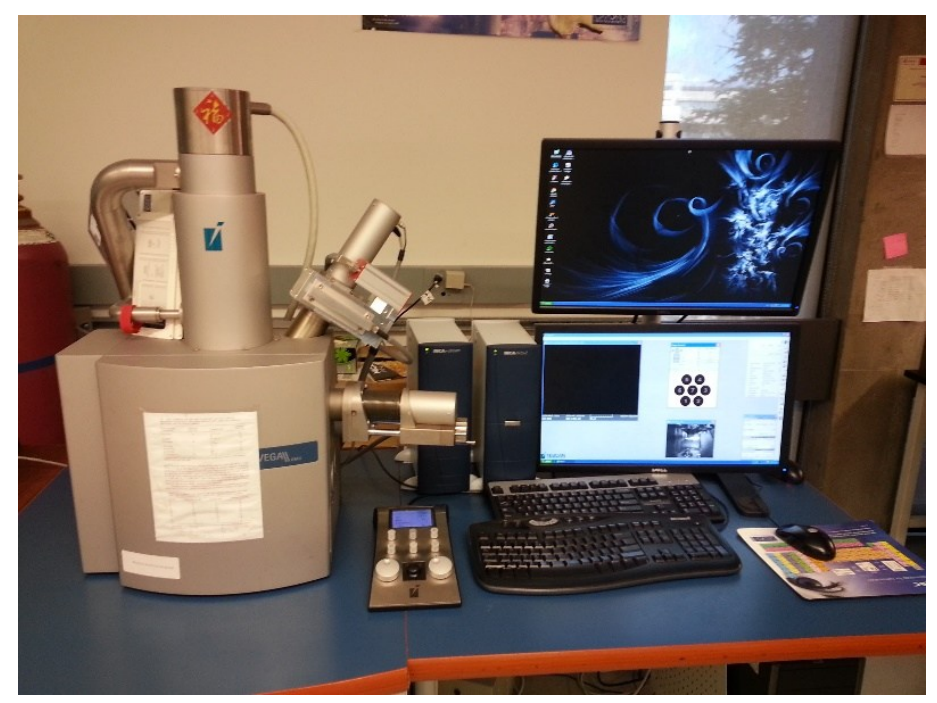

Figure 4-15: Tescan Vega-II XMU Scanning Electron Microscope (SEM) with an Energy Dispersive X-ray (EDX) spectroscopy system.

\subsubsection{Polyurethane and Advanced Liquid Glass Coatings}

The polyurethane and advanced liquid glass coated coins, processed at $500 \mathrm{rpm}, 700$ rpm, and $1000 \mathrm{rpm}$, were analyzed with SEM at 80X and 1000X magnifications. The images were taken at the center and at the edge of the specimens to examine the uniformity and coverage of the coatings.

The SEM images displayed in Figure 4-16 and Figure 4-17 are the microstructures 
of the coins coated with polyurethane and advanced liquid glass, respectively, processed at a rotational speed of $500 \mathrm{rpm}$. From the images taken at the center of the polyurethane coated coin in Figure 4-16 (a) and (c), the coating seems uniform and flat because the color/contrast is uniform. However, there are some bright spots observed at the center (Figure 4-16(c)). The advanced liquid glass coating is not as uniform as the polyurethane coating. The image in Figure 4-16(b) is quite fuzzy, which was not caused by the equipment; the uneven coating surface made the focusing impossible under a low magnification. Figure 4-16(d), taken at $1 \mathrm{kX}$, is much clear. Also no bright spots or color difference are observed form this image.

Figure 4-17 shows the SEM images from the edges of the coins. The coatings at the edge look less uniform than that at the center of the coins. For polyurethane, more bright spots are found at the edge in addition to the presence of small cracks (Figure 4-17(c)). No obvious cracks or defects are observed on the advanced liquid glass coating (Figure 4-17(d)).

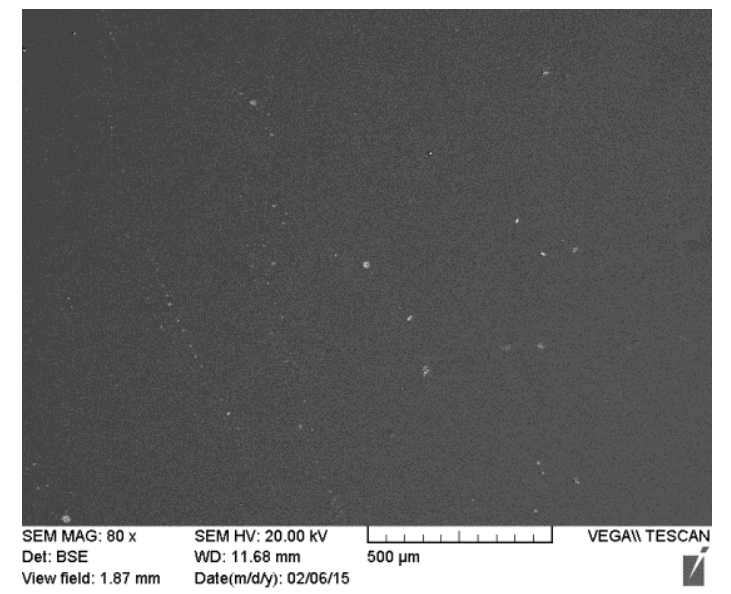

(a)

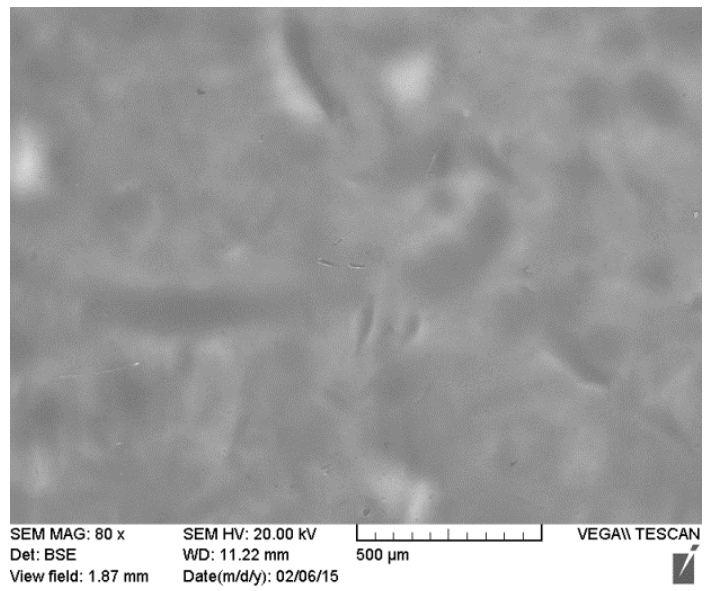

(b) 


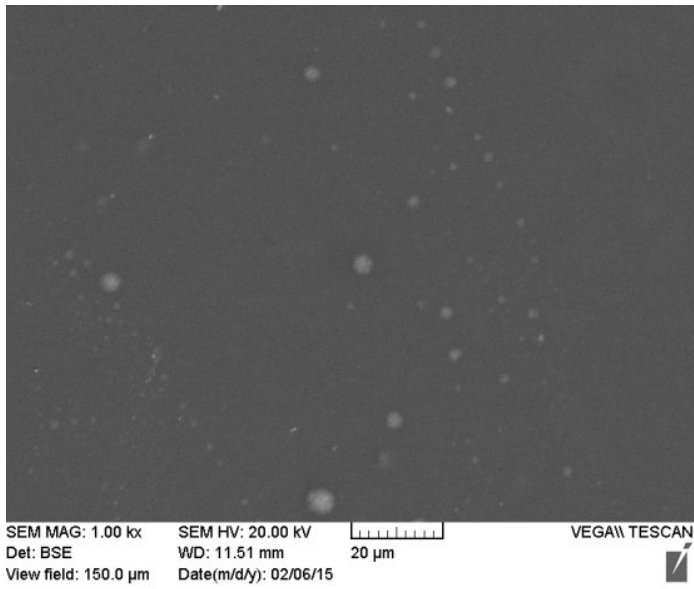

(c)

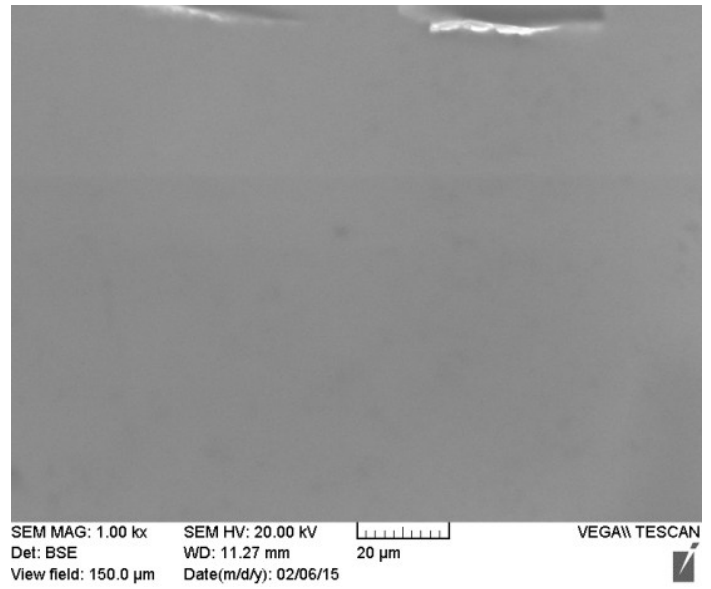

(d)

Figure 4-16: SEM images of microstructure at the center of the polyurethane and advanced liquid glass coated coins processed at 500 rpm: (a) PUR coating at 80X, (b) ALG coating at 80X, (c) PUR coating at $1 \mathrm{kX}$, and (d) ALG coating at $1 \mathrm{kX}$.

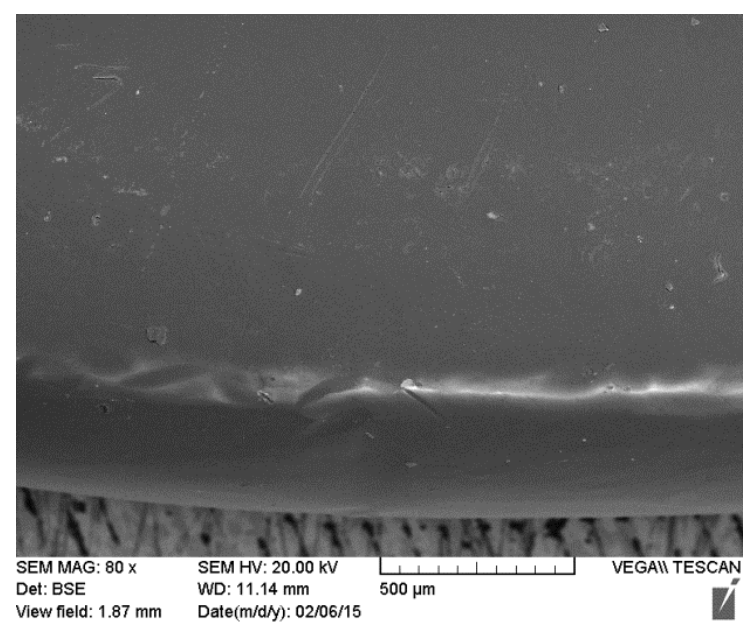

(a)

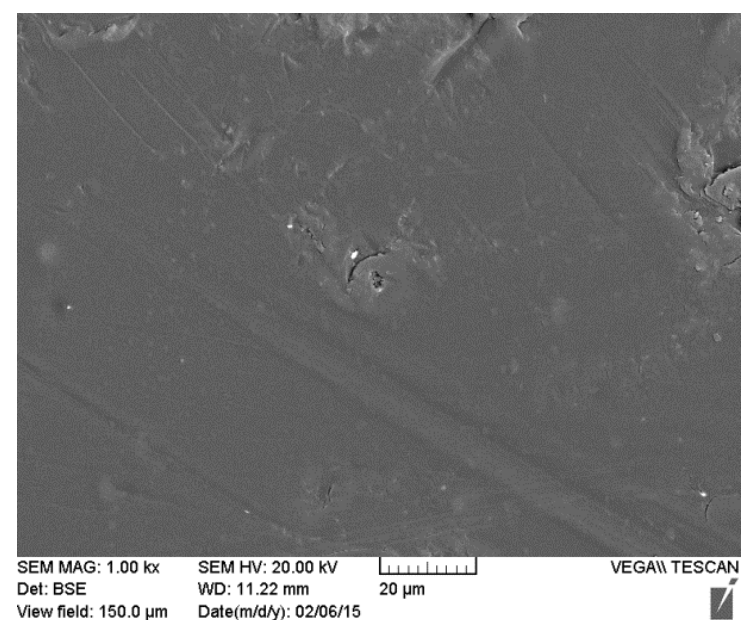

(c)

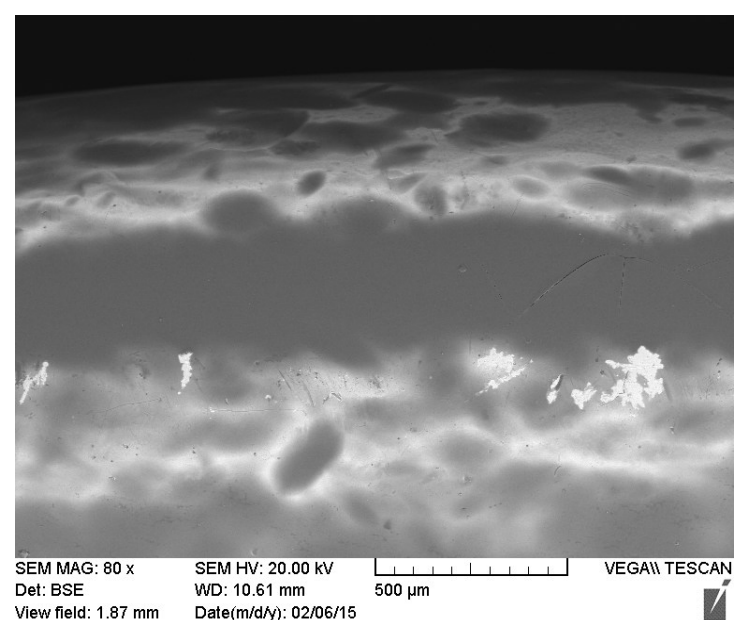

(b)

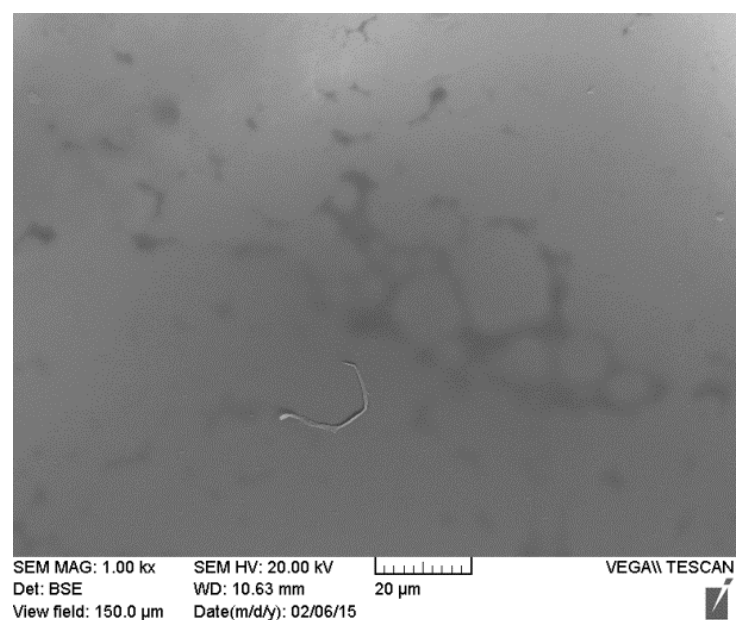

(d)

Figure 4-17: SEM images of microstructure at the edge of polyurethane and advanced liquid glass coated coins processed at 500 rpm: (a) PUR coating at 80X, (b) ALG coating at 80X, PUR coating at $1 \mathrm{kX}$, and (d) ALG coating at $1 \mathrm{kX}$. 
Figure 4-18 and Figure 4-19 show the SEM images of the coated coins processed at $700 \mathrm{rpm}$. For advanced liquid glass, the coatings applied at $500 \mathrm{rpm}$ and $700 \mathrm{rpm}$ have no obvious difference at the center and at the edge. However, for polyurethane, the coating produced at $700 \mathrm{rpm}$ has more bumps and bright spots, in particular, at the edge of the coin, as seen in Figure 4-19(c).

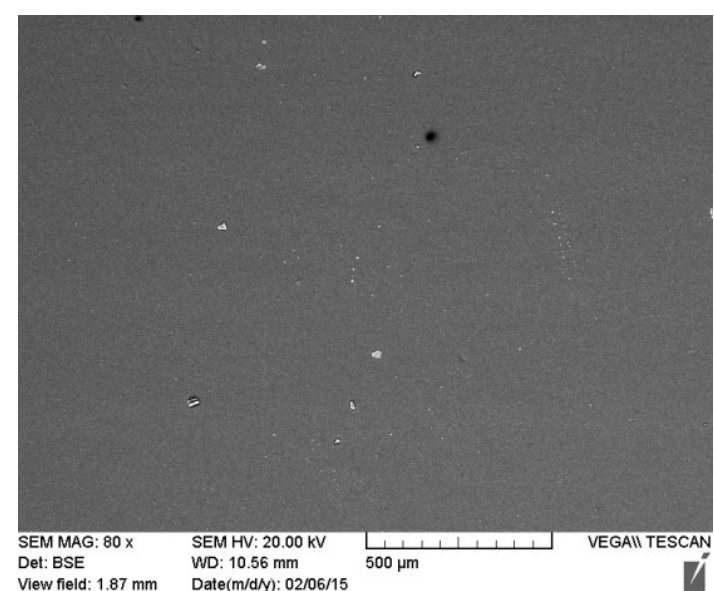

(a)

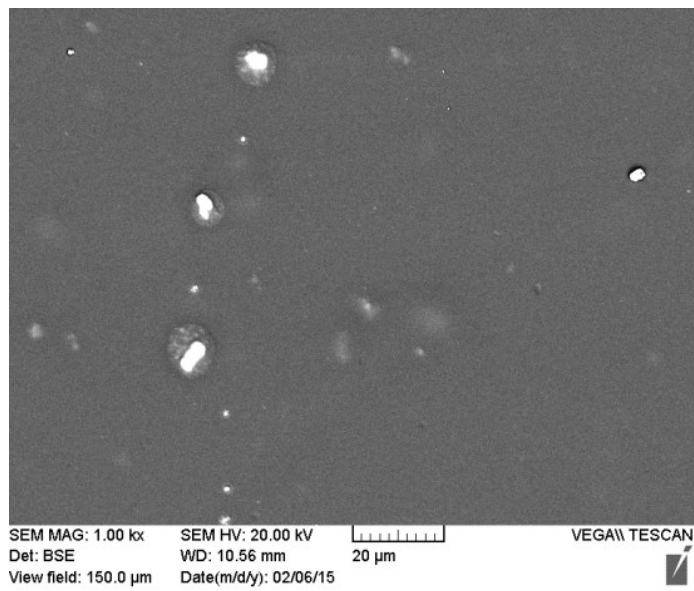

(c)

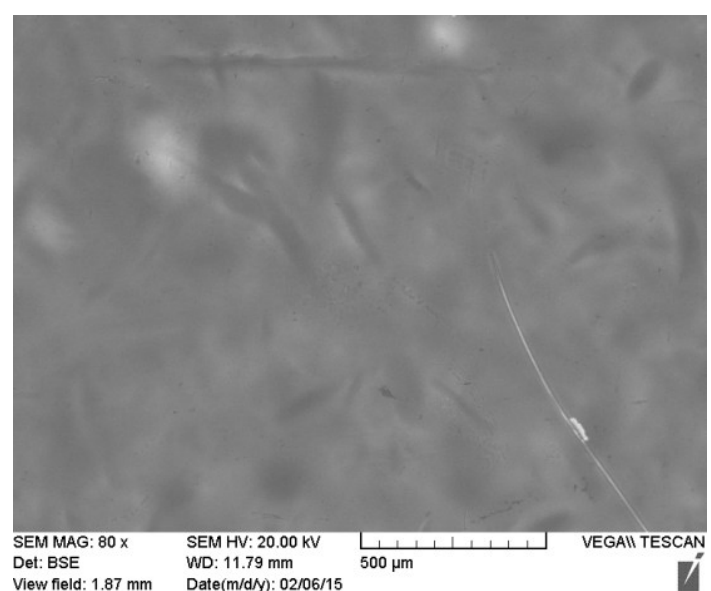

(b)

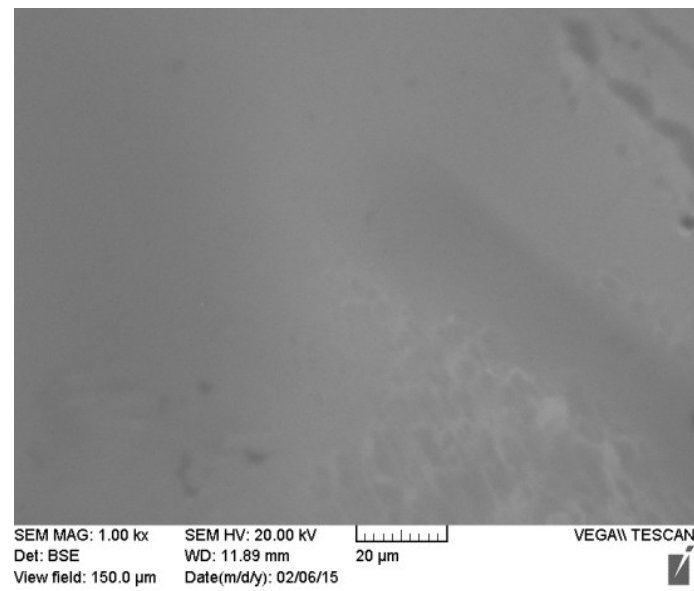

(d)

Figure 4-18: SEM images of microstructure at the center of polyurethane and advanced liquid glass coated coins processed at 700 rpm: (a) PUR coating at 80X, (b) ALG coating at 80X, PUR coating at $1 \mathrm{kX}$, and (d) ALG coating at $1 \mathrm{kX}$. 


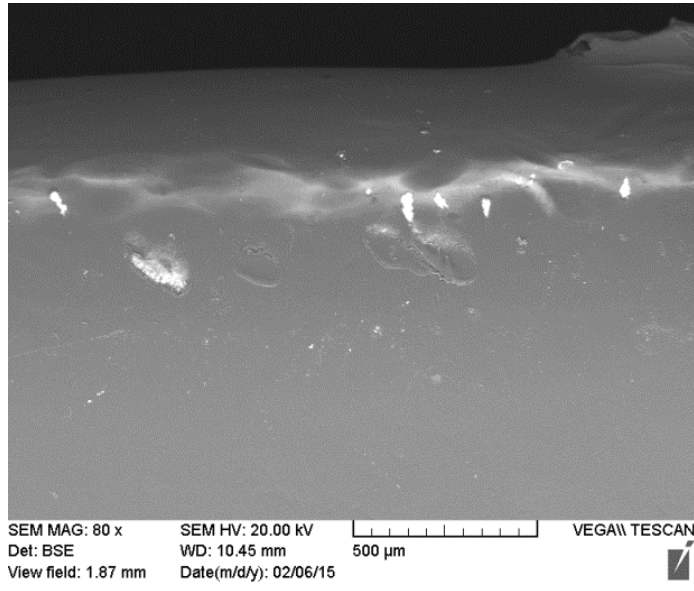

(a)

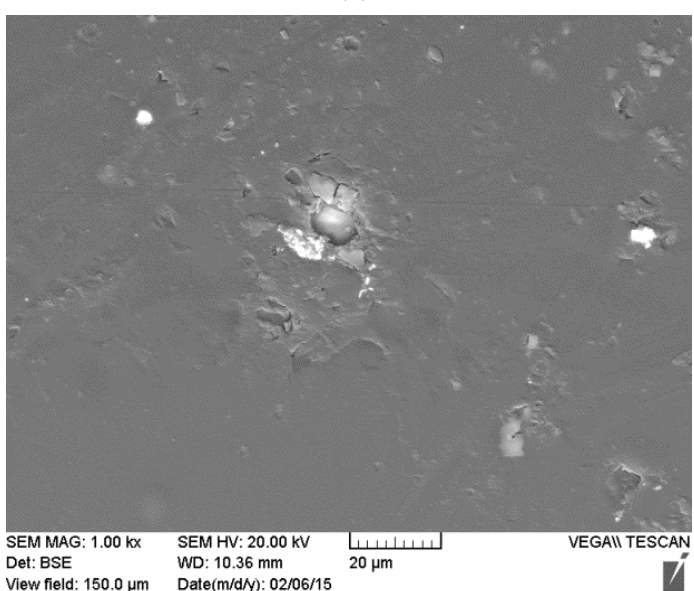

(c)

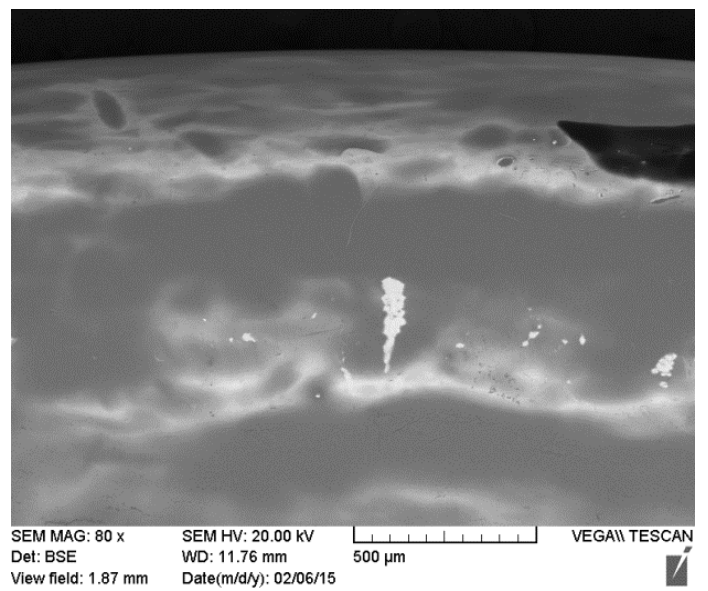

(b)

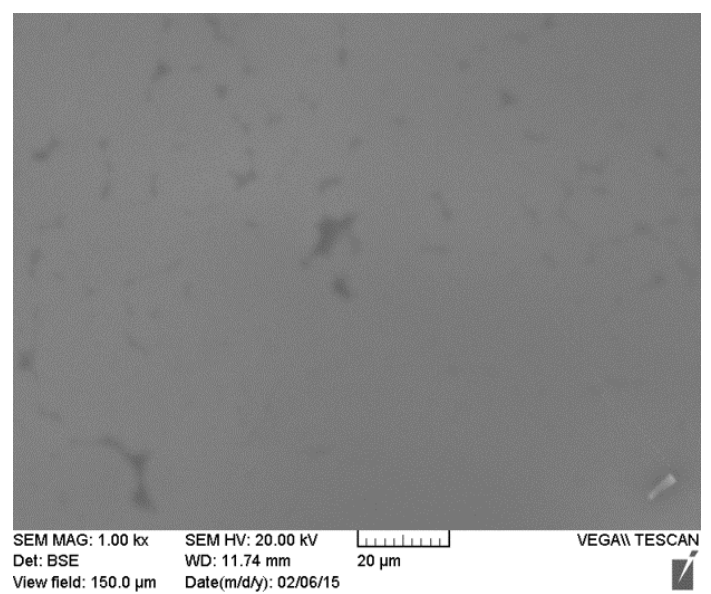

(d)

Figure 4-19: SEM images of microstructure at the edge of polyurethane and advanced liquid glass coated coins processed at 700 rpm: (a) PUR coating at 80X, (b) ALG coating at 80X, (c) PUR coating at $1 \mathrm{kX}$, and (d) ALG coating at $1 \mathrm{kX}$. 
Figure 4-20 and Figure 4-21 show the images of the coated coins processed at 1000 rpm. At this rotating speed, the polyurethane coating is better than the others. The polyurethane coating looks uniform and has complete coverage, and also no obvious defects are found on the entire coating surface. Meanwhile, the advance liquid glass coating produced at $1000 \mathrm{rpm}$ also has better overall quality than those produced at lower spin speeds.

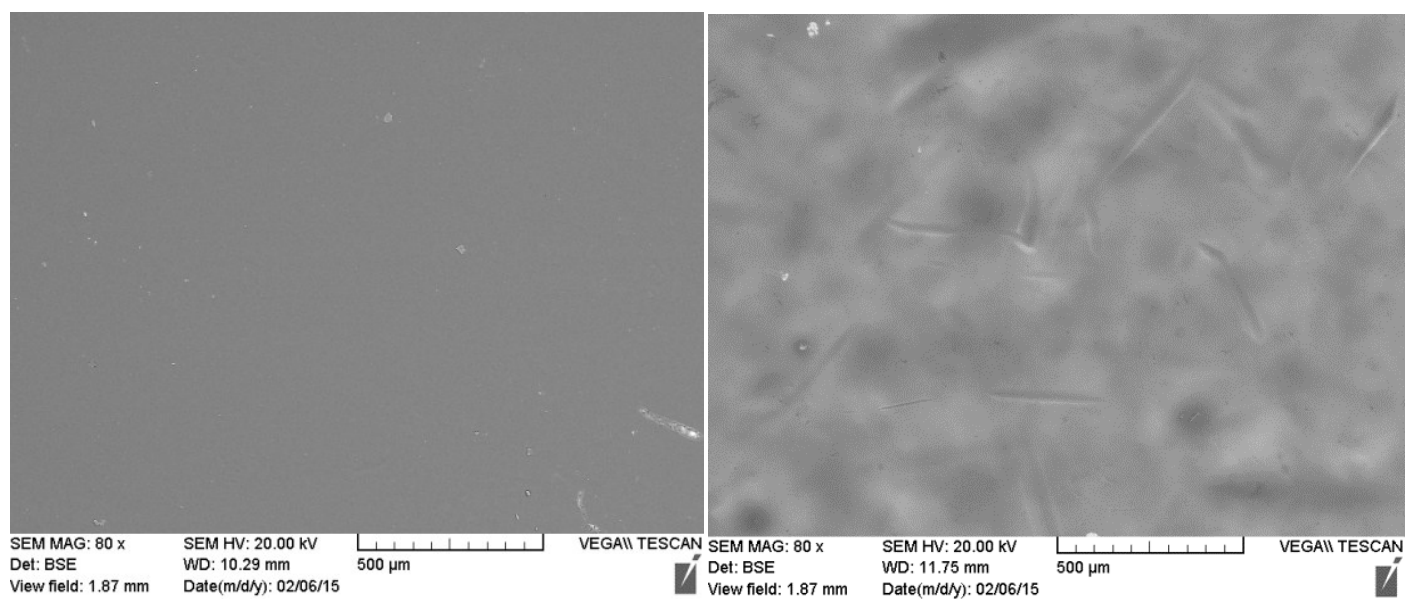

(a)

(b)

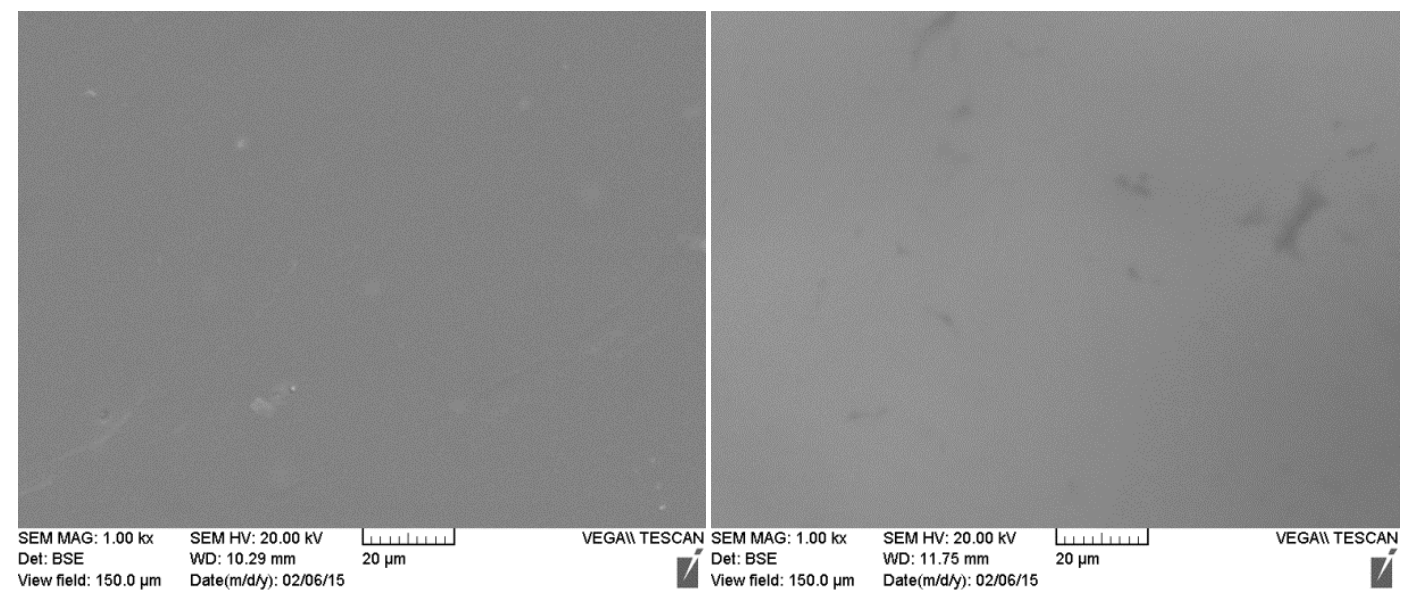

(c)

(d)

Figure 4-20: SEM images of microstructure at the center of polyurethane and advanced liquid glass coated coins processed at 1000 rpm: (a) PUR coating at 80X, (b) ALG coating at 80X, PUR coating at $1 \mathrm{kX}$, and (d) ALG coating at $1 \mathrm{kX}$. 


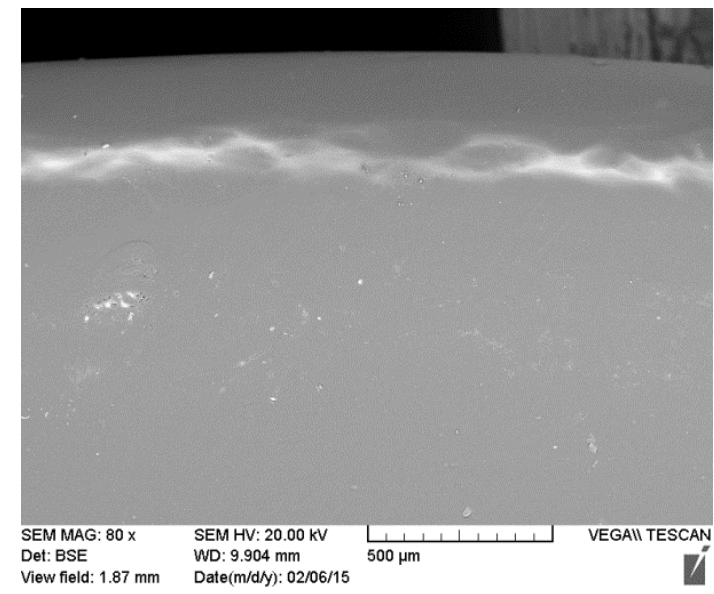

(a)

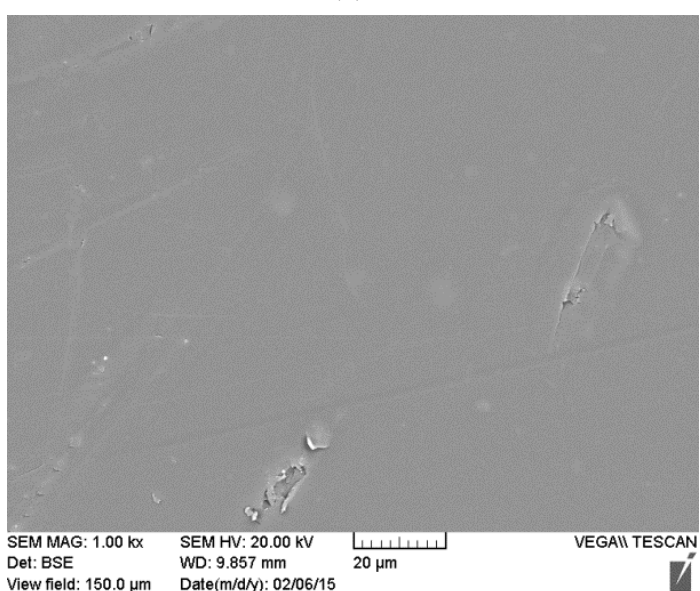

(c)

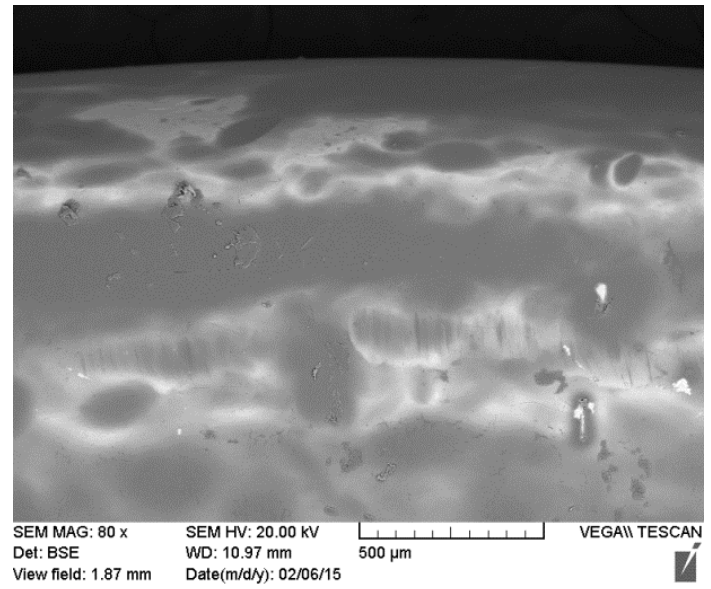

(b)

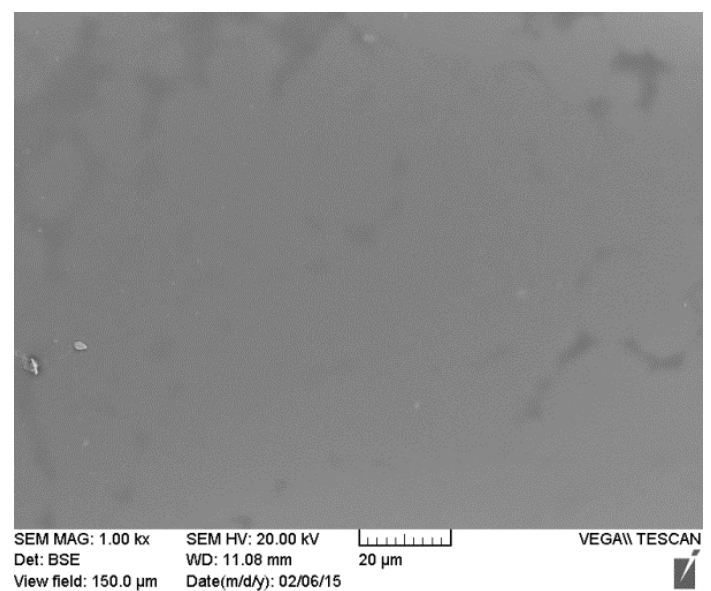

(d)

Figure 4-21: SEM images of microstructure at the edge of polyurethane and advanced liquid glass coated coins processed at 1000 rpm: (a) PUR coating at 80X, (b) ALG coating at 80X, PUR coating at $1 \mathrm{kX}$, and (d) ALG coating at $1 \mathrm{kX}$.

The EDX results of the polyurethane coated coin processed at $500 \mathrm{rpm}$ are presented in Table 4-4. The bright and dark areas were examined. It is shown that both areas contain very high carbon and oxygen, from the basic unit of polyurethane, $-\mathrm{NHCO}-\mathrm{O}-$. On the bright spots, impurities such as $\mathrm{Na}(5.12 \mathrm{wt} \%), \mathrm{Cl}(3.83 \mathrm{wt} \%)$ and $\mathrm{K}(1.52 \mathrm{wt} \%)$ were detected, likely from dust or sweat. Since polyurethane is viscous, dusts in the air were easily adhered to the coating surfaces when the coatings were dried in air. 


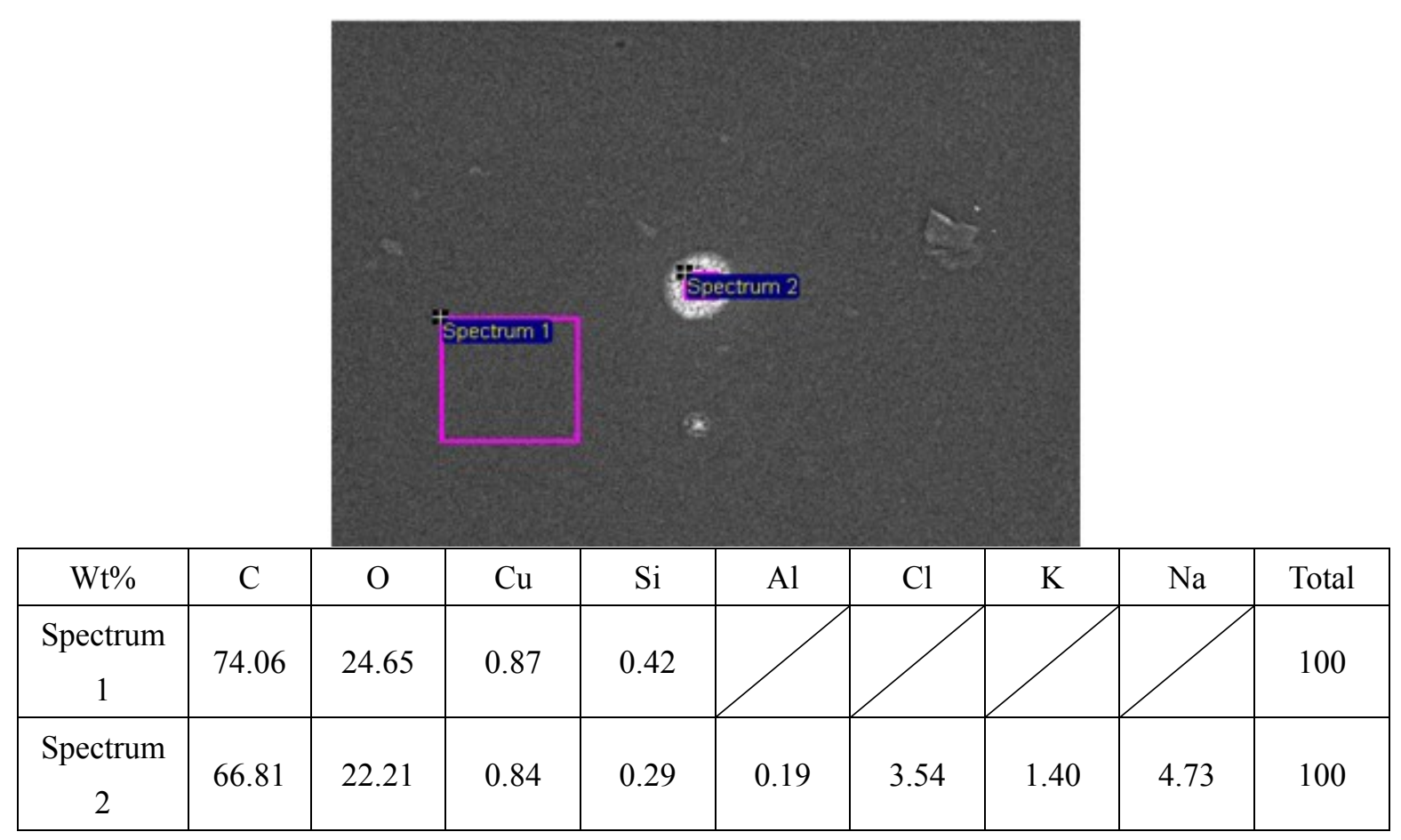

Table 4-4: EDX results of PUR coated coin processed at $500 \mathrm{rpm}$.

Table 4-5 summarizes the EDX results of the advanced liquid glass coated coin processed at $500 \mathrm{rpm}$. The copper $(28.17 \mathrm{wt} \%$ and $43.48 \mathrm{wt} \%)$ and zinc $(12.79 \mathrm{wt} \%$ and $20.32 \mathrm{wt} \%$ ) contents in the two areas detected by EDX were more than those of the PUR coating. Since the ALG coating is thin (around $6 \mu \mathrm{m}$ ) the electronic beam could pass through the coating and the elements in the coin were detected. Spectrum 1 is from the darker area of the ALG coating, and spectrum 2 from the bright area. As the silicone content of the dark area $(26.16 \mathrm{wt} \%)$ is higher than that of the bright area $(19.15 \mathrm{wt} \%)$, the dark area may either have thicker coating than the bright area or more Si containing component. Examining more locations of the ALG coating did not find other elements such as $\mathrm{Na}, \mathrm{Cl}, \mathrm{S}$, which suggests that dust did not adhere to this coating during curing. 


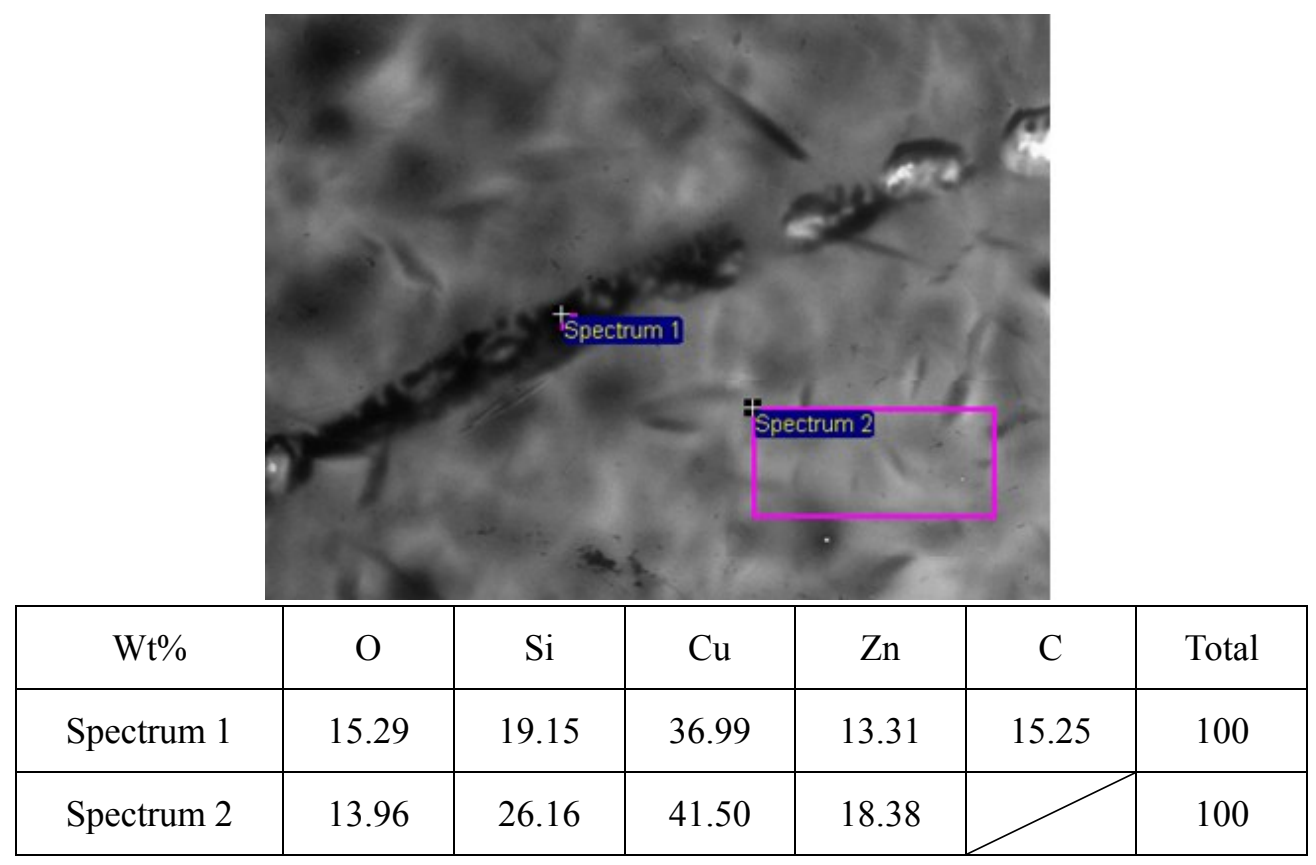

Table 4-5: EDX results of the ALG coated coin processed at $500 \mathrm{rpm}$.

\section{Silicone R-2180}

The fabrication method of the silicone R-2180 coating was different from that of other coatings; the coating thickness cannot be accurately controlled as manual brushing was used. SEM and EDX analyses were performed on the R-2180 coated coin; the results are presented in Table 4-6. Two main elements, silicon and carbon, were detected in the coating. Since no copper was detected in this coating and only very small amount of zinc was detected, it is suggested that the coating is sufficiently thick. There are small bright spots scattered across the coating surface; there is less silicone but more calcium. The source of calcium deposit is currently unknown. 


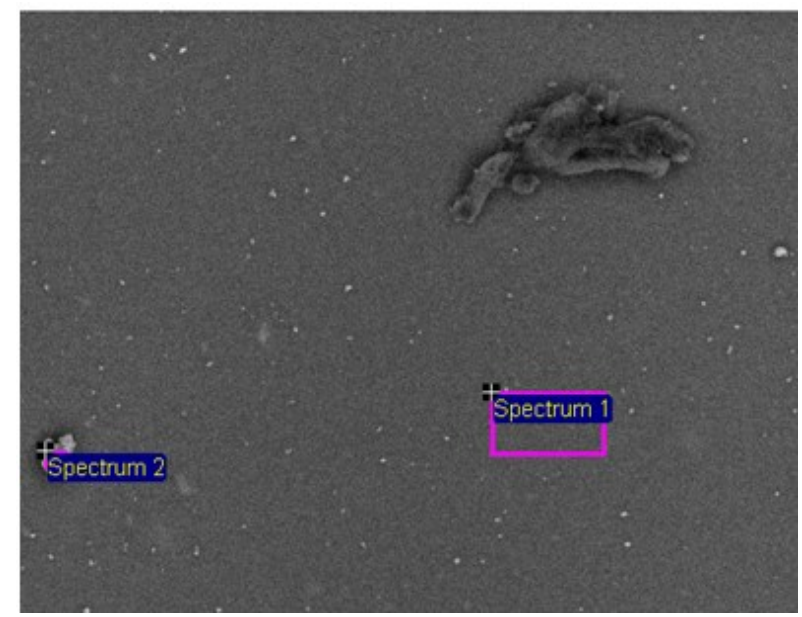

\begin{tabular}{|c|c|c|c|c|c|c|c|}
\hline $\mathrm{Wt} \%$ & $\mathrm{C}$ & $\mathrm{O}$ & $\mathrm{Si}$ & $\mathrm{Zn}$ & $\mathrm{Cu}$ & $\mathrm{Ca}$ & Total \\
\hline Spectrum 1 & 28.00 & 35.45 & 36.21 & 0.34 & & & 100 \\
\hline Spectrum 2 & 29.49 & 39.31 & 21.04 & & 0.26 & 9.90 & 100 \\
\hline
\end{tabular}

Table 4-6: EDX results of the silicone $R-2180$ coated coin.

\subsubsection{Standard Liquid Glass}

By visual examination, standard liquid glass was not recommended for coating the coins. SEM and EDX analyses were conducted on the standard liquid glass coating produced at $500 \mathrm{rpm}$. The SEM microstructure of the coating at the center of the coin is shown in Figure 4-22. Many cracks, raised dots, and pits are observed in the coating. Table 4-7 provides the EDX results of the coating. It is clear that liquid glass did not adhere on the coin surface during the deposition process because only very small amount of silicon was detected on the surface, while large amounts of copper and zinc were detected, both of which came from the coin matrix. 


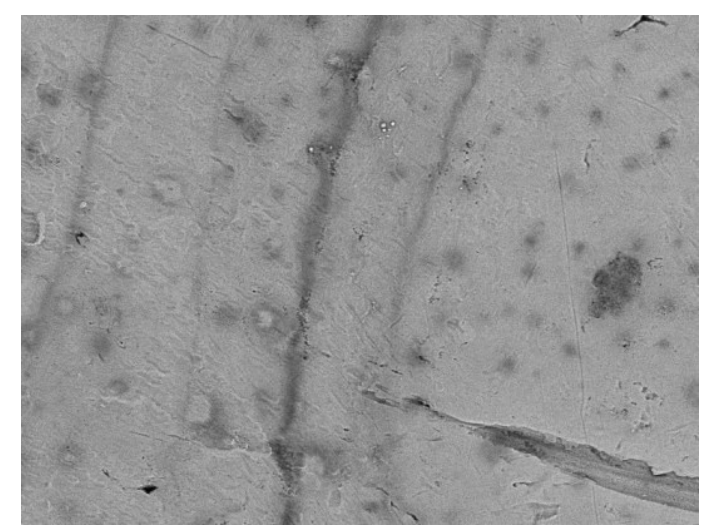

Figure 4-22: SEM image of microstructure at the center of the standard liquid glass coated coin processed at $500 \mathrm{rpm}$.

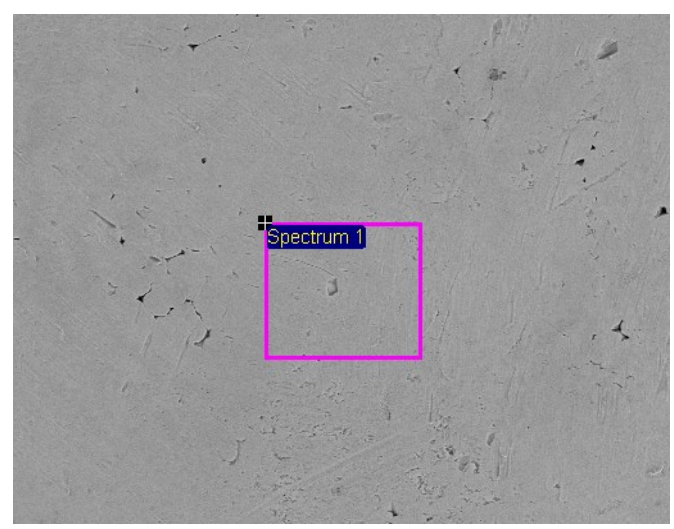

\begin{tabular}{|c|c|c|c|c|c|}
\hline $\mathrm{Wt} \%$ & $\mathrm{Si}$ & $\mathrm{Cu}$ & $\mathrm{Zn}$ & $\mathrm{O}$ & Total \\
\hline Spectrum 1 & 0.29 & 66.03 & 30.17 & 3.52 & 100 \\
\hline
\end{tabular}

Table 4-7: EDX results of the center of the standard liquid glass coated coin processed at $500 \mathrm{rpm}$.

\subsubsection{Polytetrafluorethylene}

For polytetrafluorethylene, the coating failure is characterized by color change and non-uniformity on the surface. The coatings pre-treated with different methods, produced at $700 \mathrm{rpm}$, were selected for SEM analysis; EDX analysis was not performed because the main constituents of polytetrafluorethylene are fluorine and carbon, which cannot be accurately quantified by EDX. Figure 4-23 shows the microstructures of the coatings on the coin surfaces pre-treated with three different methods. For grit blasted sample, dark craters are found on the entire coating surface. These craters induced by the sand blasting 
resulted in uneven coating on the coin surface as seen in Figure 4-23(a). In Figure 4-23(b), there were some grey bubbles observed in the coating. This may be caused by the interaction between polytetrafluorethylene and residual phosphoric acid that was used during acid etching, although the coin was ultrasonic cleaned in acetone for $5 \mathrm{~min}$. Large amounts of cracks are also observed in this coating. In Figure 4-23(c), polishing scars are clearly seen on the coating surface.

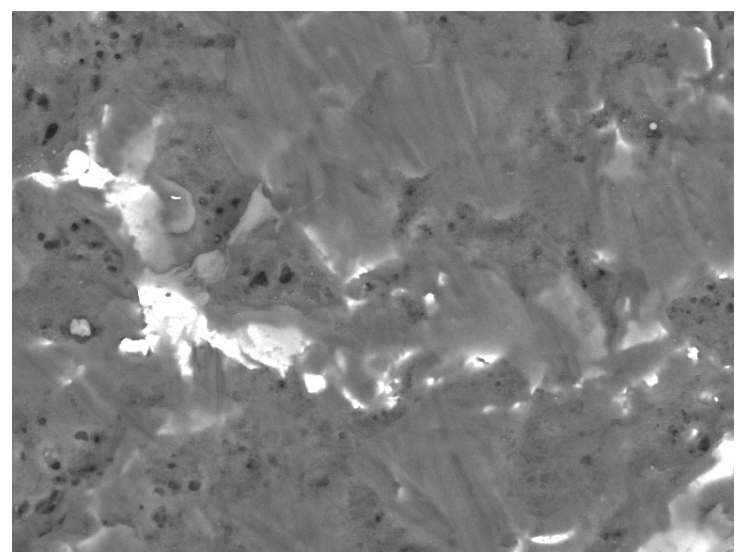

(a)

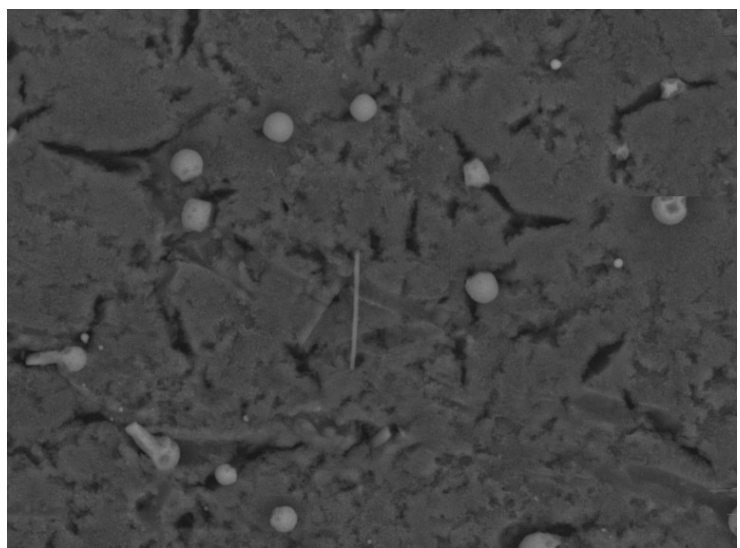

(b)

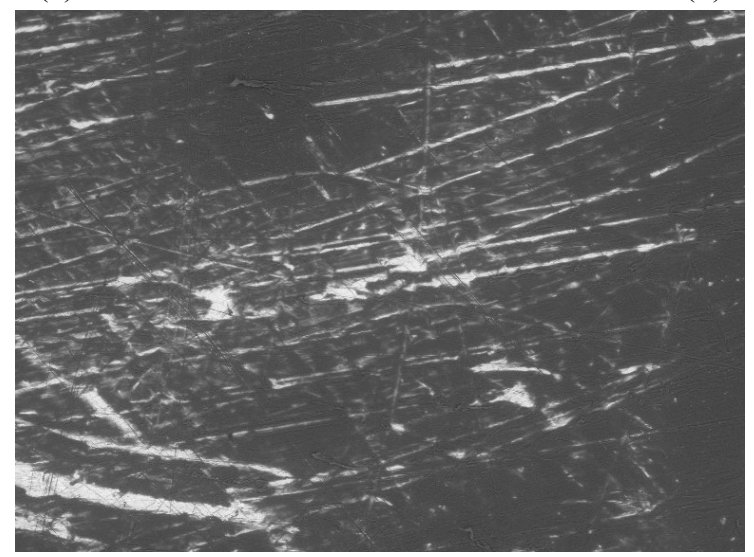

(c)

Figure 4-23: SEM images of microstructure of the polytetrafluorethylene coated coins processed at 700 rpm: (a) grit blasting, (b) acid etching, and (c) polishing. 


\section{Chapter: Corrosion Test}

Circulation coins lose original gloss and color after use in circulation for a certain period of time. This change in surface appearance is mainly caused by human sweat, an acidic aqueous solution, which damages the surfaces of coins gradually. As a result, sweat test was essential for this research to determine if these coatings can protect coins from surface appearance degradation or at least delay the corrosion process.

\subsection{Testing Solution Preparation}

Artificial sweat was synthesized first as an acidic media to characterize bare and coated coins for a day. The main ingredients in the liquid solution are sodium chloride $(\mathrm{NaCl}, 10 \mathrm{~g} / \mathrm{L})$, sodium hydroxide $(\mathrm{NaOH})$, and acetic acid $(2.5 \mathrm{~g} / \mathrm{L})$. These chemicals are shown in Figure 5-1, which were purchased from Anachemia, Canada [92].

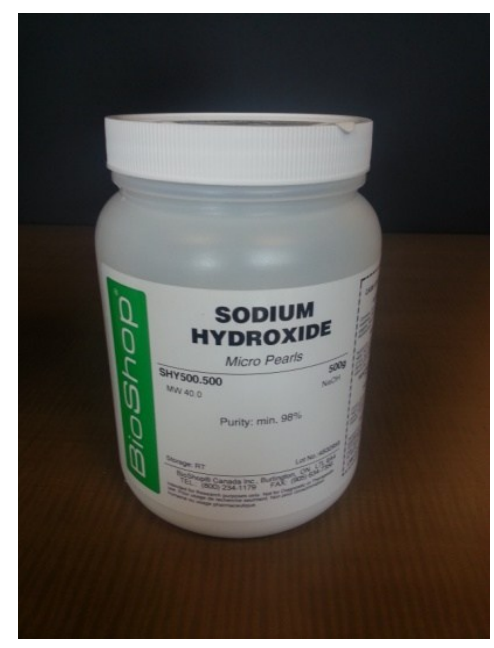

(a)

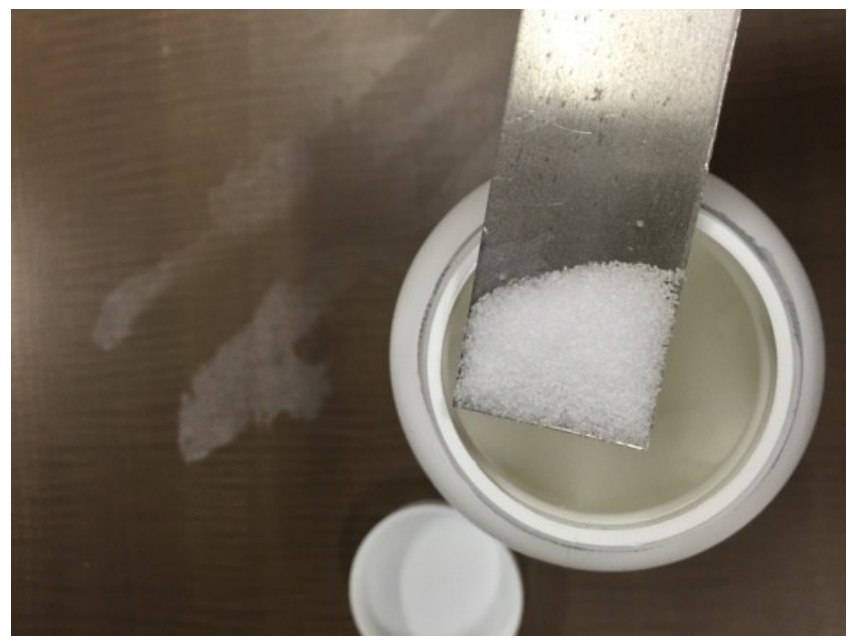

(b) 


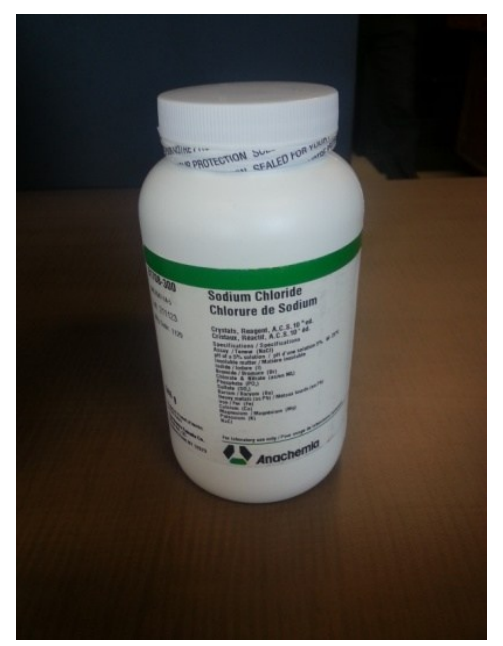

(c)

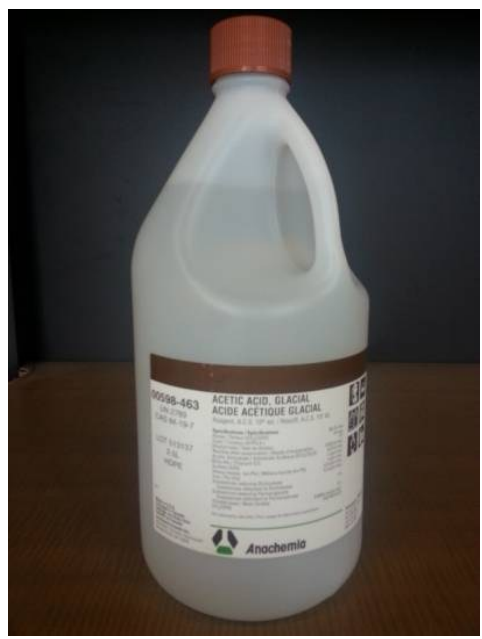

(e)

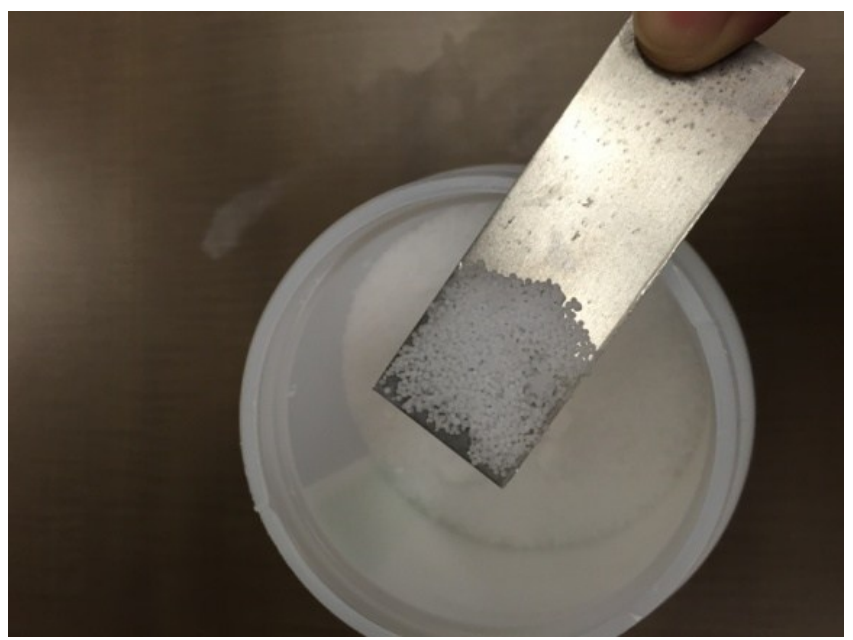

(d)

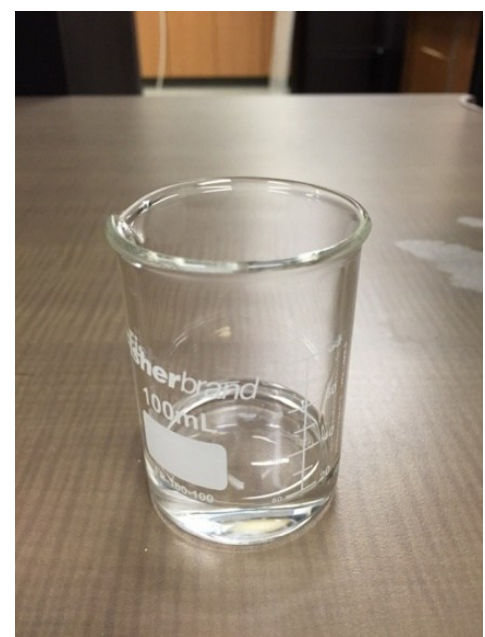

(f)

Figure 5-1: Artificial sweat chemical compositions: (a) sodium chloride, (b) sodium chloride powder, (c) sodium hydroxide, (d) sodium hydroxide powder, (d) acetic acid, and (f) acetic acid.

Sodium hydroxide works as a $\mathrm{pH}$ value controller. The $\mathrm{pH}$ value of the solution should be around 4 - 5, see Figure 5-2. The aqueous solution must be kept on a heater to maintain a temperature of $37^{\circ} \mathrm{C}$ before and during the test, which simulated the regular human body temperature. The bare coins used in this test were cleaned using standard procedure described earlier. 


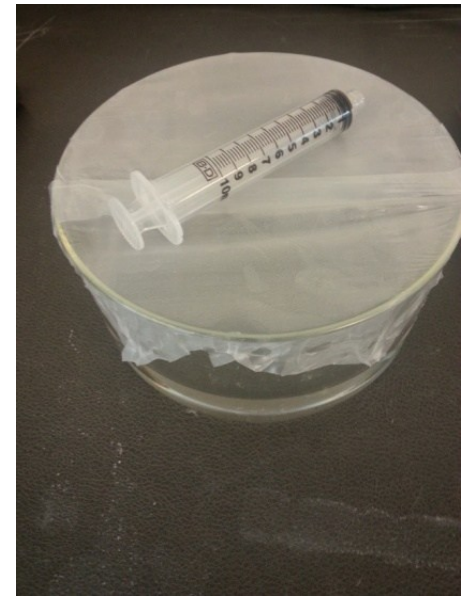

(a)

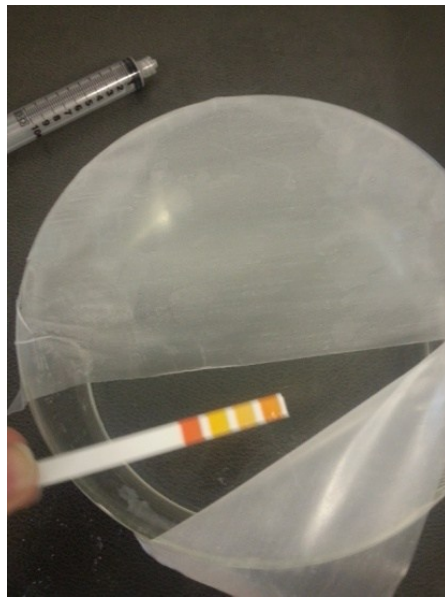

(b)

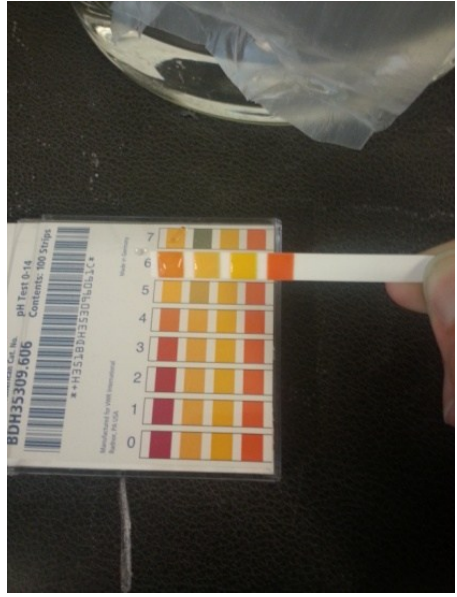

(c)

Figure 5-2: pH value controlling of artificial sweat: (a) prepared liquid solution, (b) measuring pH value, and (c) $\mathrm{pH}$ value results.

\subsection{Test Process}

In order to better study the performance of polyurathane, advanced liquid glass and silicone R-2180 against corrosion by sweat, this test was conducted using three different methods.

\subsubsection{Experiment I and Experiment II}

The details of the coins used in experiment I and experiment II are given in Table 5-1. In experiment I, six brass coins coated with ALG and six bare brass coins were tested. The coatings were applied using a spin coater rotated at $500 \mathrm{rpm}$ for $30 \mathrm{~s}$ and cured at 250 ${ }^{\circ} \mathrm{C}$ for $1 \mathrm{hr}$. These twelve coins were placed in a large beaker which was filled with the simulated sweat solution. The beaker was placed on a heater set to the temperature of $37^{\circ} \mathrm{C}$ for $24 \mathrm{hr}$, see Figure 5-3(a).

In experiment II, eight different coins were tested to determine if heat treatment and coating of both sides can influence the corrosion behavior of the coins. The eight coins were divided into two groups and each group was composed of a cleaned uncoated coin, a 
bare heat-treated coin at $250^{\circ} \mathrm{C}$ for $1 \mathrm{hr}$, a one-side ALG coated coin and a double-side ALG coated coin. These two groups of coins were placed into two beakers, respectively.

In beaker I, coins were immersed in artificial sweat, same as in experiment I. In beaker II, a few drops of sweat were syringed onto the coins, see Figure 5-3(b).

\begin{tabular}{|c|c|}
\hline Experiment I & Experiment II \\
\hline \multirow{3}{*}{ Six cleaned bare brass coins } & Two cleaned bare brass coins \\
\cline { 2 - 2 } & $\begin{array}{c}\text { Two heat-treated bare brass coins } \\
\text { Coins heated at } 250^{\circ} \mathrm{C} \text { for } 1 \mathrm{hr}\end{array}$ \\
\hline \multirow{3}{*}{$\begin{array}{c}\text { Six one-side ALG coated brass coins } \\
\text { ALG coatings produced at } 500 \mathrm{rpm} \text { for } 30 \mathrm{~s}\end{array}$} & Two one-side ALG coated brass coins \\
\cline { 2 - 2 } & Two double-side ALG coated brass coins \\
& Coating applied by dipping \\
\hline
\end{tabular}

Table 5-1: Coins used in anti-corrosion experiment I and experiment II.

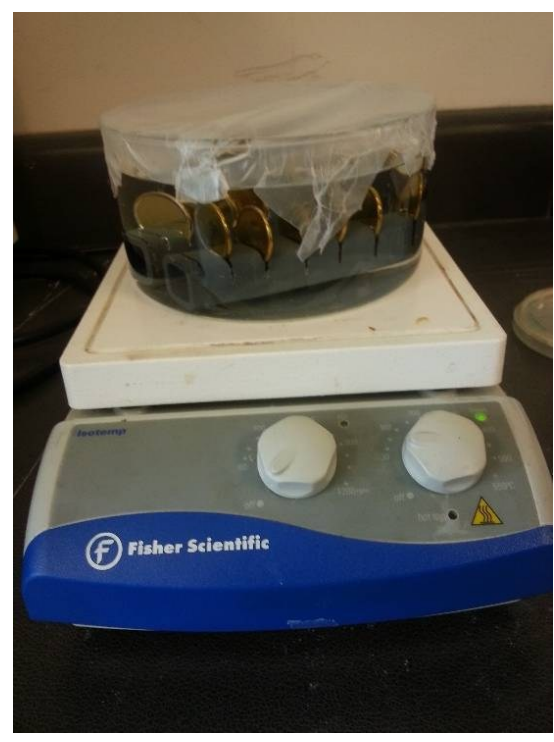

(a)

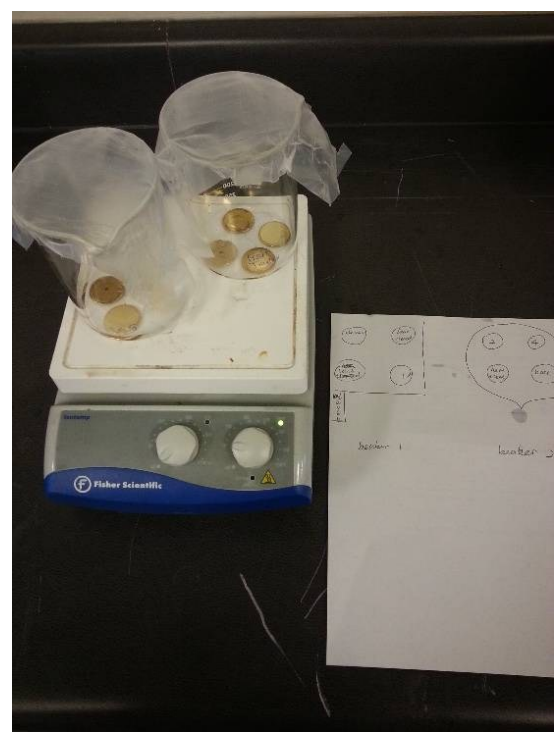

(b)

Figure 5-3: Anti-corrosion tests simulating human sweat conditions: (a) experiment I set-up, and (b) experiment II set-up.

In order to coat both sides of coins, a hole was drilled at the center of the coin surface, as shown in Figure 5-4 (a). The holed coins were cleaned by using standard procedure and then dipped into ALG with a wire hanging, as shown in Figure 5-4 (b). After dipping for $30 \mathrm{~s}$, they were removed from the beaker. When the coins were air dried, they were 
put into a furnace for curing at $250^{\circ} \mathrm{C}$ for $1 \mathrm{hr}$. As for the one-side-coated coins, the test process was the same as experiment I.

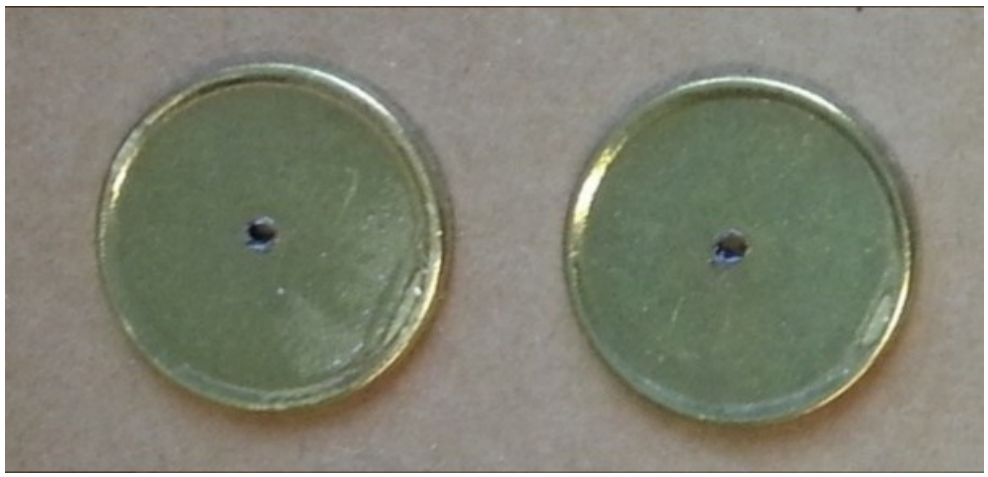

(a)

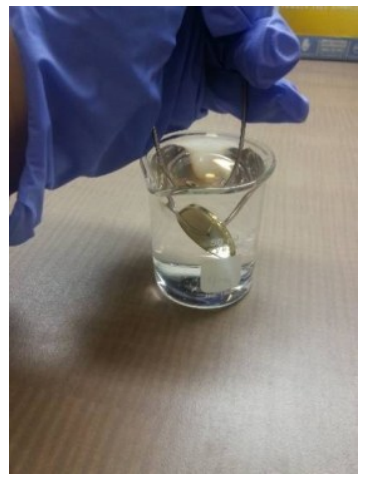

(b)

Figure 5-4: Corrosion test for double-side coated coins: (a) two coins with a hole at the center, and (b) coins dipped in ALG.

\subsubsection{Experiment III}

In the former two experiments, it was observed that all the coins were degraded by sweat solution, characterized by severe color change within $24 \mathrm{hr}$. It was suggested that this was caused by too much constant sweat solution exposure. This environment is deemed too harsh for the coins so that it was not suitable for characterizing their corrosion behavior. Adjustment was made in experiment III to introduce periodical exposure of sweat solution. Details on coin specimens tested are given in Table 5-2.

\begin{tabular}{|ccccc|}
\hline $\begin{array}{c}\text { coin } \\
\text { specimen }\end{array}$ & Coating & Coating process & Time & $\begin{array}{c}\text { Coating thickness } \\
(\boldsymbol{\mu m})\end{array}$ \\
\hline 1 & Polyurathane & $700 \mathrm{rpm}$ & $50 \mathrm{~s}$ & 25.26 \\
2 & (brass coins) & $1000 \mathrm{rpm}$ & $50 \mathrm{~s}$ & 19.42 \\
3 & & $1200 \mathrm{rpm}$ & $50 \mathrm{~s}$ & 6.08 \\
\hline 4 & Advanced liquid glass & $500 \mathrm{rpm}$ & $30 \mathrm{~s}$ & 10.53 \\
5 & (brass coins) & $700 \mathrm{rpm}$ & $20 \mathrm{~s}$ & 7.72 \\
6 & & $1000 \mathrm{rpm}$ & $40 \mathrm{~s}$ & 6.08 \\
\hline
\end{tabular}




\begin{tabular}{|c|c|c|c|c|}
\hline 7 & $\begin{array}{l}\text { Polyurathane } \\
\text { (nickel coin) }\end{array}$ & $1000 \mathrm{rpm}$ & $50 \mathrm{~s}$ & 52.83 \\
\hline 8 & $\begin{array}{l}\text { Advanced liquid glass } \\
\text { (nickel coins) }\end{array}$ & $1000 \mathrm{rpm}$ & $50 \mathrm{~s}$ & 4.26 \\
\hline 9 & $\begin{array}{l}\text { Silicone R-2180 } \\
\text { (brass coin) }\end{array}$ & brush & & \\
\hline 10 & $\begin{array}{l}\text { Silicone R-2180 } \\
\text { (nickel coin) }\end{array}$ & brush & & \\
\hline 11 & $\begin{array}{l}\text { Heat treated bare brass } \\
\text { coin }\end{array}$ & Curing at $250^{\circ} \mathrm{C}$ & $1 \mathrm{hr}$ & \\
\hline 12 & $\begin{array}{l}\text { Heat treated bare } \\
\text { nickel coin }\end{array}$ & Curing at $250^{\circ} \mathrm{C}$ & $1 \mathrm{hr}$ & \\
\hline 13 & Bare brass coin & & & \\
\hline 14 & Bare nickel coin & & & \\
\hline
\end{tabular}

Table 5-2: Coin specimens for anti-corrosion experiment III.

In order to investigate the relationship between the coating thickness and corrosion behavior, the coins were coated with different process parameters, as summarized in Figure 5-5.

Figure 5-5 shows the coins before corrosion experiment III. The mass of each coin was measured before and after coating. These data were used to compare with the thicknesses of the coated coins after the corrosion tests. 


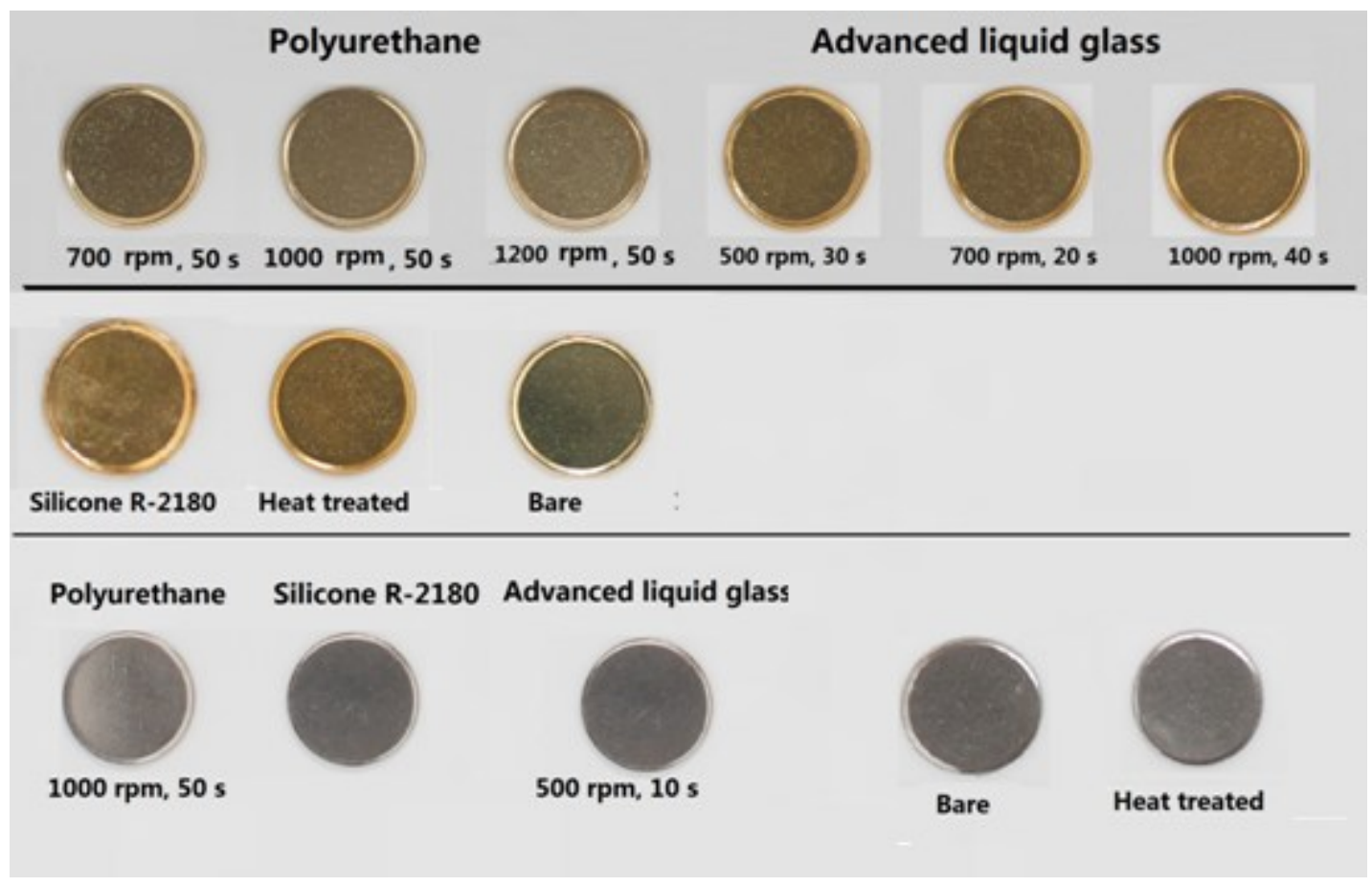

Figure 5-5: Coin specimens selected for corrosion experiment III.

After the coating process was completed, the coins were put orderly into a large beaker and each coin was coved by a piece of lint free wipe as seen Figure 5-6(a). A cotton cloth was then wetted with the artificial sweat solution, then placed onto a folded wipe. This way the solution would gradually be absorbed by the wipe, see Figure 5-6(b). The cloth was wetted again daily. The beaker with coins was placed on a heater with the temperature set to $37^{\circ} \mathrm{C}$, see Figure 5-6(c). Finally the beaker was sealed with aluminum foil to contain the moisture, see Figure 5-6(d). After the test was completed, all the coins were put into water with liquid soap for ultrasonic cleaning for $5 \mathrm{~min}$. 


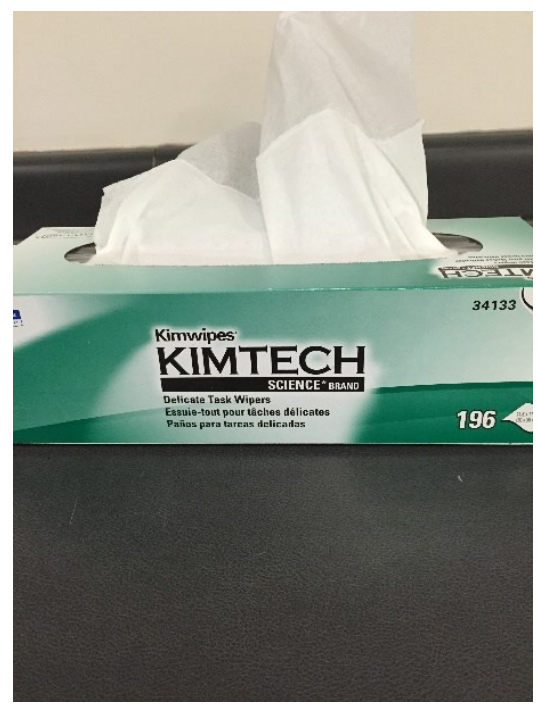

(a)

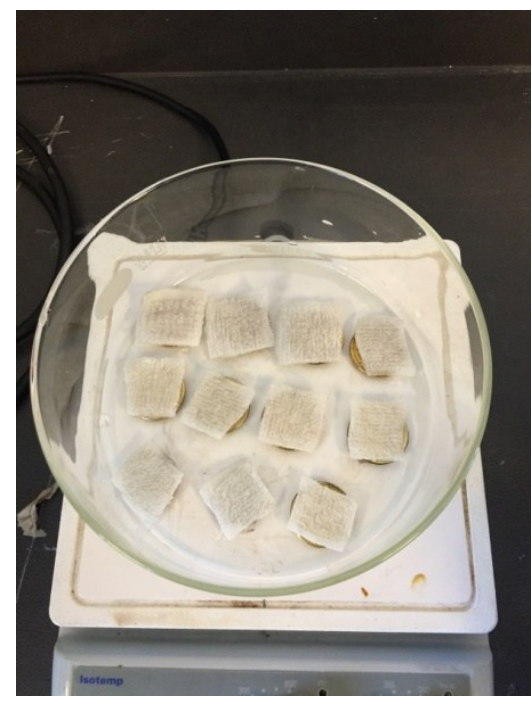

(c)

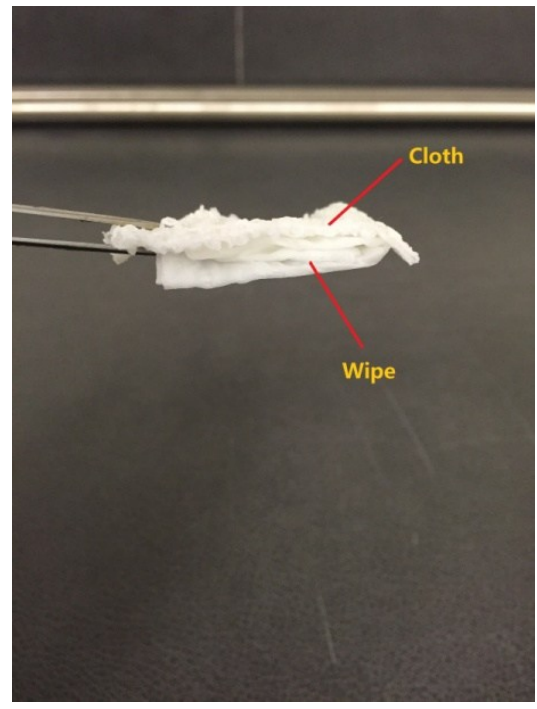

(b)

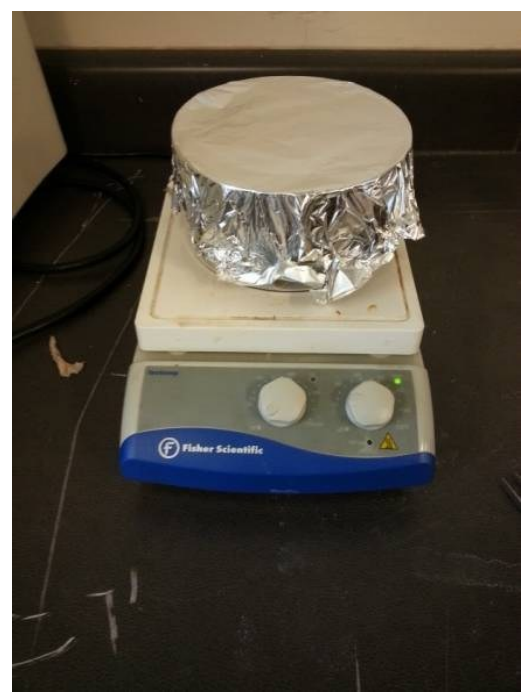

(d)

Figure 5-6: Corrosion experiment III: (a) delicate task wipe, (b) wetted cloth on the wipe, (c) beaker put on a heater, and (d) sealed beaker with aluminum foil.

\subsection{Experimental Results}

\subsubsection{Experiment I and Experiment II}

After 24-hr test, artificial sweat damaged all the coins in experiment I and experiment II, and the color of the coins changed significantly. Figure 5-7 and Figure 5-8 show the corroded coins in experiment I and experiment II, respectively. 


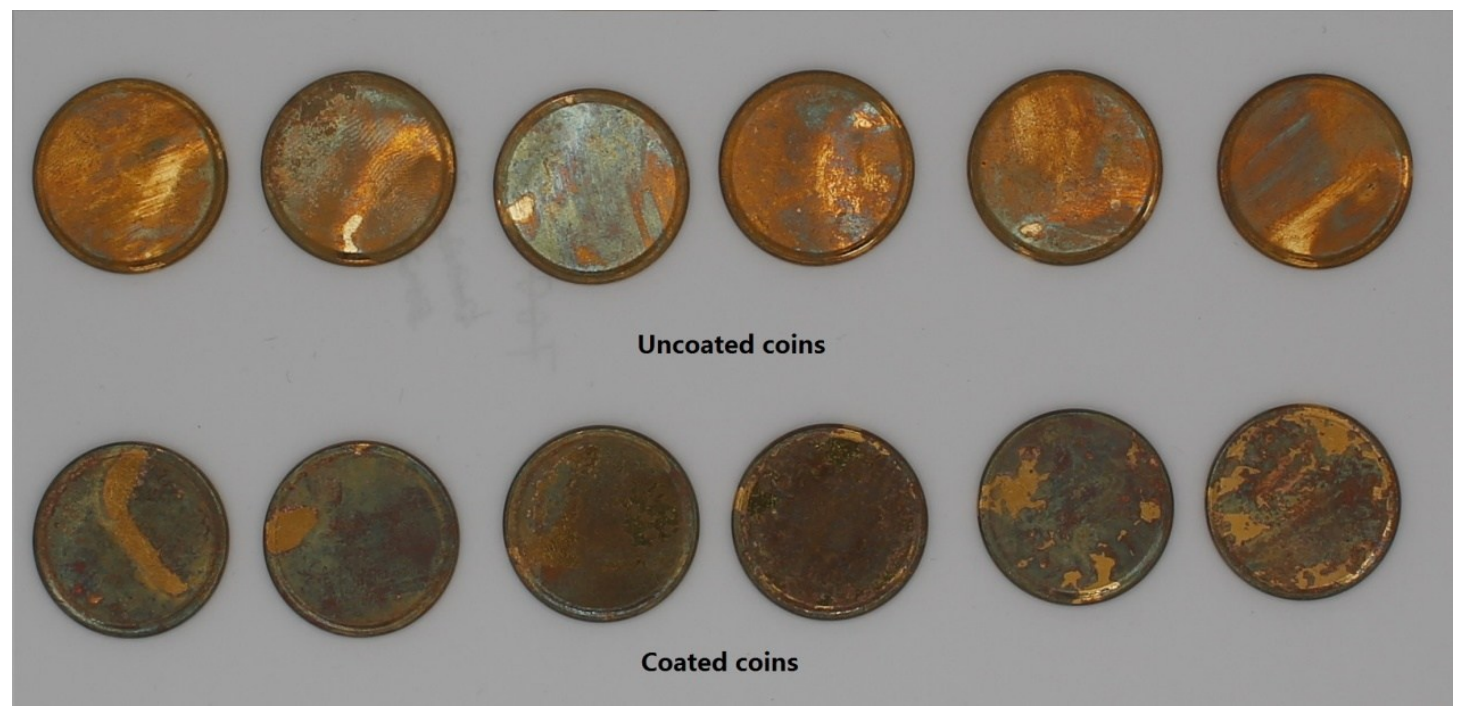

Figure 5-7: Corroded coins after experiment I.

From Figure 5-7, coated coins are apparently worse than bare ones in terms of surface corrosion. The bare coins show surface degradation but the color is still somewhat metallic. On the contrary, the color of the coated coins turned to gray and brown. Furthermore, coating was lifted off on all coins.

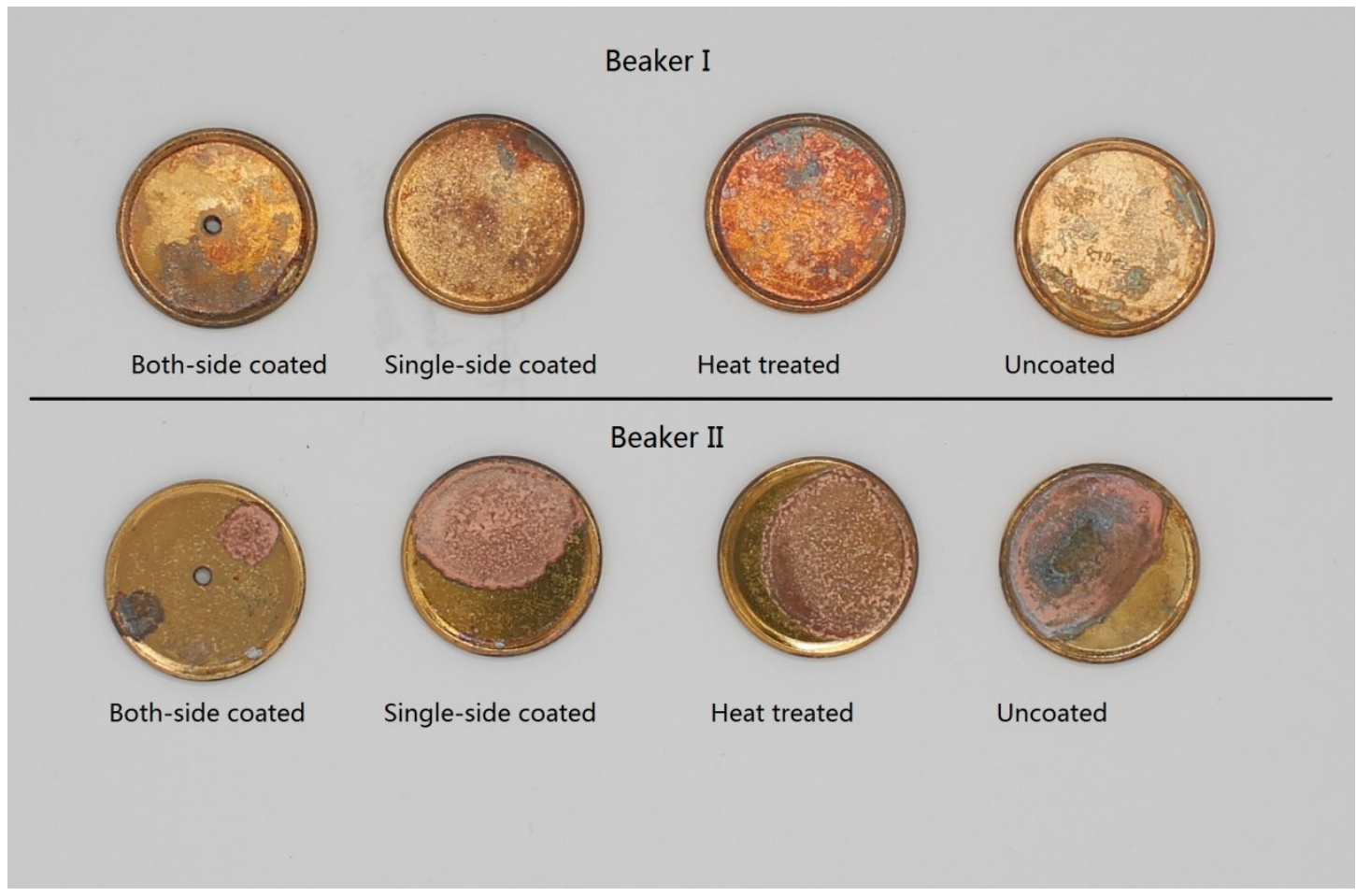

Figure 5-8: Corroded coins after experiment II.

In Figure 5-8, among the tested coins in beaker I, the double-side coated coin 
exhibits less color change while the rest suffered from discoloration. In beaker II, the uncoated coin changed it color to green, suggesting heavy oxidation during the corrosion test. The one-side coated coin is the second worst and its color became white after the test. Overall, the double-sided coatings were better than one-side-coated coatings in terms of its anti-corrosion to sweat solution; this is likely because the coating covered all metal surfaces of the coins and prevented the sweat from permeating to the coin substrate.

\subsubsection{Experiment III}

Among the three test methods experiment III is the closest to the real condition of circulation coins in use. The test condition affected significantly the corrosion behavior of the coated coins and this helped define the degree of the anti-corrosion ability of the coatings with different coating thicknesses. According to the time when first appearance change was observed, brass coins suffered from corrosion quicker than nickel coins. For this reason, the anti-corrosion ability of ALG, PUR, silicone and coatings on brass was only tested for three days. For nickel coins, the anti-corrosion test was carried out for six days to observe the differences between coatings. Visual examination, SEM and EDX analyses were carried out on the coin specimens to determine the anti-corrosion abilities of various coatings.

\subsubsection{Visual Examination}

Durations from the start of the test to the time when first sign of corrosion is observed are recorded and used as the criteria to determine the anti-corrosion abilities of the tested coins. 
For brass coins, the heat-treated coin changed color first. After $1 \mathrm{hr}$ of test, some discoloration was found on this specimen. A day later, the rest of the coins all showed corroded traces, as reported in Table 5-3. The ALG coatings are visibly the best among the specimens, as there are only occasional corroded areas observed. Among the three ALG coatings, the thinnest one $(6.08 \mu \mathrm{m})$ produced at $1000 \mathrm{rpm}$ for $40 \mathrm{~s}$ was the best, since there were only few brown traces on the surface. The PUR coatings performed the worst, as they could not prevent brass from being oxidized to $\mathrm{CuO}$ (black) and $\mathrm{Cu}_{2} \mathrm{O}$ (red). The thickest PUR coating $(25.26 \mu \mathrm{m})$ produced at $700 \mathrm{rpm}$ for $50 \mathrm{~s}$ was better than the other two thinner coatings, because it only had some black dots in the centre, while the other two coatings have corrosion indications all over the surface. The silicone coating remained intact, but the underlying brass turned darker. This color change suggested that the sweat solution might have penetrated into the coin substrate and caused chemical reaction on brass surface. For nickel coins, bare and heat-treated coins were also corroded faster than coated coins (Table 5-4). After one day, dark marks were found on the surfaces of bare and heat-treated nickel coins. The PUR coating was still transparent and its color did not change at all. The ALG coatings slightly lost original gloss. After three days, the ALG coating showed several small dark spots. After four days, the PUR coating showed several small dark dots. The color of the silicone R-2180 coated samples changed to black within three days. Overall, the bare coin was worse than the coated coins, because the whole surface changed color. 


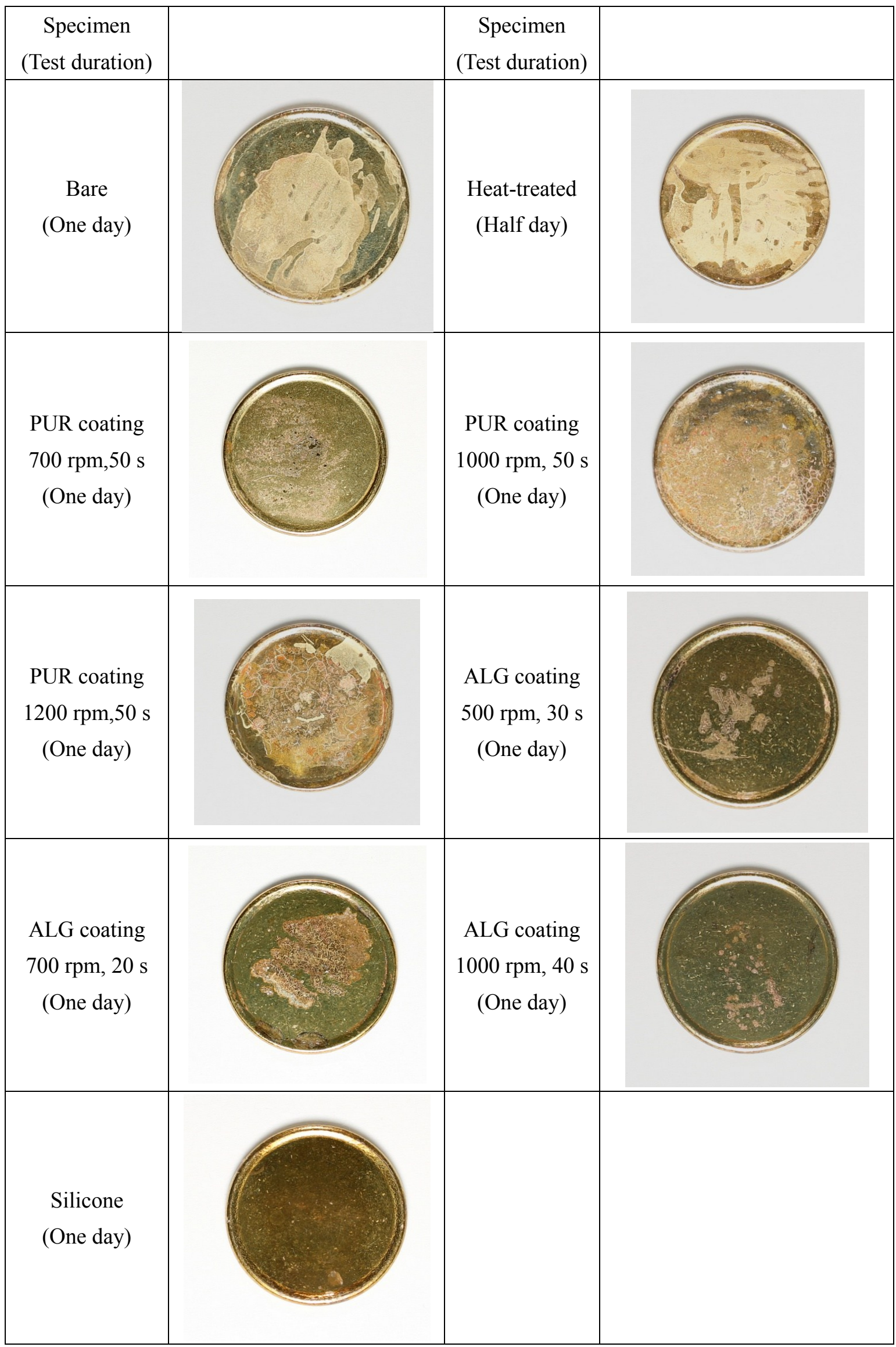

Table 5-3: Photographical showing of the corroded coatings on brass coins. 
For nickel coins, bare and heat-treated coins were also corroded faster than coated coins (Table 5-4). After one day, dark marks were found on the surfaces of bare and heat-treated nickel coins. The PUR coating was still transparent and its color did not change at all. The ALG coatings slightly lost original gloss. After three days, the ALG coating showed several small dark spots. Additionally, after four days, the PUR coating showed several small dark dots. The color of the silicone R-2180 coated sample had black spots within three days.

\begin{tabular}{|c|c|c|c|}
\hline $\begin{array}{c}\text { Specimen } \\
\text { (Test duration) }\end{array}$ & Photo & $\begin{array}{c}\text { Specimen } \\
\text { (Test duration) }\end{array}$ \\
\hline $\begin{array}{c}\text { Bare } \\
\text { (One day) }\end{array}$ & Corroded area & Photo \\
\hline PUR coating & & \\
\hline
\end{tabular}

Table 5-4: Photographical showing of corroded areas on nickel coins. 


\subsubsection{SEM Examination}

The SEM images in Table 5-5 show coating surfaces in the backscatter electron mode, sensitive to surface composition. The bare and heat treated coins exhibit bright contrast due to the presence of $\mathrm{Cu}$ and $\mathrm{Zn}$. However, if polymer remains on the surface, the contrast will be darker, due to the presence of low atomic number elements $(\mathrm{C}, \mathrm{O}$, or H). The SEM images of PUR coated coins suggests the presence of some coating delamination (the bright contrast signals bare metal surface) on the PUR coated brass coins after corrosion test. As the coating thickness reduces (with higher RPM), there is more bare metal exposure, hence more severe corrosion damage to the coating.

Spin Velocity
(rpm), Time (s)




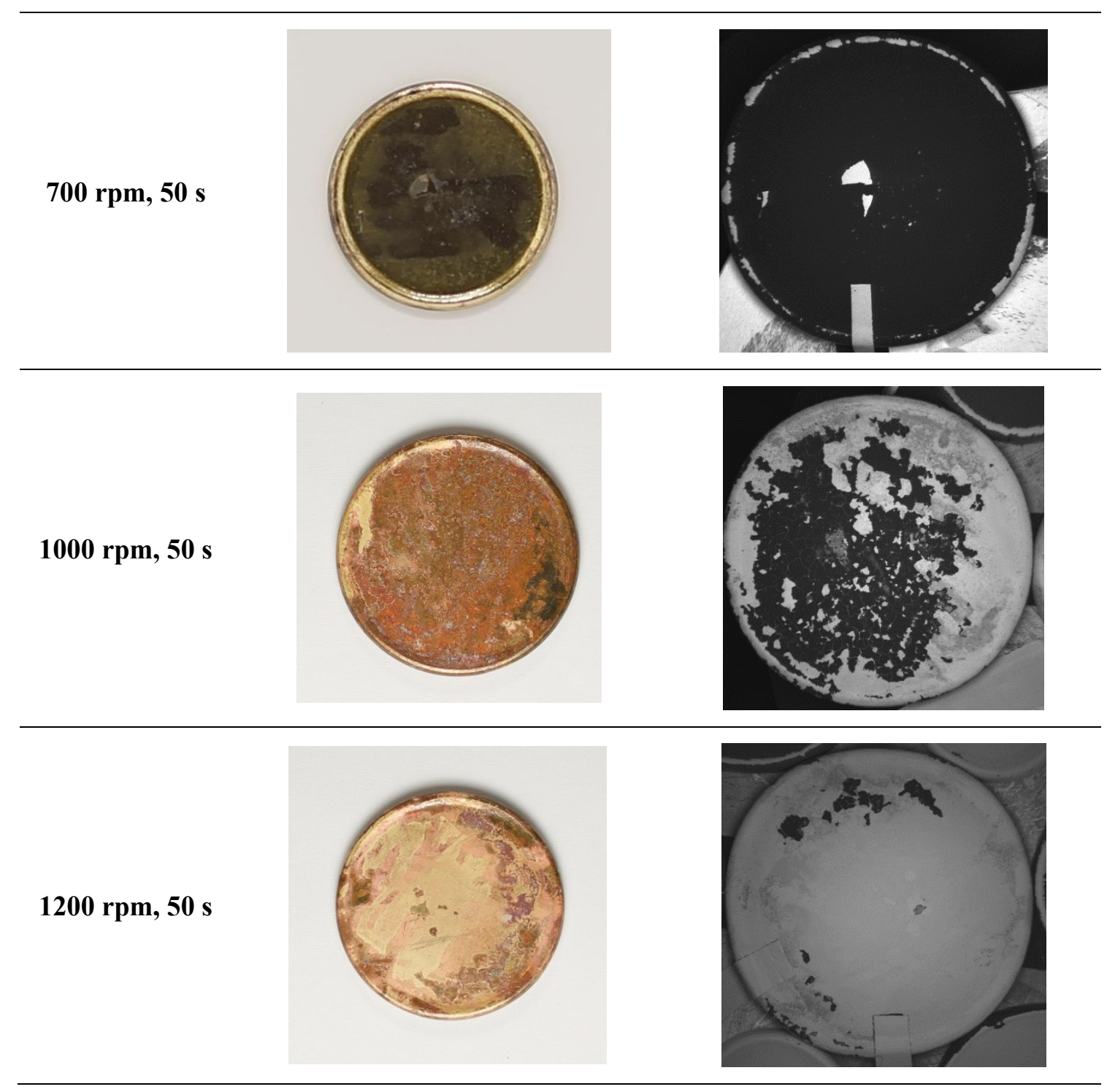

Table 5-5: Photos and SEM images of PUR coated coins after corrosion test.

Table 5-6 summarizes the corrosion test results of ALG coated brass coins. From the SEM images of ALG coated coins (Table 5-6), partial coating removal can be observed after corrosion test, exposing bare metal surface indicated by the bright contrast. Coating deposited under $1000 \mathrm{RPM}$ for 40s provided better corrosion resistance to the artificial sweat. The silicone coating seems to offer much better anti-corrosion (Table 5-7), judging from the presence of very little brightly contrasted area. 


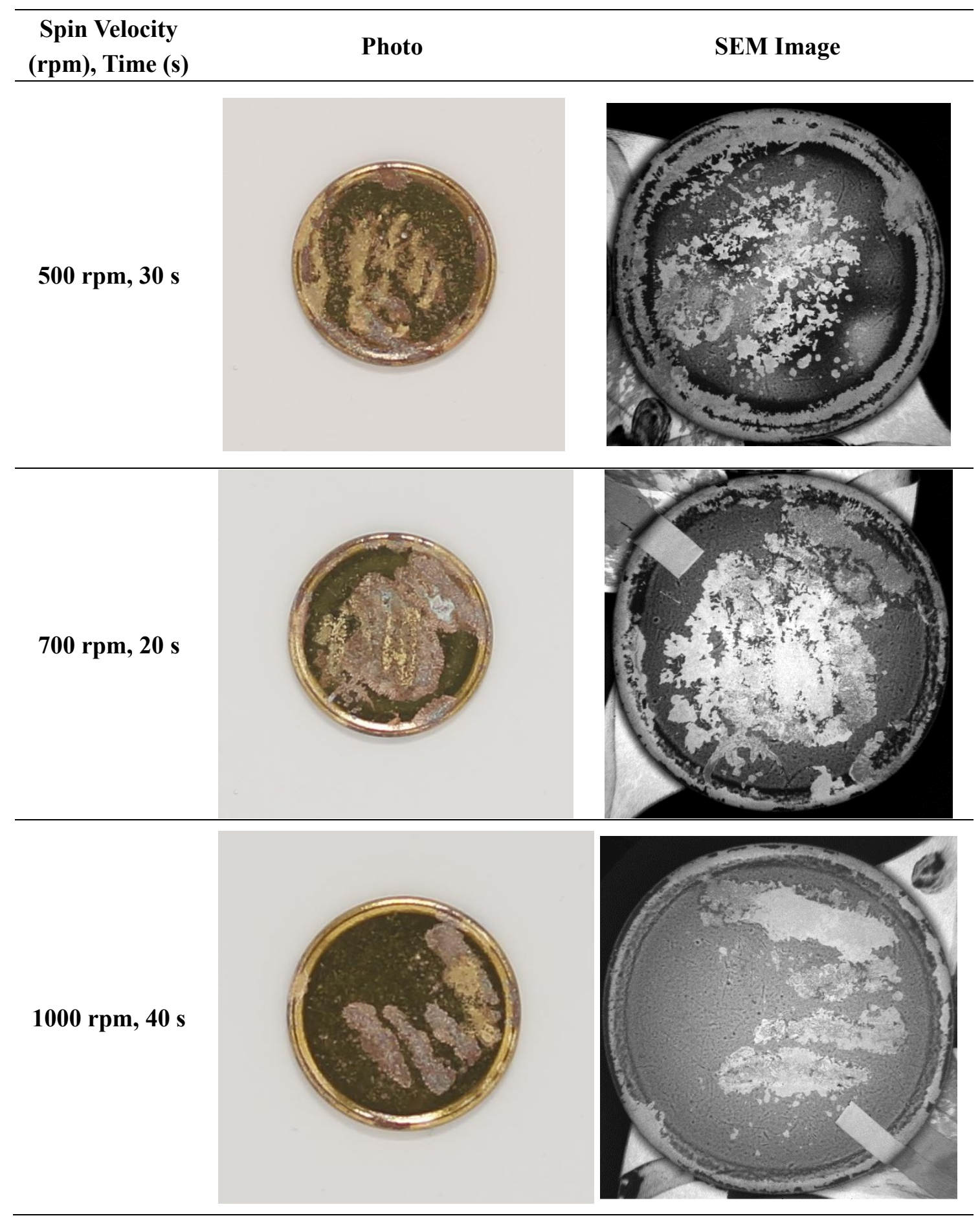

Table 5-6: Photos and SEM images of ALG coated coins after anti-corrosion test. 


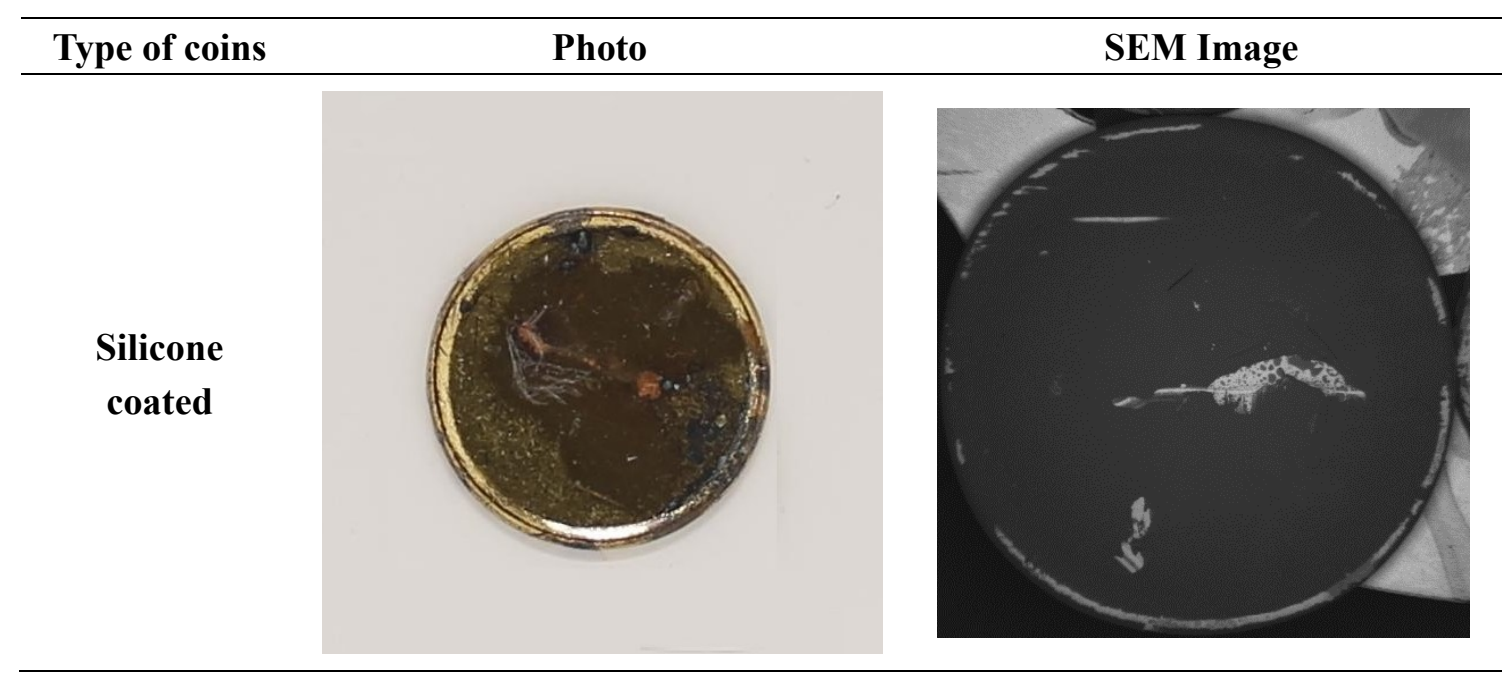

Table 5-7: Photos and SEM images of silicone R-2180 coated coin after anti-corrosion test.

SEM images displayed in Figure 5-8 showed complete metal surface after corrosion test for both bare and heat treated nickel coins. ALG coin seemed to have suffered severe corrosion as the metal surface is completely exposed after sweat testing. PUR coated nickel coin also lost large portion of the coating as more than $60 \%$ of coin surface showed strong signals from the metal surface (bright contrast). Similar to brass coins, silicone coated nickel also had very little corrosion damage, with only occasional spots showing bare metal surface. 


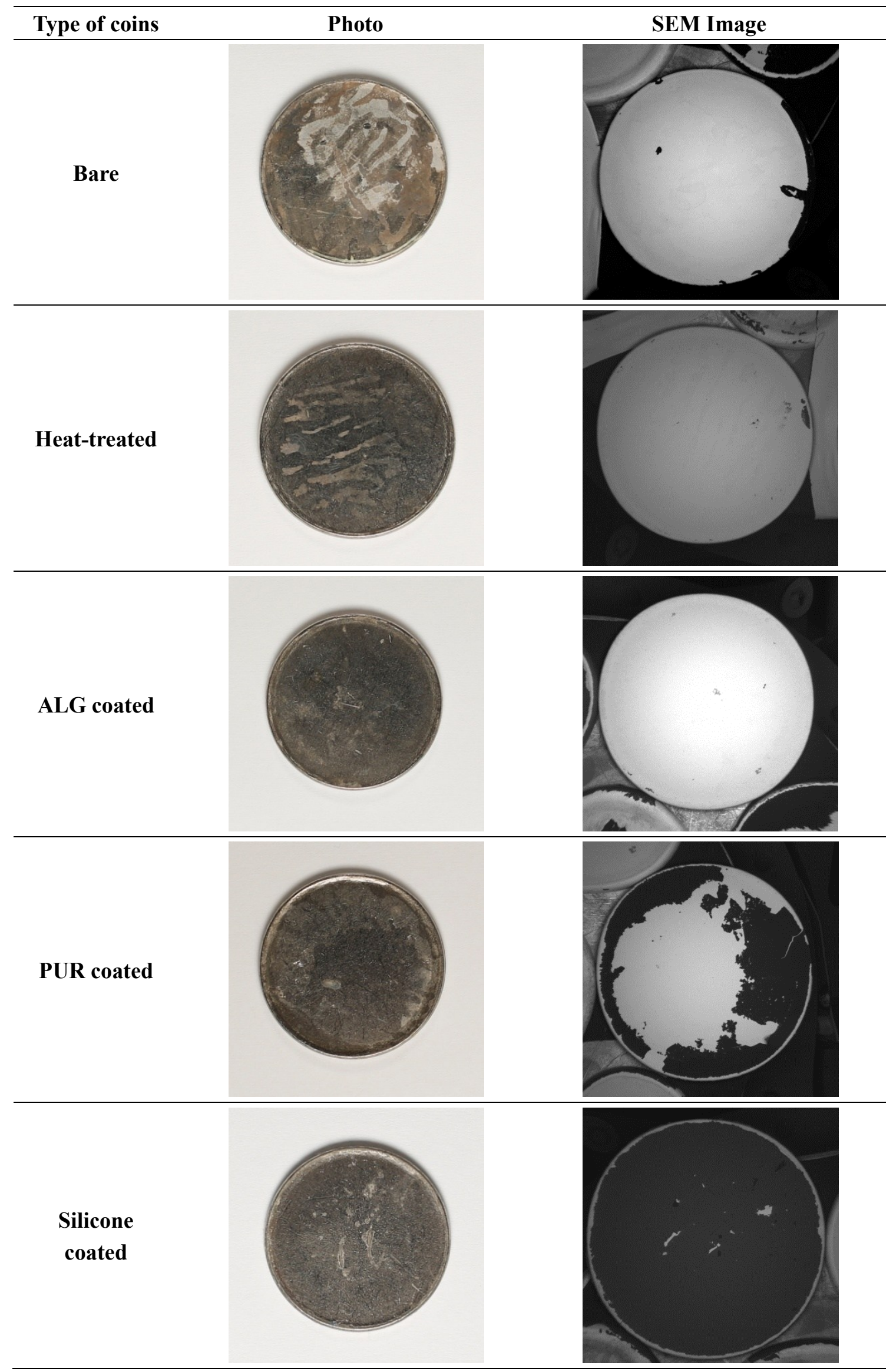

Table 5-8: Photos and SEM images of coated, bare and heat-treated nickel coins after corrosion test. 


\subsubsection{EDX Analysis}

EDX analysis was also performed on the coin specimens after the anti-corrosion test.

\section{Polyurethane}

Both coated brass and nickel samples were further analyzed for compositional changes after corrosion test. EDX analysis was conducted on coated brass sample in areas with different color contrast. As shown in Table 5-9, the areas of where spectrum 1 and spectrum 2 were taken, the coating was believed to have peeled off due to the bright contrast. The presence of large amounts of copper and zinc confirmed the bare metal exposure. In the area where spectrum 3 was taken, the coating still existed because of the high carbon and oxygen counts (and low amounts of metallic elements). Chlorine was found on all three locations, suggesting either chloride formation or simply some residue from sweat solution.

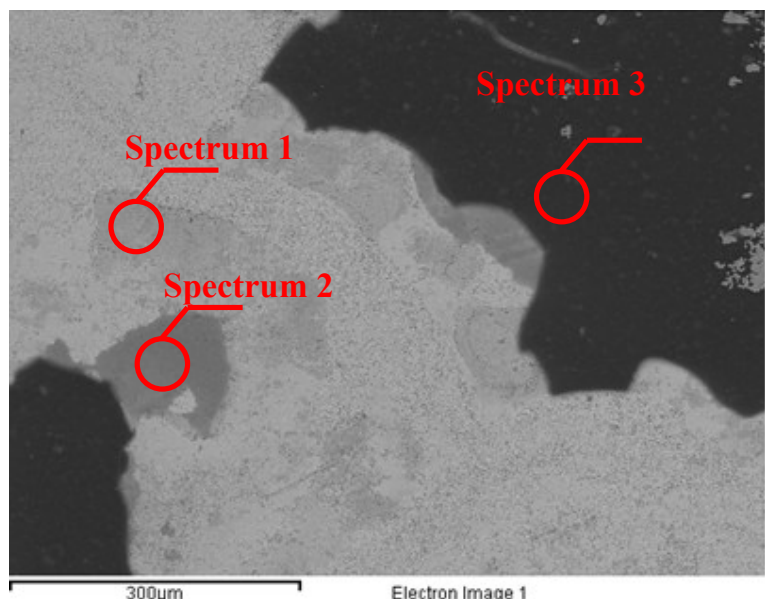

\begin{tabular}{|c|c|c|c|c|c|c|c|c|c|}
\hline $\mathrm{Wt} \%$ & $\mathrm{C}$ & $\mathrm{O}$ & $\mathrm{Cu}$ & $\mathrm{Zn}$ & $\mathrm{Cl}$ & $\mathrm{Ni}$ & $\mathrm{Al}$ & $\mathrm{Si}$ & Total \\
\hline Spectrum 1 & 14.65 & 12.63 & 58.00 & 12.80 & 1.43 & & 0.49 & & 100 \\
\hline Spectrum 2 & 9.53 & 28.33 & 25.55 & 35.58 & 0.60 & 0.41 & & & 100 \\
\hline Spectrum 3 & 72.24 & 22.93 & 2.04 & 1.02 & 0.28 & & & 1.49 & 100 \\
\hline
\end{tabular}

Table 5-9: EDX results of PUR coated brass coin processed at $1200 \mathrm{rpm}$ for $50 \mathrm{~s}$.

Table 5-10 presents the EDX results of PUR coated nickel coin. The bright area 
where spectrum 1 was measured, the coating is believed to have spalled off, leaving exposed nickel surface. Spectrum 2 was taken from a darker area where coating was still left based on the high counts of $\mathrm{C}$ and $\mathrm{O}$. Here chlorine was found only on the coating surface, possibly due to the sweat residue.

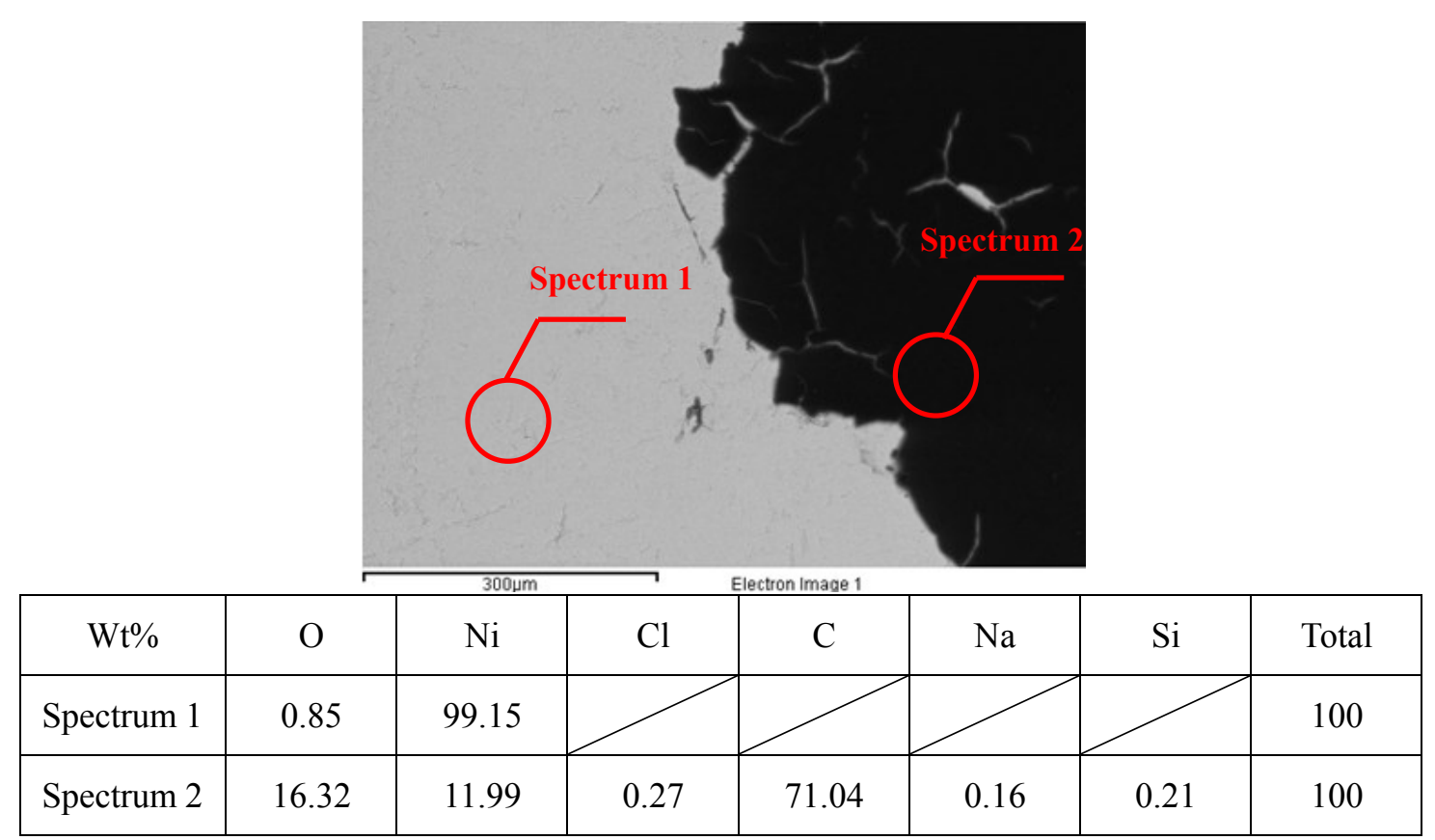

Table 5-10: EDX results of PUR coated nickel coin processed at $1000 \mathrm{rpm}$ for $50 \mathrm{~s}$.

\section{Advanced Liquid Glass Coatings}

As there are several shades of contrast on the SEM images, EDX was carried out in an attempt to capture the compositional changes corresponding to different contrasts. Among the four areas analyzed (Table 5-11), only area where spectrum 4 was taken has remaining Si-containing coating. Other areas are mostly exposed metal surface. The different contrast was caused by the difference in $\mathrm{Cu}$ and $\mathrm{Zn}$ content. 


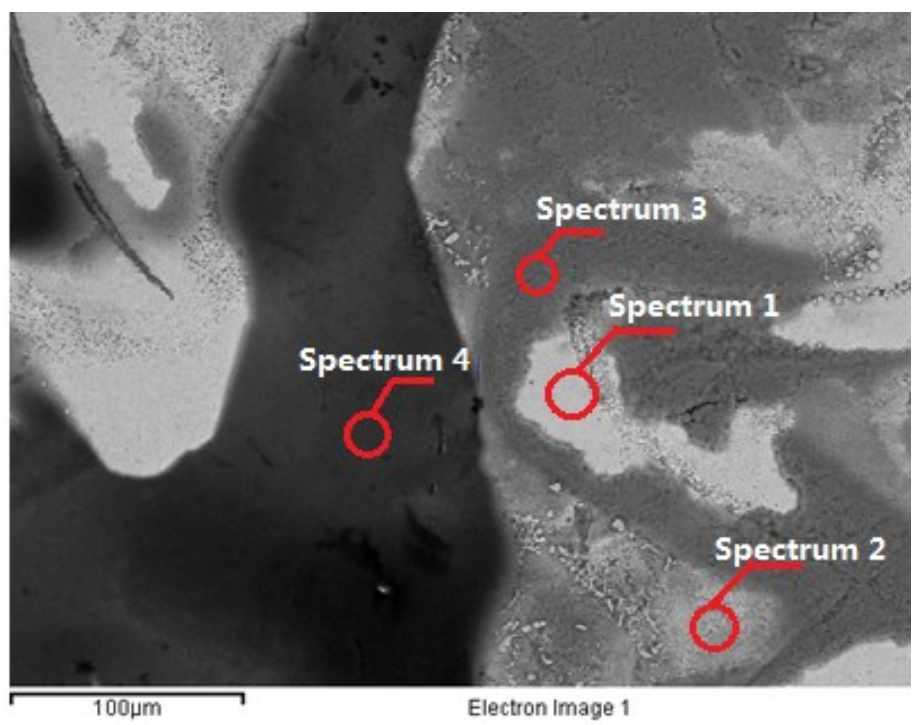

\begin{tabular}{|c|c|c|c|c|c|c|c|c|c|}
\hline $\mathrm{Wt} \%$ & $\mathrm{O}$ & $\mathrm{Cu}$ & $\mathrm{Zn}$ & $\mathrm{Ni}$ & $\mathrm{Cl}$ & $\mathrm{Si}$ & $\mathrm{C}$ & $\mathrm{S}$ & Total \\
\hline Spectrum 1 & 0.67 & 70.48 & 28.46 & 0.39 & & & & & 100 \\
\hline Spectrum 2 & 11.68 & 76.06 & 12.68 & & 2.04 & & & & 100 \\
\hline Spectrum 3 & 29.86 & 18.23 & 46.29 & 0.45 & 0.37 & & 4.53 & 0.27 & 100 \\
\hline Spectrum 4 & 21.84 & 44.82 & 6.5 & & 1.17 & 25.52 & & & 100 \\
\hline
\end{tabular}

Table 5-11: EDX results of ALG coated brass coin processed at $700 \mathrm{rpm}$ for $20 \mathrm{~s}$.

Table 5-12 reports the EDX results of the ALG coating on nickel coin. As shown in Table 5-8, the ALG coating was almost completely removed from the coin surface, except few small pieces of ALG coating remaining. The data from spectrum 1 and 2 are similar, both with large percentage of iron and no presence of Si. Coating must have completely spalled off during corrosion test. Spectrum 3 indicates remain coating as there is a presence of silicon. 


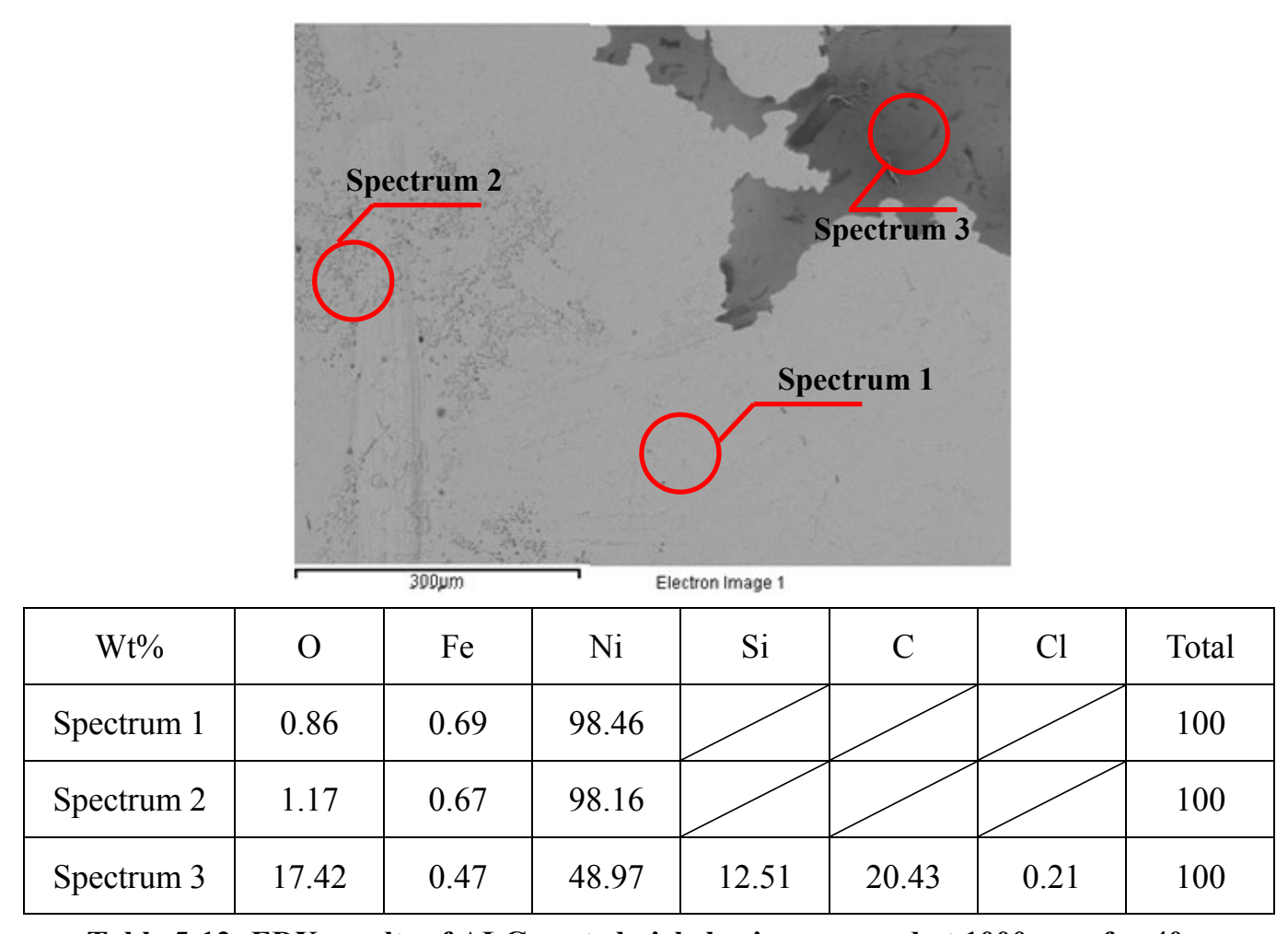

Table 5-12: EDX results of ALG coated nickel coin processed at $1000 \mathrm{rpm}$ for $40 \mathrm{~s}$.

\section{Silicone R-2180}

According to the SEM image (Table 5-1) for the silicone coating on brass coin, most areas are uniformly black, indicating good coating presence. The occasional bright areas on the specimen surface, represented by spectrum 1 , are bare metal surface as very little silicone was detected in this area. In the light grey area, circled as spectrum 2, the coating peeled off. For area where spectrum 3 was measured, there is also no indication of coating presence. 


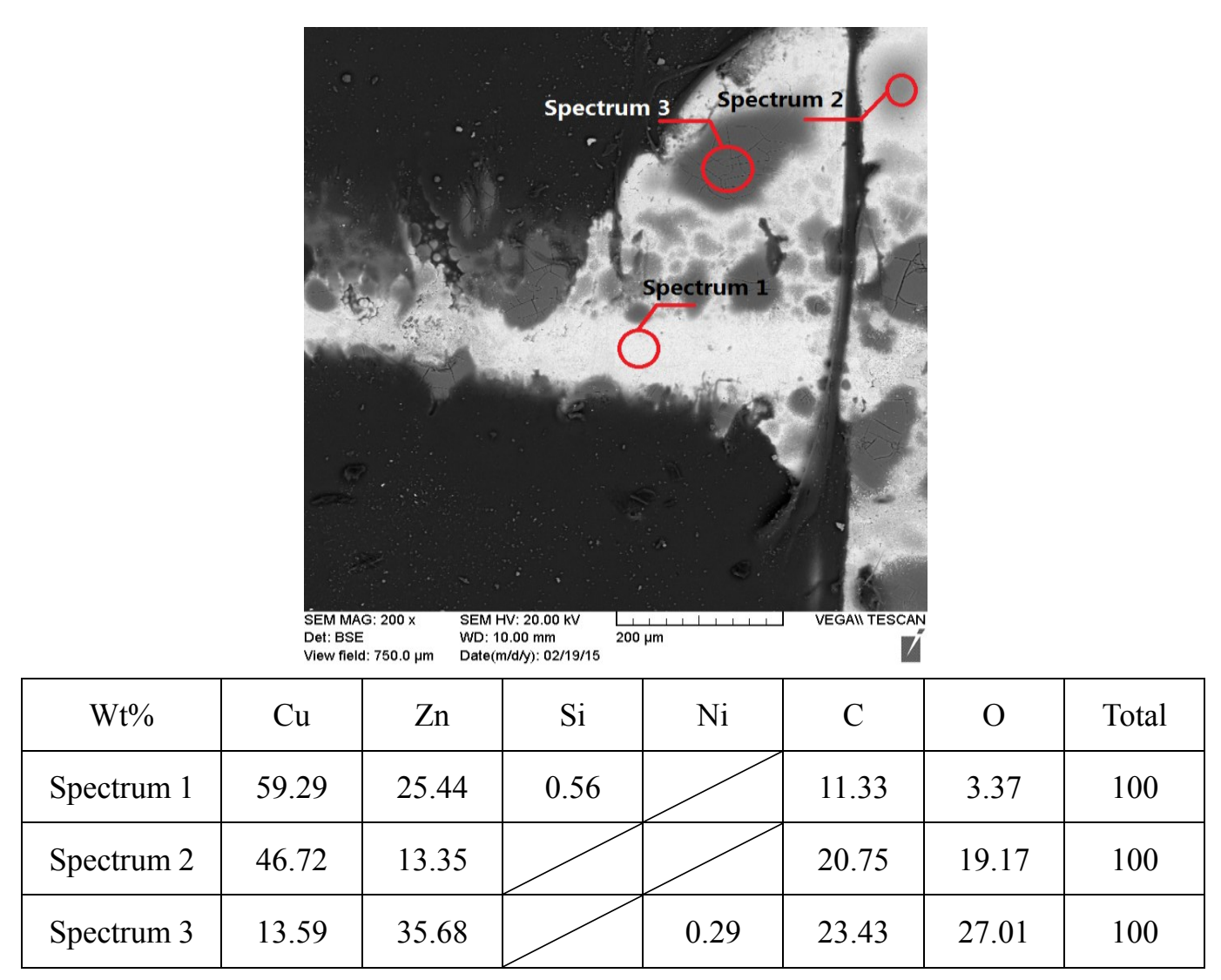

Table 5-13: EDX results of silicone $R-2180$ coated brass coin.

As reported in Table 5-7, silicone R-2180 coated nickel coins performed the best in the corrosion test, since the coating layer remained intact, except a few bright areas on the coin surface (Table 5-14). Spectrum from the bright area indicates bare surface; in fact the coating can be seen to have detached and flipped over to the left side. There were some $\mathrm{Na}$ and $\mathrm{Cl}$ measured on the surface. In the area where spectrum 2 was taken, the coating is clearly present as high amount of Si was detected.

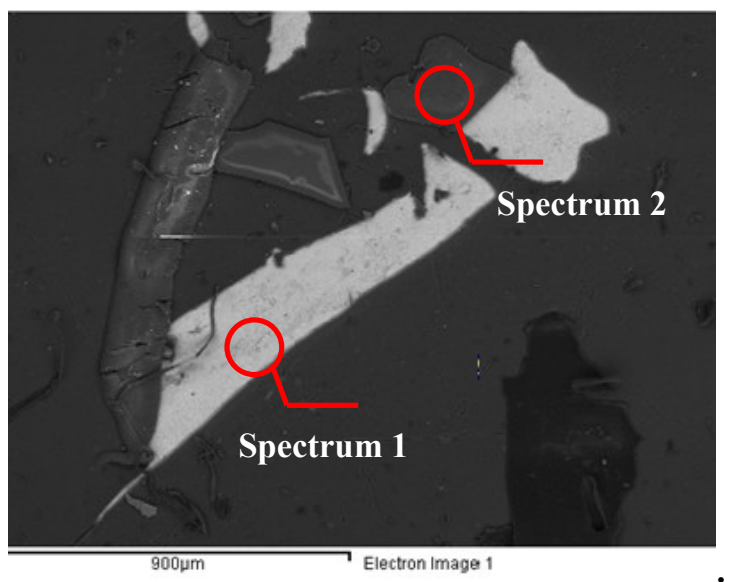




\begin{tabular}{|c|c|c|c|c|c|c|c|c|}
\hline $\mathrm{Wt} \%$ & $\mathrm{Ni}$ & $\mathrm{Si}$ & $\mathrm{Fe}$ & $\mathrm{Cl}$ & $\mathrm{Na}$ & $\mathrm{O}$ & $\mathrm{C}$ & Total \\
\hline Spectrum 1 & 94.68 & & 0.67 & 0.55 & 2.84 & 1.26 & & 100 \\
\hline Spectrum 2 & 0.79 & 38.67 & & & & 34.86 & 25.67 & 100 \\
\hline
\end{tabular}

Table 5-14: EDX results of silicone $R-2180$ coated nickel coin.

\section{Bare and Heat-treated Coins}

Table 5-15 reports the EDX results of bare and heat-treated brass coins after corrosion test. While both coins suffered from corrosion (oxidation precisely) during their exposure to sweat solution, the heat-treated brass coin (spectrum 2) corroded more than bare brass coin (spectrum 1) judging by the larger area of corrosion and also the higher oxygen and nickel, and lower $\mathrm{Zn}$ and $\mathrm{Cu}$ percentages measured on the surface. Note that some of the oxygen on the heat treated sample could have resulted from the heat treatment prior to corrosion test.

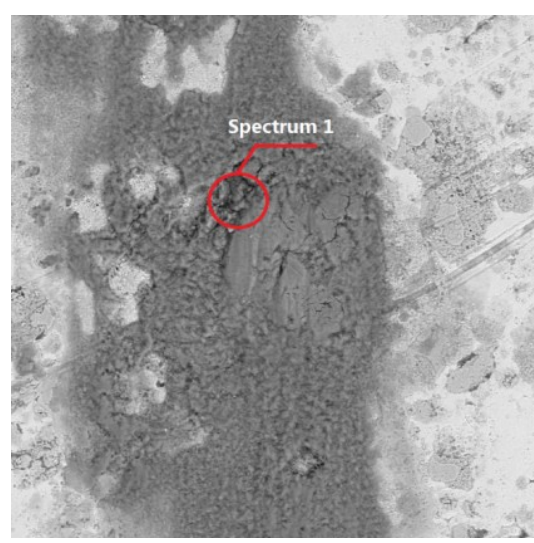

(a) bare brass coin

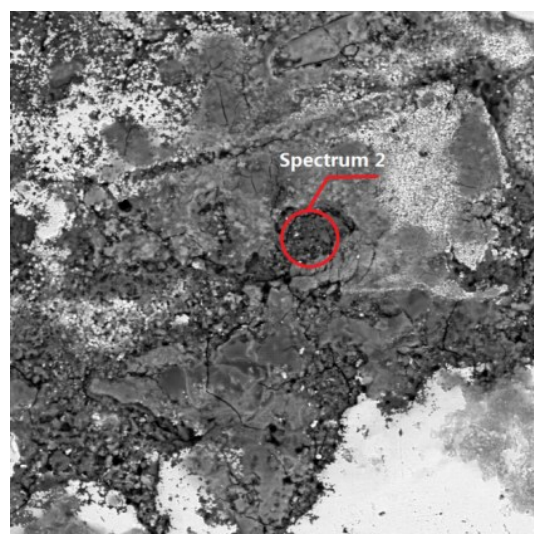

(b) heat treated brass coin

\begin{tabular}{|c|c|c|c|c|c|c|c|c|c|}
\hline $\mathrm{Wt} \%$ & $\mathrm{Cu}$ & $\mathrm{Zn}$ & $\mathrm{Ni}$ & $\mathrm{Cl}$ & $\mathrm{O}$ & $\mathrm{C}$ & $\mathrm{Al}$ & $\mathrm{Ca}$ & Total \\
\hline Spectrum 1 & 15.30 & 35.42 & 0.33 & 5.70 & 30.51 & 12.73 & & & 100 \\
\hline Spectrum 2 & 5.23 & 26.88 & 1.47 & 3.05 & 43.54 & 17.43 & 2.18 & 0.22 & 100 \\
\hline
\end{tabular}

Table 5-15: EDX results of bare and heat-treated brass coins.

The spectra 1, 2 and 3 of Table 5-16 are collected from bare nickel coin after corrosion test, and spectrum 4 is from the heat-treated nickel coin. From the SEM images, heat-treated coin has more severe corrosion than that on the bare coin, similar to the brass 
coins. The bare nickel coin contains nickel, iron and trace amount of oxygen. However, the heat-treated coin contains more oxygen and some phosphorus (from sweat solution) .

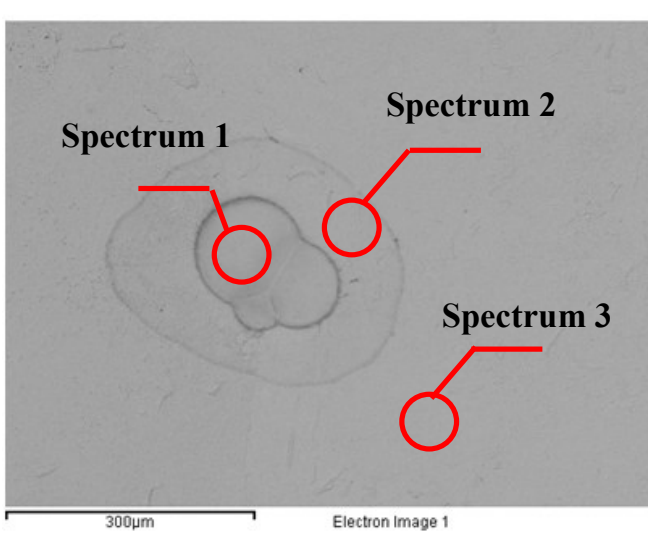

(a) bare nickel coin

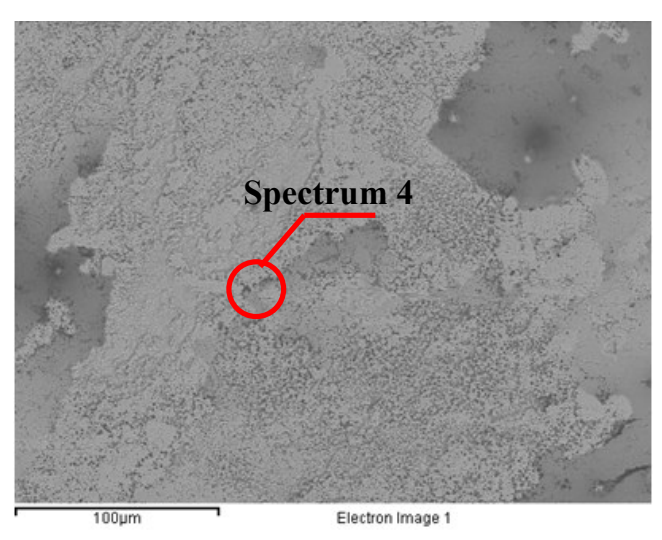

(b) heat treated nickel coin

\begin{tabular}{|c|c|c|c|c|c|c|}
\hline $\mathrm{Wt} \%$ & $\mathrm{O}$ & $\mathrm{Ni}$ & $\mathrm{Fe}$ & $\mathrm{Al}$ & $\mathrm{P}$ & Total \\
\hline Spectrum 1 & 1.87 & 98.13 & & & & 100 \\
\hline Spectrum 2 & 1.49 & 98.26 & 0.26 & & & 100 \\
\hline Spectrum 3 & 0.95 & 99.05 & & & & 100 \\
\hline Spectrum 4 & 4.49 & 93.77 & 0.59 & 0.61 & 0.53 & 100 \\
\hline
\end{tabular}

Table 5-16: EDX results of bare and heat-treated nickel coins. 


\section{Chapter: Anti-bacteria Test}

Circulation coins attract large amount of bacteria during currency circulation, presenting a potential health issue. Therefore antibacterial function is an important criterion for assessing these new coatings. Based on the results from wear, hardness, and artificial sweat tests (wear and hardness tests are reported in the thesis of another team member), the ALG coating possesses the best characteristics and has potential as a coating material for the coins. Therefore the ALG coating was further investigated in bacterial function test.

\subsection{Experimental Preparation}

\subsubsection{Selection of Test Methods}

Lysogeny broth (LB) medium is widely used for the growth of bacteria. In this study, LB medium is used to transfer and grow bacteria on the coins.

A liquid medium containing a mixture of agar and LB is commonly used for the growth of microorganisms such as bacteria and fungi. The bacterial culture from a source (in this study, the growth solution) can be added into the mixture; they would grow into colonies and subsequently be counted visually. Once the amount of bacteria is determined, the concentration of the original bacterial culture can be calculated. Agar works as a solid support in the medium, thus bacterial colonies can form on the surface. In addition, agar is not consumed during the process of growth, therefore the bacteria growth does not affect the stability of agar.

Colony-forming unit (CFU) is a measure of how much bacteria is present in a solution. After serial dilution, with a constant factor, the concentration of microorganism 
decreased exponentially. Since the size of bacterial colonies grown on LB-agar plates depended on the concentration of microorganism in LB solution, serial dilutions can be used to calculate the CFU. Figure 6-1 shows the principle and the process of the CFU method. The countable colonies were used to calculate the concentration of microorganism with Eq. (6.1):

$\mathrm{CFU} / \mathrm{ml}=($ No. of colonies $\times$ dilution factor $) /$ volume of culture plate

In general, micropipettors $(<1 \mathrm{ml})$ are used to transfer bacterial culture for dilutions and each dilution is dotted onto petri dishes for cultivation. They have three sizes of pipes in three ranges of volumes: $\mathrm{P} 20=0.5-20 \mu \mathrm{l}, \mathrm{P} 200=20-200 \mu \mathrm{l}$, and P1000 $=200-1000$ $\mu 1$, see Figure 6-2. In this test, P1000 was used to make dilution, P200 was used to transfer bacterial culture onto coins, and P20 was used for dotting.

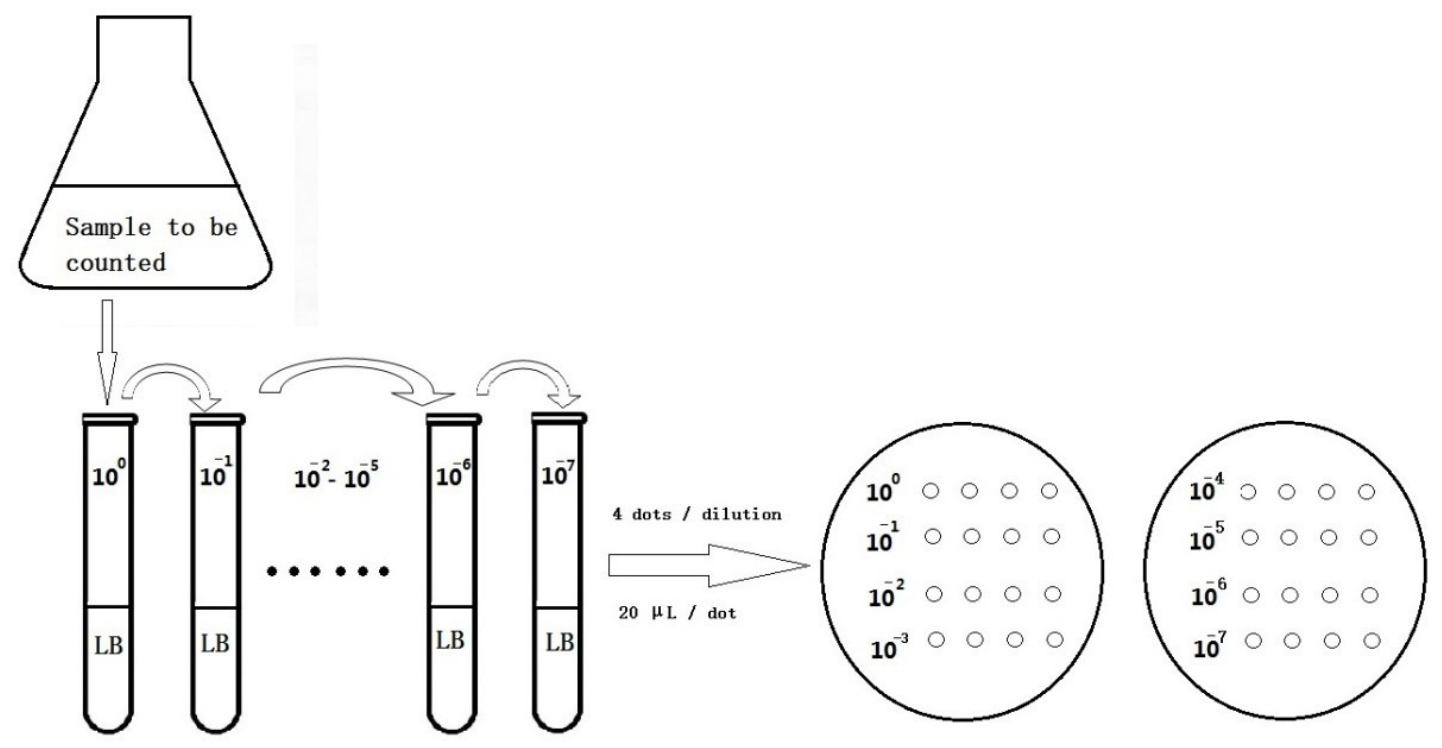

Figure 6-1: Schematic of CFU theory. 


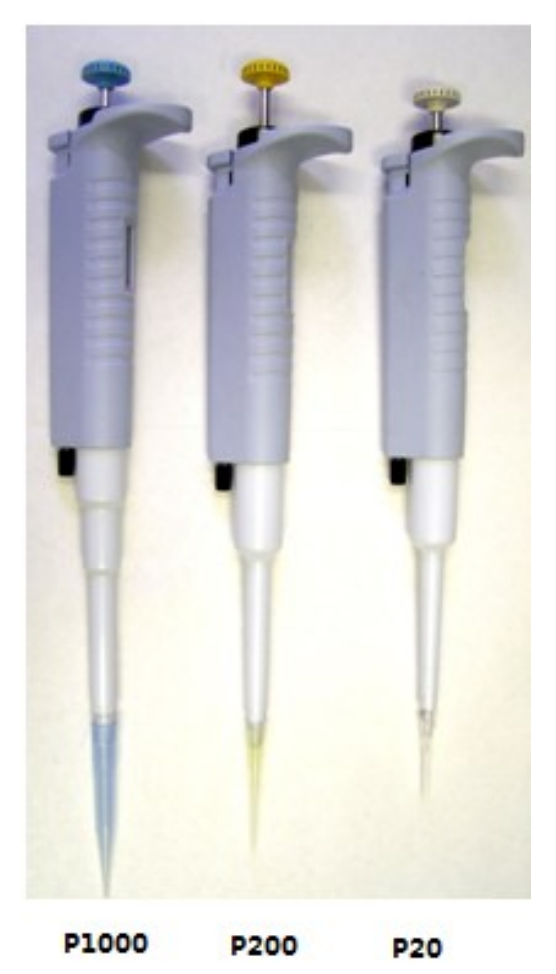

Figure 6-2: Three sizes of micropipettors.

\subsubsection{Preparation Process}

LB and agar used to make the culture and growth solution were all purchased from Anachemia, Canada, see Figure 6-3(a). To produce the culture solution, add 3 g agar and $5 \mathrm{~g}$ LB into $400 \mathrm{ml}$ water (Figure 6-3(b)). The solution was then stirred to dissolve the solid matters. The solution was then placed into an autoclave for 20 liquid cycle that is one option of the autoclave, see Figure 6-3(c) and (d). This standard option is always used to sterilize the solution and produce the medium. The temperature of this cycle is maintained at $121^{\circ} \mathrm{C}$ for $2 \mathrm{hr}$. Since agar can remain as a gel at a temperature up to $65^{\circ} \mathrm{C}$ and solidify between $32^{\circ} \mathrm{C}$ to $40^{\circ} \mathrm{C}$, the $\mathrm{LB}$ and agar solution was put into a water bath after autoclave treatment. This water bath was set to a temperature of $65^{\circ} \mathrm{C}$ to control the state of the solution, see Figure 6-3(e). When the solution was heated to $65^{\circ} \mathrm{C}$, it was poured into plastic dishes to form petri dishes, see Figure 6-3(f). 
The growth medium, used to transfer bacteria from coins to the solution, contained $0.025 \mathrm{~g} / \mathrm{ml}$ of LB. The process was the same as for the LB-agar culture plate, except the last step. After the autoclaving process was completed, the solution was placed at room temperature to cool.

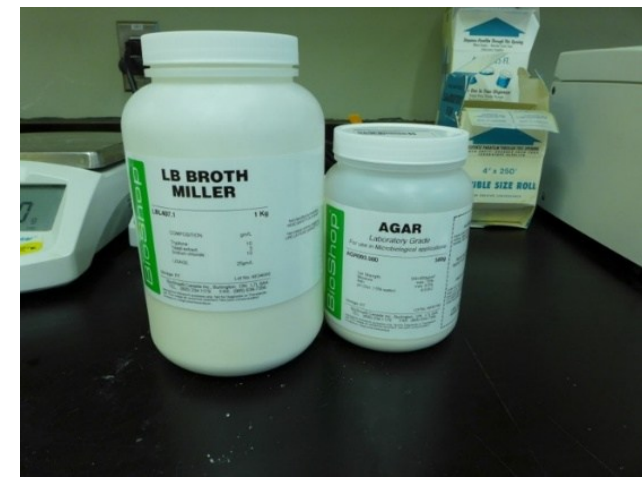

(a)

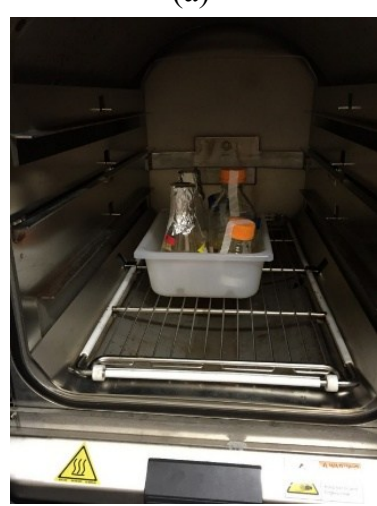

(c)

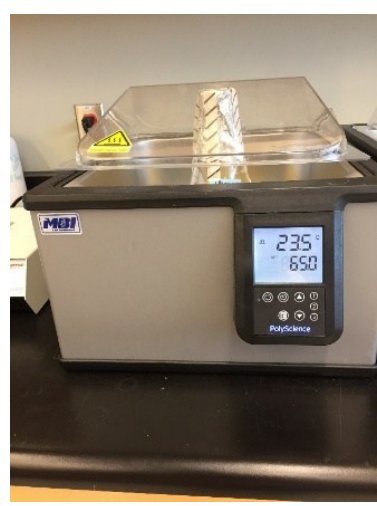

(e)

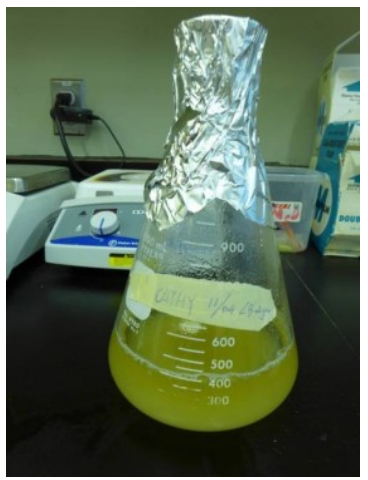

(b)

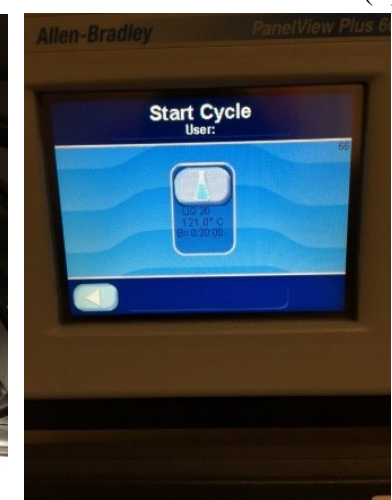

(d)

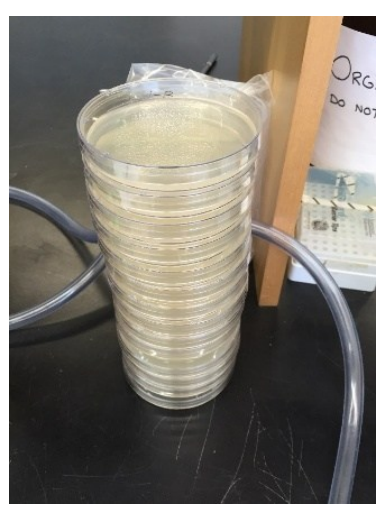

(f)

Figure 6-3: Operating procedures for preparation of petri dishes: (a) LB and agar, (b) liquid solution of the mixture of LB and agar, (c) bottles in an autoclave, (d) liquid 20 cycle selected, (e) digital water bath, and (f) completed LB - agar plates. 


\subsection{Experimental Process}

In this test, two methods were used to determine the concentrations of bacteria on the coins. First experiment was aimed to calculate the amount of bacteria after daily use of the coins. In the second test, MCN 520 (E.coli), known bacteria, was added onto the coins to compare the bacteria resistance of coated coins to uncoated coins.

\subsubsection{Experiment I}

Because copper itself has antibacterial function, it was very difficult to compare bare copper coins with the ALG coated coins. In order to measure the antimicrobial ability of ALG, this test was carried out on five different bare and coated coins. They are bare copper (one unit), double-side coated copper (with ALG), nickel (25 cent), aluminum (Chinese coin) and plastic, see Figure 6-4. These coins were cleaned first using standard method, and then put in the pockets with frequent touch by hands for a week. In this case, the amount of bacteria on each coin was the same theoretically.

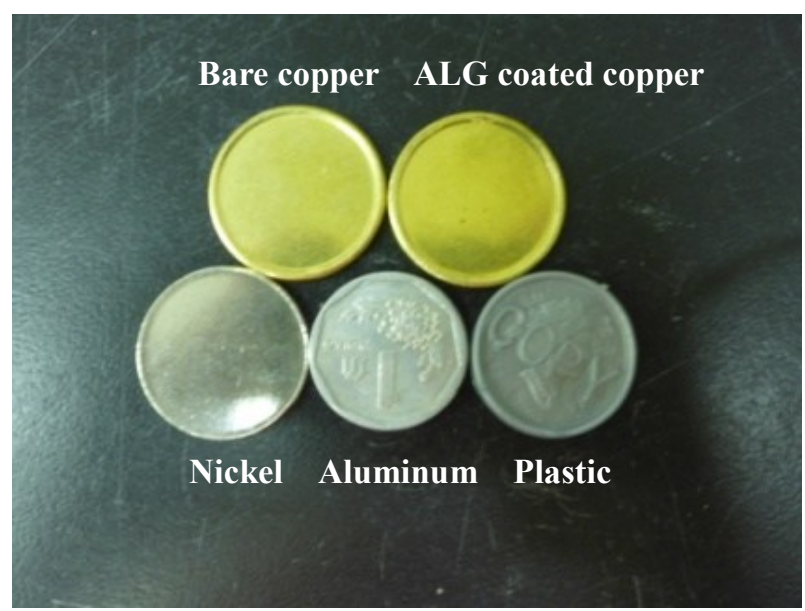

Figure 6-4: Tested coins. (top left - bare copper, top right - ALG coated copper, lower left - nickel, lower middle-Al, and lower right - plastic).

In this test, it was imperative to keep the environment sterile. Air, hands, and benches may be the media to transmit onto the coins and into the LB solutions. Therefore during 
the test, the operator should always wear gloves which had been sterilized by ethanol, the bench was cleaned also by ethanol and the flame was turned on during test in order to establish a clean environment nearby, see Figure 6-5.

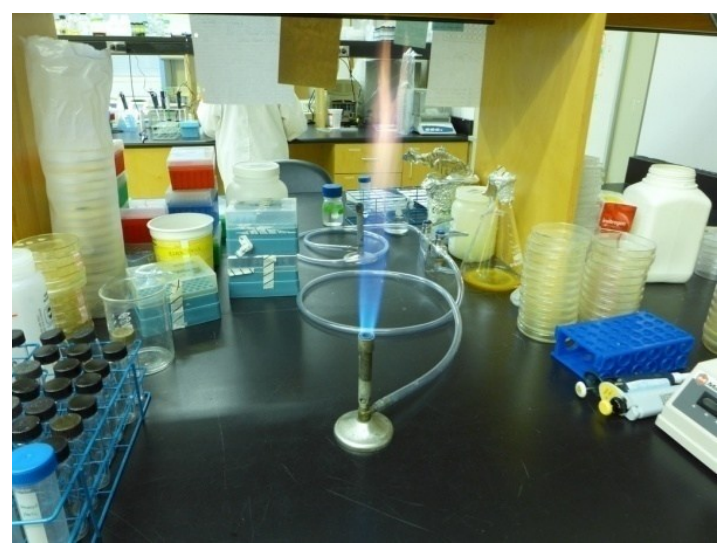

(a)

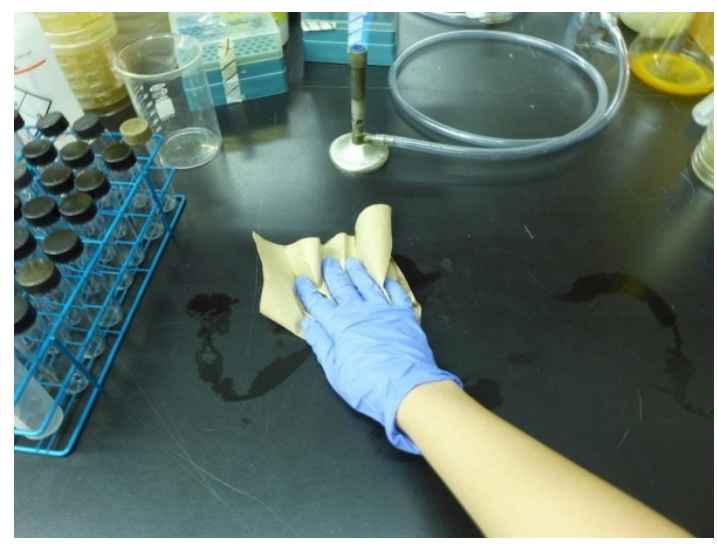

(b)

Figure 6-5: Experiment I preparation process: turning on the flame, and (b) cleaning the bench by ethanol.

The second step was to transfer the bacteria on the coins to the growth medium. Each coin was placed into a blue tube and the tubes were named by coins types. $5 \mathrm{ml} \mathrm{LB}$ solution was added to the tubes, then the tubes were vibrated for $10 \mathrm{~s}$. Since each solution containing different type of coins to be diluted seven times, seven black tubes were placed behind each blue tube. All eight tubes for every type of coins were labeled from $10^{-0}$ to $10^{-7}$ according to diluting sequence. Every black tube contained $4500 \mu \mathrm{LB}$ solution, see Figure 6-6.

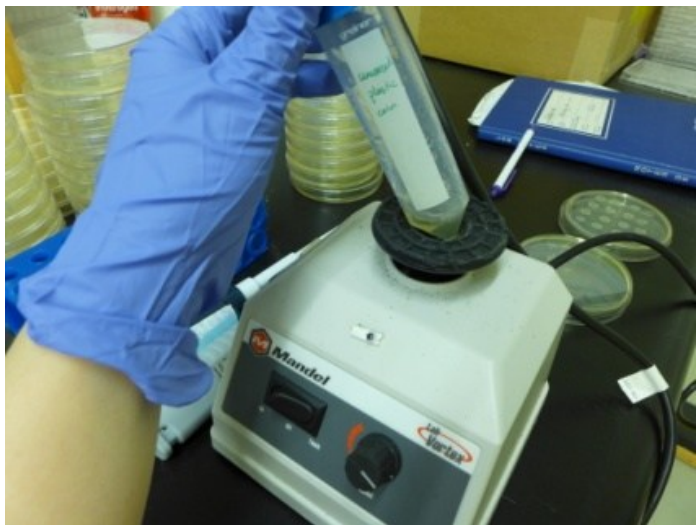

(a)

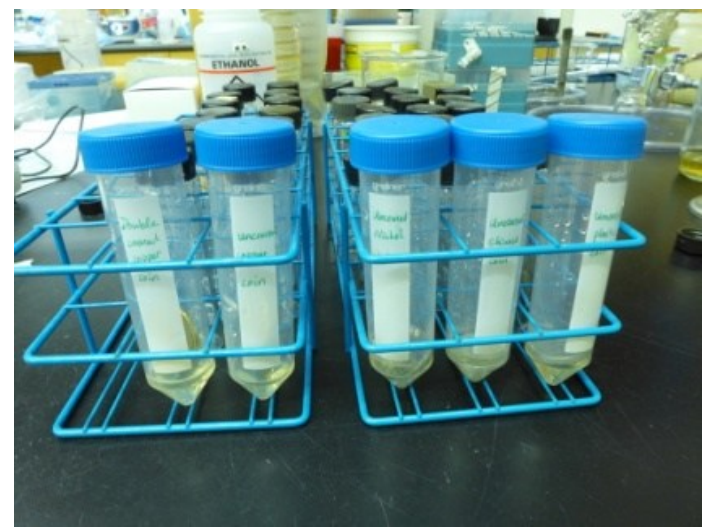

(b) 


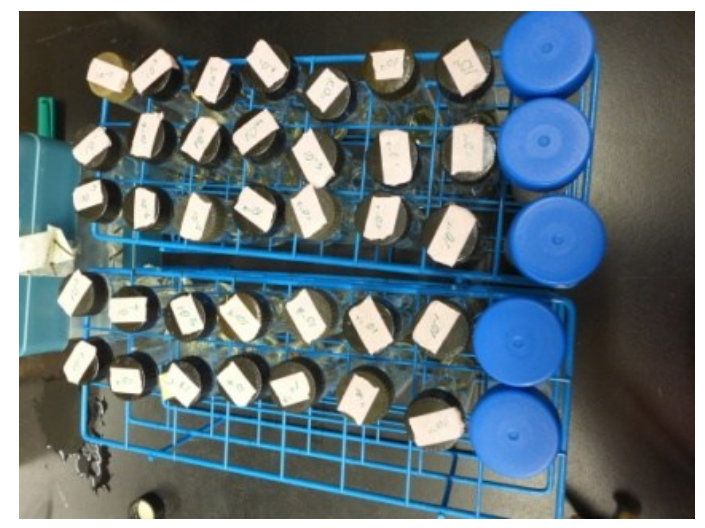

(c)

Figure 6-6: Transferring process: (a) vibrating blue tubes, (b) naming blue tubes by coin types, and (c) labeling black tubes.

The third step was serial dilution. The operator vibrated the $10^{-0}$ tube, transferred 500 $\mu \mathrm{l}$ culture to the $10^{-1}$ tube, and then vibrated $10^{-1}$ tube. These three steps were repeated seven times for all tubes containing different coins, see Figure 6-7.

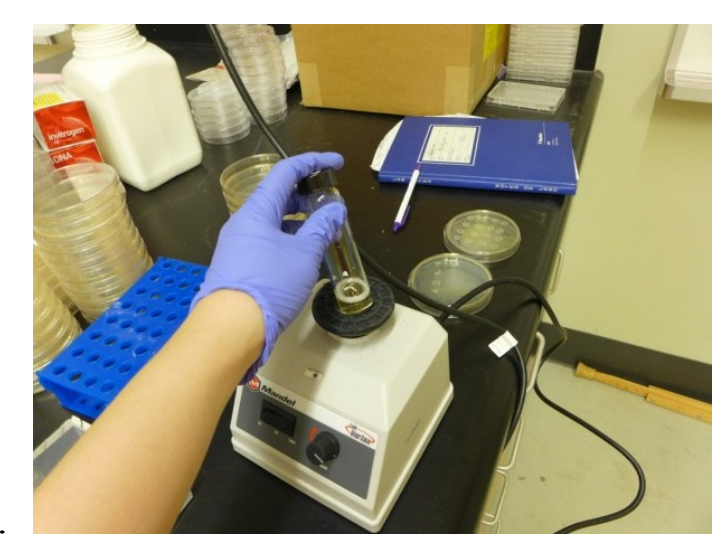

(a)

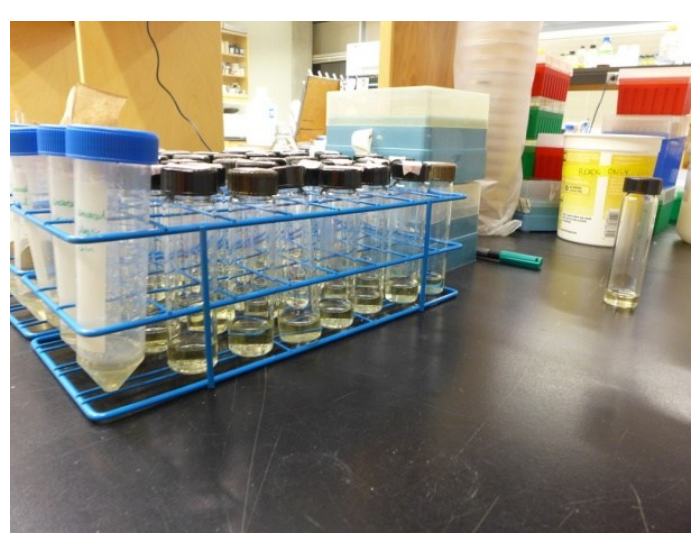

(b)

Figure 6-7: Serial dilution: (a) vibrating black tubes, and (b) completed dilutions.

Before the dilutions were dotted onto the plates, date, the type of coins and dilution number was written on the dishes. For every dilution, dotting was made four times with $20 \mu \mathrm{l}$ bacteria culture, see Figure 6-8. 


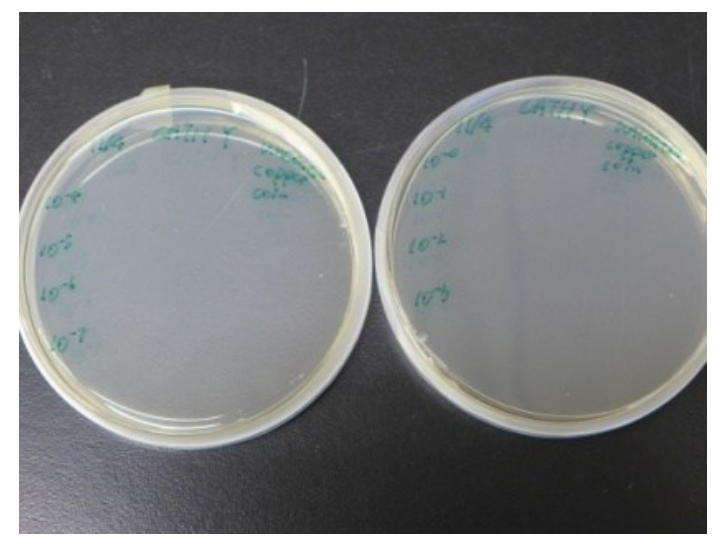

(a)

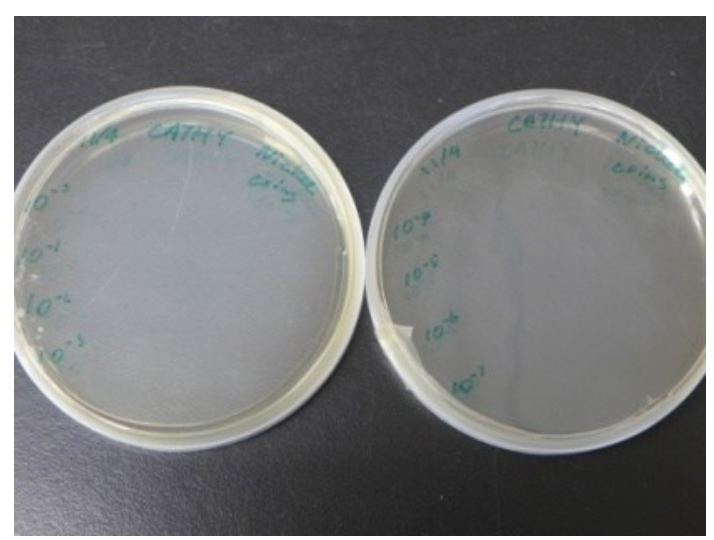

(c)

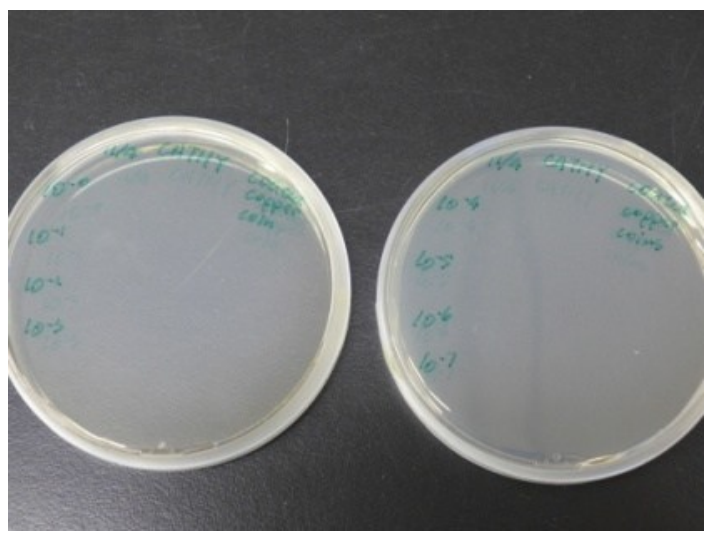

(b)

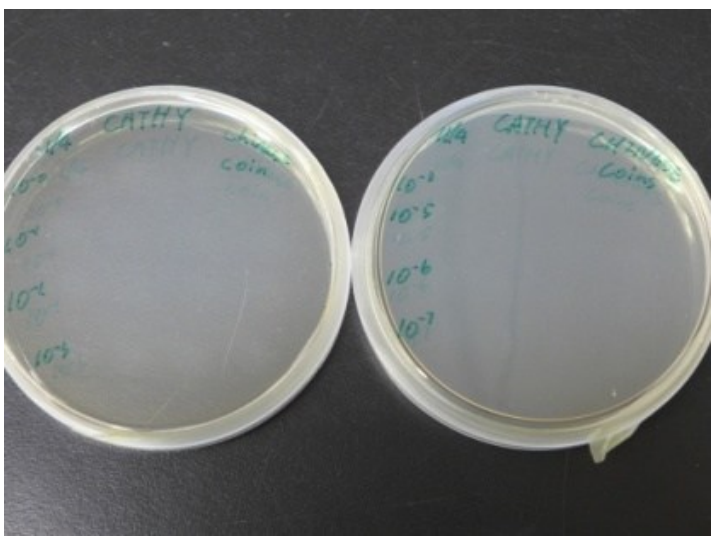

(b)

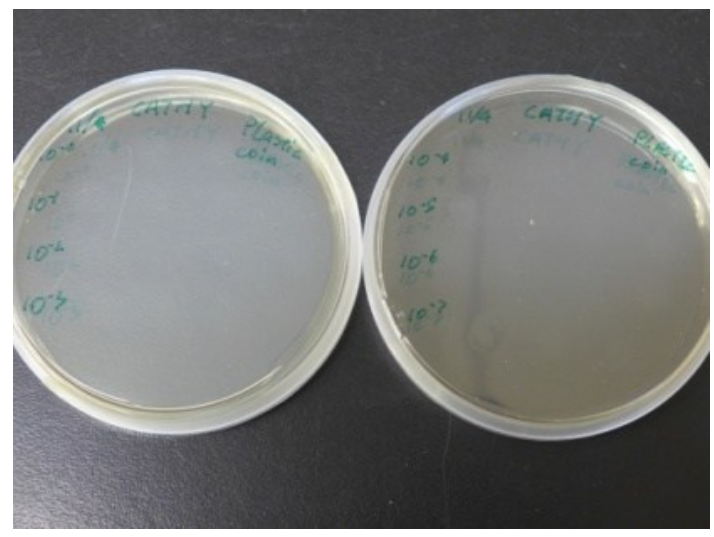

(e)

Figure 6-8: Completed petri dishes for various coins: (a) nickel coin plates, (b) plastic coin plates, (c) Chinese coin plates, (d) double-side coated coin plates, and (e) bare copper coin plates.

The final step was to grow the colonies. Colonies can grow faster when they are in a steady, source of warm environment. The temperatures from $20^{\circ} \mathrm{C}$ to $37^{\circ} \mathrm{C}$ are ideal, therefore the dishes were placed into an incubator set to an optimal temperature of $37^{\circ} \mathrm{C}$. Humidity is also controlled to help the growth of the bacteria, see Figure 6-9. 


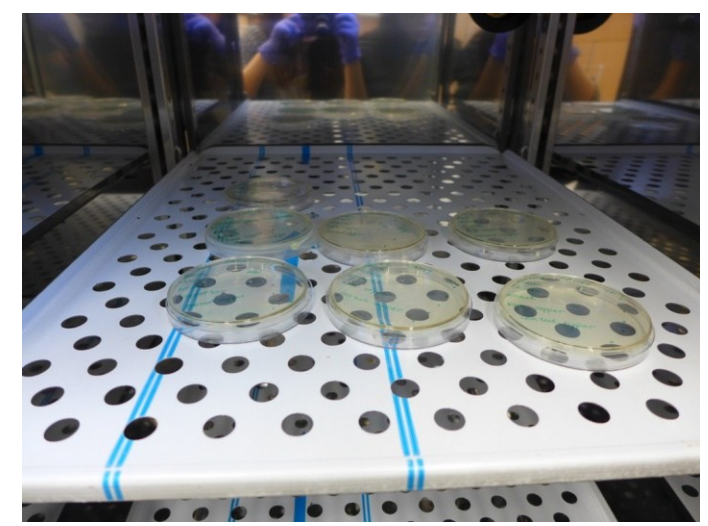

(a)

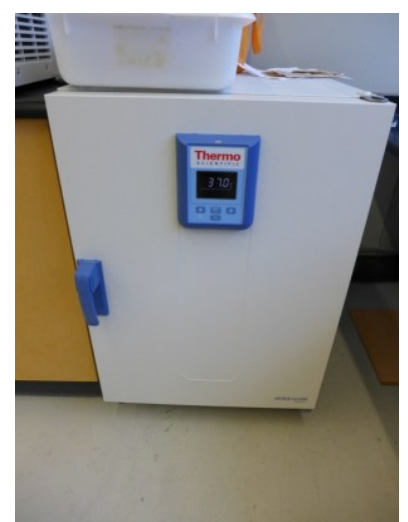

(b)

Figure 6-9: Culturing process: (a) dishes in the incubator, and (b) incubator.

\subsubsection{Experiment II}

In this test, a known type of bacteria, MCN520 Escherichia coli bacterial culture, was added onto the ALG coated bare nickel and bare brass coins to determine the anti-bacteria ability of these three types of coins. Escherichia coli (E. coli) is a gram-negative, rod-shaped bacterium of the genus Escherichia. It is a common bacterium in the intestine of warm-blooded organisms. Most E. coli strains are harmless, while some serotypes are toxic. A petri dish containing some MCN 520 colonies was used to generate the bacterial culture in this test. The P20 micropipettor was used to pick up one single colony of the bacteria and it was then added to $5 \mathrm{ml} \mathrm{LB}$ solution. The solution was placed into an autoclave for one day. When the solution changed from clear to cloudy, the process was deemed successful.

Since the original bacterial culture had too much bacteria, the culture was serially diluted three times to decrease the concentration. This process is the same as the dilution in experiment I. $500 \mu 1$ of MCN520 was transferred into $4500 \mu \mathrm{LB}$ solution, see Figure 6-10. The dilutions from $10^{0}$ to $10^{-3}$ were then labeled. Finally, $10^{-3} \mathrm{MCN} 520$ was added onto the coins. 


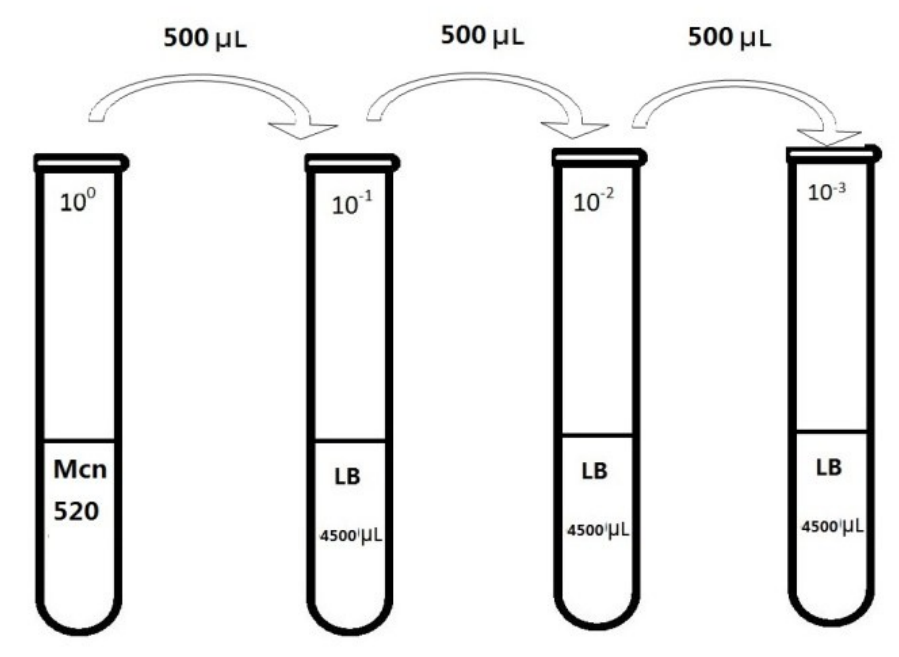

Figure 6-10: Schematic of MCN 520 serial dilution process.

As mentioned in Chapter 2, if aqueous solutions of bacteria are applied onto copper directly, its antibacterial function will be weaker than it is under dry condition, because $\mathrm{Cu}^{+}$is more toxic than $\mathrm{Cu}^{+2}$. In order to determine possible types of copper are present on the surface, LB and 10 $0^{-3}$ MCN520 solutions were added directly onto two bare brass coins, respectively, which contain approximately $60 \%$ copper, see Figure 6-11. Visibly, the LB solution turned part of the coin blue (presence of $\mathrm{Cu}^{+2}$ ) while the coin with bacterial culture on is not discolored. The pure LB solution with high nutrient may oxidize the coin or dissolve $\mathrm{CuO}$ and produce $\mathrm{Cu}^{+2}$ ions in the solution The bacteria must have reacted with the $\mathrm{Cu}^{2+}$ converting it to $\mathrm{Cu}^{+}$ion.

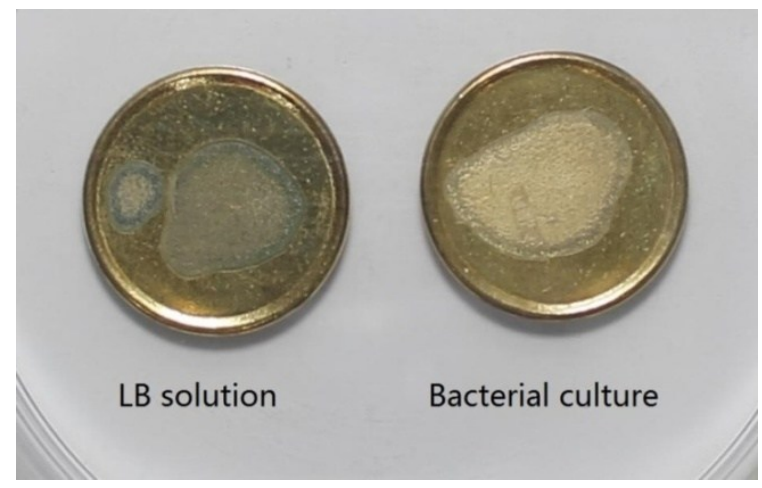

Figure 6-11: Comparison in color change between the brass coins with LB solution and MCN 520 culture. 
In this case, coins cannot be cleaned by ethanol because ethanol might be left on the surfaces of the coins, which would help kill the bacteria and influence the results of the test. Therefore the coins were sterilized in an autoclave at $180^{\circ} \mathrm{C}$ for $1 \mathrm{hr}$.

In order to keep a sterile environment during the processes of adding MCN520 onto the coins and adding the bacterial culture into the LB solution, all bottles, P200 micropipettor, and the gloves were disinfected by ethanol, see Figure 6-12(a). After that, $100 \mu \mathrm{l}$ of the $10^{-3}$ MCN520 dilution was added onto the coated and uncoated coins. In order to investigate the relationship between the time and remaining bacterial amount, the bacteria was collected after 1,3 , and $24 \mathrm{hr}$, respectively and the CFU calculation was later on conducted for each time period. For collecting remaining bacteria from the coins into the LB solution, cotton tips were used.1 $\mathrm{ml} \mathrm{LB}$ solution was first added to all green tubes shown in Figure 6-12(a). The cotton tips were wetted by the LB solution and then used to wipe the surfaces of the coins (Figure 6-12 (b), (c) and (d)). Figure 6-13 details the procedure in the process of experiment II.

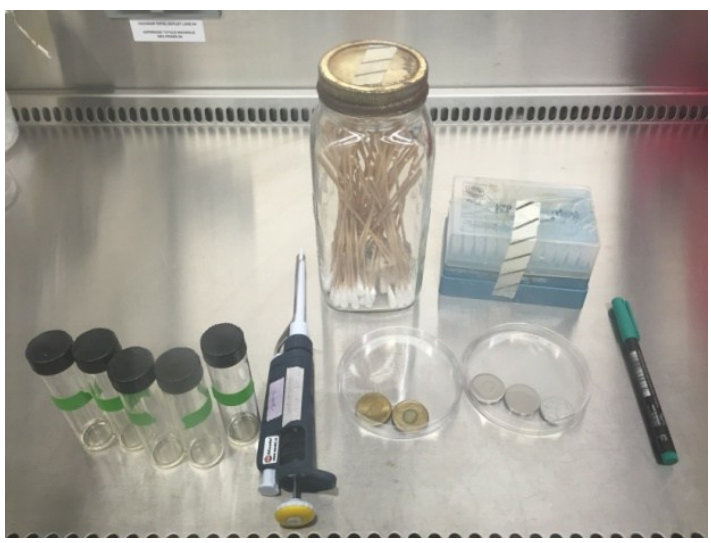

(a)

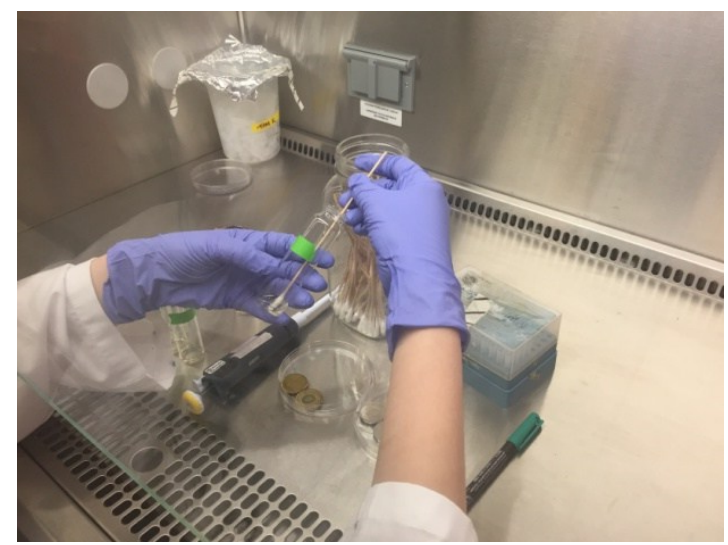

(b) 


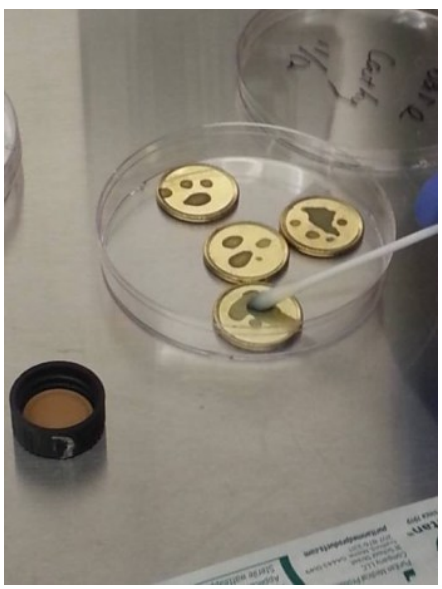

(c)

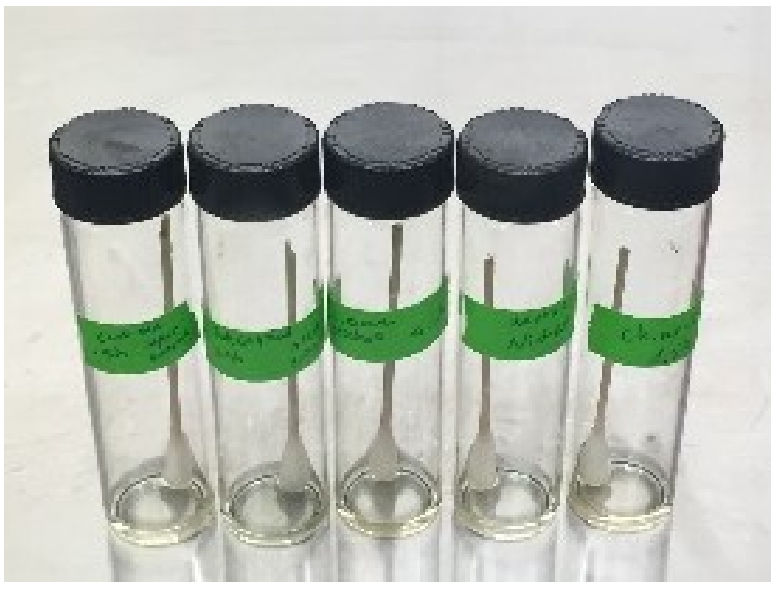

(d)

Figure 6-12: Collecting bacteria process in a sterile chamber: (a) cleaned components in the sterile chamber, (b) wetting cotton tips with LB solution, (c) wiping the surfaces of coins, and (d) labeled tubes.

After the extraction of bacteria on the coil into the LB solution,, serial dilution and dotting were implemented in a similar way as in experiment I. Finally, all petri dishes were placed into an incubator for one day.

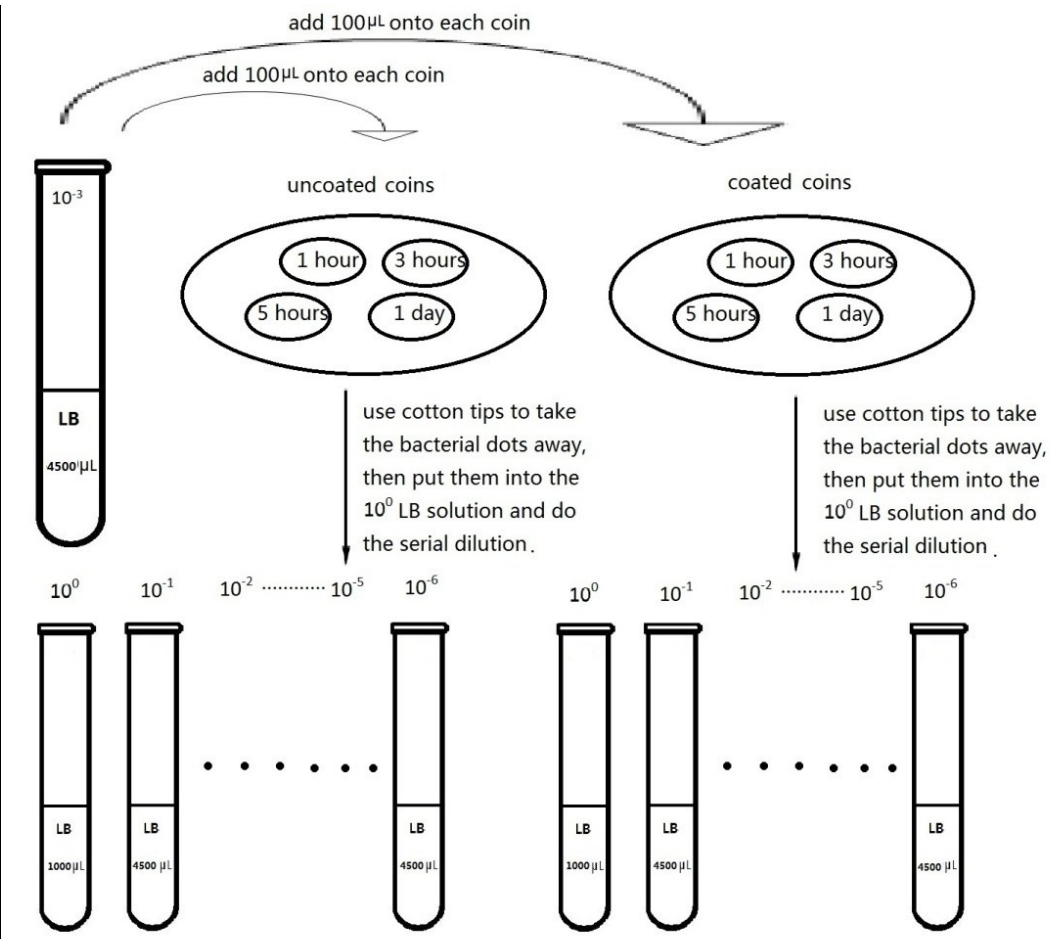

Figure 6-13: Schematic of experiment II process. 


\subsection{Experimental Results}

\subsubsection{Experiment I Results}

After petri dishes were in the incubator for one day, no bacteria colonies were grown on all dishes. This indicated that coins carried in the pockets for two weeks did not carry enough bacteria for this test. Furthermore, the type of bacteria on the coins may not be cultivated by the LB solution. To further evaluate the presence of bacteria on actual circulation coins, commercially circulated coins (1 dollar, 25 cent, and 1 cent Canadian coins from 1991, and 50 cent and 1 cent Chinese coins from 2009, see Figure 6-14) were tested. Similarly, no bacteria colonies were grown on the petri dishes.

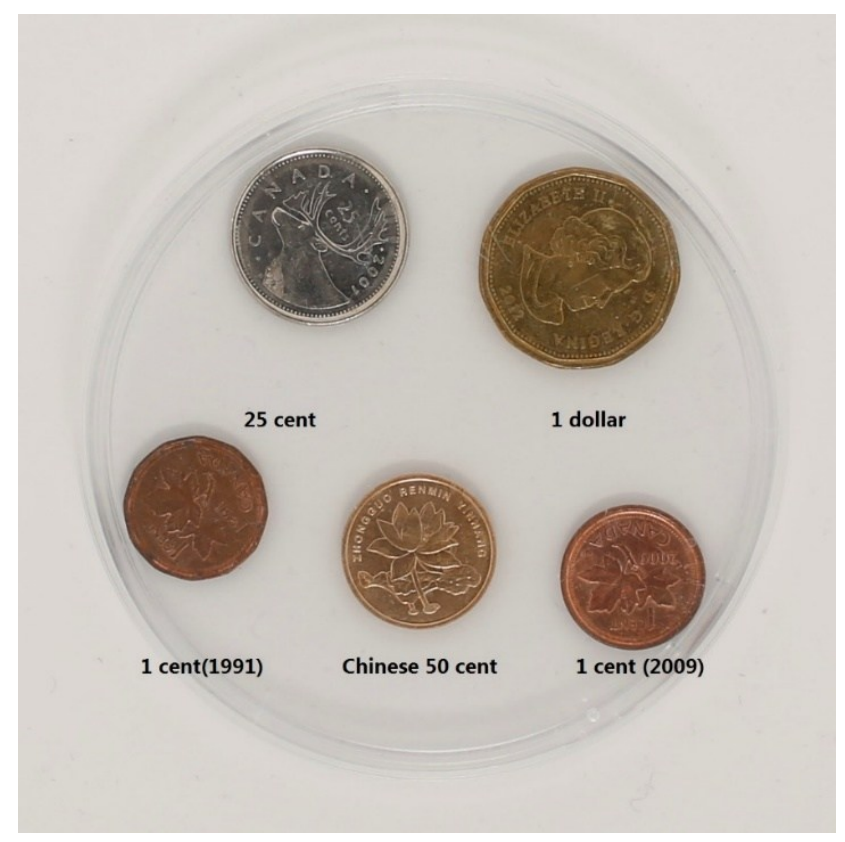

Figure 6-14: Real circulation coins studied in bacteria growth test.

\subsubsection{Experiment II Results}

Figure 6-15, Figure 6-16, and Figure 6-17 present antibacterial ability of bare nickel, coated nickel and bare brass coins. The anti-bacterial ability of bare brass coin is outstanding. Figure 6-15 shows that the bare brass coin can kill $99 \%$ bacterial within 90 
min. For bare nickel and ALG coated nickel coins, the antibacterial ability were not as effective as brass coins. According to the results in Figure 6-16 and Figure 6-17, ALG coatings performed better than bare nickel coins. Nickel coin has can only kill $33 \%$ of bacteria on the coin within $24 \mathrm{hr}$, while the ALG coatings can kill 96\% and 99\% bacteria in 3 and 24 hr, respectively. Table 6-1, Table 6-, and Table 6- summarize the detailed results of experiment II.

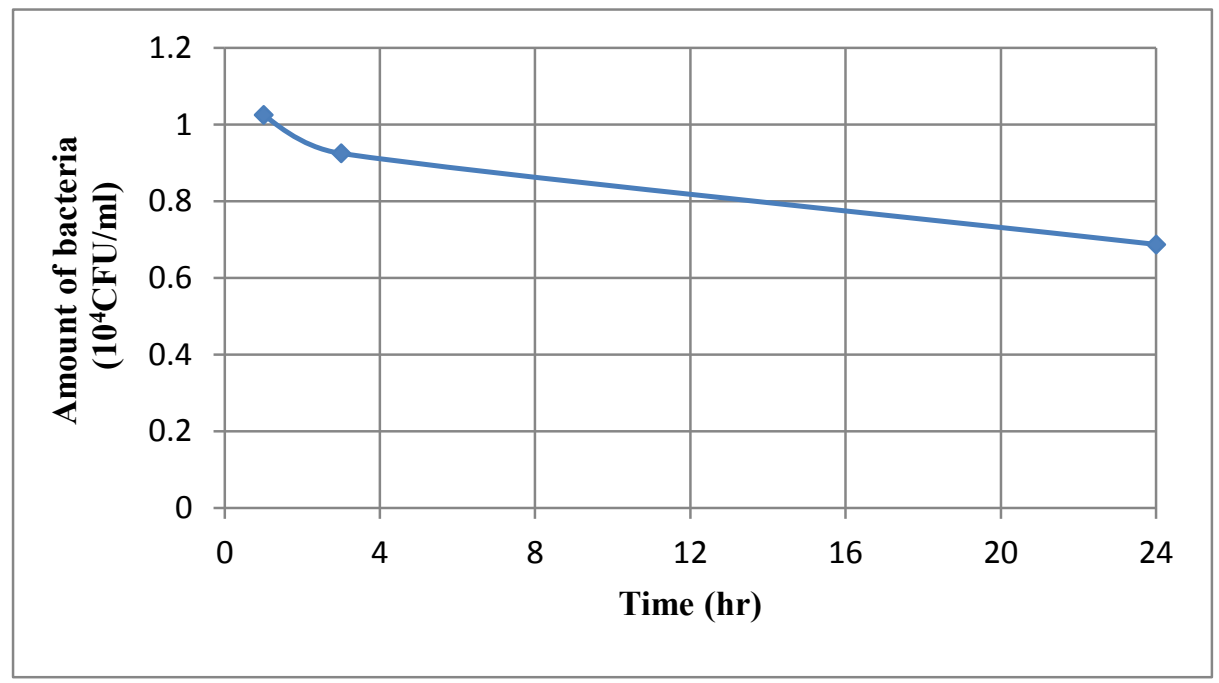

Figure 6-15: Antibacterial ability of bare nickel coin: CFU vs. time.

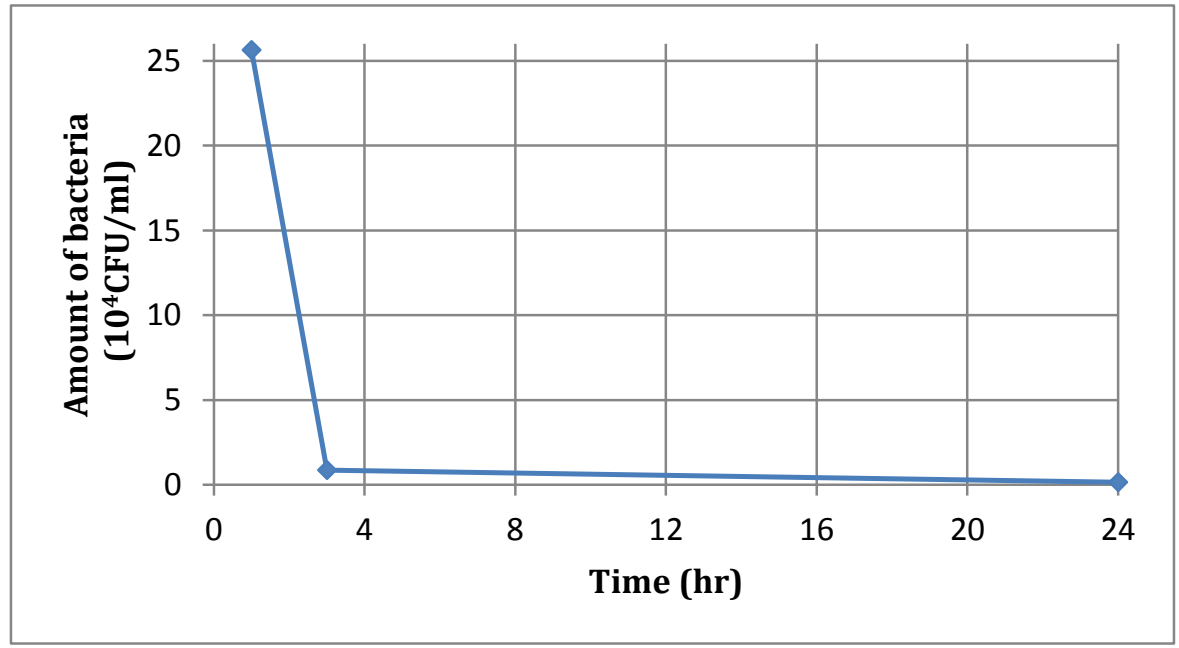

Figure 6-16: Antibacterial ability of ALG coating on nickel coin: CFU vs. time. 


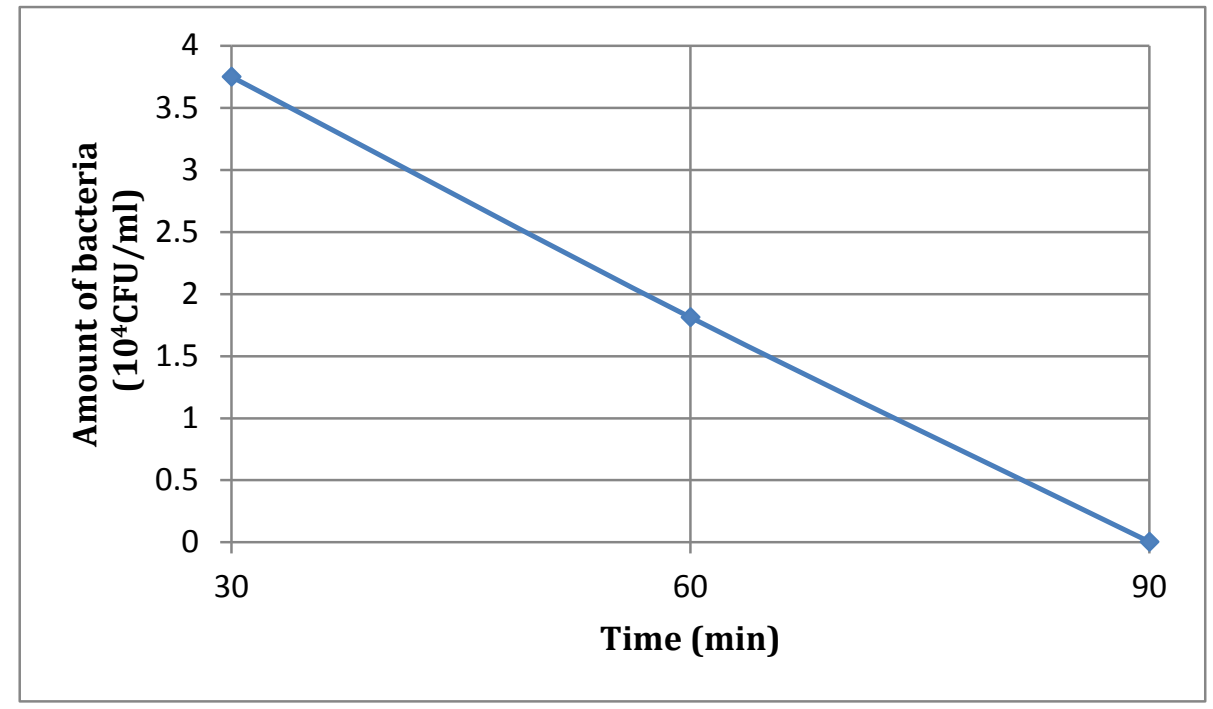

Figure 6-17: Antibacterial ability of bare brass coin: CFU vs. time. 
$1 \mathrm{hr}$ test for bare nickel coins

\begin{tabular}{cccc} 
& $10^{-1}$ & $10^{-2}$ & Image \\
\hline $1^{\text {st }}$ dot & 21 & 6 \\
$2^{\text {nd }} \mathrm{dot}$ & 18 & 2 \\
$3^{\text {rd }} \mathrm{dot}$ & 20 & 2 \\
$4^{\text {th }} \mathrm{dot}$ & 23 & 2.5 \\
Avg. No. & 20.5 & $1.25 \times 10^{4}$ \\
Average CFU $/ \mathrm{ml}$ & $1.025 \times 10^{4}$ &
\end{tabular}

$3 \mathrm{hr}$ test for bare nickel coins

\begin{tabular}{cccc} 
& $10^{-1}$ & $10^{-2}$ & Image \\
\hline $1^{\text {st }}$ dot & 20 & 5 \\
$2^{\text {nd }} \mathrm{dot}$ & 19 & 4 \\
$3^{\text {rd }} \mathrm{dot}$ & 17 & 5 \\
$4^{\text {th }} \mathrm{dot}$ & 18 & 3.5 \\
Avg. No. & 18.5 & $1.75 \times 10^{4}$ \\
Average CFU $/ \mathrm{ml}$ & $9.25 \times 10^{3}$ &
\end{tabular}

$24 \mathrm{hr}$ test for bare nickel coins

\begin{tabular}{cccc} 
& $10^{-1}$ & $10^{-2}$ & Image \\
\hline $1^{\text {st }}$ dot & 14 & 3 \\
$2^{\text {nd }} \mathrm{dot}$ & 10 & 3 \\
$3^{\text {rd }} \mathrm{dot}$ & 16 & 1 \\
$4^{\text {th }} \mathrm{dot}$ & 15 & 3 \\
Avg. No. & 13.75 & 2.5 \\
Average CFU $/ \mathrm{ml}$ & $6.875 \times 10^{3}$ & $1.25 \times 10^{4}$
\end{tabular}

Table 6-1: Antibacterial ability of bare nickel coins. 


\begin{tabular}{|c|c|c|c|}
\hline \multicolumn{4}{|c|}{$1 \mathrm{hr}$ test for coated nickel coins } \\
\hline & $10^{-2}$ & $10^{-3}$ & Image \\
\hline $1^{\text {st }}$ dot & 50 & 8 & \\
\hline $2^{\text {nd }}$ dot & 54 & 17 & \\
\hline $3^{\text {rd dot }}$ & 52 & 13 & \\
\hline $4^{\text {th }} \operatorname{dot}$ & 49 & 11 & \\
\hline Avg. No. & 51.25 & 12.25 & \\
\hline Average CFU/ml & $2.563 \times 10^{5}$ & $6.125 \times 10^{5}$ & \\
\hline \multicolumn{4}{|c|}{$3 \mathrm{hr}$ test for coated nickel coins } \\
\hline & $10^{-1}$ & $10^{-2}$ & Image \\
\hline $1^{\text {st }} \mathrm{dot}$ & 19 & 4 & \\
\hline $2^{\text {nd }}$ dot & 17 & 5 & \\
\hline $3^{\text {rd }}$ dot & 19 & 5 & \\
\hline $4^{\text {th }}$ dot & 14 & 5 & \\
\hline Avg. No. & 17.25 & 4.75 & \\
\hline Average CFU/ml & $8.625 \times 10^{3}$ & $2.375 \times 10^{4}$ & \\
\hline \multicolumn{4}{|c|}{$24 \mathrm{hr}$ test for coated nickel coins } \\
\hline & $10^{-0}$ & $10^{-1}$ & Image \\
\hline $1^{\text {st }}$ dot & 27 & 2 & \\
\hline $2^{\text {nd }}$ dot & 30 & 5 & \\
\hline $3^{\text {rd }}$ dot & 36 & 5 & $\because$ \\
\hline $4^{\text {th }}$ dot & 30 & 6 & \\
\hline Avg. No. & 30.75 & 4.5 & \\
\hline Average CFU/ml & $1.538 \times 10^{3}$ & $2.25 \times 10^{3}$ & \\
\hline
\end{tabular}

Table 6-2: Antibacterial ability of ALG coated nickel coins. 


\begin{tabular}{|c|c|c|c|}
\hline \multicolumn{4}{|c|}{30 min test for bare brass coins } \\
\hline & $10^{-1}$ & $10^{-2}$ & Image \\
\hline $1^{\text {st }}$ dot & 70 & 7 & \\
\hline $2^{\text {nd }}$ dot & 75 & 8 & \\
\hline $3^{\text {rd }}$ dot & 78 & 12 & \\
\hline $4^{\text {th }} \operatorname{dot}$ & 77 & 6 & \\
\hline Avg. No. & 75 & 8.25 & \\
\hline Average $\mathrm{CFU} / \mathrm{ml}$ & $3.75 \times 10^{4}$ & $4.125 \times 10^{4}$ & \\
\hline \multicolumn{4}{|c|}{60 min test for bare brass coins } \\
\hline & $10^{-1}$ & $10^{-2}$ & Image \\
\hline $1^{\text {st }} \operatorname{dot}$ & 24 & 8 & \\
\hline $2^{\text {nd }}$ dot & 42 & 2 & \\
\hline $3^{\text {rd dot }}$ & 39 & 7 & \\
\hline $4^{\text {th }} \operatorname{dot}$ & 40 & 2 & \\
\hline Avg. No. & 36.25 & 4.75 & \\
\hline Average CFU/ml & $1.81 \times 10^{4}$ & $2.38 \times 10^{4}$ & \\
\hline \multicolumn{4}{|c|}{90 min test for bare brass coins } \\
\hline & $10^{-0}$ & & Image \\
\hline $1^{\text {st }} \mathrm{dot}$ & 1 & & \\
\hline $2^{\text {nd }} \operatorname{dot}$ & 1 & & \\
\hline $3^{\text {rd }}$ dot & 1 & & \\
\hline $4^{\text {th }} \mathrm{dot}$ & 1 & & \\
\hline Avg. No. & 1 & & \\
\hline Average CFU/ml & 50 & & \\
\hline
\end{tabular}

Table 6-3: Antibacterial ability of bare brass coins. 


\section{Chapter: Discussion on the Results}

\subsection{Qualifying Candidate Coating Materials}

Five candidate materials were considered in this research for circulation coins. Based on initial visual examination, polyurethane, advanced liquid glass, and silicone R-2180 were selected for further evaluation. Under bright day light, polyurethane can be seen to influence the reflectivity of brass coins somewhat and advanced liquid glass coated coins are slightly darker than bare brass coins due to the oven curing process; nevertheless these differences are hardly noticeable. Since silicone R-2180 is very viscous, the coating thickness cannot be controlled accurately using manual process but should be further evaluated once a different coating process can be used to apply coating with controlled thickness. Standard liquid glass (causing blue tint from curing process) and polytetrafluoroethylene (poor adhesion), were not recommended as coatings for circulation. Although three surface treatments, grit-blasting, acid etching and polishing, were used in an attempt to enhance the coating adhesion, all had cause changes to coin's texture and color. As such, they are not recommended.

\subsection{Coating Thickness}

The relationship between coating thickness and coating process parameter, spin speed and spin time, is shown in Figure 7-1 and Figure 7-2 for the two coatings of interest. According to the requirements of the Royal Canadian Mint, an ideal coating thickness is in the range of $8-12 \mu \mathrm{m}$. The PUR coatings are thicker than the ALG coatings. This is due to the fact that the viscosity of PUR $(50 \mathrm{mPa} \cdot \mathrm{s})$ is higher than that of ALG $(4 \mathrm{mPa} \cdot \mathrm{s})$, 
resulting in thicker coating when a spin coater was used. Other coating processes, such as electrostatic or ultrasonic spraying, may be applicable to apply thin layer of PUR. As seen in Figure 7-1, the ALG coating thickness became stable when the spin speed reached 500 rpm. In addition, the curves of the ALG coating on nickel and brass coins overlap, which means that the ALG coatings are not sensitive to substrate variations. On the other hand, the difference between the PUR coating thickness on nickel $(52-91 \mu \mathrm{m})$ and brass coins $(10-45 \mu \mathrm{m})$ is much greater. The surface tension between PUR and brass or nickel must exert more impact on the flow of PUR with higher viscosity. For both coatings spin speeds below $500 \mathrm{rpm}$ resulted in unacceptable coating thickness and thickness uniformity.

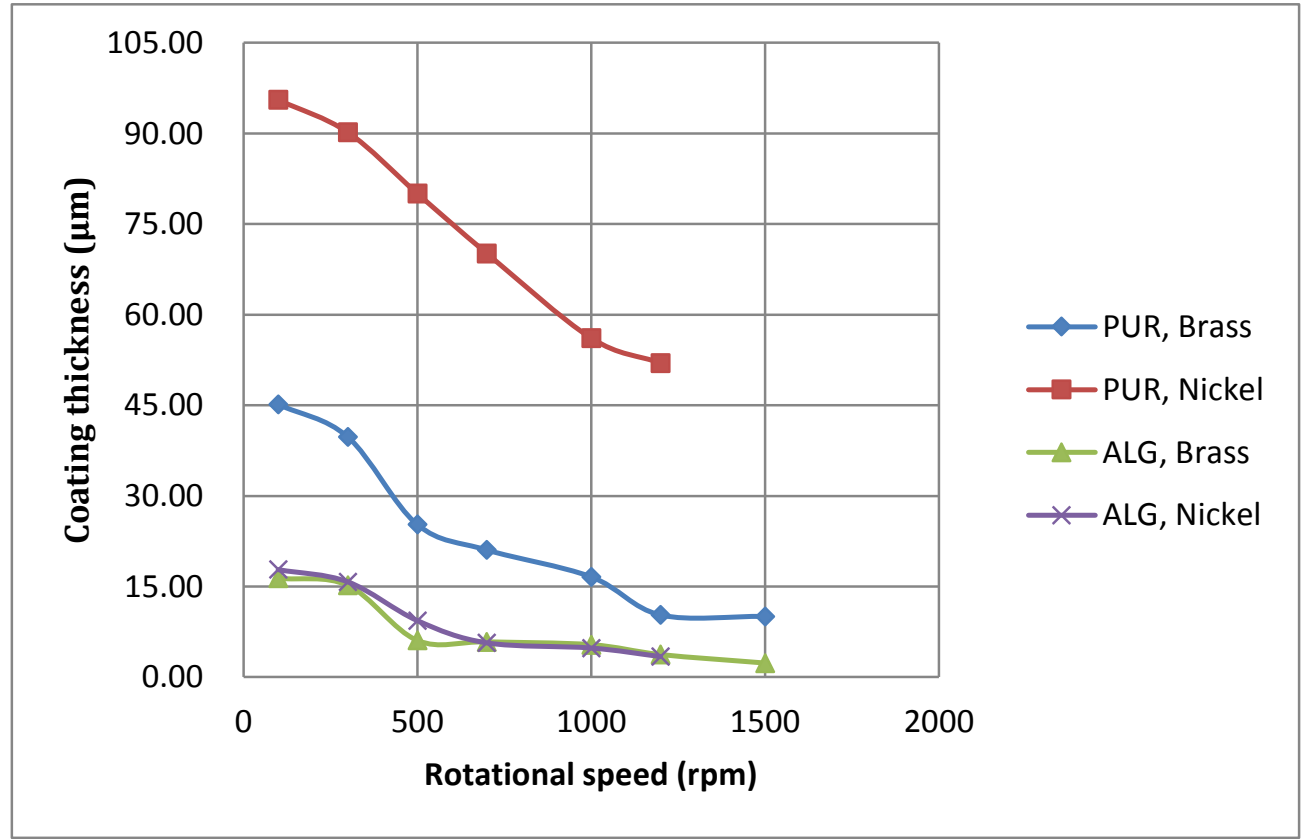

Figure 7-1: Coating thicknesses VS. rotational speed for the PUR and ALG coatings produced for 30 s spin duration on brass and nickel coins. 


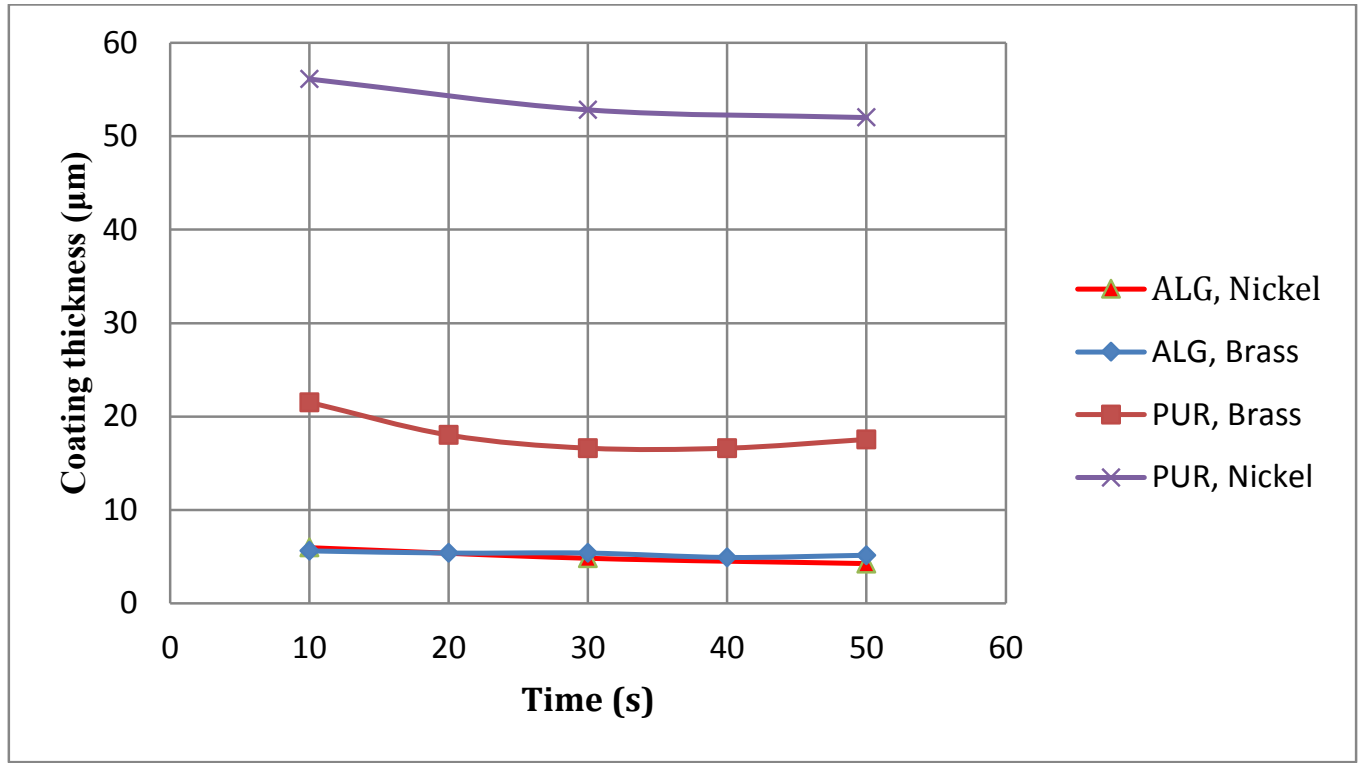

Figure 7-2: Coating thickness variations with spin time for the PUR and ALG coatings produced at 1000 rpm on brass and nickel coins.

According to Figure 7-2, when spin speed reached 1000 rpm, the coating thickness approached to constant for all the coatings, therefore this spin speed was used to find the spin duration to give the ideal thickness for each coating, as illustrated in Figure 7-2. The curves of coating thickness are all quite flat, which means that the coating thickness was not influenced appreciably by spin time when the spin speed was greater than $1000 \mathrm{rpm}$.

Table 7-1 reports the approximate minimum thickness of the ALG and PUR coatings on the coins applied by spin coater.

\begin{tabular}{c|ccc}
\hline & & & $\begin{array}{c}\text { ALG coatings on } \\
\text { brass and on } \\
\text { nickel coins }\end{array}$ \\
\hline $\begin{array}{c}\text { Minimum thickness } \\
(\mu \mathrm{m})\end{array}$ & $\approx 10$ & PUR on nickel coins & $\approx 52$ \\
\hline
\end{tabular}

Table 7-1: Approximate minimum thickness of the PUR and ALG coatings on brass and nickel coins.

\subsection{Coating Microstructure}

The microstructural analysis was aimed to determine if the coatings were uniform 
and if there were any cracks or defects in the coatings, which could not be found by visual examination. Polyurethane, advanced liquid glass and silicone all had good surface coverage on the coins and no bare areas were observed on the coated coins.

The PUR coatings, although quite uniform, had some bright spots on the coating surfaces due to dust collecting on the surface during drying process. The ALG coatings were not as flat as the PUR coatings microscopically, but there were no dust and cracks found.

\subsection{Corrosion Test Results}

Since the corrosion resistance of nickel coins was better than that of brass coins, the test duration for nickel coins was further extended to six days, while three-day test was used for brass ones.

For brass coins, heat-treated coin had the worst corrosion resistance as it changed its color within half a day. The thinnest ALG coating $(6.08 \mu \mathrm{m})$ performed the best as very little red/brown spots were found at the center of the coin after a day exposure to sweat solution. PUR suffered from more corrosion damage than ALG, except that the thickest PUR coating $(25.26 \mu \mathrm{m})$ had relatively lesser corrosion associated discoloration. The silicone coating did not break or crack, however, the color of the coating darkened. The bare brass coin had similar corrosion damage as the thin PUR coatings but it had inferior corrosion resistance than other coated brass coins.

For nickel coins, all coated coins were better than uncoated ones. The heat-treated and bare coins showed traces of corrosion products on the surface after one day, while the ALG coating exhibited corrosion, in the form of dark spots, after three days. Silicone and 
PUR coatings both showed signs of corrosion after four days.

Based on the overall corrosion test results, the advantage of coating the coins is clearly seen. There are some differences between the coating on brass and nickel coins.; these may be attributed to weaker coating bonding to brass coins (PUR, for example) or occasional coating defects. In both instances, the sweat solution may have permeated through the coatings and reached the coin substrate, leading to the corrosion of the substrate material.

Although these coatings offered corrosion resistance to the coins, different process parameter produced differences in coating performance against sweat. Among ALG coated coins, the coin processed at $1000 \mathrm{rpm}$ for $40 \mathrm{~s}(6.28 \mu \mathrm{m})$ performed the best during the corrosion test. In addition, according to the results of experiment II, double-side ALG coated coins had even better corrosion resistance than one-side ALG coated ones. The PUR coated coins processed at $700 \mathrm{rpm}(25.26 \mu \mathrm{m})$ for $50 \mathrm{~s}$ was rated the best among the three PUR coatings tested. Silicone R-2180 offered better corrosion resistance than ALG on nickel coins. This observation suggests that process parameters play an important role in coating's corrosion resistance, in addition to the coating types. The coatings tested in this study can still be improved using a systematic approach where each parameter is examined sequentially.

In terms of corrosion mechanism(s) and resulted corrosion products, EDX analysis can help provide indications. Before corrosion test, brass contains $70 \mathrm{wt} \%$ copper and 30 $\mathrm{wt} \%$ zinc. For nickel coins, the composition of the surface layer before the test was 100 wt $\%$ nickel. 
Dezincification is a form of corrosion which generally happens on the brass alloys containing less than $85 \%$ copper. In this corrosion, zinc is separated from the alloy by dissolution from copper. Dezincification is also called de-alloying process. There are two types of dezincification: uniform type (layer type) which occurs mainly on $\alpha-\beta$ brass; plug type which is mostly found in $\alpha$ - brass. The brass coin falls into $\alpha$-brass class. And when it is exposed to $\mathrm{NaCl}$, dezincification in the form of plug will occur [91].

Figure 7-3 shows schematically the corrosion process of brass coins in the wet/dry cyclic conditions. In the initial stage, brass is covered by air-formed oxide film and the corrosion rate is the highest because the dissolution of the oxide film is accelerated in acidic medium (sweat solution contains $\mathrm{NaCl}$ and $\mathrm{Ph}=4-5$ ). Zinc is removed from brass faster than copper due to dezincification (Eq. (7.1) and Eq. (7.2)). When this happens, the surface will have less than $30 \%$ zinc. In the middle stage, the corrosion products of zinc are formed; part of them is washed off by the medium solution, with the rest retaining on the surface ( $\mathrm{ZnO}$ formation as expressed by Eq. (7.3)).

$$
\begin{aligned}
& \mathrm{Zn}+4 \mathrm{Cl}^{-} \rightarrow \mathrm{ZnCl}_{4}^{2-}+2 \mathrm{e}^{-} \\
& \mathrm{Zn}+2 \mathrm{CuCl}_{2}^{-} \rightarrow 2 \mathrm{Cu}+\mathrm{ZnCl}_{4}^{2-} \\
& \mathrm{ZnCl}_{4}^{2-}+\mathrm{H}_{2} \mathrm{O} \rightarrow \mathrm{ZnO}+2 \mathrm{H}^{+}
\end{aligned}
$$




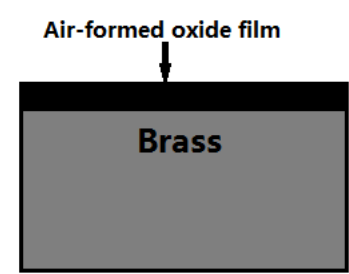

I - Before immersion

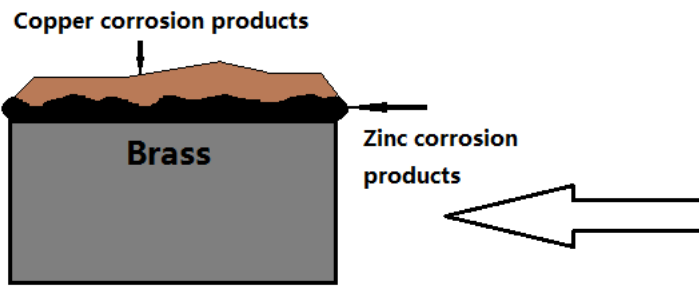

IV- During the last stage
$\mathrm{NaCl}+\mathrm{H}_{2} \mathrm{O}+\mathrm{O}_{2}$

ニニニニニニニニニ

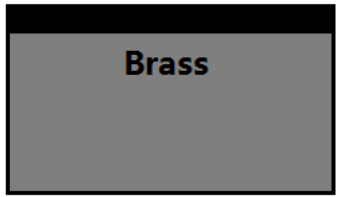

II- During initial stage

(Immersion period)

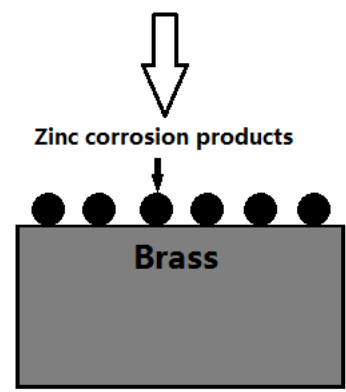

III - During the middle stage

Figure 7-3: Schematic diagram for the mechanism of brass corrosion under wet-dry cyclic conditions [93].

In the last stage, corrosion products of copper may form as the amount of zinc in the alloy reduces. These products can assume the compositions such as $\mathrm{Cu}_{2} \mathrm{O}, \mathrm{Cu}_{2} \mathrm{Cl}(\mathrm{OH})_{3}$ [93]; the reactions are provided in Eq. (7.4)-(7.6). For formation of copper corrosion products formed the so called "plug" on top of Zn corrosion product.

$$
\begin{gathered}
\mathrm{Cu}+\mathrm{Cl}^{-} \rightarrow \mathrm{CuCl}_{\mathrm{ads}}+\mathrm{e}^{-} \\
\mathrm{CuCl}_{\mathrm{ads}}+\mathrm{Cl}^{-} \rightarrow \mathrm{CuCl}_{2}^{-} \\
2 \mathrm{CuCl}_{2}^{-}+\mathrm{H}_{2} \mathrm{O} \rightarrow \mathrm{Cu}_{2} \mathrm{O}+2 \mathrm{H}^{+}+4 \mathrm{Cl}^{-}
\end{gathered}
$$

where ads represents absorbed, the reaction in Eq. (7.4) occurs at the interface between the brass and medium. Future study should be carried out to examine the type of corrosion products on each sample and understand the sequence of chemical reactions leading to the discolorations observed. 


\subsection{Anti-bacterial Test}

From this research, the anti-bacterial ability of brass coin is clearly seen. As such, it is not necessary to coat brass coins. However, for other circulation coins, such as quarters and toonies (with nickel rim), ALG coatings can offer anti -bacteria features as the experimental results in Chapter 6 showed that the ALG coatings can kill 99\% of bacteria on the surface within $24 \mathrm{hr}$, while the bare nickel coins will remove only $33 \%$ bacteria within $24 \mathrm{hr}$.

\subsection{Summary of Observations}

Table 7-2 summarizes the results of the visual inspection, coating thickness, microstructure analysis, anti-corrosion test and anti-bacterial test. ALG has covered a wide spectrum of desirable features as a coating for circulation coins.

\begin{tabular}{|c|c|c|c|c|c|}
\hline & $\begin{array}{c}\text { Vision } \\
\text { inspection } \\
\text { (compare to } \\
\text { the bare coins) }\end{array}$ & $\begin{array}{l}\text { Coating } \\
\text { thickness }\end{array}$ & $\begin{array}{l}\text { Microstructure } \\
\text { analysis }\end{array}$ & Anti-corrosion & Anti-bacteria \\
\hline $\begin{array}{l}\text { ALG } \\
\text { (brass) }\end{array}$ & $\begin{array}{c}\text { Slightly } \\
\text { darker }\end{array}$ & Thinnest & \multirow{2}{*}{$\begin{array}{c}\text { Good coverage } \\
\text { Not flat } \\
\text { No dust }\end{array}$} & Best & \multirow{2}{*}{$\begin{array}{l}\text { Better than } \\
\text { bare nickel, } \\
\text { worse than } \\
\text { bare brass. }\end{array}$} \\
\hline $\begin{array}{c}\text { ALG } \\
\text { (nickel) }\end{array}$ & Same & Thinnest & & $\begin{array}{c}\text { Worst (better } \\
\text { than bare) }\end{array}$ & \\
\hline $\begin{array}{c}\text { PUR } \\
\text { (brass) }\end{array}$ & $\begin{array}{c}\text { Slightly lost } \\
\text { original gloss }\end{array}$ & Medium & \multirow{2}{*}{$\begin{array}{c}\text { Good coverage } \\
\text { Flat } \\
\text { Some dust }\end{array}$} & Worst & \multirow{4}{*}{ No } \\
\hline $\begin{array}{c}\text { PUR } \\
\text { (nickel) }\end{array}$ & Same & Thick & & Medium & \\
\hline $\begin{array}{c}\text { Silicone } \\
\text { (brass) }\end{array}$ & $\begin{array}{l}\text { Slightly } \\
\text { Darker }\end{array}$ & Thickest & \multirow{2}{*}{$\begin{array}{c}\text { Thickest } \\
\text { Uniform } \\
\text { Many impurities }\end{array}$} & Medium & \\
\hline $\begin{array}{l}\text { Silicone } \\
\text { (nickel) }\end{array}$ & Same & Thickest & & Best & \\
\hline
\end{tabular}

Table 7-2: Summary of test results. 


\section{Chapter: Conclusions and Future Work}

Wear, corrosion and bacteria resistance are important features for circulation coins. Initially, five candidate materials were investigated in this study. By visual examination of coating adhesion to substrate coins and color change of the coated coins, three of the candidates were preliminarily selected; they were polyurethane, advanced liquid glass, and silicone R-2180. Spin coating technique was used for PUR and ALG while silicone R-2180 was applied by brushing. All three coatings were subjected to corrosion test in simulated sweat solution while only ALG was tested for its anti-bacterial capability. Based on the observations of experimental results, the following conclusions can be derived:

(1) From visual examination, PUR, ALG and R-2180 were found to be able to maintain the color and reactivity of the circulation coins. The mass change depended upon the coating thickness. Silicone R-2180 coating, due to its high viscosity, could not meet the coating thickness/mass change requirement stipulated by RCM.

(2) With respect to coating thickness and surface quality, the achievable ALG coating thickness is more desirable than PUR and R-2180 as the thickness range of ALG coatings, ranging from $3 \mu \mathrm{m}$ to $16 \mu \mathrm{m}$, falls within the requirement of the RCM. Although PUR coating thickness can vary from $10 \mu \mathrm{m}$ to $45 \mu \mathrm{m}$ on brass coins, the coating thickness is much thicker on nickel coins, ranging from $52 \mu \mathrm{m}$ to $91 \mu \mathrm{m}$. Additionally, PUR has more tendency to collect dust than ALG during curing cycle and transport.

(3) The anti-corrosion abilities of polyurethane, advanced liquid glass, and silicone 
R-2180 were also assessed. The results show that for brass coins, both the bare and heat-treated coins changed color within or after one day following exposure to sweat solution. ALG coatings performed the best among the three coatings, while the color of brass coins coated silicone changed to darker shade. For nickel coins, all heat-treated and bare coins changed color after a day, however, all coated coins showed traces of corrosion after three to four days. It was also observed that silicone R-2180 coating coins had the best overall anti-corrosion ability among all the coatings, however, the color of brass coins was changed by the silicone R-2180 coating during curing/heat treatment process. If the coating thickness of R-2180 can be controlled, it will offer the best corrosion protection to nickel coins while ALG works best for brass coins. Coating process parameters also played a role in determining the corrosion behaviour. While thinner coatings (e.g., ALG) has the likelihood of containing small pinholes leading to localized corrosion, thicker coating is known to affect the coating adhesion (usually coating adhesion reduces as the thickness increases). As such there is a need to balance these two aspects with further process development to optimize the coating performance.

(4) It was found that brass coins are naturally resistant to bacteria growth on the surface. As such there is no need to apply ALG coating for bacteria control purpose. However, ALG coating can improve the anti-bacterial ability of nickel coins according to the results of anti-bacterial experiments carried out in this study.

The contributions made through this thesis work include the following:

(1) realization of the relationship between spin coating process parameter and resulted coating thickness and quality. 
(2) development of a procedure that can be used to assess the antibacterial ability of a coating surface.

(2) a method to differentiate coatings based on transparency, corrosion and bacteria resistance.

(3) recommendation of ALG for brass and R-2180 for nickel coins to provide corrosion resistance.

(4) understanding of the bacteria resistance of ALG and its potential use on non-copper containing surfaces.

Further investigations should be focused on the following activities:

(1) Examination of wear resistance of the three candidate coatings in terms their resistance in sliding wear, abrasive wear and simulated wear (tumbling).

(2) Further improvement to the anti-bacterial function of ALG with additives such nano-Ag. However, keeping in mind that the transparency feature of the coating should not be compromised.

(3) Development of a process that can be used to apply R-2180 on coins and achieve controllable coating thickness.

(4) Lastly, since circulation coins are commonly used in vending machines, the EMS property of coated coins must be assessed before these coatings can be applied to circulation coins. 


\section{References}

[1] Avramovic, Z., \& Antonijevic, M. (2004). Corrosion of cold-deformed brass in acid sulphate solution. Corrosion Science, 46(11), 2793-2802.

[2] Anonymous. (1998). New Metals Handbook Desk Edition Shows How to Re-Make and Improve A Metals Classic. Metals Park: ASM International.

[3] F. Furno, K. Morley, B. Wong, B. Sharp, P. Arnold, S. Howdle, R. Bayston. P. Brown, P. Whinship and H. Raid, Silver nanoparticles and Polymeric Medical Devices: a New Approach to Prevention of Infection. J. Antimicrobial Chemotherapy, 54 (1004), pp. 1019-1024.

[4] G. Gosselino, A. Giovanni Dell'Aquila ad D. Romero, Hygienic Coatings by UV Curing of Diacrylic Oligomers with Added Triclosan, J. Coat. Technol. Res., 7(2), 2010, pp. 167-173.

[5] Howgego, C. J., \& Taylor \& Francis Group. (1995). Ancient history from coins. New York; London: Routledge.

[6] Giovannelli, G., Natali, S., \& Bozzini, B. (2006). Silver Coated Lead Coins: An Appraisal Of Ancient Technology. Journal of Applied Electrochemistry, 36(8), 951-956.

[7] Ingo, G., Balbi, S., Caro, T., Fragalà, I., Riccucci, C., \& Bultrini, G. (2006). Microchemical Investigation of Greek and Roman silver and gold plated coins: Coating techniques and corrosion mechanisms. Applied Physics A, 83(4), 623-629.

[8] NumisBids: Search All Sales. (n.d.). Retrieved February 25, 2015, from https:/www.numisbids.com/n.php?p=sale\&sid=550\&cid=14853\&pg=2\&search=

[9] Canovaro, C., Calliari, I., Asolati, M., Grazzi, F., \& Scherillo, A. (2013). Characterization of bronze Roman coins of the fifth century called nummi through different analytical techniques. Applied Physics A, 113(4), 1019-1028.

[10]Leitão, P., Teixeira, A., Rodrigues, J., \& Martins, P. (1997). Development of an industrial process for minting a new type of bimetallic coin. Journal of Materials Processing Technology, 70(1-3), 178-184.

[11]The New \$1 Coin. (n.d.). Retrieved February 25, 2015, from http://www.mint.ca/store/mint/learn/the-new-1-coin-6800004\#.VO4_rvnF-0c

[12] New one- and two-dollar coins arrive. (2012, Apr 12). Nepean Barrhaven EMC Retrieved from http://search.proquest.com/docview/1000169881?accountid=9894

[13] Royal canadian mint credits patented multi-ply plating for record year in minting international circulation coins. (2007, Dec 13).Canada News Wire Retrieved from http://search.proquest.com/docview/455262074? accountid=9894

[14] Goverment, U. S. (n.d.). Manufacturing Process for U.S. Coins. Retrieved 2015, from U.S. Department Of the Treasury http://www.treasury.gov/about/education/Pages/manufacturing.aspx

[15] Goverment, U. S. (n.d.). United States Mint. Retrieved 1 2015, from http://www.usmint.gov/policy/?action=TermsOfUse

[16]Ruscoe, M. (1987). A Predictive Test for Coin Wear in Circulation. Wear, 119(3), 329-342.

[17]Liu, Y., Yan, G., Che, H., Wang, X., \& Guo, Q. (2011). Transparent polysilicone 
coatings as protecting films for gold commemorative coins. Journal of Applied Polymer Science, 119(2), 1156-1160.

[18]Liang, C., Yang, C., \& Huang, N. (2011). Investigating the tarnish and corrosion mechanisms of Chinese gold coins. Surface and Interface Analysis, 43(4), 763-769.

[19]Martins, C., \& Martins, J. (2011). Identification of corrosion products on a medieval copper-silver coin. Protection of Metals and Physical Chemistry of Surfaces, 43(4), 128-132.

[20]Baron S, Salton MRJ, Kim KS (1996). "Structure". In Baron S et al. Baron's Medical Microbiology (4th ed.). Univ of Texas Medical Branch

[21]JKN Kuria, RG Wahome, M Jobalamin, and SM Kariuki. Profile of bacteria and fungi on money coins. East African medical journal, 86(4), 2009.

[22] Carla CCR Carvalho and Maria Jose. Bacterial diversity assessed by cultivation-based techniques shows predominance of staphylococcus species on coins collected in lisbon and casablanca. FEMS microbiology ecology, 88(1):26-37, 2014.

[23] Wang, D., \& Bierwagen, G. (2009). Sol-gel coatings on metals for corrosion protection. Progress in Organic Coatings, 64(4), 327-338.

[24] Hammer, P., Santos, F., Cerrutti, B., Pulcinelli, S., \& Santilli, C. (2012). Highly corrosion resistant siloxane-polymethyl methacrylate hybrid coatings. Journal of Sol-Gel Science and Technology, 63(2), 266-274.

[25] Mikhailova, A., Tamboura, M., \& Jia, M. (2012). Heat-Resistant and Anti-Corrosion Urethane-Silicone-based Coatings. Silicon, 4, 197-208.

[26] Riaz, U., Nwaoha, C., \& Ashraf, S. M. (2014). Recent advances in corrosion protective composite coatings based on conducting polymers and natural resource derived polymers. Progress in Organic Coatings, 77(4), 743-756.

[27] Yang, X., Li, B., Wang, H., \& Hou, B. (2010). Anticorrosion performance of polyaniline nanostructures on mild steel. Progress in Organic Coatings, 69(3), 267-271.

[28] Tan, C., \& Blackwood, D. (2003). Corrosion protection by multilayered conducting polymer coatings. Corrosion Science, 45, 545-557.

[29] Ocón, P., Cristobal, A., Herrasti, P., \& Fatas, E. (2005). Corrosion performance of conducting polymer coatings applied on mild steel. Corrosion Science, 47(3), 649-662.

[30] Aramaki, K. (2002). Preparation of chromate-free, self-healing polymer films containing sodium silicate on zinc pretreated in a cerium (III) nitrate solution for preventing zinc corrosion at scratches in $0.5 \mathrm{M} \mathrm{NaCl}$. Corrosion Science, 44(6), 1375-1389.

[31] Koh, E., Kim, N., Shin, J., \& Kim, Y. (2014). Polyurethane microcapsules for self-healing paint coatings. RSC Advances, 4(31), 16214-16214.

[32] Stankiewicz, A., Szczygieł, I., \& Szczygieł, B. (2013). Self-healing coatings in anti-corrosion applications. Journal of Materials Science, 48(23), 8041-8051.

[33] Balagna, C., Perero, S., Ferraris, S., Miola, M., Fucale, G., Manfredotti, C., Ferraris, M. (2012). Antibacterial coating on polymer for space application. Materials Chemistry and Physics, 135(2-3), 714-722. 
[34] Thome, J., Holländer, A., Jaeger, W., Trick, I., \& Oehr, C. (2003). Ultrathin antibacterial polyammonium coatings on polymer surfaces. Surface and Coatings Technology, 174-175, 584-587.

[35] Høiby, N., Bjarnsholt, T., Givskov, M., Molin, S., \& Ciofu, O. (2010). Antibiotic resistance of bacterial biofilms. International Journal of Antimicrobial Agents, 35(4), 322-332.

[36] Tiller, J., Lee, S., Lewis, K., \& Klibanov, A. (2002). Polymer surfaces derivatized with poly(vinyl-N-hexylpyridinium) kill airborne and waterborne bacteria. Biotechnology and Bioengineering, 79(4), 465-471.

[37] Grass, G., Rensing, C., \& Solioz, M. (2011). Metallic Copper As An Antimicrobial Surface Applied and Environmental Microbiology, 77(5), 1541-1547.

[38] Hans, M., Erbe, A., Mathews, S., Chen, Y., Solioz, M., \& Mücklich, F. (2013). Role of copper oxides in contact killing of bacteria. Langmuir: The ACS Journal of Surfaces and Colloids, 29(52), 16160.

[39] Mathews, S., Hans, M., Mucklich, F., \& Solioz, M. (2013). Contact Killing of Bacteria on Copper Is Suppressed if Bacterial-Metal Contact Is Prevented and Is Induced on Iron by Copper Ions. Applied and Environmental Microbiology, 79(8), 2605-2611.

[40] Hong, R., Kang, T., Michels, C., \& Gadura, N. (2012). Membrane Lipid Peroxidation in Copper Alloy-Mediated Contact Killing of Escherichia coli. Applied and Environmental Microbiology,78(6), 1776-1784.

[41] Ren, G., Hu, D., Cheng, E., Vargas-Reus, M., Reip, P., \& Allaker, R. (n.d.). Characterisation of copper oxide nanoparticles for antimicrobial applications. International Journal of Antimicrobial Agents, 33(6), 587-590. Retrieved December 8, 2014.

[42] Kangwansupamonkon, W., Lauruengtana, V., Surassmo, S., \& Ruktanonchai, U. (2009). Antibacterial effect of apatite-coated titanium dioxide for textiles applications. Nanomedicine: Nanotechnology, Biology and Medicine, 5(2), 240-249.

[43] Nonami, T., Hase, H., \& Funakoshi, K. (n.d.). Apatite-coated titanium dioxide photocatalyst for air purification. Catalysis Today, 96(3), 113-118. Retrieved December 8, 2014.

[44] Tiller, J., Lee, S., Lewis, K., \& Klibanov, A. (2002). Polymer surfaces derivatized with poly(vinyl-N-hexylpyridinium) kill airborne and waterborne bacteria. Biotechnology and Bioengineering, 79(4), 465-471.

[45] Rai, M., Yadav, A., \& Gade, A. (2009). Silver nanoparticles as a new generation of antimicrobials. Biotechnology advances, 27(1), 76-83.

[46] Kim, S. H., Kim, Y., Kim, J., Kim, J. S., Kuk, E., Yu, K. N., \& Cho, M. (2007). Antimicrobial effects of silver nanoparticles. Nanomedicine: Nanotechnology, Biology, and Medicine, 3(1), 95-101

[47] Lynch, I., Dawson, K. A., Luch, A., Reidy, B., \& Haase, A. (2013). Mechanisms of silver nanoparticle release, transformation and toxicity: A critical review of current knowledge and recommendations for future studies and applications. Materials, 6, 2295-2350.

[48] Martínez-Castañón, G. A., Niño-Martínez, N., Martínez-Gutierrez, F., 
Martínez-Mendoza, J. R., \& Ruiz, F. (2008). Synthesis and antibacterial activity of silver nanoparticles with different sizes. Journal of Nanoparticle Research, 10(8), 1343-1348.

[49] Guo, L., Yuan, W., Lu, Z., \& Li, C. (2013). Polymer/nanosilver composite coatings for antibacterial applications. Colloids and Surfaces A: Physicochemical and Engineering Aspects, 439, 69-83.

[50] Zhang, Z., Zhao, B., \& Hu, L. (1996). PVP Protective Mechanism of Ultrafine Silver Powder Synthesized by Chemical Reduction Processes. Journal of Solid State Chemistry, 121(1), 105-110.

[51] Kittler, S., Greulich, C., Köller, M., \& Epple, M. (2009). Synthesis of PVP-coated silver nanoparticles and their biological activity towards human mesenchymal stem cells. Materialwissenschaft Und Werkstofftechnik, 40(4), 258-264.

[52] Sharma, S., Chauhan, G., Gupta, R., \& Ahn, J. (2010). Tuning anti-microbial activity of poly(4-vinyl 2-hydroxyethyl pyridinium) chloride by anion exchange reactions. Journal of Materials Science: Materials in Medicine, 21(2), 717-724.

[53] Alamri, A., El-Newehy, M., \& Al-Deyab, S. (n.d.). Biocidal polymers: Synthesis and antimicrobial properties of benzaldehyde derivatives immobilized onto amine-terminated polyacrylonitrile. Chemistry Central Journal, 6(1), 111-111. Retrieved November 23, 2014.

[54] Timofeeva, L., \& Kleshcheva, N. (2011). Antimicrobial polymers: Mechanism of action, factors of activity, and applications. Applied Microbiology and Biotechnology, 89(3), 475-492.

[55] No, H. (2002). Antibacterial activity of chitosans and chitosan oligomers with different molecular weights. International Journal of Food Microbiology, 74(1-2), 65-72.

[56] Rinaudo, M. (2006). Chitin and Chitosan: Properties and Applications.Progress in Polymer Science, 31(7), 603-632.

[57] Pinto, R., Fernandes, S., Freire, C., Sadocco, P., Causio, J., Neto, C., \& Trindade, T. (2012). Antibacterial activity of optically transparent nanocomposite films based on chitosan or its derivatives and silver nanoparticles. Carbohydrate Research, 348, 77-83.

[58] Huang, M., Khor, E., \& Lim, L. (2004). Uptake and Cytotoxicity of Chitosan Molecules and Nanoparticles: Effects of Molecular Weight and Degree of Deacetylation. Pharmaceutical Research, 21(2), 344-353.

[59] Hill, R. (2002). Silicone surfactants - new developments. Current Opinion in Colloid \& Interface Science, 7(5-6), 255-261.

[60] Goyal, A., Kumar, A., Patra, P., Mahendra, S., Tabatabaei, S., Alvarez, P., Ajayan, P. (2009). In situ Synthesis of Metal Nanoparticle Embedded Free Standing Multifunctional PDMS Films. Macromolecular Rapid Communications, 30(13), 1116-1122.

[61] Schubert, D. W., \& Dunkel, T. (2003). Spin coating from a molecular point of view: its concentration regimes, influence of molar mass and distribution. Materials research innovations, 7(5), 314-321.

[62] Hall, D., Underhill, P., \& Torkelson, J. (1998). Spin Coating Of Thin And Ultrathin 
Polymer Films. Polymer Engineering \& Science, 2039-2045.

[63] Faustini, M., Ceratti, D., Louis, B., Boudot, M., Albouy, P., Boissière, C., \& Grosso, D. (2014). Engineering Functionality Gradients by Dip Coating Process in Acceleration Mode. ACS Applied Materials \& Interfaces, 17102-17110.

[64] Raut, H., Ganesh, V., Nair, A., \& Ramakrishna, S. (2011). Anti-reflective coatings: A critical, in-depth review. Energy \& Environmental Science, 4(10), 3779-3779.

[65] Hu, Z., Zhang, J., Xiong, S., \& Zhao, Y. (2012; 2011). Performance of polymer solar cells fabricated by dip coating process. Solar Energy Materials and Solar Cells, 99, 221-225.

[66] Strawbridge, I., \& James, P. (1986). The factors affecting the thickness of sol-gel derived silica coatings prepared by dipping. Journal of Non-Crystalline Solids, 86(3), 381-393.

[67] Bose, S., Keller, S., Alstrøm, T., Boisen, A., \& Almdal, K. (2013). Process Optimization of Ultrasonic Spray Coating of Polymer Films. Langmuir, 29(23), 6911-6919. Retrieved November 30, 2014.

[68] Qiao, L., Sartor, R., Gasilova, N., Lu, Y., Tobolkina, E., Liu, B., \& Girault, H. (2012). Electrostatic-spray ionization mass spectrometry. Analytical Chemistry, 84(17), $7422-7430$.

[69] Applications of Electrostatics. (n.d.). Retrieved January 22, 2015, from http://philschatz.com/physics-book/contents/m42329.html

[70] Mauer, G., Hospach, A., \& Vaßen, R. (2013). Process development and coating characteristics of plasma spray-PVD. Surface and Coatings Technology, 220(15), 219-224.

[71] Bárdos, L., \& Baránková, H. (2010). Cold atmospheric plasma: Sources, processes, and applications. Thin Solid Films, 518(23), 6705-6713.

[72] Tendero, C., Tixier, C., Tristant, P., Desmaison, J., \& Leprince, P. (2006). Atmospheric pressure plasmas: A review. Spectrochimica Acta Part B: Atomic Spectroscopy, 61(1), 2-30.

[73] Smith, M., Hall, A., Fleetwood, J., \& Meyer, P. (2011). Very Low Pressure Plasma Spray-A Review of an Emerging Technology in the Thermal Spray Community. Coatings, 1(2), 117-132.

[74] Fu, G., Zuo, L., Longtin, J., Nie, C., \& Gambino, R. (2013). Thermoelectric properties of magnesium silicide fabricated using vacuum plasma thermal spray. Journal of Applied Physics, 114(14), 144905-144905.

[75] Young, E. J., Mateeva, E., Moore, J. J., Mishra, B., \& Loch, M. (2000). Low pressure plasma spray coatings. Thin Solid Films, 377(1-2), 788-792

[76] Tereshatov, V., Makarova, M., Senichev, V., \& Slobodinyuk, A. (2012). Interrelationship between ultimate mechanical properties of variously structured polyurethanes and poly(urethane urea)s and stretching rate thereof. Colloid and Polymer Science, 290(7), 641-651.

[77] Stachowiak, G. (2005). Wear--materials, mechanisms and practice (pp. 1-6). Chichester, England: Wiley.

[78] Krol, P. (2007). Synthesis methods, chemical structures and phase structures of linear polyurethanes. Properties and applications of linear polyurethanes in polyurethane 
elastomers, copolymers and ionomers. Progress in Materials Science, 52(6), 915-1015.

[79] Crawford, D., \& Escarsega, J. (2000). Dynamic mechanical analysis of novel polyurethane coating for military applications. Thermochimica Acta, 357, 161-168.

[80] Oprea, S. (2009). Structure and properties of cross-linked polyurethane copolymers. Advances in Polymer Technology, 28(3), 165-172.

[81] Husic, S. (2005). Thermal and mechanical properties of glass reinforced soy-based polyurethane composites. Composites Science and Technology, 65(1), 19-25.

[82] Unal, H., Mimaroglu, A., Kadioglu, U., \& Ekiz, H. (2004). Sliding Friction And Wear Behaviour Of Polytetrafluoroethylene And Its Composites Under Dry Conditions. Materials \& Design, 25(3), 239-245.

[83] Blanchet, T., \& Kennedy, F. (1992). Sliding wear mechanism of polytetrafluoroethylene (PTFE) and PTFE composites. Wear, 153(1), 229-243.

[84] Tanaka, K., \& Ueda, S. (1976). The mechanism of wear of polytetrafluoroethylene above the melting point. Wear, 39(2), 323-333.

[85] Vijayan, K., \& Biswas, S. (1990). Wear of polytetrafluoroethylene: Some crystallographic observations. Wear, 150(1), 267-273.

[86] Steijn, R. (1968). The sliding surface of polytetrafluoroethylene: An investigation with the electron microscope. Wear, 12(3), 193-212.

[87] Khedkar, J., Negulescu, I., \& Meletis, E. (2002). Sliding wear behavior of PTFE composites. Wear, 252(5), 361-369.

[88] Bahadur, S., \& Tabor, D. (1989). The Wear of Filled Polytetrafluoroethylene is . Wear, 134(2), 1-13.

[89] Anusuya Choudhury, Anil K Bhowmick, and Christopher Ong. Novel role of polymer-solvent and clay-solvent interaction parameters on the thermal. Mechanical and optical properties of polymer nanocomposites. Polymer, 50(1): 201-210, 2009.

[90] (n.d.). Retrieved March 11, 2015, from http://www.ossila.com/support/spin_coating_guide/speed_duration.php

[91] Ahmad, Z. (2006). Principles of corrosion engineering and corrosion control. Boston, MA: Elsevier/BH.

[92] Liang, C., Wang, S., Huang, N., \& Wang, P. (2015). Corrosion behavior of brass coinage in synthetic sweat solution. Transactions of nonferrous Metals Society of China, 25(2), 654-660.

[93] El-Mahdy, G. (2005). Electrochemical impedance study on brass corrosion in $\mathrm{NaCl}$ and (NH4)2SO4 solutions during cyclic wet-dry conditions. Journal of Applied Electrochemistry,35(3), 347-353. 


\section{Appendices}

\section{Appendix A}

\begin{tabular}{|c|c|c|c|c|c|}
\hline Specimen & $\begin{array}{c}\text { Spin speed } \\
\text { (rpm), Time (s) }\end{array}$ & $\begin{array}{l}\text { Weight (g) } \\
\text { (Bare coin) }\end{array}$ & $\begin{array}{c}\text { Weight (g) } \\
\text { (Coated coin) }\end{array}$ & $\begin{array}{r}\Delta \mathbf{W} \\
(\mathrm{g})\end{array}$ & $\begin{array}{c}\text { Coating } \\
\text { thickness }(\mu \mathrm{m})\end{array}$ \\
\hline 1 & $100 \mathrm{rpm}, 30 \mathrm{~s}$ & 6.2888 & 6.3081 & 0.0193 & 45.15 \\
\hline 2 & $300 \mathrm{rpm}, 30 \mathrm{~s}$ & 6.3337 & 6.3507 & 0.017 & 39.77 \\
\hline 3 & $500 \mathrm{rpm}, 10 \mathrm{~s}$ & 6.3929 & 6.4075 & 0.0146 & 34.15 \\
\hline 4 & $500 \mathrm{rpm}, 20 \mathrm{~s}$ & 6.2993 & 6.3107 & 0.0114 & 26.67 \\
\hline 5 & $500 \mathrm{rpm}, 30 \mathrm{~s}$ & 6.3232 & 6.334 & 0.0108 & 25.26 \\
\hline 6 & $500 \mathrm{rpm}, 40 \mathrm{~s}$ & 6.3165 & 6.3277 & 0.0112 & 26.20 \\
\hline 7 & $500 \mathrm{rpm}, 50 \mathrm{~s}$ & 6.2872 & 6.2983 & 0.0111 & 25.97 \\
\hline 8 & $700 \mathrm{rpm}, 10 \mathrm{~s}$ & 6.3363 & 6.3477 & 0.0114 & 26.67 \\
\hline 9 & $700 \mathrm{rpm}, 20 \mathrm{~s}$ & 6.3325 & 6.3422 & 0.0097 & 22.69 \\
\hline 10 & $700 \mathrm{rpm}, 30 \mathrm{~s}$ & 6.3413 & 6.3503 & 0.009 & 21.05 \\
\hline 11 & $700 \mathrm{rpm}, 40 \mathrm{~s}$ & 6.2893 & 6.2985 & 0.0092 & 21.52 \\
\hline 12 & $700 \mathrm{rpm}, 50 \mathrm{~s}$ & 6.3216 & 6.3306 & 0.009 & 21.05 \\
\hline 13 & $1000 \mathrm{rpm}, 10 \mathrm{~s}$ & 6.3187 & 6.3279 & 0.0092 & 21.52 \\
\hline 14 & $1000 \mathrm{rpm}, 20 \mathrm{~s}$ & 6.3094 & 6.3171 & 0.0077 & 18.01 \\
\hline 15 & $1000 \mathrm{rpm}, 30 \mathrm{~s}$ & 6.3476 & 6.3547 & 0.0071 & 16.61 \\
\hline 16 & $1000 \mathrm{rpm}, 40 \mathrm{~s}$ & 6.3054 & 6.3125 & 0.0071 & 16.61 \\
\hline 17 & $1000 \mathrm{rpm}, 50 \mathrm{~s}$ & 6.2787 & 6.2862 & 0.0075 & 17.55 \\
\hline 18 & $1200 \mathrm{rpm}, 30 \mathrm{~s}$ & 6.3013 & 6.3057 & 0.0044 & 10.29 \\
\hline 19 & $1500 \mathrm{rpm}, 30 \mathrm{~s}$ & 6.3116 & 6.3159 & 0.0043 & 10.06 \\
\hline
\end{tabular}

Summary of PUR coating thickness on brass coins. 


\section{Appendix B}

\begin{tabular}{|c|c|c|c|c|c|}
\hline Specimen & $\begin{array}{c}\text { Spin speed } \\
(\mathbf{r p m}), \text { Time (s) }\end{array}$ & $\begin{array}{c}\text { Weight }(\mathbf{g}) \\
\text { (Bare coin) }\end{array}$ & $\begin{array}{c}\text { Weight (g) } \\
\text { (Coated coin) }\end{array}$ & $\begin{array}{c}\Delta \mathbf{W} \\
(\mathbf{g})\end{array}$ & $\begin{array}{c}\text { Coating } \\
\text { thickness }(\boldsymbol{\mu m})\end{array}$ \\
\hline 1 & $500 \mathrm{rpm}, 10 \mathrm{~s}$ & 4.4821 & 4.4932 & 0.0111 & 91.62 \\
\hline 2 & $500 \mathrm{rpm}, 30 \mathrm{~s}$ & 4.5187 & 4.5284 & 0.0097 & 80.06 \\
\hline 3 & $500 \mathrm{rpm}, 50 \mathrm{~s}$ & 4.5333 & 4.5428 & 0.0095 & 78.41 \\
\hline 4 & $700 \mathrm{rpm}, 10 \mathrm{~s}$ & 4.5567 & 4.5669 & 0.0102 & 84.19 \\
\hline 5 & $700 \mathrm{rpm}, 30 \mathrm{~s}$ & 4.5021 & 4.5106 & 0.0085 & 70.16 \\
\hline 6 & $700 \mathrm{rpm}, 50 \mathrm{~s}$ & 4.4729 & 4.4809 & 0.0080 & 66.03 \\
\hline 7 & $1000 \mathrm{rpm}, 10 \mathrm{~s}$ & 4.4795 & 4.4884 & 0.0089 & 73.46 \\
\hline 8 & $1000 \mathrm{rpm}, 30 \mathrm{~s}$ & 4.5143 & 4.5211 & 0.0068 & 56.13 \\
\hline 9 & $1000 \mathrm{rpm}, 50 \mathrm{~s}$ & 4.4748 & 4.4812 & 0.0064 & 52.83 \\
\hline 10 & $1200 \mathrm{rpm}, 30 \mathrm{~s}$ & 4.5289 & 4.5352 & 0.0063 & 52.00 \\
\hline
\end{tabular}

Summary of PUR coating thickness on nickel coins.

\section{Appendix C}

\begin{tabular}{|c|c|c|c|c|c|}
\hline Specimen & $\begin{array}{c}\text { Spin speed } \\
(\mathbf{r p m}), \text { Time (s) }\end{array}$ & $\begin{array}{c}\text { Weight }(\mathbf{g}) \\
\text { (Bare coin) }\end{array}$ & $\begin{array}{c}\text { Weight }(\mathbf{g}) \\
(\text { Coated coin) }\end{array}$ & $\begin{array}{c}\Delta \mathbf{W} \\
(\mathbf{g})\end{array}$ & $\begin{array}{c}\text { Coating } \\
\text { thickness }(\boldsymbol{\mu m})\end{array}$ \\
\hline 1 & $500 \mathrm{rpm}, 10 \mathrm{~s}$ & 4.5001 & 4.5044 & 0.0043 & 12.20 \\
\hline 2 & $500 \mathrm{rpm}, 30 \mathrm{~s}$ & 4.5021 & 4.5054 & 0.0033 & 9.36 \\
\hline 3 & $500 \mathrm{rpm}, 50 \mathrm{~s}$ & 4.5051 & 4.5079 & 0.0028 & 7.94 \\
\hline 4 & $700 \mathrm{rpm}, 10 \mathrm{~s}$ & 4.5006 & 4.5031 & 0.0025 & 7.09 \\
\hline 5 & $700 \mathrm{rpm}, 30 \mathrm{~s}$ & 4.4768 & 4.4788 & 0.002 & 5.67 \\
\hline 6 & $700 \mathrm{rpm}, 50 \mathrm{~s}$ & 4.5064 & 4.5083 & 0.0019 & 5.39 \\
\hline 7 & $1000 \mathrm{rpm}, 10 \mathrm{~s}$ & 4.493 & 4.4951 & 0.0021 & 5.96 \\
\hline 8 & $1000 \mathrm{rpm}, 30 \mathrm{~s}$ & 4.5198 & 4.5215 & 0.0017 & 4.82 \\
\hline 9 & $1000 \mathrm{rpm}, 50 \mathrm{~s}$ & 4.4678 & 4.4693 & 0.0015 & 4.26 \\
\hline 10 & $1200 \mathrm{rpm}, 30 \mathrm{~s}$ & 4.4923 & 4.4935 & 0.0012 & 3.40 \\
\hline
\end{tabular}

Summary of ALG coating thickness on nickel coins 


\section{Appendix D}

\begin{tabular}{|c|c|c|c|c|c|}
\hline Specimen & $\begin{array}{l}\text { Spin Velocity } \\
\text { (rpm), Time(s) }\end{array}$ & $\begin{array}{l}\text { Weight (g) } \\
\text { (Bare coin) }\end{array}$ & $\begin{array}{c}\text { Weight }(\mathrm{g}) \\
\text { (Coated coin) }\end{array}$ & $\begin{array}{c}\Delta \mathrm{W} \\
(\mathrm{g})\end{array}$ & $\begin{array}{c}\text { Coating } \\
\text { thickness }(\mu \mathrm{m})\end{array}$ \\
\hline 1 & $100 \mathrm{rpm}, 30 \mathrm{~s}$ & 6.3223 & 6.3293 & 0.007 & 16.38 \\
\hline 2 & $300 \mathrm{rpm}, 30 \mathrm{~s}$ & 6.3491 & 6.3556 & 0.0065 & 15.21 \\
\hline 3 & $500 \mathrm{rpm}, 10 \mathrm{~s}$ & 6.3557 & 6.359 & 0.0033 & 7.72 \\
\hline 4 & $500 \mathrm{rpm}, 20 \mathrm{~s}$ & 6.3271 & 6.3299 & 0.0028 & 6.55 \\
\hline 5 & $500 \mathrm{rpm}, 30 \mathrm{~s}$ & 6.345 & 6.3476 & 0.0026 & 6.08 \\
\hline 6 & $500 \mathrm{rpm}, 40 \mathrm{~s}$ & 6.3396 & 6.342 & 0.0024 & 5.61 \\
\hline 7 & $500 \mathrm{rpm}, 50 \mathrm{~s}$ & 6.3476 & 6.3499 & 0.0023 & 5.38 \\
\hline 8 & $700 \mathrm{rpm}, 10 \mathrm{~s}$ & 6.2829 & 6.2859 & 0.003 & 7.02 \\
\hline 9 & $700 \mathrm{rpm}, 20 \mathrm{~s}$ & 6.307 & 6.3096 & 0.0026 & 6.08 \\
\hline 10 & $700 \mathrm{rpm}, 30 \mathrm{~s}$ & 6.2791 & 6.2816 & 0.0025 & 5.85 \\
\hline 11 & $700 \mathrm{rpm}, 40 \mathrm{~s}$ & 6.3277 & 6.3299 & 0.0022 & 5.15 \\
\hline 12 & $700 \mathrm{rpm}, 50 \mathrm{~s}$ & 6.3501 & 6.3523 & 0.0022 & 5.15 \\
\hline 13 & $1000 \mathrm{rpm}, 10 \mathrm{~s}$ & 6.3191 & 6.3215 & 0.0024 & 5.61 \\
\hline 14 & $1000 \mathrm{rpm}, 20 \mathrm{~s}$ & 6.3376 & 6.3399 & 0.0023 & 5.38 \\
\hline 15 & $1000 \mathrm{rpm}, 30 \mathrm{~s}$ & 6.3266 & 6.3289 & 0.0023 & 5.38 \\
\hline 16 & $1000 \mathrm{rpm}, 40 \mathrm{~s}$ & 6.3741 & 6.3762 & 0.0021 & 4.91 \\
\hline 17 & $1000 \mathrm{rpm}, 50 \mathrm{~s}$ & 6.3532 & 6.3554 & 0.0022 & 5.15 \\
\hline 18 & $1200 \mathrm{rpm}, 30 \mathrm{~s}$ & 6.3094 & 6.311 & 0.0016 & 3.74 \\
\hline 19 & $1200 \mathrm{rpm}, 30 \mathrm{~s}$ & 6.2926 & 6.2936 & 0.001 & 2.34 \\
\hline
\end{tabular}

Summary of ALG coating thickness on brass coins 